\title{
Influence of accelerator pedal position control on heavy duty diesel engine emissions and performance
}

\author{
Michael Ursic \\ West Virginia University
}

Follow this and additional works at: https://researchrepository.wvu.edu/etd

\section{Recommended Citation}

Ursic, Michael, "Influence of accelerator pedal position control on heavy duty diesel engine emissions and performance" (2009). Graduate Theses, Dissertations, and Problem Reports. 2025.

https://researchrepository.wvu.edu/etd/2025

This Thesis is protected by copyright and/or related rights. It has been brought to you by the The Research Repository @ WVU with permission from the rights-holder(s). You are free to use this Thesis in any way that is permitted by the copyright and related rights legislation that applies to your use. For other uses you must obtain permission from the rights-holder(s) directly, unless additional rights are indicated by a Creative Commons license in the record and/ or on the work itself. This Thesis has been accepted for inclusion in WVU Graduate Theses, Dissertations, and Problem Reports collection by an authorized administrator of The Research Repository @ WVU. For more information, please contact researchrepository@mail.wvu.edu. 


\title{
Influence of Accelerator Pedal Position Control on Heavy Duty Diesel Engine Emissions and Performance
}

\author{
Michael Ursic
}

Thesis submitted to the

\author{
College of Engineering and Mineral Resources \\ at West Virginia University \\ in partial fulfillment of the requirements \\ for the degree of:
}

\author{
Master of Science \\ in \\ Mechanical Engineering
}
Gregory J. Thompson, Ph.D., Chair
Nigel Clark, Ph.D.
Mridul Gautam, Ph.D.

Department of Mechanical and Aerospace Engineering

\author{
Morgantown, West Virginia \\ 2009
}

Keywords: Diesel Emissions, FTP, APPC, Fueling Control 


\section{ABSTRACT \\ Influence of Accelerator Pedal Position Control on Heavy Duty Diesel Engine Emissions and Performance \\ Michael Christopher Ursic}

Heavy-duty diesel engines (HDDEs) typically burn hydrocarbon fuels and as a result

their emissions cause harmful products of combustion to be emitted into the atmosphere. Due to these harmful emissions, the United States Environmental Protection Agency (EPA) has created strict emissions standards for these heavy-duty engine manufacturers to meet. Engine manufacturers strive to meet these stringent standards while maintaining performance requirements set forth by the consumer. The EPA currently mandates laboratory testing of all HDDE families on an engine dynamometer utilizing a standard testing procedure. One standard testing procedure that HDDEs must execute is commonly known as a Federal Testing Procedure (FTP).

The FTP is a transient test performed over a prescribed period of time governed by a set of engine speed and load points. For a test to be valid, the measured engine speed and loads during the FTP are compared to the prescribed, or set, engine speed and load points. There is some latitude between the actual and preset engine speed and load points which are confirmed through a regression analysis.

Currently, each laboratory conducting HDDE testing develops their own control algorithm to achieve the engine speed and load points prescribed by the FTP. This study investigated the effects that variations in accelerator pedal position control (APPC) have on emissions, performance, and tolerances of the FTP. 
Five engines were utilized for this study including a 1991 DDC S60, 1992 DDC S60, 1992 rebuilt DDC S60, 1999 Cummins ISM, and a 2004 Cummins ISM engine. Three control algorithms were developed to control the accelerator pedal. However, initial investigations of throttle setting 2 of the control algorithms revealed that this APPC mimicked that of throttle setting 1 and was not further investigated.

Emissions varied significantly for most measured constituents for the two different APPCs. The older DDC engines saw the greatest response in regards to emissions when varying APPC. Of the three DDC's used for testing, the 1991 exhibited the greatest variations in the emissions. Oxides of nitrogen (NOx) were reduced by 2.4\% under control of throttle 1 , the more aggressive APPC setting. Total particulate matter (TPM) was reduced by $17.6 \%$ under guidance of throttle 3, the less aggressive APPC setting. Hydrocarbons (HC) were reduced by $15.0 \%$ under control of throttle 1 compared to the throttle 3. Carbon monoxide (CO) was reduced significantly by throttle 3, compared to the throttle 1 , with a $29.0 \%$ reduction. Fuel consumption (FC) and work were both slightly elevated by the more aggressive throttle 1 compared to throttle 3.

Emissions responded more to the variations in APPC on the older engines due to lack of additional engine control devices, such as variable geometry turbochargers, as seen on the newer Cummins engines. The DDC engines experienced longer turbo-lag during transient conditions causing rich equivalence ratios during this time. Therefore, variations in transient load conditions led to different emissions results for the different APPCs. Both throttle 1 and throttle 3 provided valid transient tests under FTP regression requirements. It is suggested that these tolerances be tightened to better suit result comparisons from laboratory to laboratory. 


\section{Table of Contents}

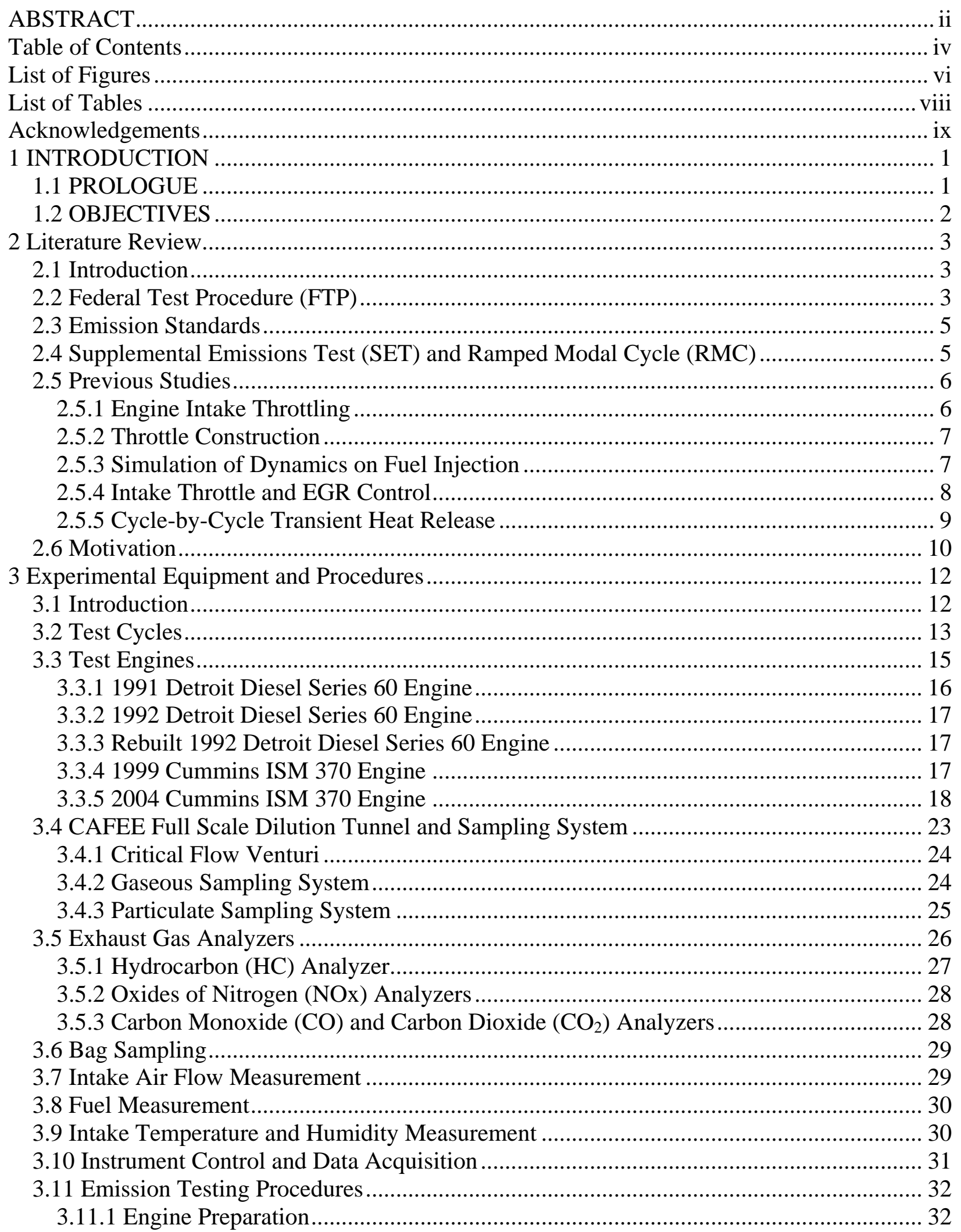




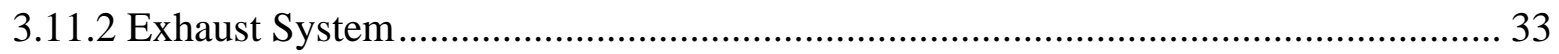

3.11.3 Calibration of Analyzers ....................................................................................... 33

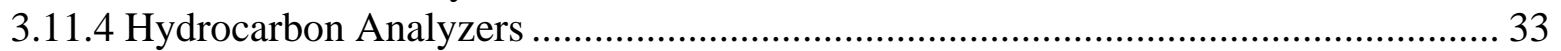

3.11.5 Oxides of Nitrogen Analyzers ..................................................................................... 34

3.11.6 Carbon Monoxide and Carbon Dioxide Analyzers.......................................................... 34

3.11.7 Heated Lines and Probes............................................................................................... 35

3.11.8 Particulate and Filter Weighing ……………........................................................... 35

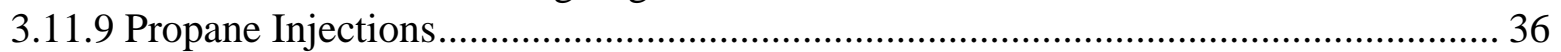

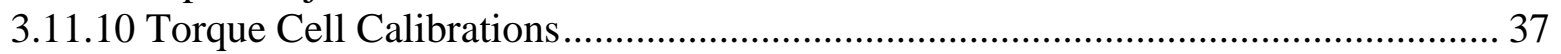

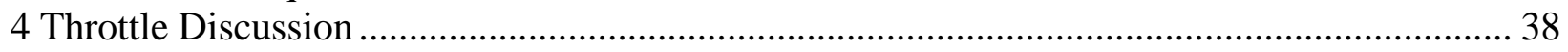

4.1 Test Engines and Examined Fuels ………………...................................................... 38

4.2 Throttle Profiles ……………………........................................................................ 39

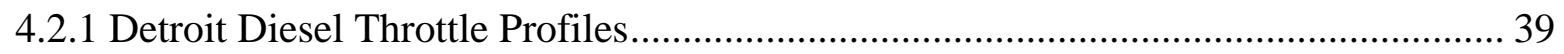

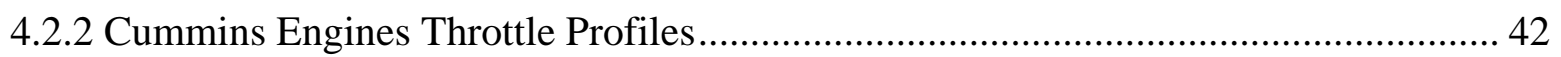

4.3 Throttle Programming................................................................................................... 43

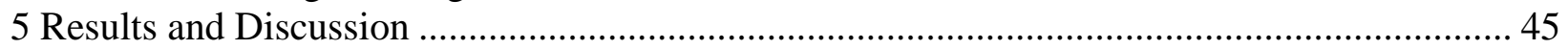

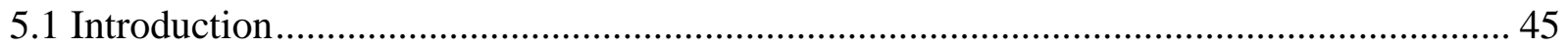

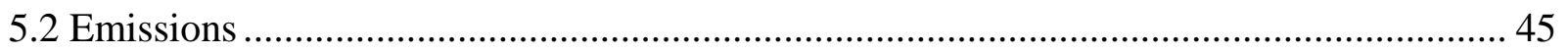

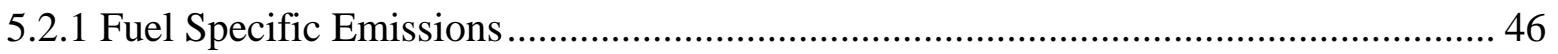

5.2.2 Oxides of Nitrogen Emissions ………………........................................................... 49

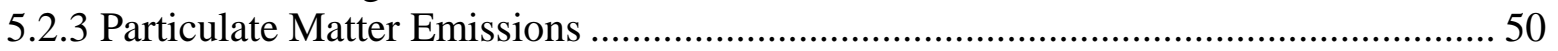

5.2.4 Carbon Monoxide Emissions ......................................................................................... 51

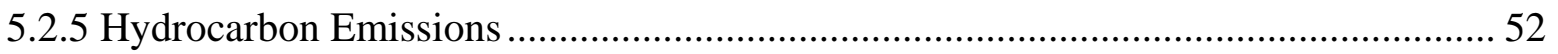

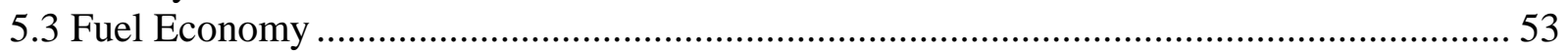

5.4 Engine Performance ............................................................................................. 55

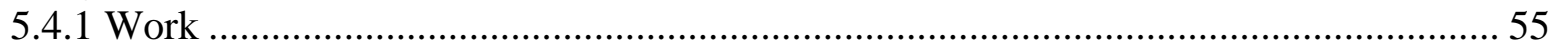

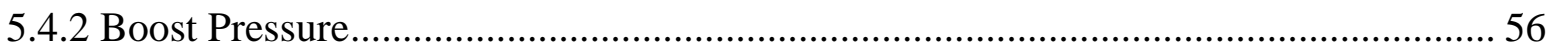

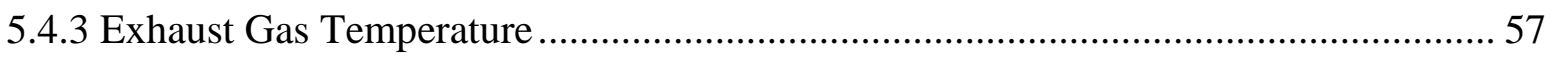

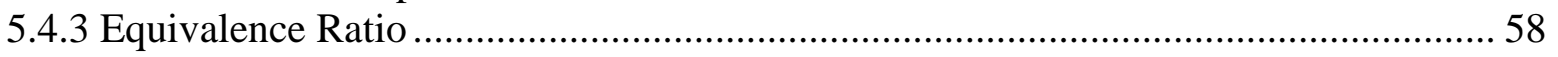

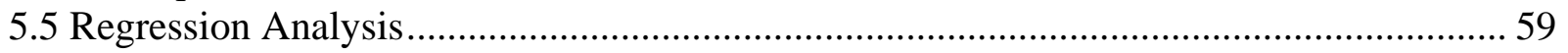

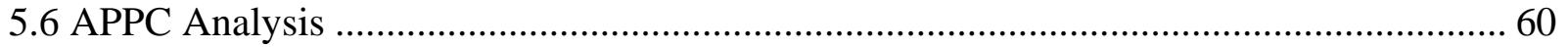

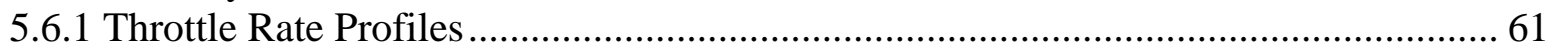

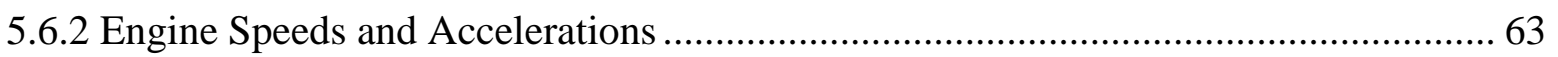

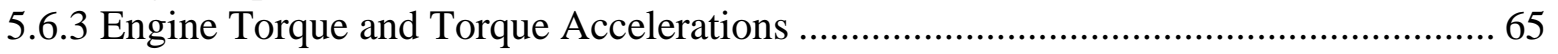

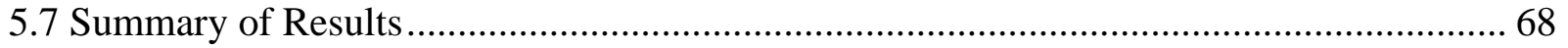

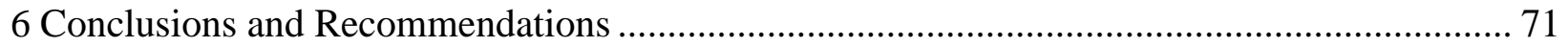

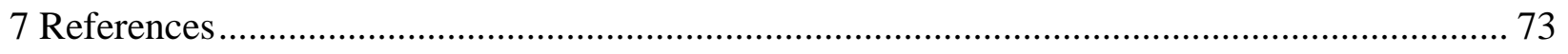

8 Appendices.................................................................................................................... 75 


\section{List of Figures}

Figure 2-1: Diesel engine with EGR valve and intake throttle [7] ..........................................9

Figure 3-1 Engine Speed as a Function of Time for a FTP ….........................................14

Figure 3-2 Engine Torque as a Function of Time for a FTP …...........................................15

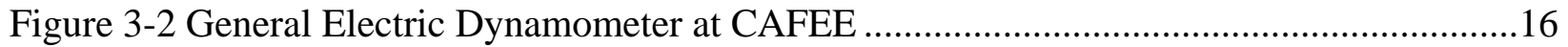

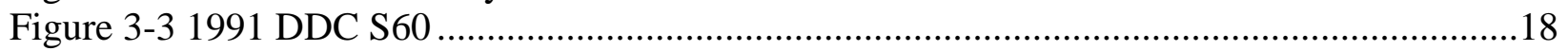

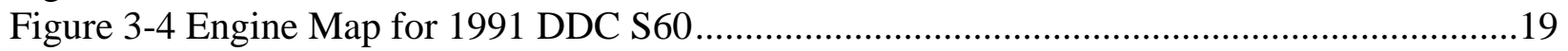

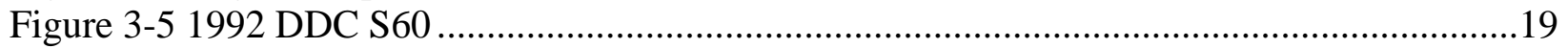

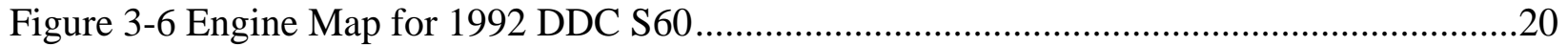

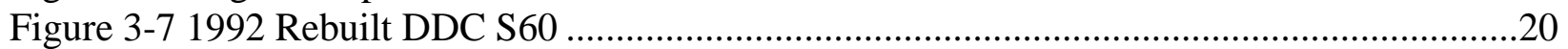

Figure 3-8 Engine Map for Rebuilt 1992 DDC S60 .............................................................21

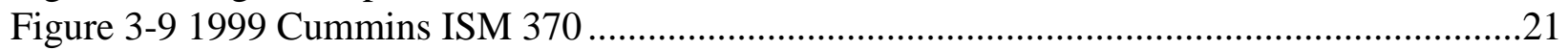

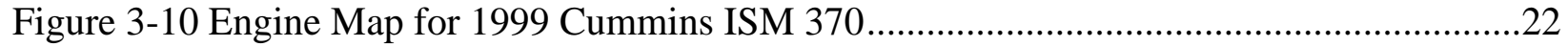

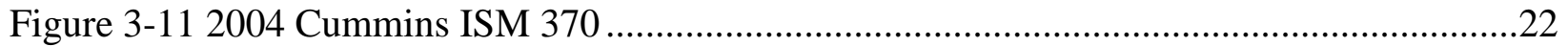

Figure 3-12 Engine Map for 2004 Cummins ISM 370 ....................................................23

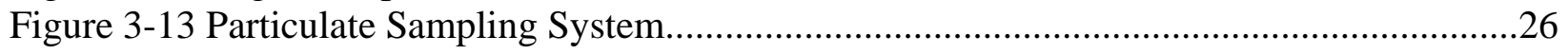

Figure 3-14 Exhaust Gas Analyzer Bench......................................................................27

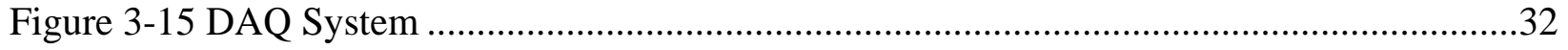

Figure 3-16 Clean Room Filter Scale Configuration............................................................36

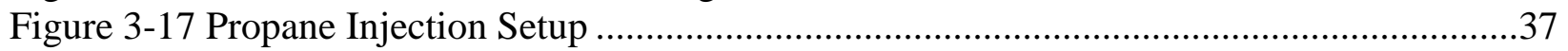

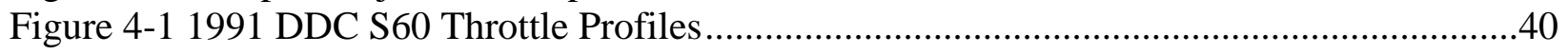

Figure 4-2 1992 DDC S60 Throttle Profiles ........................................................................41

Figure 4-3 Rebuilt 1992 DDC S60 Throttle Profiles ...............................................................41

Figure 4-4 1999 Cummins ISM 370 Throttle Profiles..............................................................42

Figure 4-5 2004 Cummins ISM 370 Throttle Profiles.............................................................43

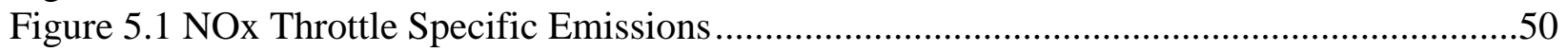

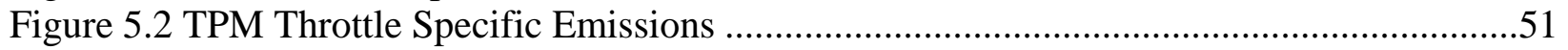

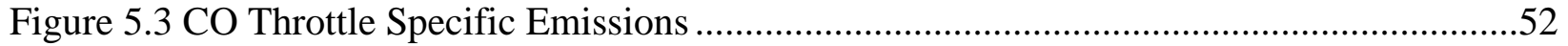

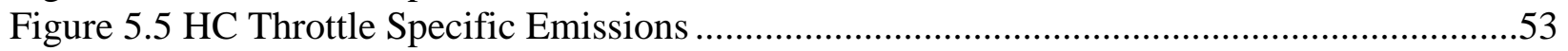

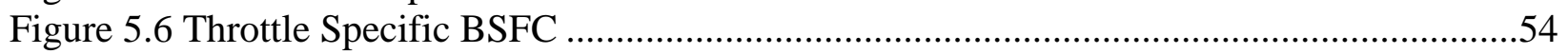

Figure 5.7 Throttle Specific Fuel Consumption ................................................................55

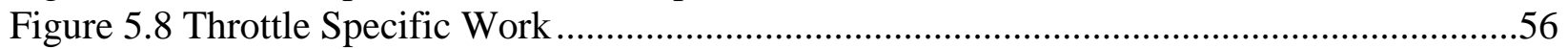

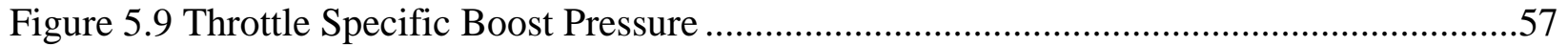

Figure 5.10 Throttle Specific EGT .....................................................................................58

Figure 5.11 ER and APP vs. Time for 1991 DDC with CP 0.05 Cert Fuel.................................59

Figure 5.12 Throttle 1 Throttle Position and Rate of Change for 1991 DDC Engine ..................61

Figure 5.13 Throttle 3 Throttle Position and Rate of Change for 1991 DDC Engine ...................62

Figure 5.14 Throttle Position and Rate of Change for 1991 DDC Engine ..................................62

Figure 5.15 Throttle 1 Engine Speeds and Accelerations for 1991 DDC Engine .......................63

Figure 5.16 Throttle 1 Engine Speeds and Accelerations for 1991 DDC Engine .......................64

Figure 5.17 Engine Speeds and Accelerations for 1991 DDC Engine .....................................64

Figure 5.18 Throttle 1 Engine Torque and Engine Torque Rate of Change for 1991 DDC Engine..... .65

Figure 5.19 Throttle 3 Engine Torque and Engine Torque Rate of Change for 1991 DDC Engine 
Figure 5.20 Engine Torque and Engine Torque Rate of Change for 1991 DDC Engine .............66

Figure 5.12 1991 DDC 5TH Order Polynomial Trendline for NOx.......................................69

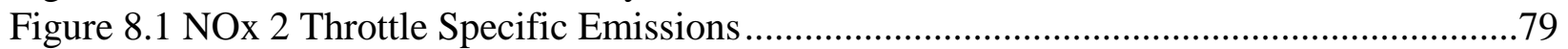

Figure 8.2 Throttle 1 Throttle Position and Rate of Change for 1992 DDC Engine ....................79

Figure 8.3 Throttle 3 Throttle Position and Rate of Change for 1992 DDC Engine ....................80

Figure 8.4 Throttle Position and Rate of Change for 1992 DDC Engine ...................................80

Figure 8.5 Throttle 1 Throttle Position and Rate of Change for 1992 Rebuilt DDC Engine ........81

Figure 8.6 Throttle 3 Throttle Position and Rate of Change for 1992 Rebuilt DDC Engine ........81

Figure 8.7 Throttle Position and Rate of Change for 1992 Rebuilt DDC Engine ........................82

Figure 8.8 Throttle 1 Throttle Position and Rate of Change for 1999 Cummins Engine..............82

Figure 8.9 Throttle 3 Throttle Position and Rate of Change for 1999 Cummins Engine..............83

Figure 8.10 Throttle Position and Rate of Change for 1999 Cummins Engine..........................83

Figure 8.11 Throttle 1 Position and Rate of Change for 2004 Cummins Engine.........................84

Figure 8.12 Throttle 3 Throttle Position and Rate of Change for 2004 Cummins Engine ............84

Figure 8.13 Throttle Position and Rate of Change for 2004 Cummins Engine...........................85

Figure 8.14 Throttle 1 Engine Speeds and Accelerations for 1992 DDC Engine ........................85

Figure 8.15 Throttle 3 Engine Speeds and Accelerations for 1992 DDC Engine .......................86

Figure 8.16 Engine Speeds and Accelerations for 1992 DDC Engine ......................................86

Figure 8.17 Throttle 1 Engine Speeds and Accelerations for 1992 Rebuilt DDC Engine.............87

Figure 8.18 Throttle 3 Engine Speeds and Accelerations for 1992 Rebuilt DDC Engine.............87

Figure 8.19 Engine Speeds and Accelerations for 1992 Rebuilt DDC Engine ...........................88

Figure 8.20 Throttle 1 Engine Speeds and Accelerations for 1999 Cummins Engine .................88

Figure 8.21 Throttle 3 Engine Speeds and Accelerations for 1999 Cummins Engine .................89

Figure 8.21 Engine Speeds and Accelerations for 1999 Cummins Engine ................................89

Figure 8.22 Throttle 1 Engine Speeds and Accelerations for 2004 Cummins Engine .................90

Figure 8.23 Throttle 3 Engine Speeds and Accelerations for 2004 Cummins Engine .................90

Figure 8.24 Engine Speeds and Accelerations for 2004 Cummins Engine .................................91

Figure 8.25 Throttle 1 Engine Torque and Torque Rate of Change for 1992 DDC Engine..........91

Figure 8.26 Throttle 3 Engine Torque and Torque Rate of Change for 1992 DDC Engine..........92

Figure 8.27 Engine Torque and Torque Rate of Change for 1992 DDC Engine.........................92

Figure 8.28 Throttle 1 Engine Torque and Torque Rate of Change for 1992 Rebuilt DDC

Engine

Figure 8.29 Throttle 3 Engine Torque and Torque Rate of Change for 1992 Rebuilt DDC

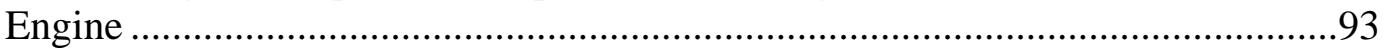

Figure 8.30 Engine Torque and Torque Rate of Change for 1992 Rebuilt DDC Engine..............94

Figure 8.31 Throttle 1 Engine Torque and Torque Rate of Change for 1999 Cummins Engine...94

Figure 8.32 Throttle 3 Engine Torque and Torque Rate of Change for 1999 Cummins Engine...95

Figure 8.33 Engine Torque and Torque Rate of Change for 1999 Cummins Engine ...................95

Figure 8.34 Throttle 1 Engine Torque and Torque Rate of Change for 2004 Cummins Engine...96

Figure 8.34 Throttle 3 Engine Torque and Torque Rate of Change for 2004 Cummins Engine...96

Figure 8.35 Engine Torque and Torque Rate of Change for 2004 Cummins Engine .97 


\section{List of Tables}

Table 2-1 EPA Emission Standards (g/bhp-hr) for Heavy-Duty Diesel Engines...........................3

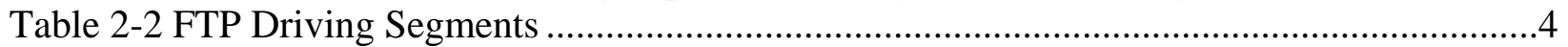

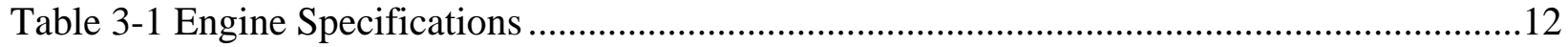

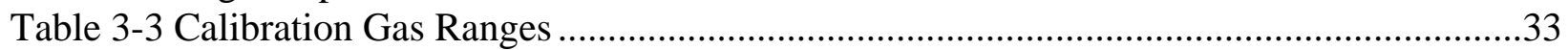

Table 4-1 Throttle Algorithms Examined with their Corresponding Engines and Fuels ..............38

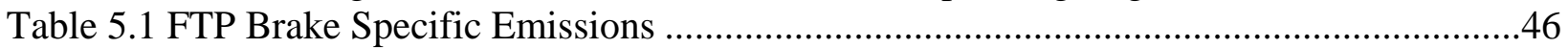

Table 5.2 FTP Throttle Specific Results for 1991 DDC S60 …...........................................48

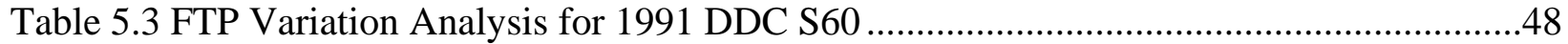

Table 5.4 Regression Analysis for 1991 DDC S60 Engine ...................................................60

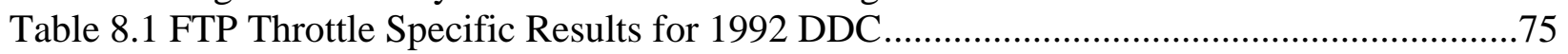

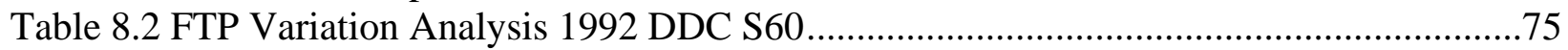

Table 8.3 FTP Throttle Specific Results for 1992 Rebuilt DDC S60 ........................................76

Table 8.4 FTP Variation Analysis 1992 Rebuilt DDC S60 ...................................................76

Table 8.5 FTP Throttle Specific Results for 1999 Cummins ISM 370 .....................................77

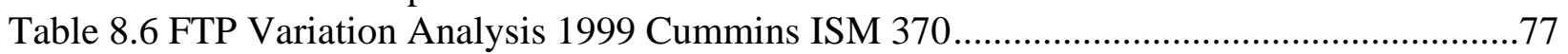

Table 8.7 FTP Throttle Specific Results for 2004 Cummins ISM 370 ....................................78

Table 8.8 FTP Variation Analysis 2004 Cummins ISM 370 .................................................78 


\section{Acknowledgements}

When I started my career as a master’s student in the summer of 2006, I never thought I would still be in school as the summer of 2009 approaches. During this time my appreciation for life has grown in an un-paralleled fashion. Completing my masters’ thesis started off as a mission, but turned into a promise. This promise was not only made to me, but to everyone who believed in and supported me. I have always been one to step up to challenges, and face them with the utmost strength and determination, but what I faced midway through my career as a master's student was unlike any challenge I had ever faced before. Over time, I have learned to live with this daily burden and even though it often threatens my physical strength, my mental and spiritual strength have grown to new heights that no disease could ever bring down.

First, I must thank all the doctors and nurses who cared for, diagnosed, and brought me back to a normal state of life. Without them, completing my masters' degree as well as this thesis would not have become a reality, and for that I thank them immensely.

I would like to thank Dr. Gregory J. Thompson for believing in me, and sticking with me, so that I could complete this thesis. He went above and beyond his role as my committee chairman in helping me through all aspects of this thesis. Many thanks to Dr. Mridul Gautam and Dr. Nigel Clark for providing me with invaluable technical contributions throughout my collegiate career. I thank Dr. John Nuszkowski for all the help that he provided towards this thesis, as well as Bradley Ralston for educating me in regards to all aspects of the ERC operation.

Many thanks to Wes Hardin, Ray Tincher, and Kevin Flaim for making long research hours in the test cell more enjoyable as well as being life long friends. The "Dynocologist” is a position everyone will long for! 
Finally many thanks to my parents and siblings, Thomas, Nancy, Bryan, Jenny, Kyle, and Kevin Ursic, who have provided me with continuous motivation and support through all my endeavors. 


\section{INTRODUCTION}

\subsection{PROLOGUE}

Since the creation of the Environmental Protection Agency (EPA) in 1970, the EPA has been targeting manufacturers of internal combustion engines in an effort to reduce emissions. Mobile sources of emissions are one of the areas of concern of the EPA, especially heavy-duty diesel engines (HDDE). HDDE manufacturers have been targeted to reduce emission constituents, especially oxides of nitrogen $\left(\mathrm{NO}_{\mathrm{x}}\right)$ and total particulate matter (TPM). $\mathrm{NO}_{\mathrm{x}}$ is a primary concern for the EPA as it is a component for formation of ground level ozone, produces acid rain and causes respiratory problems [2]. TPM is also a primary concern of the EPA as it can lead to health problems such as decreased lung function, asthma, chronic bronchitis, irregular heartbeat and can lead to heart attacks. TPM can also lead to environmental problems such as reduced visibility, higher levels of acidity in lakes and rivers, depletion of soil nutrients, as well as staining of important objects such as statues and monuments [2].

Due to these problems, the EPA in recent years has placed increasingly more stringent emission standards into effect. As a result, all HDDE's are required to be tested via the transient Federal Test Procedure (FTP). The FTP was designed to simulate the common operating modes of a bus or a truck driving in or around a city. More details are provided in Chapter 2. By 2010, manufacturers are required to meet the maximum allowable emission of $0.2 \mathrm{~g} / \mathrm{bhp}-\mathrm{hr}$ of $\mathrm{NO}_{\mathrm{x}}$ and $0.01 \mathrm{~g} / \mathrm{bhp}-\mathrm{hr}$ for TPM. This is a 95\% reduction in $\mathrm{NO}_{\mathrm{x}}$ and a $98 \%$ reduction in TPM when compared to their corresponding 1988 levels which was the first year of regulated HDDE emissions by the EPA [1]. Manufacturers have improved in-cylinder combustion processes from the 1980's through the 1990's to meet theses standards but since circa 2002 have had to implement external devices to reduce emissions such as selective catalyst reduction (SCR), 
particulate traps, and exhaust gas recirculation (EGR). But in order to meet these increasing stringent standards, more advancement in emission reduction must be achieved.

Variations in APPC during a transient engine operation can significantly vary the amount of emissions. APPC also has significant impact on the performance of HDDE's as well. However, literature lacks significant data in characterizing APPC and its effect on emissions and performance.

\subsection{OBJECTIVES}

The purpose of this thesis is to observe the effect of emissions on HDDE's when varied levels of APPC are applied and exercised on an engine during a FTP test (objective 1). Major concern for objective 1 examined emission constituents including $\mathrm{NO}_{\mathrm{x}}$ and TPM. Fuel consumption was another criterion investigated when varying APPC (objective 2). Several engines and multiple fuel types will be utilized and researched for the possibility of any correlation between the engine/fuel combination and throttle aggression on emissions and fuel economy.

Better understanding of the relationship between boost pressure, power, and exhaust gas temperature (EGT) during transient throttle changes is another goal of this investigation (objective 3). Better understanding of these relationships could lead to optimization of throttle aggression towards reduction of emissions and improved fuel economy. 


\section{Literature Review}

\subsection{Introduction}

Emissions created by HDDEs have been studied and regulated by the EPA since the 1970s. The Cape 21 study conducted in the early 1970's set the foundation for future HDDE emission testing. This study developed background criteria for typical transient routes commonly experienced by heavy duty trucks throughout urban areas. This study contributed to future methods of testing of HDDE emissions. For California, even more strict regulations have been set forth by the California Air Research Board (CARB). The EPA and CARB are primarily concerned with NOx, TPM, carbon monoxide (CO), and hydrocarbons (HC). Emission regulations for the past 20 years are displayed in Table 2-1 [2]. Units for all emissions are in grams per horsepower hour (g/hp-hr).

Table 2-1 EPA Emission Standards (g/bhp-hr) for Heavy-Duty Diesel Engines

\begin{tabular}{|c|c|c|c|c|c|c|}
\hline Year & HC & CO & NOx & TPM & $\begin{array}{c}\text { NMHC } \\
+ \text { NOx }\end{array}$ & NMHC \\
\hline 1988 & 1.3 & 15.5 & 10.7 & 0.6 & n/a & n/a \\
\hline 1990 & 1.3 & 15.5 & 6 & 0.6 & n/a & n/a \\
\hline 1991 & 1.3 & 15.5 & 5 & 0.25 & n/a & n/a \\
\hline 1994 & 1.3 & 15.5 & 5 & 0.1 & n/a & n/a \\
\hline 1998 & 1.3 & 15.5 & 4 & 0.1 & n/a & n/a \\
\hline $\begin{array}{c}2004 * \\
\text { (option 1) }\end{array}$ & 1.3 & 15.5 & n/a & 0.1 & 2.4 & n/a \\
\hline $\begin{array}{c}2004^{*} \\
\text { (option 2) }\end{array}$ & 1.3 & 15.5 & n/a & 0.1 & 2.5 & 0.5 \\
\hline $\begin{array}{c}2007- \\
2010^{* *}\end{array}$ & 1.3 & 15.5 & 0.2 & 0.01 & n/a & 0.14 \\
\hline $\begin{array}{l}* 2004 \text { was moved to October 2002 } \\
* * 2007-2010 \text { is a phase in period }\end{array}$ \\
\hline
\end{tabular}

\subsection{Federal Test Procedure (FTP)}

The FTP engine dynamometer cycle (hereafter referred to as “FTP”) was developed in the 1970s to study the emissions from on road heavy-duty vehicles. The FTP cycle was designed 
to simulate on road driving cycles for a heavy-duty diesel engine but with the engine exercised on an engine dynamometer. The FTP was developed from the same dataset that the Urban Dynamometer Driving Schedule (UDDS) chassis dynamometer cycle was developed from. It is noted that the UDDS is a 1060 second transient chassis dynamometer test designed to mimic 5.55 miles of typical urban roadways [2]. The FTP cycle is divided into four segments where the first and last segments are the same. Table 2-2 lists these driving segments. The FTP test procedure consists of three 20 minute events. The first event consists of the engine started from ambient conditions (termed a cold start) and exercised over the transient FTP test. The second 20 minute section consists of a 20 minute soak period with the engine turned off; post test procedures are performed and include samples taken, and analyzers checked for calibration, and data from the 20 minute transient test is reduced. The final 20 minute section of the test consists of the engine started from a warm condition (termed a hot start) and exercised over the same transient FTP test as in the cold start test. Similar to the second section, post test procedures are performed after the hot start section. The final emissions and fuel consumption are calculated such that one-seventh of the cold start and six-seventh of the hot start values are used as weighting functions.

Table 2-2 FTP Driving Segments

\begin{tabular}{|c|}
\hline Route \\
\hline 1. New York Non Freeway \\
2. Los Angeles Non Freeway \\
3. Los Angeles Freeway \\
4. New York Non Freeway \\
\hline
\end{tabular}




\subsection{Emission Standards}

Emission standards for heavy-duty diesel truck engines have been enforced since 1988. These emission standards were created by the EPA in order to protect the environment. As years pass and technology improves, these emission standards continue to become more stringent. These emissions standards can be found in Table 2-1, which displays how the EPA continues to reduce the allowable amount of TPM and NOx emissions emitted from heavy-duty diesel onroad engines. Note that $\mathrm{HC}$ and $\mathrm{CO}$ have not been reduced over this time period although the NMHC have been combined with the NOx emissions. HC and CO emissions from properly operating on-road HDDEs are typically an order of magnitude lower than regulated limit when the engine is exercised over the FTP cycle.

\subsection{Supplemental Emissions Test (SET) and Ramped Modal Cycle (RMC)}

A steady state supplemental emissions test (SET) was also created to study steady state emissions from newer heavy-duty diesel engines. The SET is a 28 minute test with 13 different steady state values, called modes in a SET. The SET was modeled off the European stationary cycle (ESC).

The ramped modal cycle (RMC) is another test cycle developed by the EPA thru input of industry [19]. The RMC is an extension of the SET where exhaust gases are continuously collected throughout the test, as opposed to samples being taken from portions of each mode of the SET. This test was designed to investigate the response from future catalyst systems like NOx absorbers which are expected to be used on future diesel engines. 
As seen in Table 2-1, regulations on NOx and TPM continue to demand for lower emissions. For 2010, the EPA is requiring a maximum of $0.2 \mathrm{~g} / \mathrm{hp}$-hr of NOx emissions. In order to meet those demands, new technologies must be applied to heavy-duty diesel engines.

Although the SET and RMC are powerful tools used to research emissions, they were not utilized towards this work, as they are geared for steady state situations. It is worth noting though, as the SET was used by my colleagues towards their masters' theses $[10,11,18]$. Future testing of variations of APPC could benefit from the RMC, as it incorporates transient conditions.

\subsection{Previous Studies}

Due to continual constraints placed on emission standards by the EPA, investigations into reduction of emissions have become imperative for diesel engine manufacturers. All aspects of heavy duty diesel engines are currently being examined for possibilities in reducing emission levels to meet the strict EPA's standards. This section covers previous studies which have relevance towards variations of pedal response, in efforts for reduction of emissions. It is noted that there is limited information available on the influence of APPC on the emissions generated during the FTP test.

\subsubsection{Engine Intake Throttling}

Mayer et al. [3] conducted a study on engine intake throttling for active regeneration of diesel particle filters. The throttle used in this study was for controlling air flow and not fueling

as found in a conventional HDDE. A method to increase exhaust temperature when required by throttling intake air-flow was presented. It was concluded that throttling of the intake 
downstream of the turbocharger compressor provides intriguing potential and that this system can be applied to retrofit applications in combination with catalytic methods [3].

\subsubsection{Throttle Construction}

Tabata et al. [4] at the New A.C.E. Institute conducted a study on the effects of multihole nozzles with throttle construction on diesel combustion and emissions with high-pressure fuel injection. The throttle used in this study was for controlling fuel flow at the injector and not the accelerator pedal as is studied in this research. A standard fuel injector nozzle was retrofitted with a larger throttle construction. Standard nozzles (STD) had production like sac volumes while the modified throttle construction (NTC) nozzles had an extension on the throttle down to the needle valve in the fuel injector. A single cylinder direct injection diesel engine with a four valve head configuration was utilized. The fuel injection was of the pressure intensifier type, a form of high pressure fuel injection. In performance, the modified NTC nozzle had no significant change in NOx emissions or fuel consumption, but smoke at high engine loads was reduced. With the aid of a high speed camera, spray profiles were also recorded. At lower pressures, sprays had no significant change in profile but at high pressures, sprays had a remarkable change in flow pattern.

\subsubsection{Simulation of Dynamics on Fuel Injection}

Itoh and Ishii conducted a simulation and analysis on dynamic characteristics of diesel fuel injection systems. They claim that the dynamic characteristics of a diesel fuel injection system have a significant role in how cyclic fluctuation of engine speed occurs. This fluctuation was termed "hunting." Experiments were conducted to examine the mechanical governor's frequency response. It was shown that: 
(1) The "overshoot" or "undershoot" phenomena occur within a limited zone, and therefore cannot be eliminated from the "hunting" criteria.

(2) This phenomenon is directly affected by the change in residual pressure in the injection pipe.

Based on the above criteria, Itoh and Ishii created a simulation model for investigating the dynamics of fuel delivery. With the results of their investigation, Itoh and Ishii anticipate their work would help in development of new improved fuel injection systems [5].

\subsubsection{Intake Throttle and EGR Control}

Van Nieuwstadt conducted an investigation on coordinated control of the EGR valve and the intake throttle for better fuel economy in diesel engines. He stated that modern heavy-duty diesel engines may be equipped with an intake throttle (ITH) and an EGR. The ITH assists the EGR in depressing intake manifold pressure, thus resulting in a greater pressure differential across the EGR valve. It also helps to flow EGR at low engine speeds.

Van Nieuwstadt proposed installing a throttle plate on the intake to help EGR at low engine speeds. This is displayed in Figure 2-1. When exhaust gases after the turbocharger have achieved positive boost pressure there is sufficient flow through the EGR valve. At lower engine speeds and loads, where the turbocharger is not making positive boost pressure, recirculation of exhaust gases becomes a problem due to the higher pressure in the intake manifold.

Van Nieuwstadt states that EGR can be optimized with the aid of a throttle in the intake, and therefore reducing NOx emissions. Through feedback from the mass air flow (MAF) sensor, EGR can be optimized and fuel economy can be increased. At low load, the EGR valve is fully open and the intake throttle is deactivated, resulting in reduced pumping losses. This is the cause of the increased fuel economy. Joining the intake throttle and EGR valve with the MAF sensor also reduces calibrations, due to the EGR following the MAF setpoints [7]. 


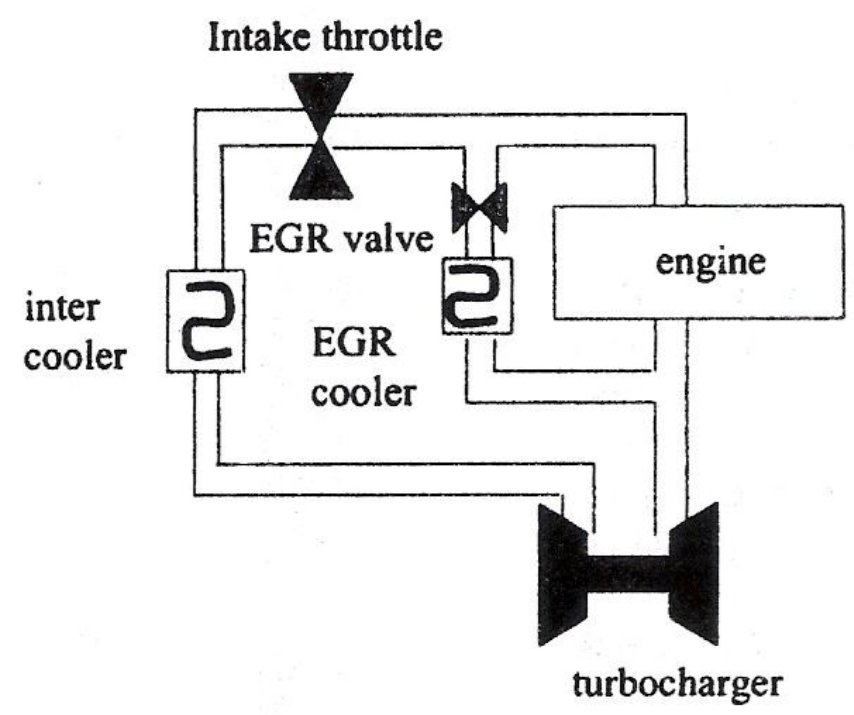

Figure 2-1: Diesel engine with EGR valve and intake throttle [7]

\subsubsection{Cycle-by-Cycle Transient Heat Release}

Assanis et al. conducted a study in order to develop a systematic methodology for performing transient heat release analysis in a diesel engine. Motivation for their analysis spawned from invaluable contributions to the development of combustion chambers and fuel injection systems that steady-state heat release analysis has provided. Strategies for characterizing the mass of air trapped in the cylinder and the mass of fuel injected on a cycle-bycycle basis were developed.

Cycle-by-cycle measurements of fuel utilization required novel techniques to be developed. Assanis et al. developed a method for profiling the fuel injection pressure per cycle through measurement of the rocker arm strain gain signal. Along with other currently available criteria the instantaneous mass flow rate of fuel injected into the cylinder was inferred.

Cycle-by-cycle measurement of the mass of air trapped in the cylinder has presented challenges for previous studies, including steady-state investigations, due to the presence of the 
valve overlap period, where the intake and exhaust valves are simultaneously open, therefore allowing air to pass through the cylinder chamber without being part of the combustion process.

Turbocharged engines pose an even greater challenge for this measurement as the valve overlap period is typically prolonged to cool the cylinder chamber and enhance scavenging effects. This study attempted to determine trapped air mass by splitting the induction process into two stages; one stage being when the exhaust valves are closed and the second stage occurring when the intake and exhaust valves are both open, thus overlap occurring. An equation was developed for measurement of air trapped in the cylinder on a cycle-by-cycle basis.

The techniques for measurement or trapped air mass and fuel injected on a cycle-by-cycle basis provided a means of characterizing heat release properties for transient engine conditions. Instantaneous thermodynamic properties of the combustion chamber were analyzed. Assansis et al. concluded that the specific heat ratio of the working fluid can vary significantly within the engine cycle and from cycle to cycle. Turbo-lag during load changes was shown to cause longer ignition delays and more pronounced premix burning. This study showed that when the mass of fuel injected reaches its maximum value, the intake manifold pressure is still increasing. At this state, the fuel-air equivalence ratio was observed to be significantly higher than at the corresponding steady state values.

\subsection{Motivation}

Since diesel emission regulations were instituted, many studies have been conducted on reducing the emission levels. Through these studies, emission levels have drastically dropped to meet the EPA's strict standards. With the EPA continuing to demand lower levels of emissions, more investigations in methods of reduction of emissions must be conducted. Few studies conducted on variations in throttle aggression have sparked curiosity in possibilities of reduced 
emissions. Likewise, the effects that throttle aggression has on emissions are also of interest to the emissions inventory modeling community. 


\section{Experimental Equipment and Procedures}

\subsection{Introduction}

This section outlines the equipment utilized in this study and the general procedures followed. Studies were conducted at the Center for Alternative Fuels, Engines and Emissions (CAFEE) at West Virginia University, which operates under the specifications of 40 CFR Part 86, subpart N, and the standards set by ISO 8178. Table 3-1 lists the engines and their specifications utilized in the study.

Table 3-1 Engine Specifications

\begin{tabular}{|c|c|c|c|c|c|}
\hline Engine Manufacturer & $\begin{array}{l}\text { Detroit Diesel } \\
\text { Corporation }\end{array}$ & $\begin{array}{l}\text { Detroit Diesel } \\
\text { Corporation }\end{array}$ & $\begin{array}{l}\text { Detroit Diesel } \\
\text { Corporation }\end{array}$ & Cummins & Cummins \\
\hline Engine Model \& Year & $\begin{array}{c}\text { DDC Series 60, } \\
1991\end{array}$ & $\begin{array}{c}\text { DDC Series 60, } \\
1992\end{array}$ & $\begin{array}{l}\text { Rebuilt DDC Series 60, } \\
1992\end{array}$ & $\begin{array}{c}\text { ISM } 370 \text { ESP, } \\
1999\end{array}$ & $\begin{array}{l}\text { ISM 370, } \\
2004\end{array}$ \\
\hline Configuration & Inline 6 cylinder & Inline 6 cylinder & Inline 6 cylinder & Inline 6 cylinder & Inline 6 cylinder \\
\hline Displacement (L) & 11.1 & 12.7 & 12.7 & 10.7 & 10.7 \\
\hline Peak Power (hp) & 345 @ 1800 rpm & $360 @ 1810$ rpm & $360 @ 1810$ rpm & $370 @ 2100$ rpm & $370 @ 2100$ rpm \\
\hline Peak Torque (ft-lbs) & $1335 @ 1200$ rpm & $1450 @ 1200$ rpm & $1450 @ 1200$ rpm & $1450 @ 1200$ rpm & $1450 @ 1200$ rpm \\
\hline Compression Ratio & 16.0:1 & $15: 1$ & $15: 1$ & $16.5: 1$ & $16.5: 1$ \\
\hline Bore \& Stroke $(\mathrm{mm})$ & $130 \times 139$ & $130 \times 160$ & $130 \times 160$ & $125 \times 147$ & $125 \times 147$ \\
\hline Forced Induction & $\begin{array}{c}\text { Turbocharged } \\
\& \\
\text { Intercooled }\end{array}$ & $\begin{array}{c}\text { Turbocharged } \\
\& \\
\text { Intercooled }\end{array}$ & $\begin{array}{c}\text { Turbocharged } \\
\& \\
\text { Intercooled }\end{array}$ & $\begin{array}{c}\text { Turbocharged } \\
\& \\
\text { Intercooled }\end{array}$ & $\begin{array}{c}\text { Variable } \\
\text { Geometry } \\
\text { Turbocharged } \\
\text { \& } \\
\text { Intercooled } \\
\end{array}$ \\
\hline Exhaust Gas Recirculation (EGR) & N/A & N/A & N/A & N/A & Cooled EGR \\
\hline
\end{tabular}

The engines used in the study have a rated maximum power output ranging from $345 \mathrm{hp}$ to $370 \mathrm{hp}$, and vary in cylinder displacement from 10.7 liters to 12.7 liters. This section outlines these engines as well as the equipment used in measuring and recording the engine performance and emissions throughout the study. 


\subsection{Test Cycles}

Test cycles are utilized for certification of emissions and to investigate the fuel economy of diesel engines. They are designed to be compatible with both chassis and engine dynamometer systems. Chassis dynamometers are used for certification of light-duty diesel engines (LDDE) (along with gasoline and other fuels) which includes truck classes 1 through 5 with a maximum gross vehicle weight rating (GVWR) of 19,500 lb. HDDE's, which utilize engine dynamometers for certification testing are classified in truck classes 6 through 8 and cover all trucks with GVWR over 19,500 lb [17].

There are several test cycles that are designed for testing of HDDE's on an engine dynamometer. Transient tests, such as the FTP, are designed to simulate on-road driving conditions. There are also other test cycles for testing steady state conditions, such as the SET or RMC tests. Prior to use of a HDDE in the United States, emissions testing is required to certify the engine (or representative number of engines in a given family). Other testing procedures are set forth for foreign countries that utilize HDDE's such as Europe which tests their emissions with the ETC transient test and ECE R49 steady state test.

This study focused on the FTP only as pedal response relates directly to a transient state, not offered on the SET, or other similarly cycles with predominately steady operation. The FTP was designed to simulate on-road transient conditions including city and freeway driving that a truck or bus would experience. The FTP is broken down into four driving segments. Each is to simulate the drive along these segments. The FTP begins with a simulation of driving a New York non-freeway (NYNF) route, followed by a typical route on a Los Angeles non-freeway route (LANF). After this LANF route, a Los Angeles freeway (LAFW) route is simulated and finally the FTP finishes with a repeat of a NYNF segment. Figures 3-1 and 3-2 display the speed 
and torque characteristics for the duration of the FTP. Note that these plots were developed from an actual FTP ran on a 1991 Detroit Diesel S60 engine.

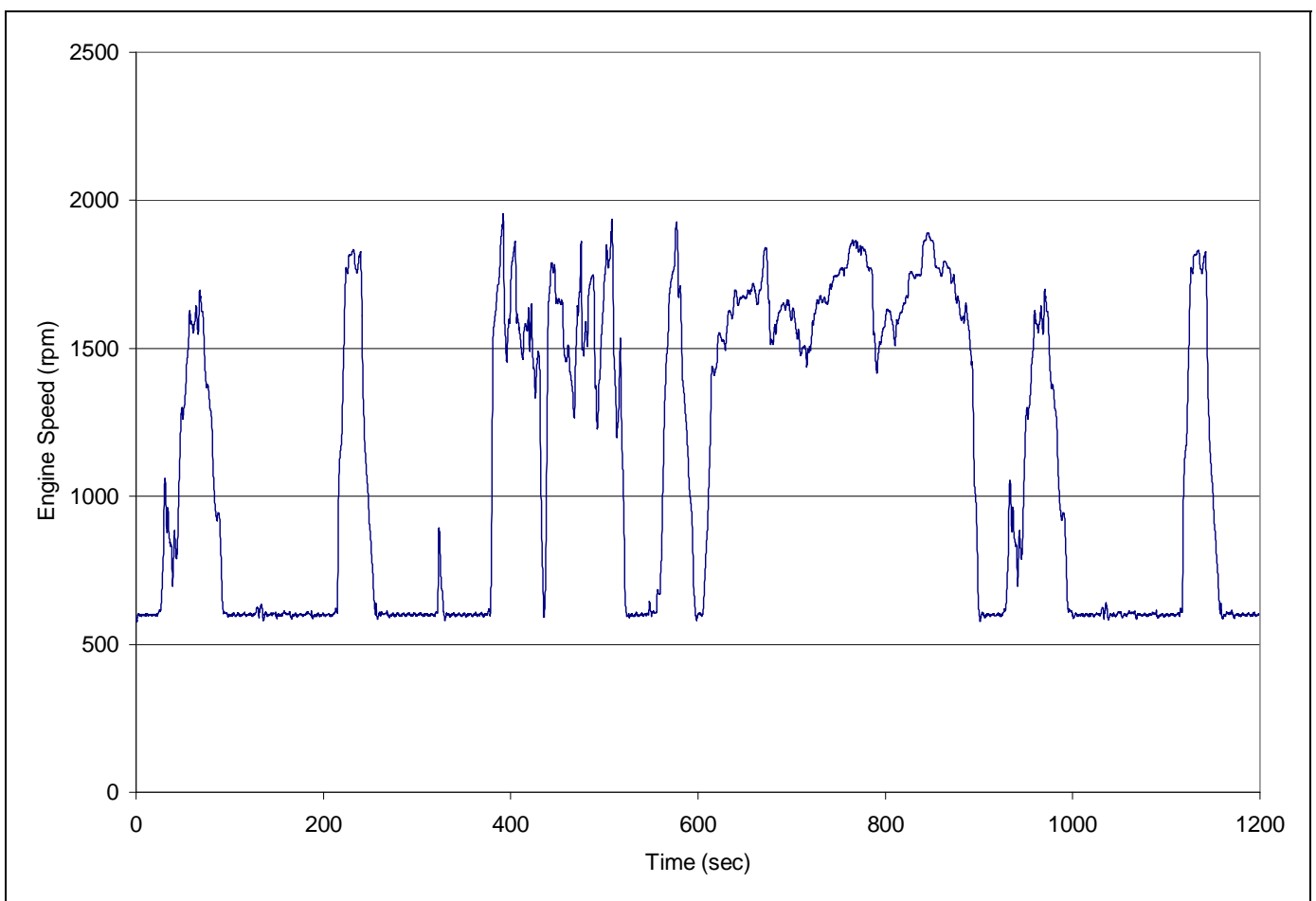

Figure 3-1 Engine Speed as a Function of Time for a FTP 


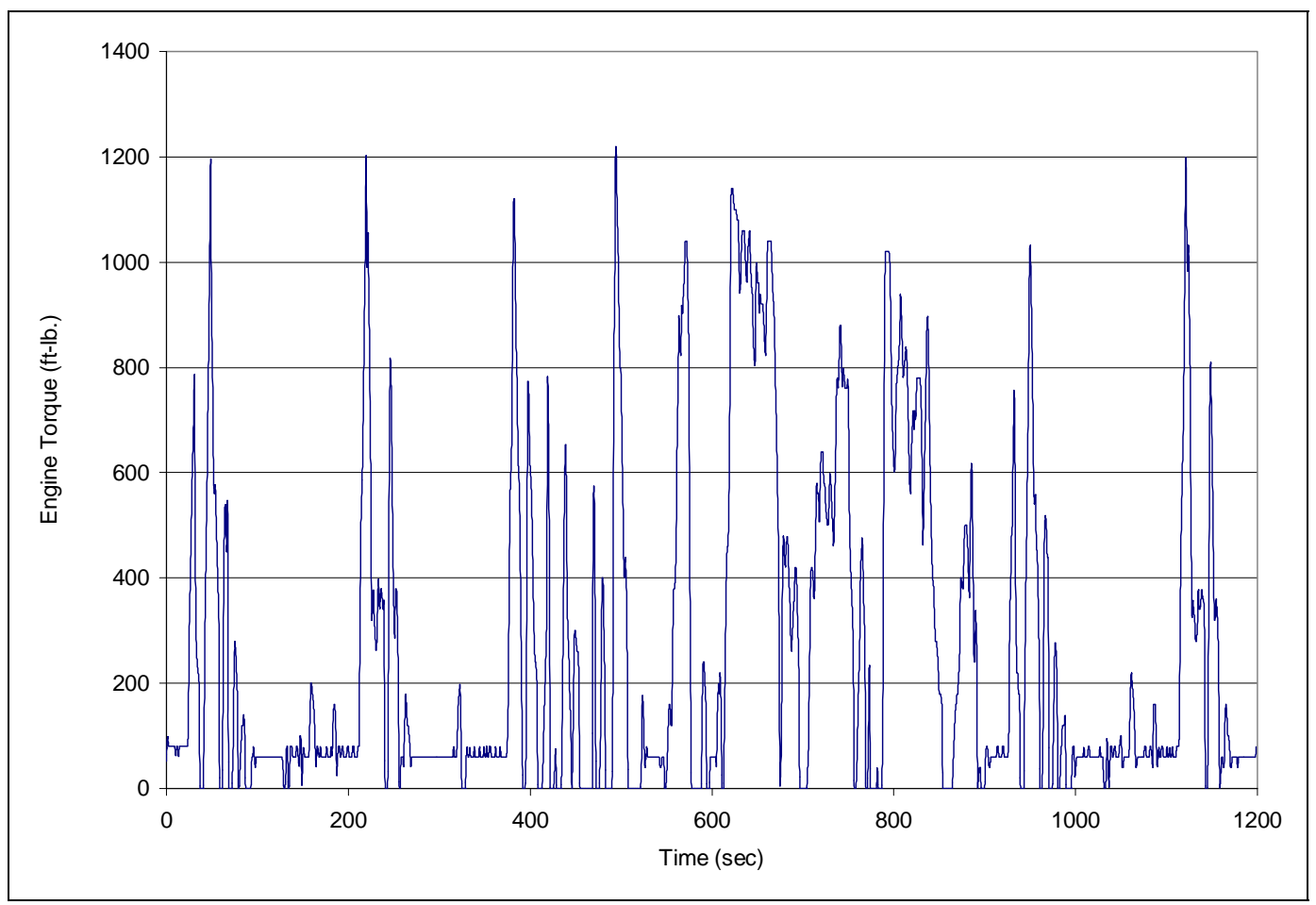

Figure 3-2 Engine Torque as a Function of Time for a FTP

\subsection{Test Engines}

Five engines were utilized in this testing. In order to properly operate a heavy-duty diesel engine inside a test cell, modifications were made to engine accessories, primarily in the cooling of its fluids. The heavy-duty diesel engines studied feature an air-to-air intercooler setup when mounted in their trucks, and rely on air passing across the fins to cool the intake charge. In the test cell the engine is stationary with no airflow, so a liquid-to-air intercooler was utilized to cool the intake charge. Similarly the radiator was replaced with a liquid-to-liquid type heat exchanger to keep the engine at proper running temperature.

The CAFEE heating, ventilating, and air-conditioning system supplied the intake air for the engine, and a laboratory-grade filtration system was utilized. An exhaust backpressure valve was incorporated in the exhaust system in order to simulate the backpressure provided by the 
original equipment manufacturer’s (OEM) exhaust. All accessories including the alternator, power steering and air-conditioning were either removed or disconnected.

Each test engine was connected to a General Electric (GE) model DYC 243 dynamometer via a driveshaft. This GE dynamometer was rated to be capable of delivering 500 hp and absorbing 550hp at a maximum speed of $3000 \mathrm{rpm}$. A load cell was attached to the armature on the dynamometer. This load cell was calibrated by applying weights to the end of the armature. Figure 3-2 displays the setup of the dynamometer and the load cell.

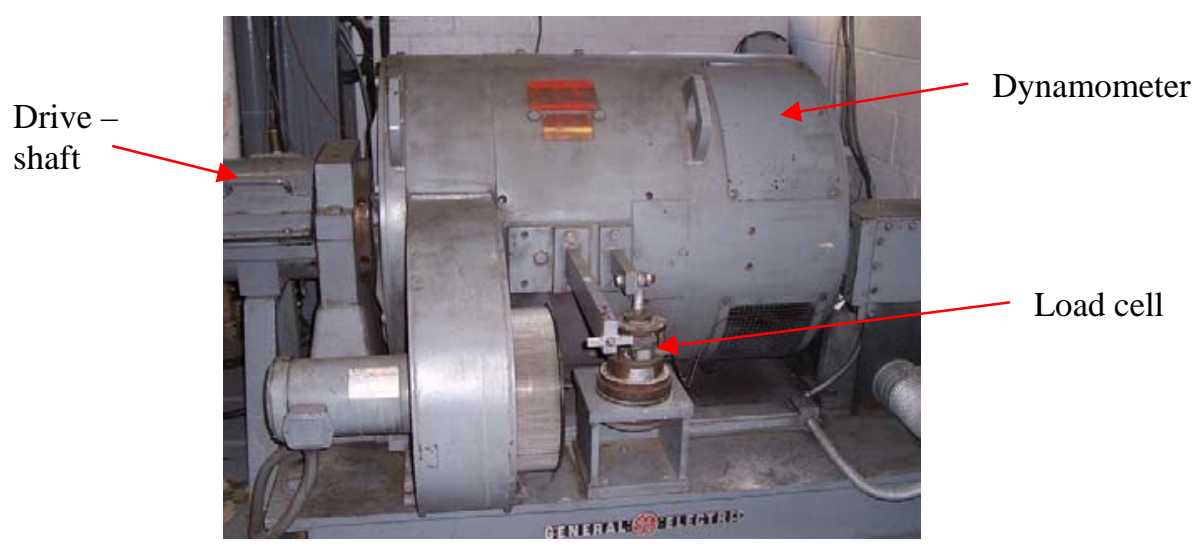

Figure 3-2 General Electric Dynamometer at CAFEE

\subsubsection{Detroit Diesel Series 60 Engine}

The 1991 DDC S60 engine was the oldest engine utilized in the study. It was acquired on loan from National Renewable Engine Laboratories (NREL). Prior to NREL acquiring this engine, it was used by the Colorado School of Mines for fuel studies. The engine was completely rebuilt according to Detroit Diesel Corporation’s specifications. It was considered a pristine laboratory engine and well qualified for testing of its emissions. Specifications for this engine are displayed in Table 3-1. The engine can be seen in Figure 3-3 and the performance of this engine can be seen in the corresponding plot, Figure 3-4. 


\subsubsection{Detroit Diesel Series 60 Engine}

The 1992 DDC S60 engine was a salvaged engine with no known history prior to WVU's CAFEE acquiring it. This engine provided a good choice in comparison with the 1991 DDC as it is a similar engine except it has a higher displacement as well as having a slightly lower compression ratio when compared to the 1991 DDC S60 engine. Prior to testing, the cylinder

head was cleaned and regular maintenance was performed. Specifications for this engine are displayed in Table 3-1. The engine can be seen in Figure 3-4 and the performance of this engine can be seen in the corresponding plot, Figure 3-5.

\subsubsection{Rebuilt 1992 Detroit Diesel Series 60 Engine}

A second 1992 DDC S60 engine was also procured by WVU CAFEE. This engine was also a salvage engine that the WVU CAFEE acquired that had no known history on it. This engine was completely rebuilt in 2006 in compliance with DDC specifications and is a sister engine to the 1992 DDC S60 engine discussed prior. The engine was then aged for 100 hours on the engine dynamometer prior to testing. As with the 1991 DDC, this engine can be considered a pristine laboratory engine and well qualified for testing of its emissions. Specifications for this engine are displayed in Table 3-1. The engine can be seen in Figure 3-6 and the performance of this engine can be seen in the corresponding plot, Figure 3-7. This engine was also used for researching in-cylinder pressure data for a dissertation conducted by Nuszkowski [12]. None of the in-cylinder results will be discussed in this work.

\subsubsection{Cummins ISM 370 Engine}

This engine was acquired directly from Cummins, Inc. for a previous study conducted by the WVU CAFEE and has remained in the inventory of the CAFEE since. This engine fits well 
with this study as it is a newer engine than the DDC's and is confined by a more strict set of emission standards from 1998. This engine is also considered a pristine laboratory engine. Specifications for this engine are displayed in Table 3-1. The engine can be seen in Figure 3-8 and the performance of this engine can be seen in the corresponding plot, Figure 3-9.

\subsubsection{Cummins ISM 370 Engine}

The 2004 Cummins ISM 370 engine was the most current engine used in this research. Its displacement, compression ratio, and power output are all identical to the 1999 ISM 370 engine, while meeting a lower emission standard; 2004 option 2 displayed in Table 2-2. This engine was also fitted with a variable-geometry turbocharger, as well as an EGR system. Specifications for this engine are displayed in Table 3-1. The engine can be seen in Figure 3-10 and the performance of this engine can be seen in the corresponding plot, Figure 3-11.

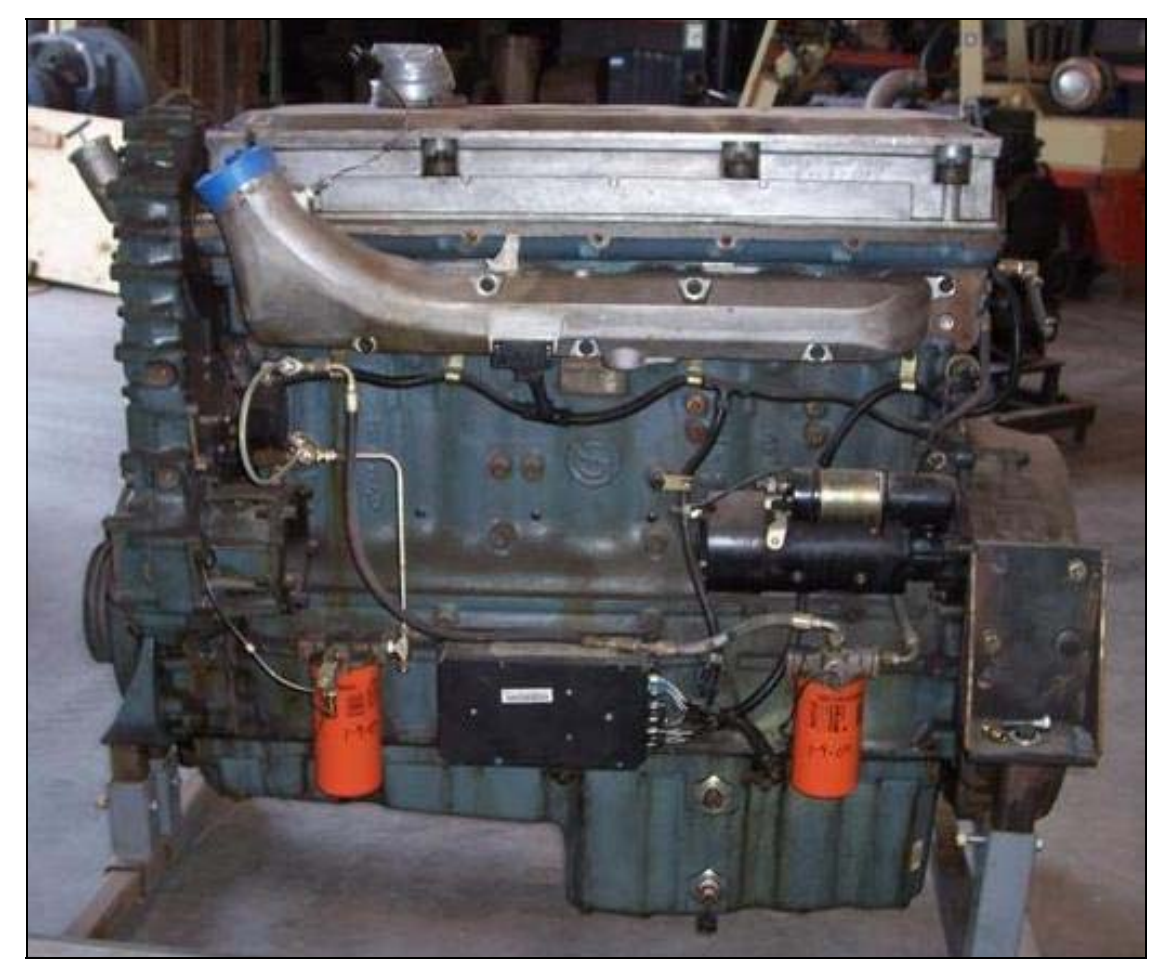

Figure 3-3 1991 DDC S60 


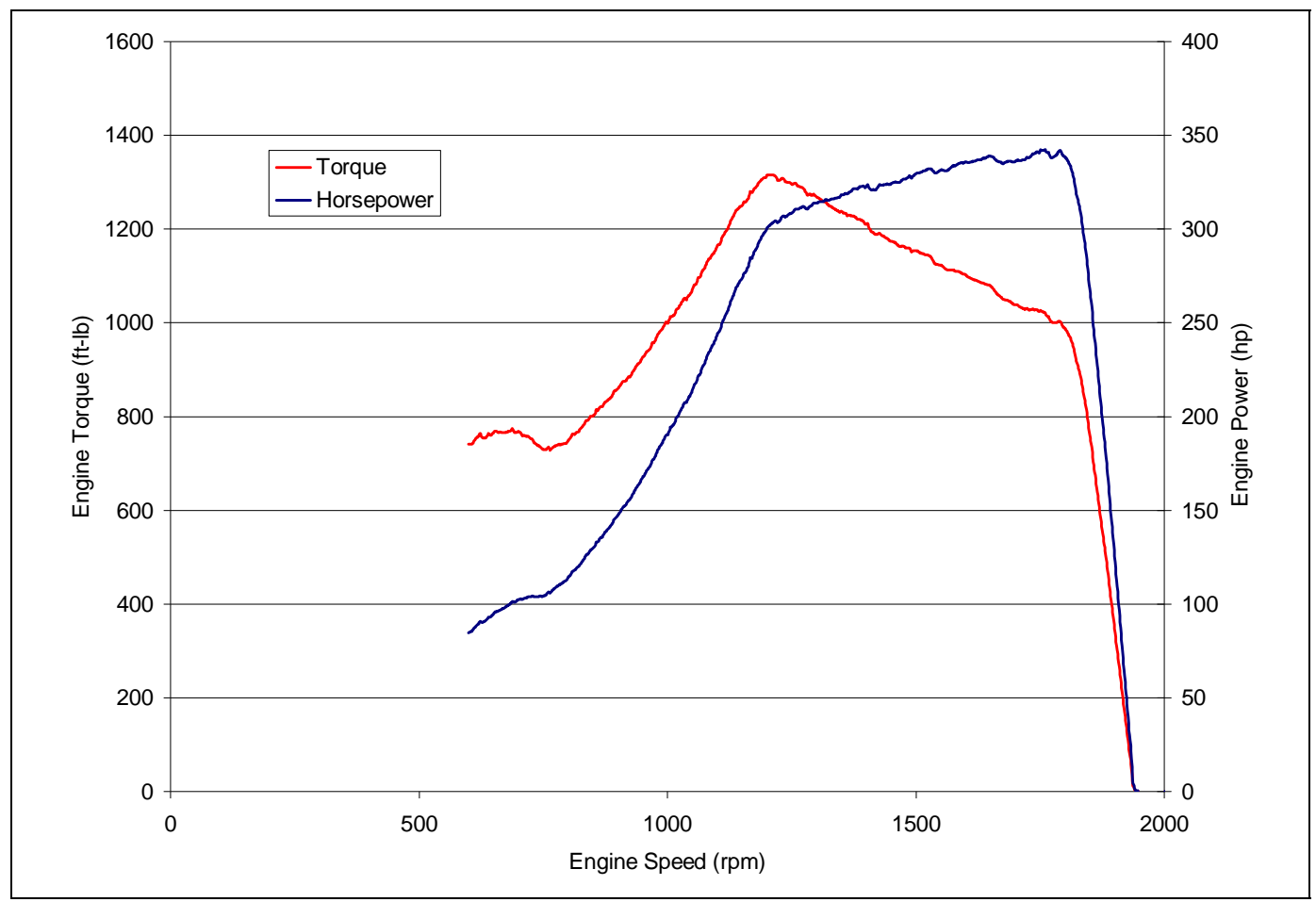

Figure 3-4 Engine Map for 1991 DDC S60

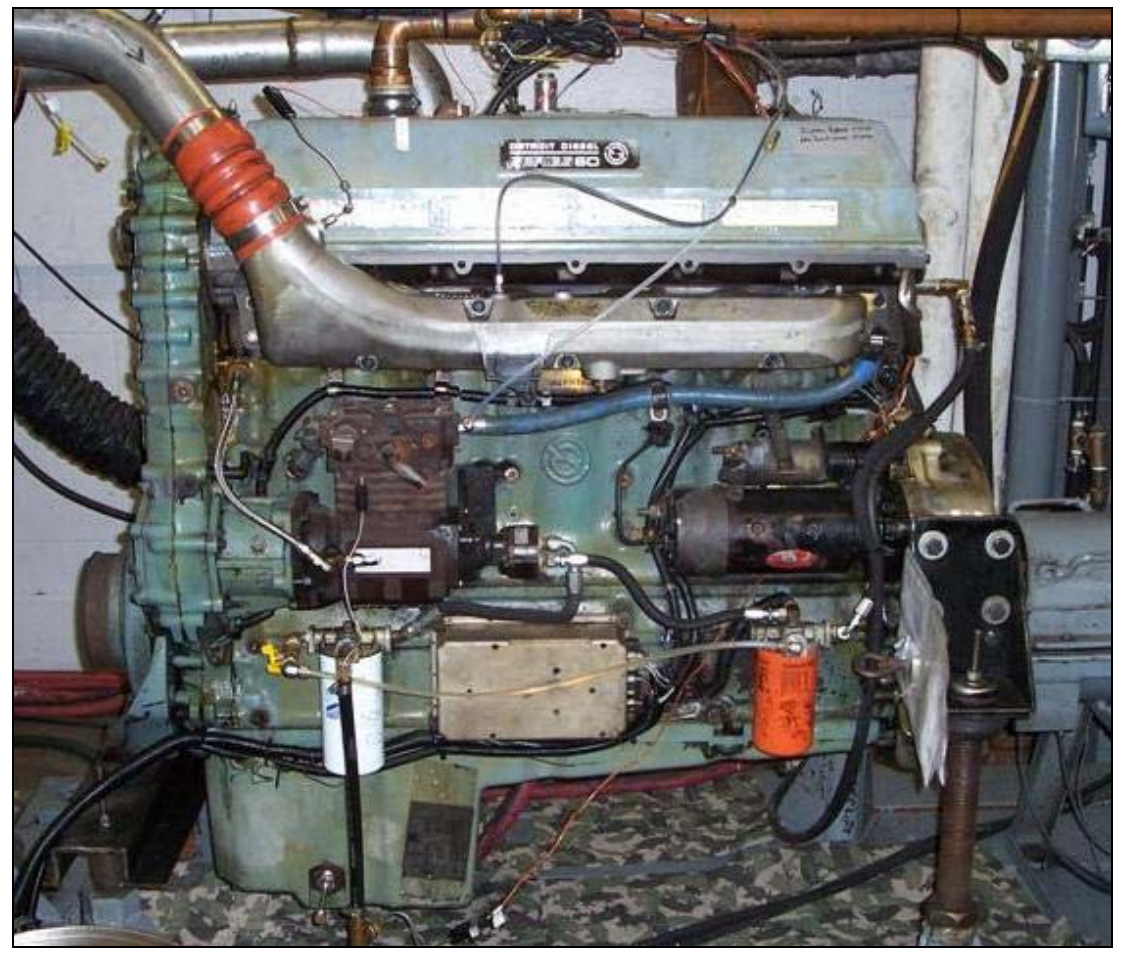

Figure 3-5 1992 DDC S60 


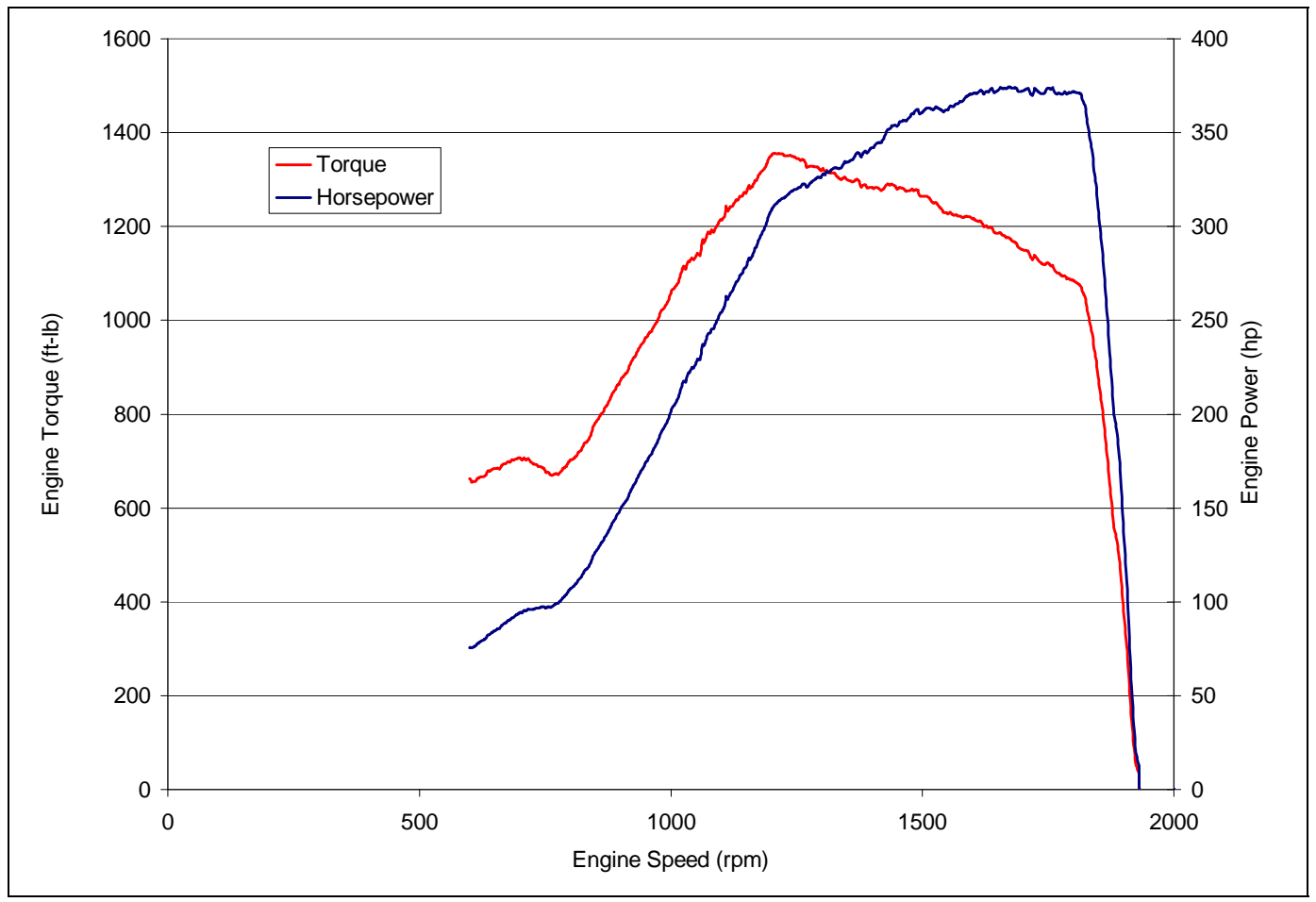

Figure 3-6 Engine Map for 1992 DDC S60

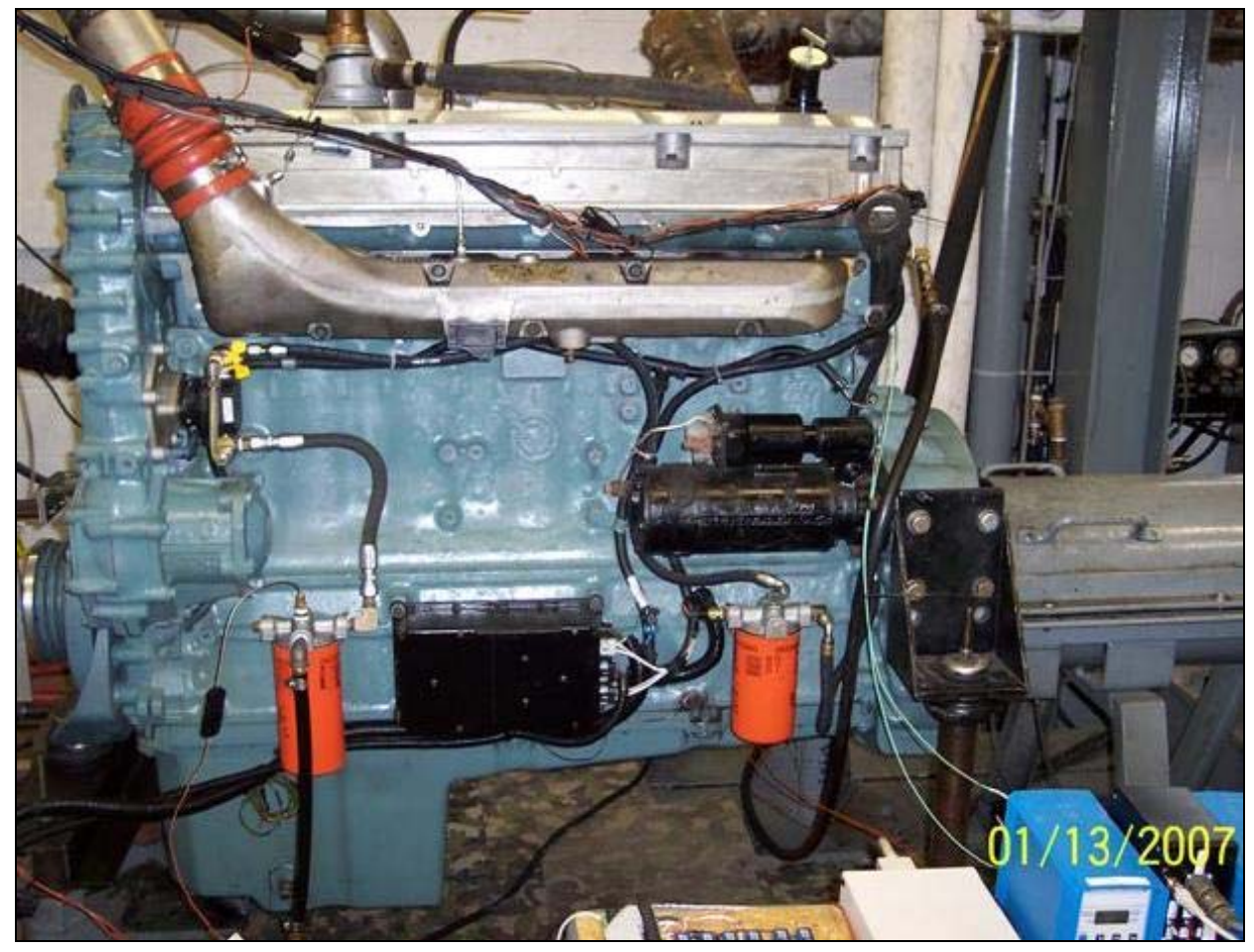

Figure 3-7 1992 Rebuilt DDC S60 


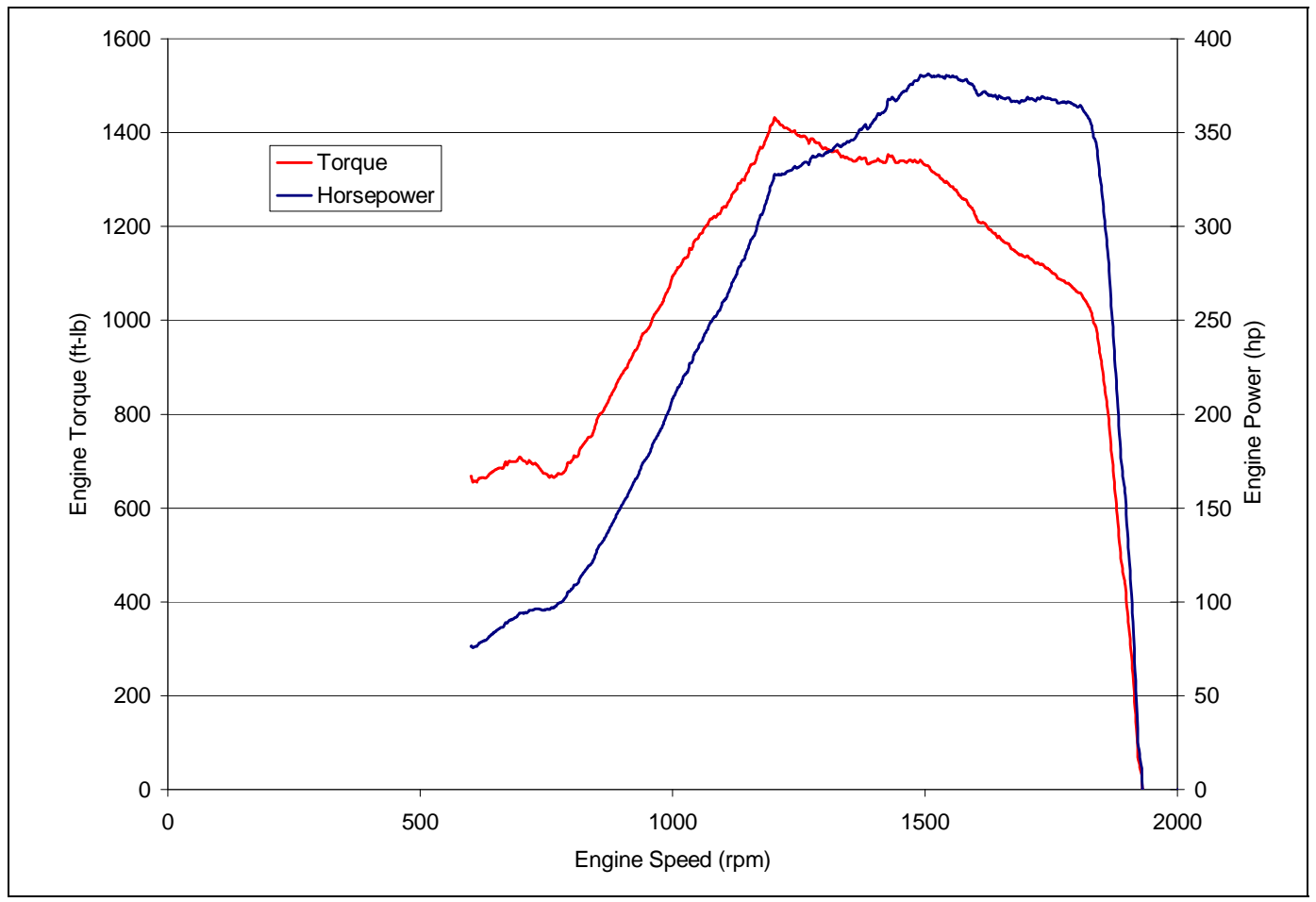

Figure 3-8 Engine Map for Rebuilt 1992 DDC S60

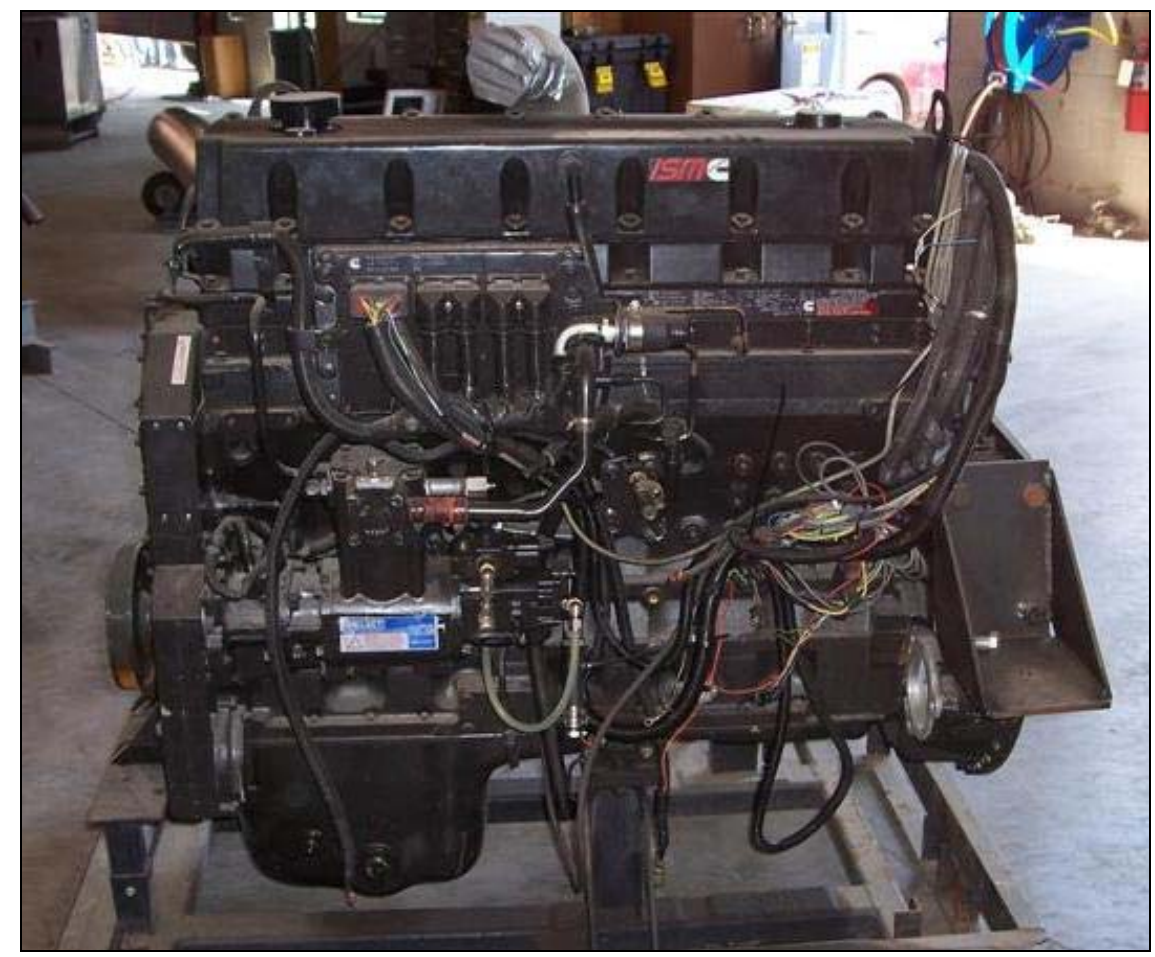

Figure 3-9 1999 Cummins ISM 370 


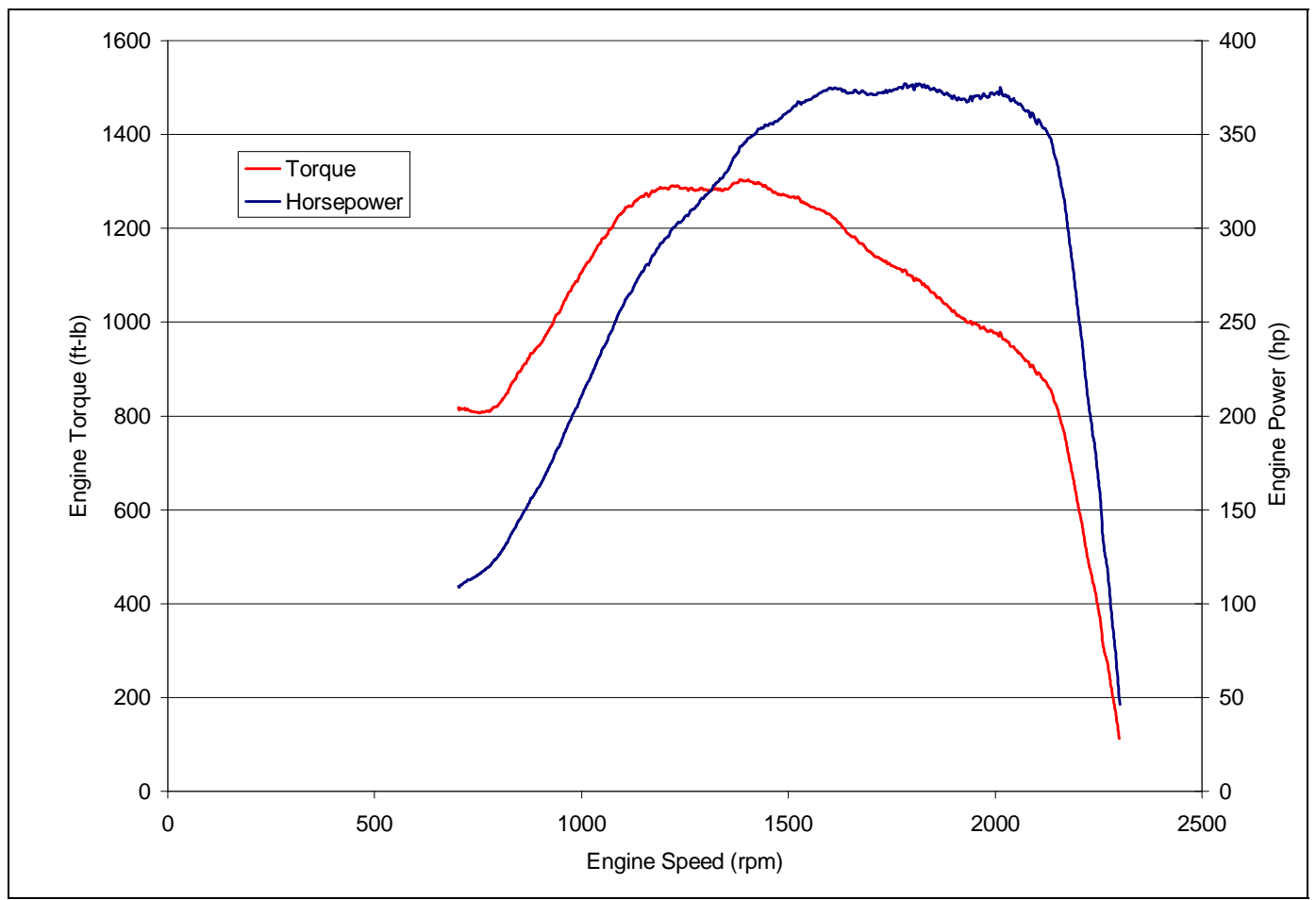

Figure 3-10 Engine Map for 1999 Cummins ISM 370

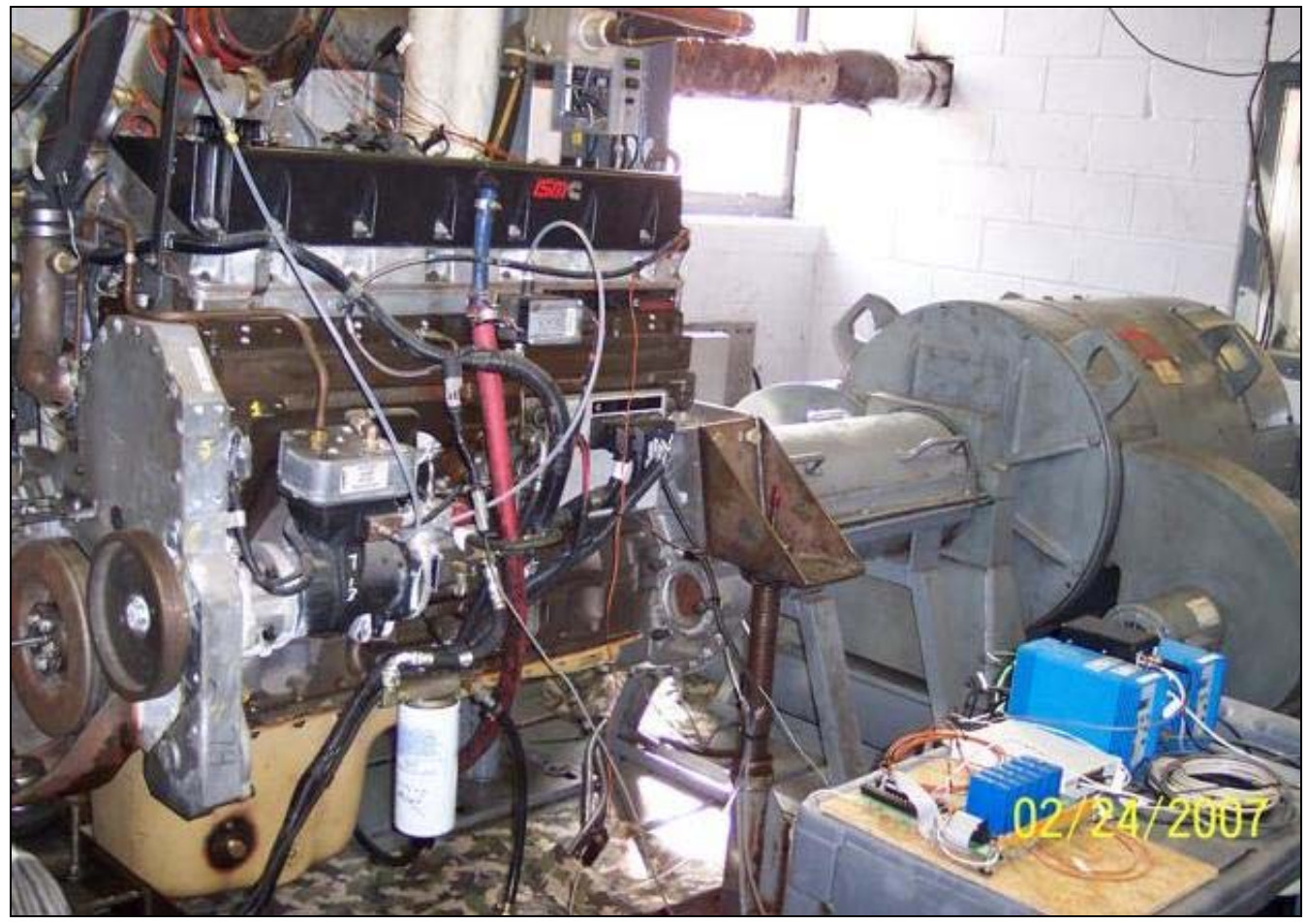

Figure 3-11 2004 Cummins ISM 370 


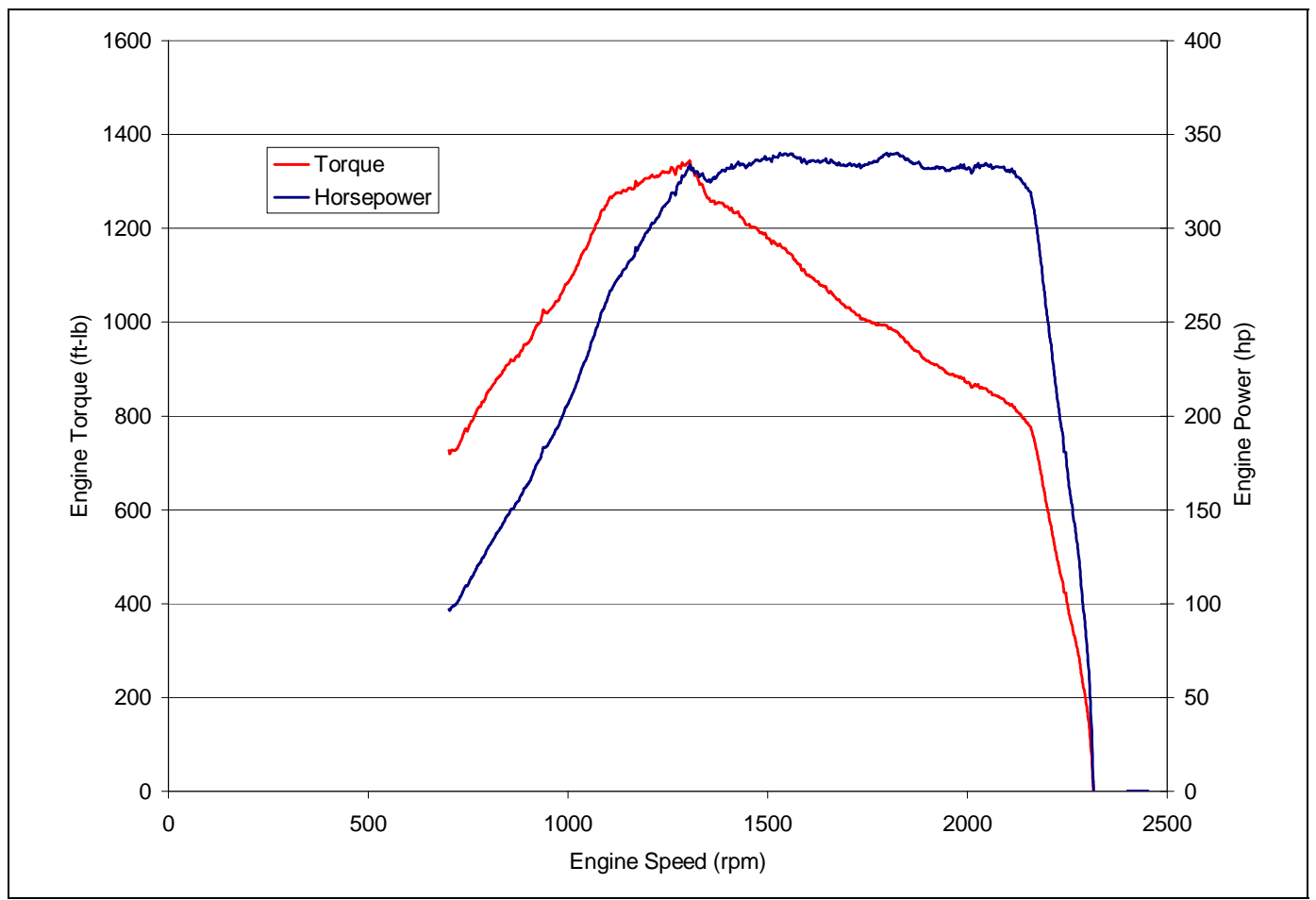

Figure 3-12 Engine Map for 2004 Cummins ISM 370

\subsection{CAFEE Full Scale Dilution Tunnel and Sampling System}

In order to simulate the effects of the emissions on the environment, a dilution tunnel was utilized. The dilution tunnel reduces the exhaust temperature as well as maintains vapor in the exhaust above its saturation point. This occurs by mixing ambient air with the exhaust gases. The dilution tunnel provides an environment for particulate matter to form as well.

The full scale dilution tunnel operates on a constant volume sampling (CVS) system principle. Diluted air from the exhaust of the engine was drawn through three critical flow venturis (two $1000 \mathrm{scfm}$ venturis and one $400 \mathrm{scfm}$ venturi) for a total of $2400 \mathrm{scfm}$ via a 75hp blower at the outlet of the dilution tunnel. The mass flow rate of the exhaust flowing through the dilution tunnel was determined through this process.

At the entrance of the dilution tunnel, exhaust gases and ambient air were joined at the mixing orifice. After properly being mixed, the diluted exhaust was sent downstream to the 
sampling plane of analyzer probes. The analyzer's sample probes and lines were heated to prevent condensation.

\subsubsection{Critical Flow Venturi}

The critical flow venturi at WVU's CAFEE was in compliance with the CFR 40, part 86, subpart $\mathrm{N}$ for the diluted exhaust flow during the testing. The venturi flow rate was directly proportional to the pressure and inversely proportional to the square root of the temperature of the diluted exhaust gases before entering the venturi throat.

The following equation displays the method for calculating the volumetric flow rate through the dilution tunnel with use of the CFV:

$$
Q=K \frac{P}{\sqrt{T}} \text { Equation 3-1 }
$$

In equation 3-1, $\mathrm{Q}$ is the volumetric flow rate (scfm), $\mathrm{K}$ is the calibration constant for operating venturis, $\mathrm{P}$ is the absolute pressure at the inlet of the venturi, and $\mathrm{T}$ is the absolute temperature of the exhaust gas at the inlet of the venturi.

\subsubsection{Gaseous Sampling System}

The gaseous sampling system at WVU’S CAFEE included heated sampling lines, heated sampling probes, heated pumps, heated filters, a chiller unit and exhaust gas analyzers. Stainless steel probes were placed 10 diameters downstream of the mixing orifice. The exhaust gases were then routed through heated lines to the emission analyzers. The heated lines and probes were maintained at elevated temperatures in order to prevent any condensation from forming.

The $\mathrm{NOx}$ and $\mathrm{CO} / \mathrm{CO}_{2}$ lines and probes were maintained at $235 \pm 20^{\circ} \mathrm{F}$ to prevent condensation of water. The HC lines and probes were maintained at $375 \pm 20^{\circ} \mathrm{F}$ in order to prevent condensation of the heavier hydrocarbons. 
The HC analyzer had an internal filter and pump. The $\mathrm{NOx}$ and $\mathrm{CO} / \mathrm{CO}_{2}$ exhaust samples were filtered with heated micro-fiber filters maintained at the nominal $235^{\circ} \mathrm{F}$. After filtration the sample was pumped into the emission analyzers by heated pumps. The CO sample was then pumped though a chiller unit prior to being supplied into the analyzers. The chiller unit was used to remove excess water in the $\mathrm{CO} / \mathrm{CO}_{2}$ line due to water interference issues. Section 3.5 describes the functions of these analyzers in more detail.

\subsubsection{Particulate Sampling System}

The particulate sampling system at WVU's CAFEE utilized during testing was based on a gravimetric approach to accurately measure TPM. A secondary dilution tunnel was incorporated to provide further dilution of the exhaust. This secondary dilution tunnel was connected to the main dilution tunnel via a slipstream. TPM matter was collected on filters that were pre-conditioned, pre-weighed, TPM collected, post conditioned, and then post weighed in an environmentally controlled clean room environment. Two filters were used in series to increase trapping efficiency of the TPM. The filters were maintained below $125^{\circ} \mathrm{F}$ during the TPM collection phase. The filters were $70 \mathrm{~mm}$ fluorocarbon-coated glass fiber filters, model T60A20. Figure 3-13 displays the particulate sampling system. 
Main dilution tunnel

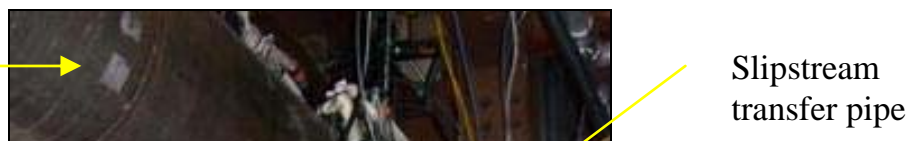

Secondary tunnel

Filter holder

Figure 3-13 Particulate Sampling System

\subsection{Exhaust Gas Analyzers}

Horiba, Rosemount Analytical Inc. and Eco Physics analyzers were utilized in the exhaust gas analyzer bench at WVU’s CAFEE. There was also a Beckman NOx efficiency tester which was used to test the converter efficiency of the NOx analyzer. This section outlines the operations and specifications of these analyzers. Figure 3-14 displays the exhaust gas analyzer bench. 


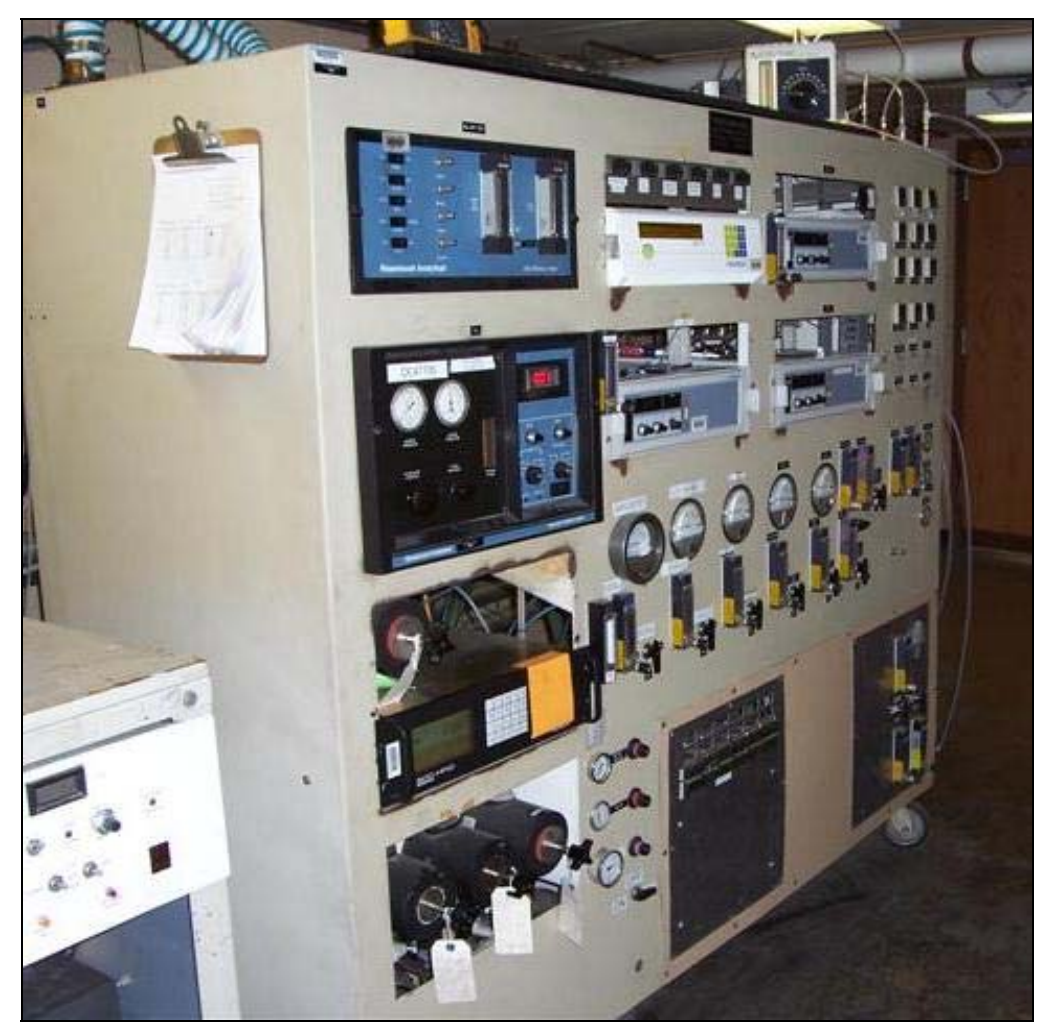

Figure 3-14 Exhaust Gas Analyzer Bench

\subsubsection{Hydrocarbon (HC) Analyzer}

The Rosemount Model 402 Heated Flame Ionization Detector (HFID) was used to measure the amount of hydrocarbon emissions present in the exhaust gases. A small flame was maintained with a mixture of $40 \%$ hydrogen and $60 \%$ helium. A flame ionization detector has polarized electrodes which creates an electrostatic field and collect positive ions. When the dilute exhaust sample passes over the burner, it is ionized within the flame and the electrostatic field causes a small current between the electrodes. This current created between the electrodes is directly proportional to the concentration of hydrocarbons in the exhaust sample. A secondary hydrocarbon analyzer, a California Analytical Model 600-HFID, was used for quality control purposes. 


\subsubsection{Oxides of Nitrogen (NOx) Analyzers}

Two oxide of nitrogen analyzers were used during the testing. The primary NOx analyzer was a Rosemount Analytical model 955 unit. The second NOx analyzer was an Eco Physics analyzer which was used as a quality control device. Both analyzers were of the heated chemiluminescent type. Prior to entering the chemiluminescent detection chamber, any $\mathrm{NO}_{2}$ in the sample stream was converted to NO through a NOx converter chamber.

Chemiluminescence is the process by which a photon is emitted via a chemical reaction. This reaction was created when the $\mathrm{NO}$ was introduced to $\mathrm{O}_{3}$ to form $\mathrm{NO}_{2}$. The $\mathrm{NO}_{2}$ is unstable and approximately $10 \%$ of the $\mathrm{NO}_{2}$ converts back to NO. During this conversion, a photon is released. These photons were then enhanced though a photo-multiplier tube and a corresponding voltage was recorded through the use of a photo-detector. This corresponding voltage was directly proportional to the number of NO molecules present. Both analyzers had a linear response curve.

\subsubsection{Carbon Monoxide (CO) and Carbon Dioxide $\left(\mathrm{CO}_{2}\right)$ Analyzers}

Two analyzer models from the Horiba Corporation were utilized during testing. Model AIA-210 was used to measure CO and model AIA-210 LE was used to measure $\mathrm{CO}_{2}$. These analyzers are non-dispersive infrared (NDIR) units. They function based on the infrared

absorption spectrum of gases. Levels of $\mathrm{CO}$ and $\mathrm{CO}_{2}$ were recorded by introducing this absorbed energy with the exhaust sample. Two AIA-210 analyzers were utilized during testing. One was used to record low CO emissions, up to $1000 \mathrm{ppm}$. The other was used to record emissions between 1000 ppm and 5000 ppm. This was prudent as to satisfy recording of different levels of emissions during an FTP for different engines and fuels. 


\subsection{Bag Sampling}

An integrated emissions analysis was conducted at WVU's CAFEE utilizing dilute and background samples collected in 80-liter Tedlar bags. The sample for the dilute bag was taken from a probe located in the sampling plane. The sample for the background bag was taken upstream of the dilution tunnel and consisted of conditioned air.

These bags were then analyzed using the equipment discussed in Section 3.5. The results were then recorded with use of the data acquisition system, which is discussed in Section 3.10. After data acquisition, the bags were evacuated in preparation for the next test. Background measurements were subtracted from the continuous exhaust emission measurements. This was to account for exhaust constituents in the ambient air. The dilute bag was used as a quality check of the continuous measurement.

\subsection{Intake Air Flow Measurement}

The intake volumetric air flow rate was measured via a laminar flow element (LFE), which was manufactured by Meriam Instruments. The LFE was used as a quality control check. An Omega differential pressure transmitter was utilized in measuring the differential pressure across the LFE. The inlet temperature was measured via a resistance temperature device. The volumetric flow rate was then calculated with the recorded inlet temperature and the change in pressure across the LFE. Upstream of the LFE, the absolute pressure was also measured and used to correct the calculated LFE flow to standard conditions. 


\subsection{Fuel Measurement}

There were three methods utilized for measuring fuel consumption. One method was based on the amount of carbon measured in the dilute exhaust. This carbon was directly proportional to the amount of carbon present in the combusted fuel, with the exception of a minimal amount of carbon absorbed in the crankcase due to blowby on the rings. Calculating fuel consumed based on combusted carbon measurement required the specific gravity of the corresponding fuel, the hydrogen-to-carbon and oxygen-to-carbon ratios of the fuel, and the mass of $\mathrm{HC}, \mathrm{CO}$, and $\mathrm{CO}_{2}$ present.

Another method of measurement utilized a Max Machinery (Model 710) fuel conditioning system to measure the flow rate of the fuel. This fuel conditioning systems primary function was to regulate the temperature of the fuel prior to entering the engine. In compliance with the regulations of the 40 CFR part 86 , subpart $\mathrm{N}$, the fuel must be maintained at a temperature at or below $109^{\circ} \mathrm{F}$. This fuel conditioning system also had an output of counts, which was a digital signal that was proportional to the mass flow rate of the fuel.

The final method was based on the mass of the fuel in the fuel tank (16 gallon barrel) prior to and after the FTP. The fuel barrel was placed on an Ohaus scale, which was accurate to approximately $0.5 \%$ of the fuel consumed in the FTP.

\subsection{Intake Temperature and Humidity Measurement}

A HX-52 temperature-humidity transmitter was utilized in measuring the temperature and humidity in the intake. The HX-52 was located upstream of the LFE. The temperature and relative humidity were also measured using a wet-bulb / dry-bulb system located just before the mixing orifice. There were slight variations in the readings because the two systems were in 
different locations of the CAFEE and different humidity levels are maintained at these two locations. A GE dew point hygrometer was also used to measure the humidity in the intake air. It was located just before the LFE. It was used in reducing the laboratory data to acquire a NOx correction factor. There was also a second hygrometer (EdgeTech Dewprime II) which was used to calibrate the GE unit.

\subsection{Instrument Control and Data Acquisition}

The laboratory data collected during the testing at WVU's CAFEE was obtained using a computer-controlled data acquisition (DAQ) system, as shown in Figure 3-15. This DAQ system measured and recorded all of the configured channels via customized software. The DAQ system was a rack of signal conditioning boards (3B series modules) that outputted an analog voltage signal which was proportional to a physical measurement. The laboratory system’s data acquisition analog inputs consist of four 12 bit, 90 kS/s, Analog Devices RTI-815 multifunction ISA DAQ cards, each of which is connected to two 3B01 16 channel backplanes. This corresponded to measurement resolution of $0.02 \%$ full scale value. The modules installed in the backplanes include voltage, current, thermocouple, RTD, and strain gauge signal conditioning. The RTI-815s cards also provide digital inputs and outputs for controlling the GE dynamometer and other devices. Digital inputs and outputs are provided by an ISA PCL-722 to control the bagging and sampling systems. An ISA RTI-802 provides 8 analog outputs at 12 bit resolution to control mass flow controllers. Software interface is done via in-house developed and maintained code. The throttle control interface had 8 bit accuracy and could output up to 256 different values. This corresponded to throttle position measurement accuracy of down to $0.4 \%$. This voltage output then was converted into a digital signal. This analog-to-digital code (ADC) was then converted in a computer to a corresponding engineering value. 


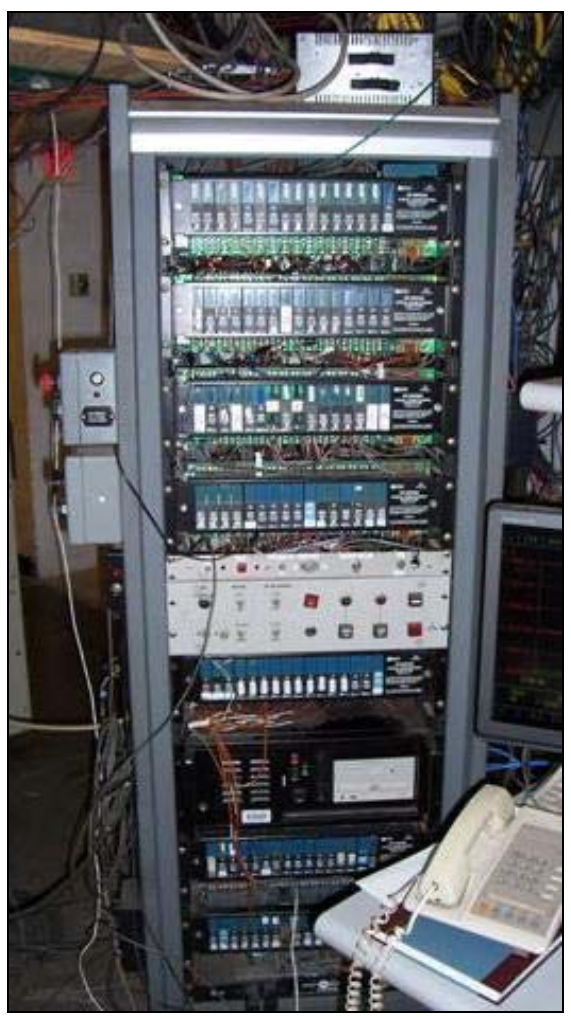

Figure 3-15 DAQ System

\subsection{Emission Testing Procedures}

In maintaining 40 CFR Part 86, subpart $\mathrm{N}$ requirements, several quality control checks were completed prior to testing. This section discusses the procedures and calibrations conducted. This included propane injections, NOx efficiency tests, interference checks for the analyzers, as well as pressure leak and temperature checks for heated lines.

\subsubsection{Engine Preparation}

All engines in this study were not modified in any other way, than what was discussed in Section 3.3, and all hardware was considered OEM. However, the rebuilt 1992 Detroit Diesel series 60 and the 2004 Cummins ISM 370 engines were outfitted with additional sensors per research conducted on in-cylinder pressure by Nuszkowski [12]. Routine maintenance was 
performed prior to testing of each engine. This included replacement of oil and coolant, their corresponding filters, as well as the fuel filters.

\subsubsection{Exhaust System}

As specified by 40 CFR Part 86, subpart N, the exhaust system consisted of the following specifications. The exhaust pipe was 5 inches in diameter, and covered with a layer of 1 inch thick fiberglass insulation. A valve was located just prior to the mixing orifice and adjusted to ensure proper backpressure for each engine.

\subsubsection{Calibration of Analyzers}

Calibrations for each analyzer were conducted as stated by 40 CFR 86, Subpart N. This included obtaining an 11-point calibration curve for each analyzer with corresponding calibration gases. These gases were traceable to within $1 \%$ as each were cross-checked with standard reference material (SRM) gases, obtained from National Institute of Standards and Technology (NIST). Each analyzer was calibrated prior to testing of each engine. Each engine was calibrated to a certain value based on emission output of each engine. Calibration gases as well as their corresponding values are displayed in Table 3-3.

Table 3-3 Calibration Gas Ranges

\begin{tabular}{|c|c|c|c|c|c|}
\hline Calibration Gas & $\begin{array}{c}\text { 1991 Detroit } \\
\text { Diesel S60 }\end{array}$ & $\begin{array}{c}\text { 1992 Detroit } \\
\text { Diesel S60 }\end{array}$ & $\begin{array}{c}\text { Rebuilt 1992 } \\
\text { Detroit Diesel } \\
\text { S60 }\end{array}$ & $\begin{array}{c}\text { 1999 Cummins } \\
\text { ISM 370 }\end{array}$ & $\begin{array}{c}\text { 2004 Cummins } \\
\text { ISM 370 }\end{array}$ \\
\hline Propane (ppm) & 10.19 & 10.19 & 10.0 & 10.19 & 10.1 \\
\hline Low CO (ppm) & 99.90 & 99.90 & 500.3 & 99.90 & 98.9 \\
\hline High CO (ppm) & 983.0 & 983.0 & 1001 & 983.0 & 985.5 \\
\hline $\mathrm{CO}_{2}(\%)$ & 3.449 & 3.449 & 3.997 & 3.449 & 4.002 \\
\hline $\mathrm{NOx}_{(\mathrm{ppm})}$ & 221.4 & 221.4 & 223.1 & 221.4 & 249.1 \\
\hline
\end{tabular}

\subsubsection{Hydrocarbon Analyzers}

The FID peak of the hydrocarbon analyzers was first determined through a maximum response test. This process included supplying various air/fuel mixtures to the analyzer and 
monitoring the response. This peak value for the HFID was first recorded prior to actual calibration of the analyzer. The calibration of the hydrocarbon analyzer consisted of supplying a specified flow of propane and an 11-point calibration curve. This process included flowing zero air and the calibration gases through the heated probe lines of the analyzer. Through these end points, the zero and full scale values were recorded. Thereafter, the $90 \%$ through zero values were then recorded via the aid of a Horiba SGD-710 gas divider. ADC values were then recorded via the DAQ system, and the recorded values were compared against the set values and a calibration curve was created. After a satisfactory calibration was performed, the calibration curve was then provided to the reduction program, which was used to convert ADC values into engineering units.

\subsubsection{Oxides of Nitrogen Analyzers}

An 11-point calibration was also conducted on the NOx analyzers. In addition to the 11point calibration, every month a NOx converter efficiency check was completed. This was to ensure proper function of the chemiluminescent detector as $\mathrm{NO}_{2}$ was converted to $\mathrm{NO}$ for $\mathrm{NOx}$ measurement. This test was performed on both the primary Rosemount Analytical unit, as well as the secondary Eco Physics unit. A 90\% or greater efficiency was required to ensure proper measurements.

\subsubsection{Carbon Monoxide and Carbon Dioxide Analyzers}

As specified by 40 CFR Part 86, subpart $\mathrm{N}$, the $\mathrm{CO}$ and $\mathrm{CO}_{2}$ analyzers were checked for water interference. This ensured that the chiller unit was functioning properly in condensing water prior to reaching the analyzers. These analyzers did not receive the same linear calibration curve procedure as the $\mathrm{HC}$ or $\mathrm{NO}_{\mathrm{x}}$ analyzers as they are of a non-linear curve type. The $\mathrm{CO}$ sample systems were checked for $\mathrm{CO}_{2}$ interference. 


\subsubsection{Heated Lines and Probes}

Periodic checks for pressure leaks and temperature variations were conducted at the WVU CAFEE. This included disconnecting the lines and inserting a thermocouple into the lines. Temperature readings were taken every four inches. The pressure leak check consisted of first flushing the line with pressurized air to eliminate any particles or residue from the system. Following the flush, one end of the line was capped off and sealed, while pressurized air was allowed to enter the open end. Pressure drop over a five minute interval was then measured. Variations in temperatures or a pressure drop in the system would result in repair or replacement of the line.

\subsubsection{Particulate and Filter Weighing}

The secondary dilution tunnel mass flow rate must be proportionally equivalent to the primary dilution tunnel with a tolerance of $\pm 5 \%$. The temperature at the face of the filter must also be accurate to within $\pm 1.9^{\circ} \mathrm{C}$. Calibrations of the mass flow meter were conducted yearly with use of a LFE, The standard temperature and pressure for calibrations were $20^{\circ} \mathrm{C}$ and 101.3 $\mathrm{kPa}$. The calibration details can be found in [1].

Pre-conditioning of the filters was conducted in compliance of 40 CFR Part 86, Subpart $\mathrm{N}$. The pre-conditioning period lasted for at least an hour inside the clean room at the WVU CAFEE. The filters were housed in Petri dishes to eliminate the possibility of contamination. Once the filters acclimated with the clean room environment $\left(22 \pm 3^{\circ} \mathrm{C}\right.$ and a dew point of $9.5 \pm$ $1^{\circ} \mathrm{C}$ ) reference filters were created to monitor the variations within the testing period or up to one month.

Following the initiation of reference filters, the test filters were weighed according to the number of tests being conducted. These filters were weighed on a Sartorius SE2-F ultra- 
microbalance in compliance with 40 CFR 86, Subpart N. After ten test filters were weighed, the balance zero was recorded and, if required, adjusted. Additionally, the reference filters were weighed every four hours if test filters were weighed throughout the day. These filters were then used for collect TPM during the tests. Figure 3-16 displays the layout of the clean room.

After a test was completed, the TPM filters were then brought back to the clean room and allowed to acclimate back to the clean room environmental conditions for at least an hour. Ambient air entering the dilution tunnel was also measured for TPM on a background filter during the test. The test TPM filters and background filters were post weighed after reacclimation and then analyzed.

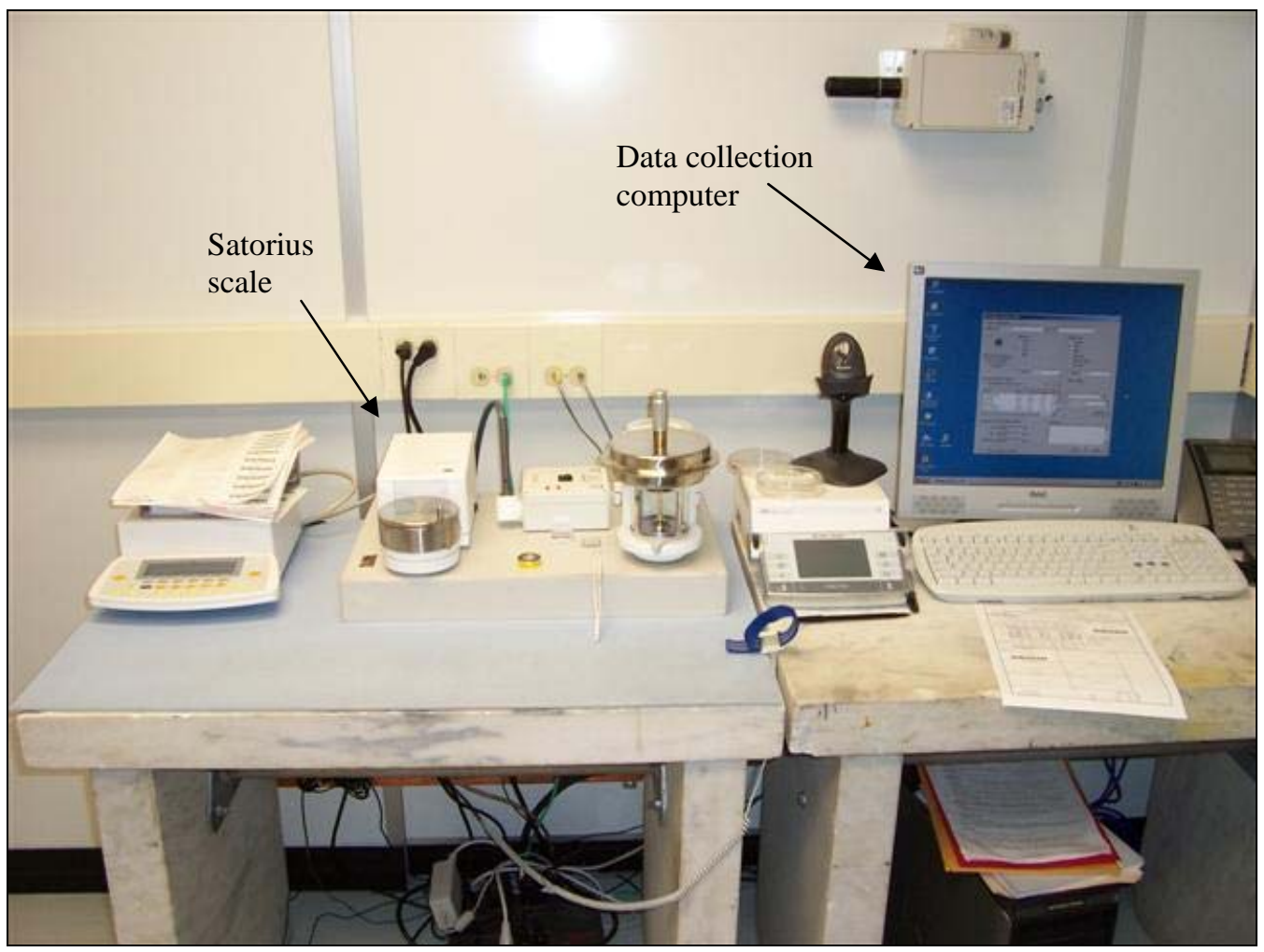

Figure 3-16 Clean Room Filter Scale Configuration

\subsubsection{Propane Injections}

Propane injections were performed in compliance with 40 CFR Part 86.131-90 to ensure proper operation of the constant volume sampling system. Propane at a controlled rate was 
injected into the dilution tunnel and monitored by the HC analyzer. The propane injection setup is displayed in Figure 3-17. A tolerance of $\pm 2 \%$ was allowed for the amount of propane measured at the HC analyzer compared to the injection rate. Three consecutive injections must also commence with a maximum deviation of $\pm 0.5 \%$ between the measured value from the HC analyzer and tunnel flow and the injected value from the injection kit.

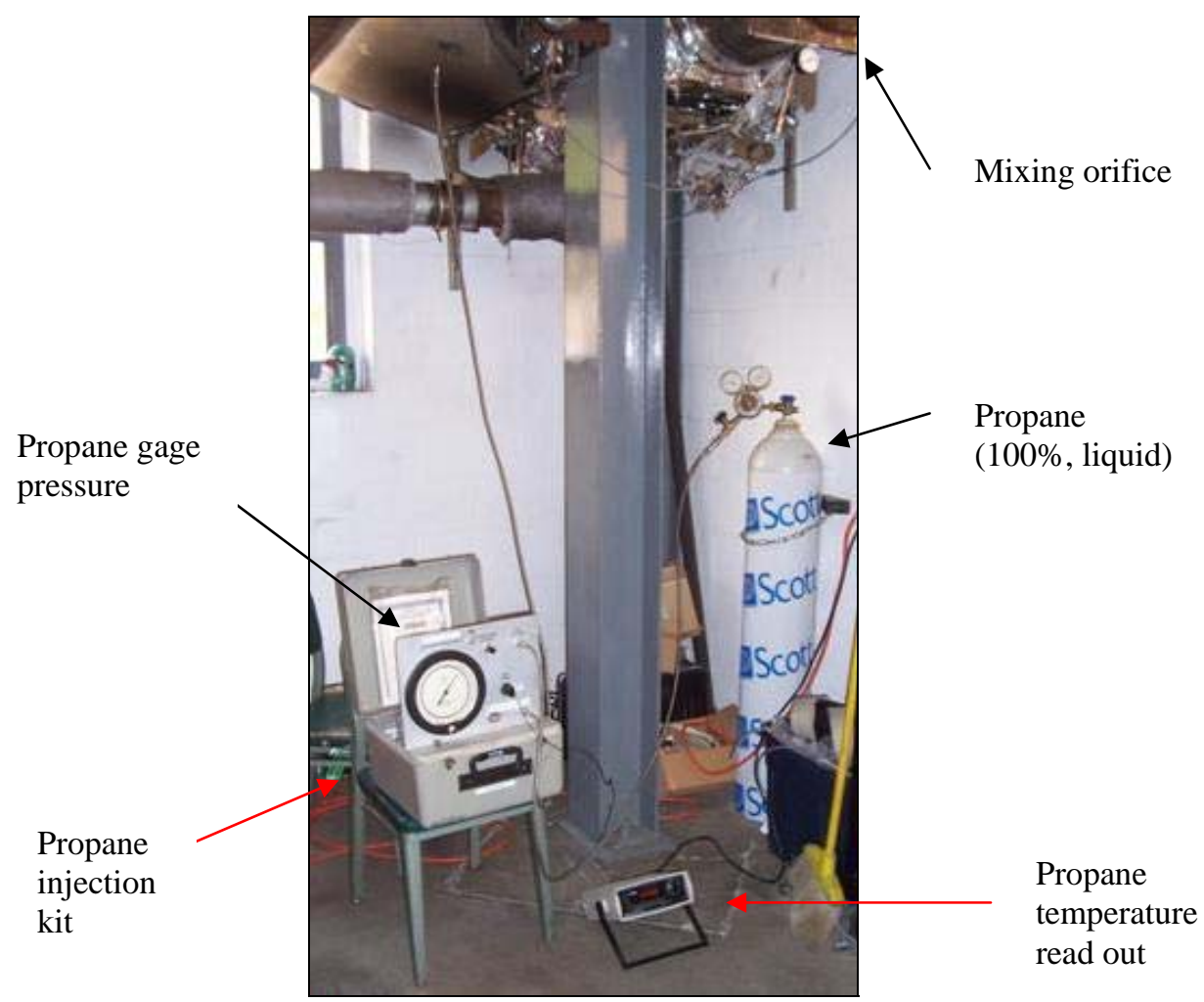

Figure 3-17 Propane Injection Setup

\subsubsection{Torque Cell Calibrations}

The torque cell was calibrated in compliance with the regulations of 40 CFR Part 86.1318-84 prior to testing. This included attaching weights to a lever arm at a distance to represent a torque. A curve fit was created in response to incremental amounts of weights simulating a torque. 


\section{Throttle Discussion}

\subsection{Test Engines and Examined Fuels}

Five engines were utilized for this study as well as multiple combinations of fuels and fuel additives. It is noted that not all fuel configurations were used for every engine, due to limited availability of these fuels. Table 4-1 displays the engines used with their corresponding throttles and fuels utilized for this study. A more in depth investigation of the effects of fuel additives on HDDE's was conducted as a master's thesis by Tincher [10], as well as a dissertation by Nuszkowski examining fuel additives and their relationship with in-cylinder pressures [12].

Table 4-1 Throttle Algorithms Examined with their Corresponding Engines and Fuels

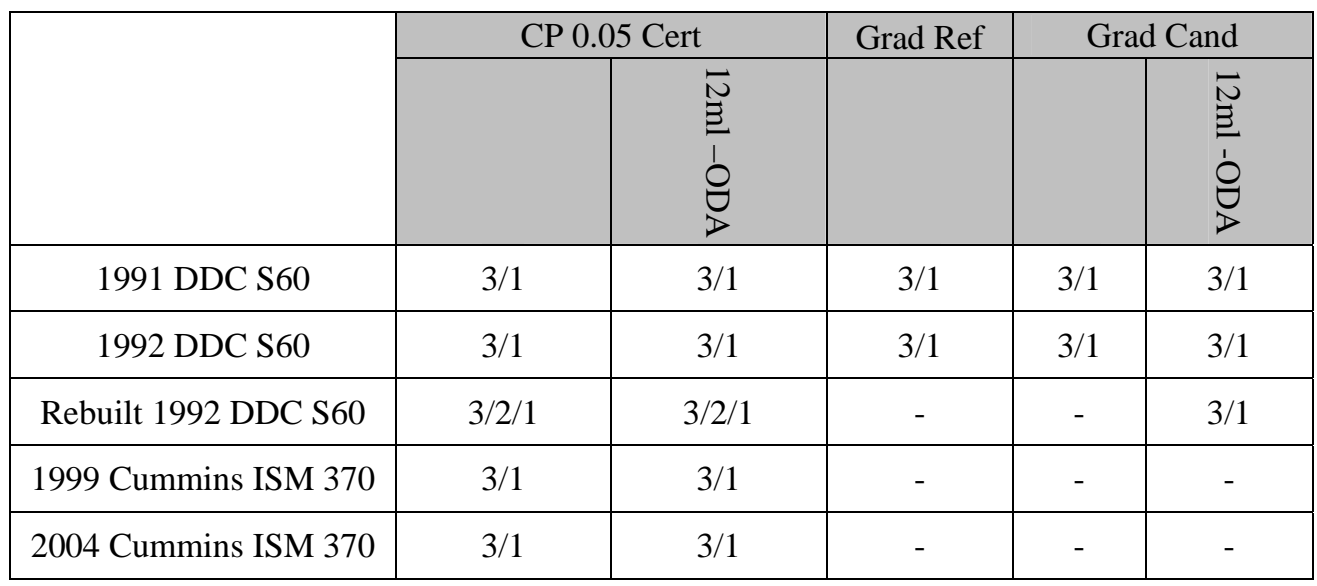

As displayed in Table 4-1, throttles 3 and 1 were tested via the five HDDE's. Moreover, these throttles were tested with several fuel combinations. The legacy DDC engines received more utilization than the newer Cummins as their results were of more interest to this study. This was because the legacy DDC engines generally emit a greater quantity of emissions than the newer Cummins. Early in testing, it was recognized that these legacy DDC engines also responded more with variations of emissions and performance when APPC was varied. Due to 
these factors, further study focused on the legacy DDC engines. Throttle 2, as displayed in Table 4-1, was ultimately discarded for use in this study after results from testing of the rebuilt 1992 DDC S60 engine showed the throttle profile to be consistent with throttle 1.

\subsection{Throttle Profiles}

Three throttle profiles with different levels of aggression were incorporated into this research. Throttle profile 2 was ultimately discarded for testing (as displayed in Table 4-1) after displaying nearly identical results with throttle 1 . Throttle 1 proved to be a more aggressive throttle than throttle 3 and this will be discussed in more detail below. Throttle 1 consistently reached a targeted throttle position during transient conditions of a FTP faster than throttle 3.

\subsubsection{Detroit Diesel Throttle Profiles}

Throttle profiles were discovered to be more repeatable on the older DDC engines rather than the newer Cummins engines. This was determined to be an artifact of the additional control parameters due to the addition of components such as EGR and VGT found on the 2004 Cummins engine. These components are not present on the older engines and engine control is not as complex with these engines as it is with the 2004 Cummins engine. Figures 4-1 through 43 display an example transient event during the FTP for both throttles 1 and 3 for the older Detroit Diesel engines between 40 to 60 seconds as an example transient event. All three display similar results with throttle 1 consistently reaching targeted throttle position faster than throttle 3 . Note the fuel utilized during the data collection for Figures 4-1 through 4-3 was CP Cert 0.05. It is noted that the set point file for the two different throttle tests for the 1991 DDC S60 engine were different as shown in Figure 4-1. Evidently, there were changes in the set point file 
between the evaluations of these two throttles. Otherwise, the set point files for the remaining engines were consistent between the two throttle evaluations for each given engine.

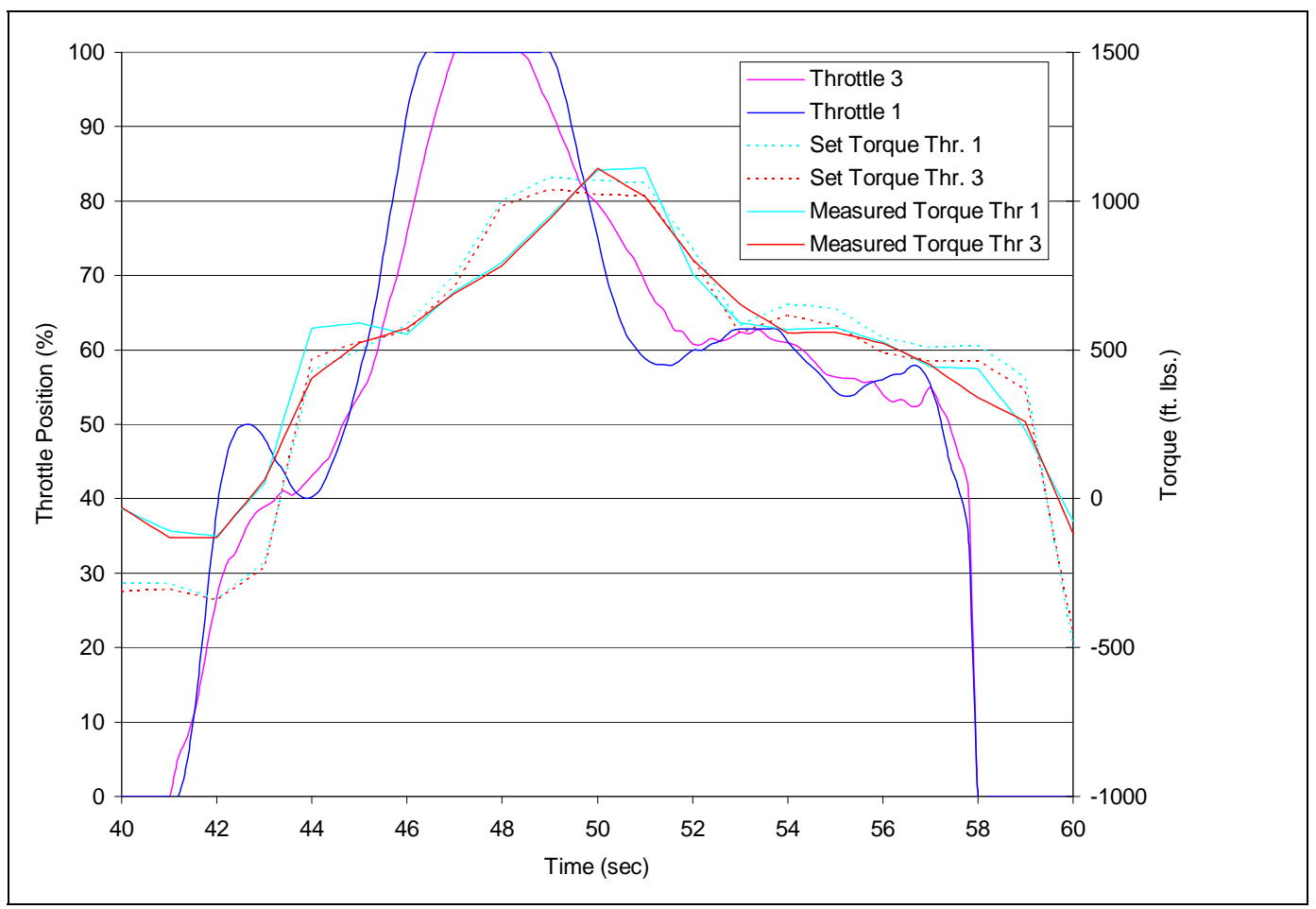

Figure 4-1 1991 DDC S60 Throttle Profiles 


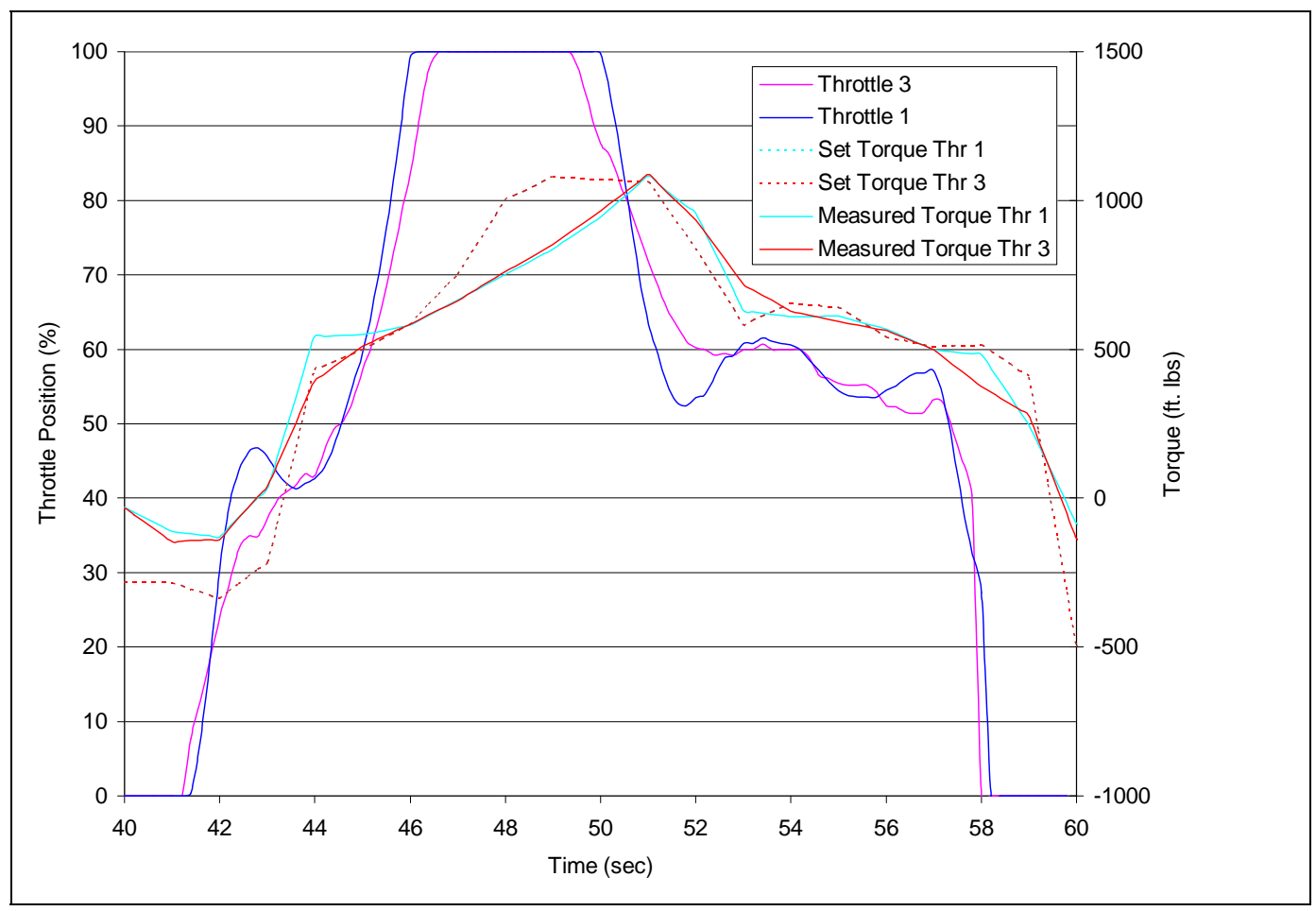

Figure 4-2 1992 DDC S60 Throttle Profiles

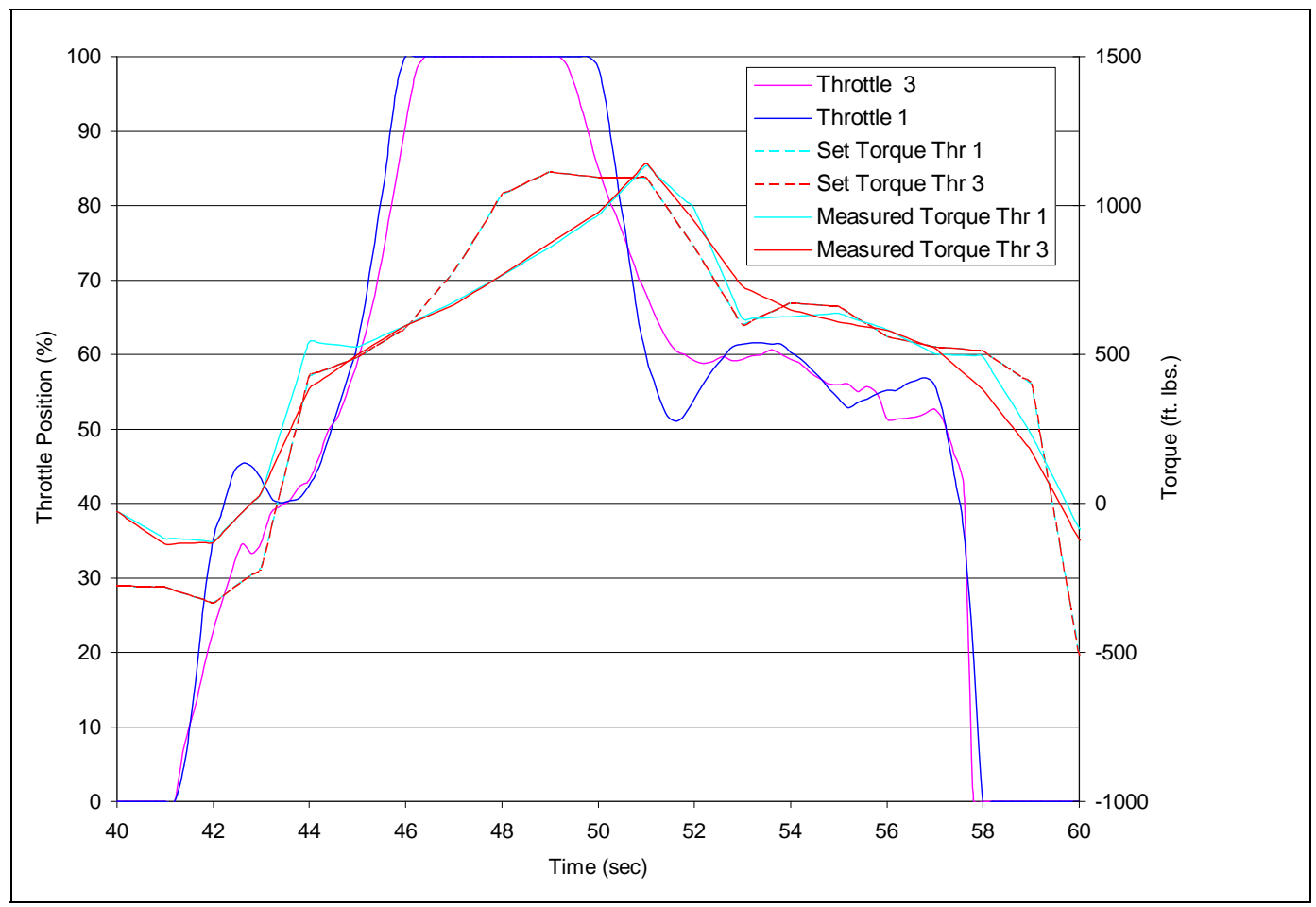

Figure 4-3 Rebuilt 1992 DDC S60 Throttle Profiles 


\subsubsection{Cummins Engines Throttle Profiles}

Two engines from Cummins were utilized for this study. Both were ISM 370 models, one from 1999 and the other a 2004 model. Both engines had different throttle position profiles when examining the results of throttle 1 and throttle 3 . At some points throttle 3 would not even reach the full targeted throttle position that throttle 1 would achieve on the 1999 Cummins. One of the most obvious trends associated with the 2004 Cummins engine was that throttle 3 showed to have a time delay in opening or closing when compared to throttle 1. Peak throttle operations were also noted to be shorter with throttle 3 when compared to throttle 1 for the 2004 Cummins. These trends are outlined in Figures 4-4 and 4-5.

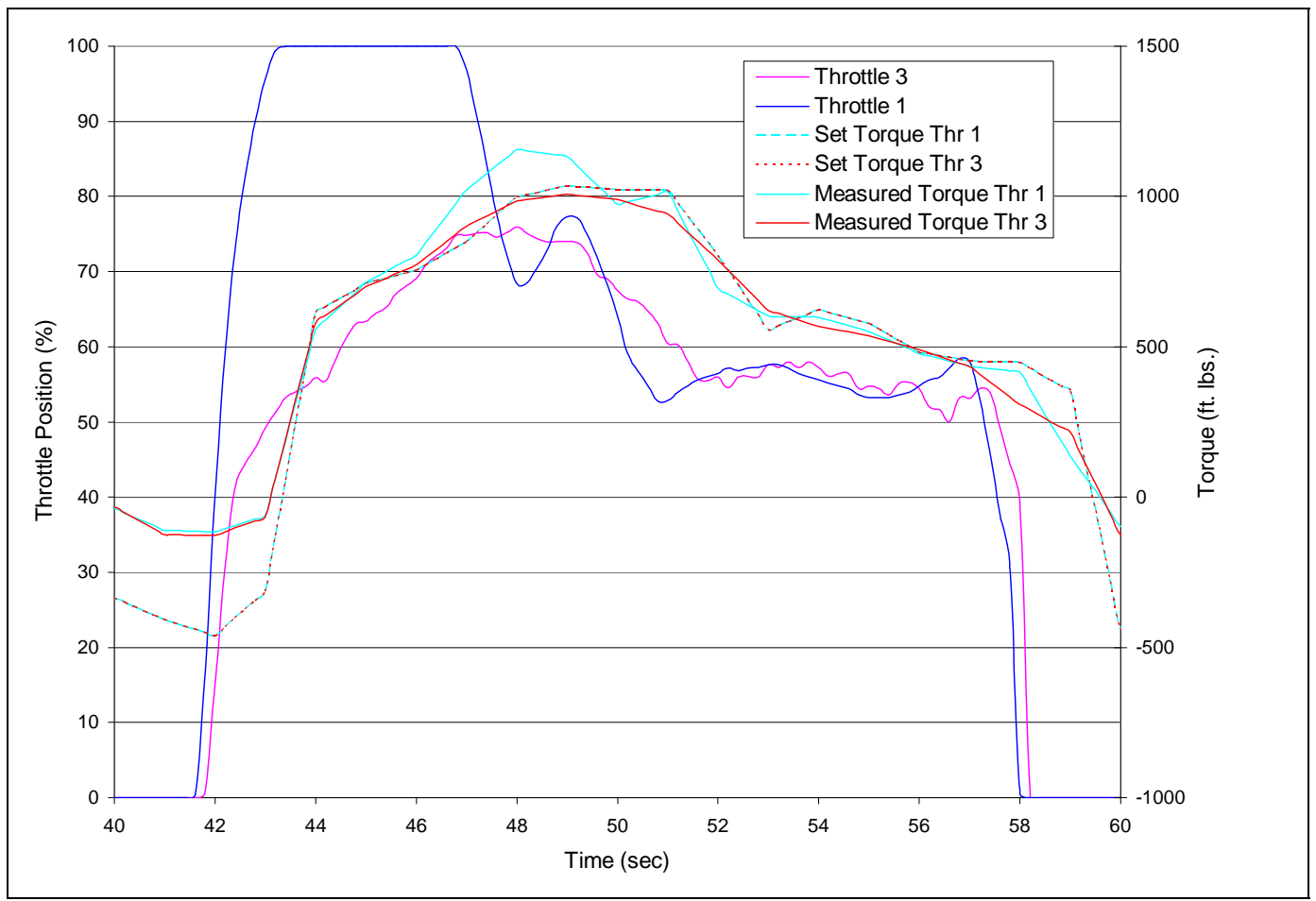

Figure 4-4 1999 Cummins ISM 370 Throttle Profiles 


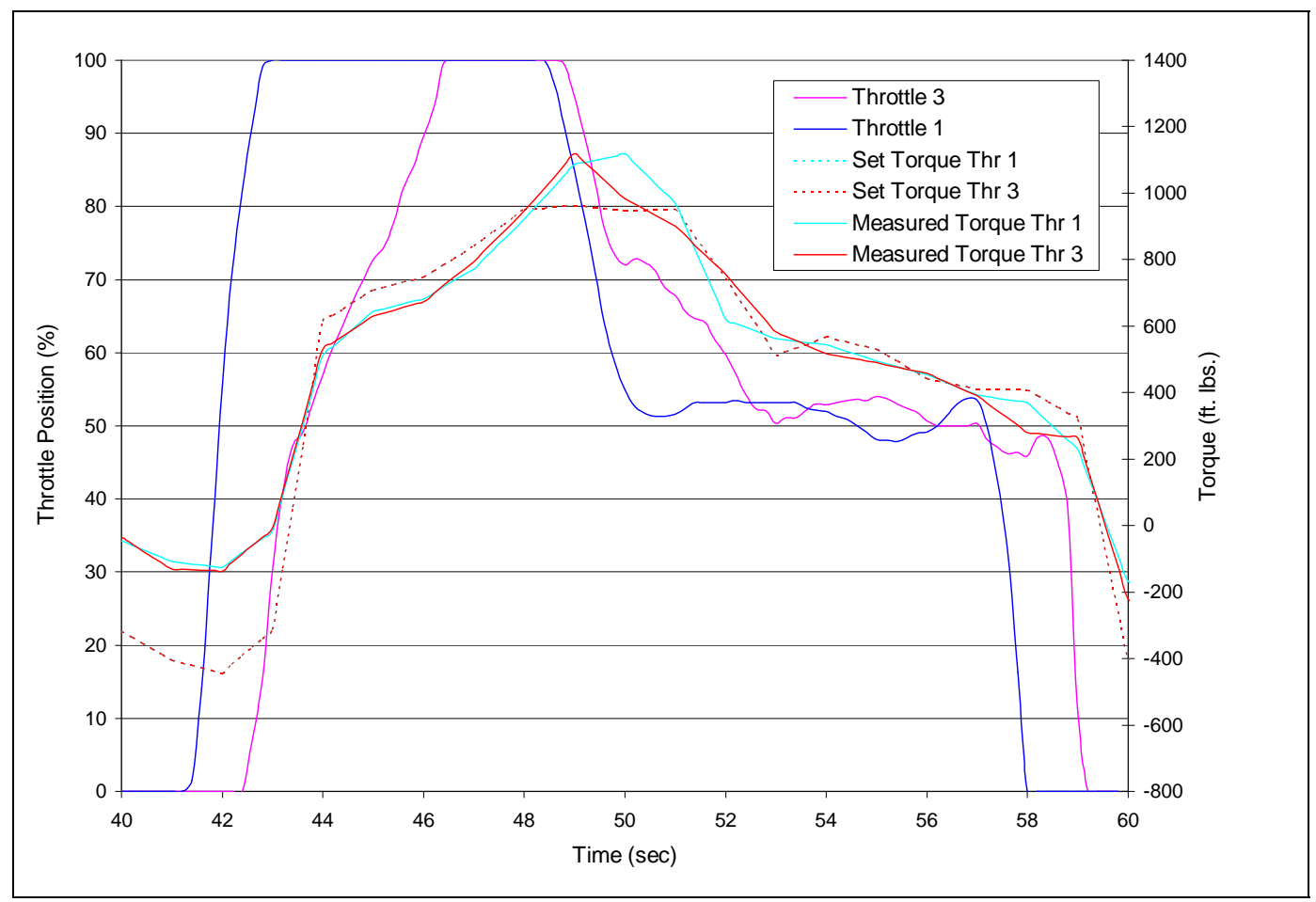

Figure 4-5 2004 Cummins ISM 370 Throttle Profiles

\subsection{Throttle Programming}

Throttles were programmed based on the desired torque for the appropriate time. A proportional - integral - derivative (PID) controller was utilized to achieve accurate throttling to meet set torque values per the regression criteria of 40 CFR part 86, subpart N. A PID controller is a generic closed loop feedback mechanism that relies on an algorithm to minimize the error in a process variable between the set point value and actual measured state. The PID controller calculations involve three parameters. The proportional condition determines the reaction to the current error. The integral condition takes into account the reaction of the sum based on recent errors, and finally the derivative condition determines the reaction to the rate at which error has been changing. 
This study's programming relied heavily on the proportional and integral values, and minimally on the derivative value. This was due to the derivative value being very sensitive to noise. The following equation displays the process for determining the controller output, $u(t)$ [1].

$$
u(t)=K_{P} e(t)+K_{i} \int_{0}^{t} e(\tau) d \tau+K_{d} \frac{d e}{d t} \quad \text { Equation } 4-1
$$

In the above equation the magnitude of each condition can be tuned by adjusting the gain values, $\mathrm{K}_{\mathrm{P}}, \mathrm{K}_{\mathrm{i}}$, and $\mathrm{K}_{\mathrm{d}}$. For transient test conditions of the FTP cycle, heavy gain was utilized on the $K_{P}$ and $K_{i}$ values. It is noted that for steady state operating conditions, throttling only relied on the $\mathrm{K}_{\mathrm{i}}$ value.

Throttle 3 was programmed relying $100 \%$ on the PID controller to regulate throttling. Throttle 1 also incorporated the PID controller for throttling, but also included a "look ahead" feature. If a transient condition was to occur resulting in a $100 \mathrm{ft} / \mathrm{lbs}$ or greater change in torque in less than one second of time, the computer would begin the transient condition at a slightly earlier time. This "look ahead" feature was incorporated as for rapid changes in torque experienced in the FTP cycle for these engines since the power ranges were similar between model years and platforms. The $100 \mathrm{ft} / \mathrm{lbs}$ per second criteria was partially based on the dynamometer's ability to change load, or inertia. The PID controller could not properly operate the throttle opening during rapid transient conditions and would reach torque set points at a later time, or not reach them at all. The "look ahead" feature gave throttle 1 the ability to reach desired torque set points with greater speed and accuracy than throttle 3 during rapid transient conditions. 


\section{Results and Discussion}

\subsection{Introduction}

This investigation was conducted in order to study the effects of APPC on emissions and fuel consumption. The relationship between APPC and engine performance was also examined. The following results are displayed and discussed with regards to the objectives of this work and in order to fulfill those objectives.

\subsection{Emissions}

Variations in APPC provided intriguing results with regards to emissions as displayed in Table 5.1. Emission constituents are displayed with regards to throttle aggressiveness. Throttle 1 (most aggressive) emissions are compared to throttle 3 (least aggressive). Legacy engines (1991 DDC, 1992 DDC, and 1992 rebuilt DDC) results were of great importance to this work, as their data recorded was more repeatable than the newer Cummins engines. This was due to the newer engines having additional technologies such as EGR and VGT’s.

APPC had a significant effect on the levels of NOx formation. Throttle 1 responded with less NOx formation than throttle 3 for all engines tested. The legacy DDC engines reductions ranged from $1.11 \%$ to $2.40 \%$. The newer Cummins engines did not respond as much as the legacy DDC engines to changes in APPC in regards to NOx (0.49-0.81\%). Variations in APPC also had a similar effect on CO output as the legacy DDC engines yielded more of a response (12.1-25.3\%) with the less aggressive throttle 3 than the newer Cummins engines (4.30-12.6\%). Throttle 1 yielded a reduction in HC formation for all engines. Legacy DDC engines provided HC reductions between $0.30 \%$ and $14.0 \%$ while the newer Cummins engines reductions ranged from $2.20 \%$ to $5.20 \%$. Variation in APPC yielded a range in variations of TPM emissions. 
Throttle 3 emitted less TPM for all engines, ranging from a 4.49\% reduction on the 2004

Cummins to a reduction of $17.9 \%$ for the 1991 DDC.

Table 5.1 FTP Brake Specific Emissions

\begin{tabular}{|c|c|c|c|c|c|c|c|c|c|c|c|}
\hline \multirow{2}{*}{ Engine } & \multirow{2}{*}{ Throttle } & \multicolumn{2}{|c|}{ NOx } & \multicolumn{2}{|c|}{$\mathrm{CO}$} & \multicolumn{2}{|c|}{$\mathrm{CO} 2$} & \multicolumn{2}{|c|}{$\mathrm{HC}$} & \multicolumn{2}{|c|}{ TPM } \\
\hline & & g/bhp-hr & Diff (\%) & g/bhp-hr & Diff (\%) & g/bhp-hr & Diff (\%) & g/bhp-hr & Diff (\%) & g/bhp-hr & Diff (\%) \\
\hline \multirow{2}{*}{1991 DDC } & 1 & 4.36 & - & 3.17 & 28.24 & 536.1 & 0.07 & 0.0530 & - & 0.155 & 17.90 \\
\hline & 3 & 4.45 & 2.00 & 2.38 & - & 535.7 & - & 0.0592 & 11.07 & 0.130 & - \\
\hline \multirow{2}{*}{1992 DDC } & 1 & 4.91 & - & 3.56 & 12.74 & 535.4 & 0.13 & 0.1109 & - & 0.259 & 8.81 \\
\hline & 3 & 5.02 & 2.08 & 3.13 & - & 534.7 & - & 0.1156 & 4.15 & 0.237 & - \\
\hline \multirow{2}{*}{1992 R. DDC } & 1 & 5.01 & - & 3.71 & 9.86 & 528.5 & 0.25 & 0.0994 & - & 0.267 & 9.09 \\
\hline & 3 & 5.07 & 1.35 & 3.36 & - & 527.2 & - & 0.1036 & 4.18 & 0.244 & - \\
\hline \multirow{2}{*}{1999 Cummins } & 1 & 4.05 & - & 1.01 & 10.47 & 523.3 & - & 0.2577 & - & 0.120 & 11.80 \\
\hline & 3 & 4.08 & 0.52 & 0.91 & - & 523.9 & 0.12 & 0.2644 & 2.55 & 0.107 & - \\
\hline \multirow{2}{*}{2004 Cummins } & 1 & 2.35 & 0.70 & 0.59 & 4.01 & 601.6 & - & 0.2018 & - & 0.074 & 4.49 \\
\hline & 3 & 2.34 & - & 0.57 & - & 607.2 & 0.93 & 0.2112 & 4.54 & 0.071 & - \\
\hline
\end{tabular}

\subsubsection{Fuel Specific Emissions}

Variations in APPC with respect to fuel properties were examined. Table 5.2 displays the FTP results of the 1991 DDC S60 Engine. Other engines FTP results can be found in Table 8.1, Table 8.3, Table 8.5, and Table 8.7. A variation analysis is displayed in Table 5.3 for the 1991 DDC S60 engine. Other engines variation analysis' can be found in Table 8.2, Table 8.4, Table 8.6, and Table 8.8. Variations in fuel properties in conjunction with APPC provided different results for each model year engine. Each engine had different methods of design and control, which lead to a different response to varying fuel properties. Additionally, engine emissions model year (1991, 1998, or 2004) dictated major changes between the different engine model years as the regulated emissions limits caused the manufacturers to reduce emissions in significant percentages from the prior emissions regulations.

Fuel additives in addition to variation in APPC proved to also provide changes in emissions. For the 1991 DDC S60 engine, throttle 1 showed a reduction of $0.45 \%$ in NOx when 
adding $12 \mathrm{ml}$ of an ODA to CP 0.05 Cert fuel when compared to running the FTP on CP 0.05 Cert alone, while throttle 3 showed a 1.13\% reduction in NOx running the FTP with the added $12 \mathrm{ml}$ of an ODA to CP 0.05 fuel when compared to burning the CP 0.05 alone. With the addition of the $12 \mathrm{ml}$ of the ODA to the CP 0.05 Cert fuel, a greater reduction in NOx was achieved. This addition of the $12 \mathrm{ml}$ of ODA to the Grad Cand fuel did not provide similar results. A 1.33\% reduction in NOx was achieved with the addition of the $12 \mathrm{ml}$ of ODA to throttle 1 while throttle 3 saw a slightly less reduction of NOx with the addition of 12ml of ODA at 1.24\%.

Adding the 12ml of ODA to the CP 0.05 Cert fuel and the Grad Cand fuel also provided varied results for TPM emissions. Adding the $12 \mathrm{ml}$ of ODA to the CP 0.05 Cert fuel caused a very small increase in TPM (0.31\%) while the $12 \mathrm{ml}$ of ODA greater reduction in TPM (2.28\%). The Grad Cand fuel had similar TPM reductions with both throttle 1 and throttle 3 when adding the $12 \mathrm{ml}$ of ODA. Throttle 1 saw a $2.34 \%$ reduction in TPM when adding the $12 \mathrm{ml}$ of ODA and throttle 3 saw a $2.30 \%$ reduction in TPM with the addition of the $12 \mathrm{ml}$ of ODA.

Further investigation on the effects of fuel additives was conducted by Tincher for a Master's thesis [10]. He concluded that fuel additives emissions reductions were dependent on engine power. At lower power levels, Tincher found that NOx was reduced by the additives while at high power levels the additives increased NOx levels slightly. Tincher concluded that the legacy engines benefited from the additives in overall reduction of NOx, while the newer Cummins engines did not see any overall benefit from the additives. 


\section{Table 5.2 FTP Throttle Specific Results for 1991 DDC S60}

\begin{tabular}{|c|c|c|c|c|c|c|c|c|c|c|}
\hline & \multicolumn{2}{|c|}{ CP 0.05 Cert } & \multicolumn{2}{|c|}{$\begin{array}{l}\text { CP } 0.05 \text { Cert with } \\
\text { 12ml - ODA }\end{array}$} & \multicolumn{2}{|c|}{ Grad Ref } & \multicolumn{2}{|c|}{ Grad Cand } & \multicolumn{2}{|c|}{$\begin{array}{c}\text { Grad Cand with } 12 \mathrm{ml} \\
\text { ODA }\end{array}$} \\
\hline & 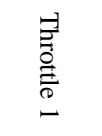 & 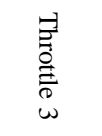 & $\begin{array}{l}\text { 当 } \\
\stackrel{0}{\circ} \\
\stackrel{D}{D} \\
⺊\end{array}$ & 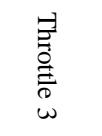 & 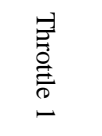 & $\begin{array}{l}\text { 当 } \\
\text { 章 } \\
\stackrel{0}{\omega} \\
\omega\end{array}$ & $\begin{array}{l}\text { 当 } \\
\text { 帝 } \\
\stackrel{D}{⺊}\end{array}$ & 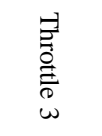 & 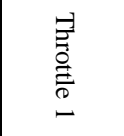 & 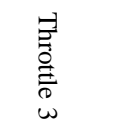 \\
\hline NOx (g/bhp-hr) & 4.501 & 4.612 & 4.481 & 4.560 & 4.117 & 4.216 & 4.389 & 4.463 & 4.331 & 4.408 \\
\hline Standard Deviation & 0.0099 & 0.0142 & 0.0108 & 0.0093 & 0.0085 & 0.0072 & 0.0060 & 0.0127 & 0.0128 & 0.0161 \\
\hline NOx 2 (g/bhp-hr) & 4.497 & 4.588 & 4.467 & 4.550 & 4.111 & 4.184 & 4.389 & 4.456 & 4.325 & 4.378 \\
\hline Standard Deviation & 0.0026 & 0.0116 & 0.0100 & 0.0107 & 0.0108 & 0.0047 & 0.0185 & 0.0101 & 0.0214 & 0.0141 \\
\hline TPM (g/bhp-hr) & 0.1593 & 0.1332 & 0.1598 & 0.1302 & 0.1567 & 0.1318 & 0.1513 & 0.1277 & 0.1478 & 0.1248 \\
\hline Standard Deviation & 0.0010 & 0.0027 & 0.0015 & 0.0010 & 0.0007 & 0.0015 & 0.0011 & 0.0010 & 0.0006 & 0.0018 \\
\hline CO (g/bhp-hr) & 3.284 & 2.453 & 3.184 & 2.351 & 3.245 & 2.453 & 3.122 & 2.370 & 2.990 & 2.282 \\
\hline Standard Deviation & 0.0427 & 0.0552 & 0.0091 & 0.0167 & 0.0049 & 0.0234 & 0.0202 & 0.0129 & 0.0265 & 0.0322 \\
\hline CO2 (g/bhp-hr) & 538.3 & 538.1 & 538.3 & 535.2 & 530.6 & 528.8 & 537.2 & 536.7 & 536.1 & 539.9 \\
\hline Standard Deviation & 1.3410 & 1.1105 & 1.0269 & 0.5515 & 1.0377 & 0.3916 & 0.9499 & 1.9469 & 1.3128 & 5.8941 \\
\hline HC (g/bhp-hr) & 0.0534 & 0.0620 & 0.0518 & 0.0564 & 0.0522 & 0.0588 & 0.0554 & 0.0607 & 0.0524 & 0.0582 \\
\hline Standard Deviation & 0.0011 & 0.0026 & 0.0025 & 0.0006 & 0.0006 & 0.0018 & 0.0013 & 0.0014 & 0.0002 & 0.0007 \\
\hline BSFC (lb/bhp-hr) & 0.3790 & 0.3786 & 0.3795 & 0.3791 & 0.3783 & 0.3771 & 0.3812 & 0.3803 & 0.3822 & 0.3801 \\
\hline Standard Deviation & 0.0002 & 0.0007 & 0.0003 & 0.0007 & 0.0003 & 0.0003 & 0.0001 & 0.0002 & 0.0016 & 0.0002 \\
\hline FC (lb) & 8.865 & 8.635 & 8.878 & 8.644 & 8.756 & 8.514 & 8.818 & 8.580 & 8.844 & 8.576 \\
\hline Standard Deviation & 0.0040 & 0.0086 & 0.0070 & 0.0142 & 0.0070 & 0.0020 & 0.0035 & 0.0091 & 0.0376 & 0.0055 \\
\hline Work (bhp-hr) & 23.39 & 22.80 & 23.39 & 22.80 & 23.14 & 22.57 & 23.13 & 22.56 & 23.14 & 22.56 \\
\hline Standard Deviation & 0.0058 & 0.0208 & 0.0058 & 0.0058 & 0.0058 & 0.0252 & 0.0000 & 0.0115 & 0.0100 & 0.0058 \\
\hline
\end{tabular}

Table 5.3 FTP Variation Analysis for 1991 DDC S60

\begin{tabular}{|c|c|c|c|c|c|c|}
\hline & \multicolumn{2}{|c|}{ Average } & \multicolumn{2}{|c|}{ Standard Deviation } & \multicolumn{2}{|c|}{ Coefficient of Variation (\%) } \\
\hline & 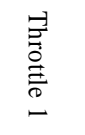 & 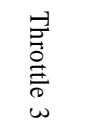 & 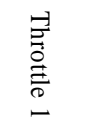 & 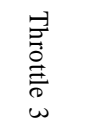 & $\begin{array}{l}\stackrel{-}{\Xi} \\
\overline{0} \\
\stackrel{\bar{D}}{\circ} \\
-\end{array}$ & $\begin{array}{l}\stackrel{-1}{\Xi} \\
\stackrel{0}{0} \\
\stackrel{\bar{\sigma}}{\omega} \\
\omega\end{array}$ \\
\hline NOx (g/bhp-hr) & 4.364 & 4.452 & 0.1543 & 0.1544 & 3.53 & 3.47 \\
\hline NOx 2 (g/bhp-hr) & 4.358 & 4.431 & 0.1534 & 0.1608 & 3.52 & 3.63 \\
\hline TPM (g/bhp-hr) & 0.155 & 0.130 & 0.0052 & 0.0034 & 3.38 & 2.59 \\
\hline CO (g/bhp-hr) & 3.165 & 2.382 & 0.1155 & 0.0727 & 3.65 & 3.05 \\
\hline CO2 (g/bhp-hr) & 536.1 & 535.7 & 3.2356 & 4.2273 & 0.60 & 0.79 \\
\hline HC (g/bhp-hr) & 0.053 & 0.059 & 0.0014 & 0.0022 & 2.71 & 3.69 \\
\hline BSFC (lb/bhp-hr) & 0.380 & 0.379 & 0.0016 & 0.0013 & 0.42 & 0.34 \\
\hline $\mathrm{FC} \mathrm{(lb)}$ & 8.832 & 8.590 & 0.0483 & 0.0524 & 0.55 & 0.61 \\
\hline Work (bhp-hr) & 23.240 & 22.659 & 0.1401 & 0.1292 & 0.60 & 0.57 \\
\hline
\end{tabular}




\subsubsection{Oxides of Nitrogen Emissions}

Reduction of NOx emissions in diesel engines has been of primary concern of the EPA. There is however, a trade off to reducing the level of NOx emissions. Typically lower combustion temperatures produce less NOx emissions. This however, in turn increases the amount of fuel consumed. NOx is mostly composed of NO. A small amount of NOx is $\mathrm{NO}_{2}$ and other nitrogen-oxygen combinations [14].

Throttle 1 provided a slight decrease in NOx emissions as displayed in Figure 5.1. The 2004 Cummins engine's emissions influence by APPC were determined to be minimal due to additional components on the engine, such as the VGT, EGR, and improved engine control. These components were assumed to cause different effects of their own on the performance and emissions of the engine. The 1991 DDC engine provided the most significant NOx reduction at 2.40\%. The 1992 DDC and rebuilt 1992 DDC responded slightly less in regards to NOx emissions (1.8\% - 1.1\%). It is noted that in Figure 5.1, and subsequent bar type plots, the error bar is a representation of the standard deviation of 3 hot start FTPs. 


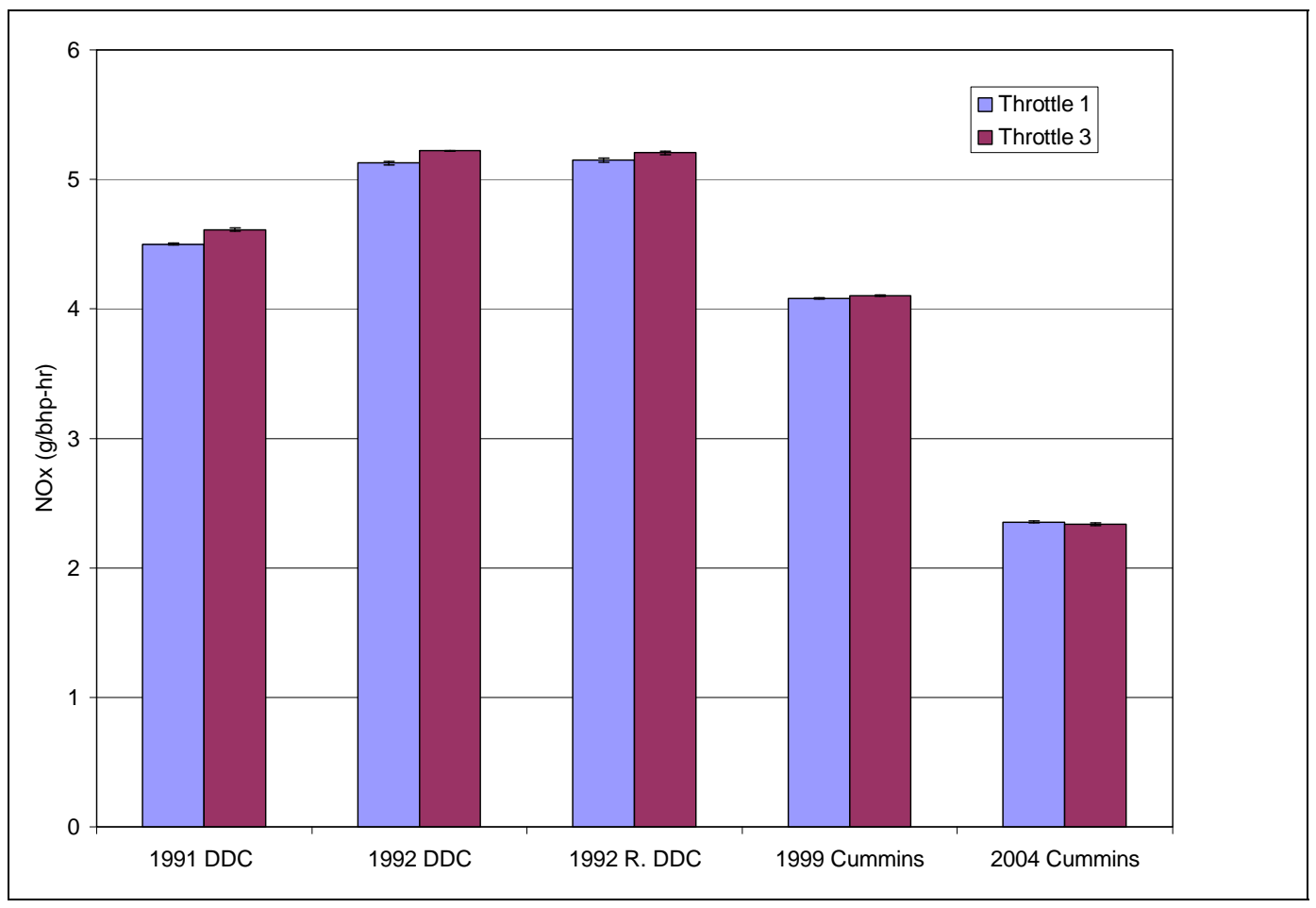

Figure 5.1 NOx Throttle Specific Emissions

\subsubsection{Particulate Matter Emissions}

TPM is another targeted emission for reduction by the EPA. TPM consists of a solid portion (carbon and ash), soluble organic fraction (SOF), and sulfates. The SOF is hydrocarbons (mostly heavy hydrocarbons) that have condensed on the carbon particles. Incomplete combustion of fuel causes this formation of solid carbon and SOF [13].

All five engines showed a reduction in TPM formation while utilizing Throttle 3. The 1991 DDC showed the greatest reduction while utilizing throttle 3 (17.6\%) while the 2004 Cummins showed the smallest reduction at 3.6\%. Throttle 1 achieved targeted torque at an earlier state than throttle 3 , and as a result, throttle 1 emitted more TPM than throttle 3 .

During rapid transient conditions, turbocharger lag can lead to higher momentary equivalence ratios (ER) than desired. As a result, TPM can increase. This could be the cause for the higher levels of TPM for throttle 1 . The newer Cummins engines utilize additional 
technologies such as EGR and VGT (2004 Cummins only) which aim to optimize ER during transient conditions. This may be why the newer Cummins responded less to the variations in APPC than the earlier legacy DDC engines.

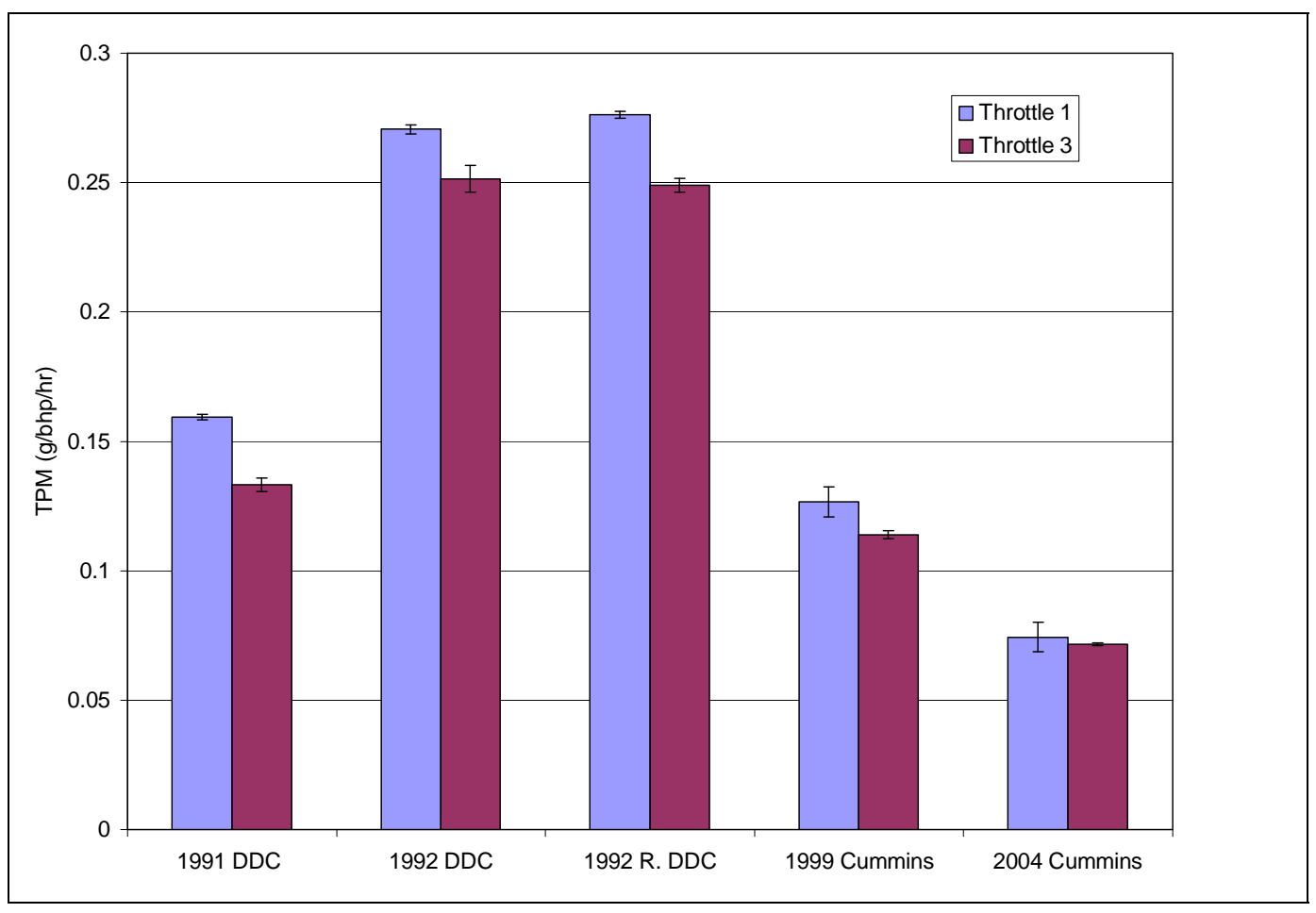

Figure 5.2 TPM Throttle Specific Emissions

\subsubsection{Carbon Monoxide Emissions}

$\mathrm{CO}$ is emitted by a diesel engine while operating under a locally fuel-rich equivalence ratio. $\mathrm{CO}$ is a colorless, odorless poisonous gas. Insufficient amounts of oxygen to convert all carbon to $\mathrm{CO}_{2}$ during combustion leads to excess fuel that does not completely oxidize. Some of the excess carbon from the unburned fuel forms CO [14].

All five engines saw a reduction in CO while utilizing throttle 3. The 1991 DDC showed the greatest reduction (29.0\%) while the 2004 showed the smallest reduction at $4.6 \%$. Fuel-rich equivalence ratios are responsible for formation of CO. Although diesel engines predominately operation under a lean-burn state, transient conditions lead to a richer equivalence ratio. Throttle 
1 resulted in more fuel use during the transient states of the FTP and had a higher equivalence ratio, resulting in more formation of $\mathrm{CO}$ than throttle 3 . $\mathrm{CO}$ emissions on a properly functioning HDDE are typically well below the regulated amount, which has been $15.5 \mathrm{~g} / \mathrm{bhp}-\mathrm{hr}$ since the creation of regulated on road emissions.

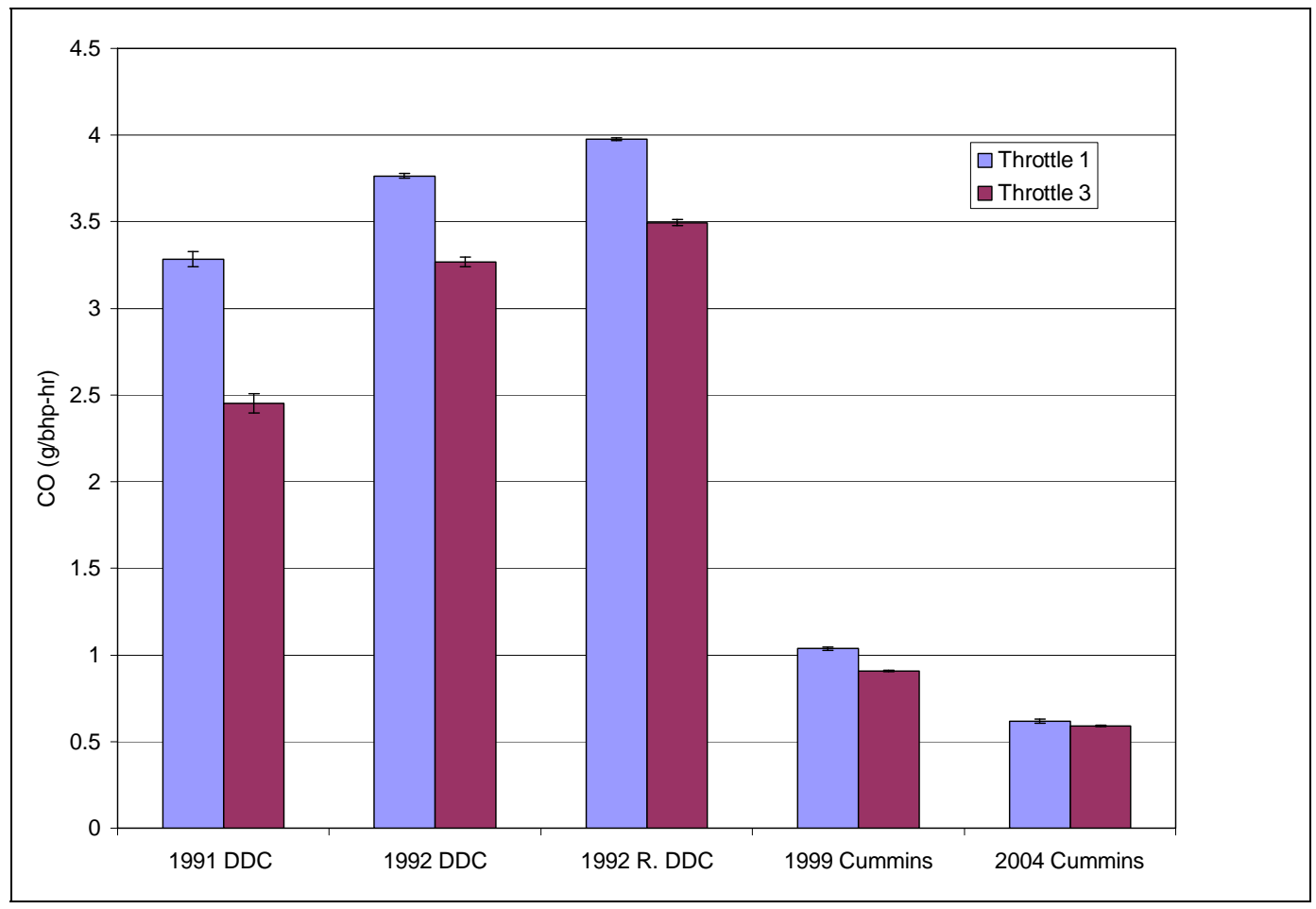

Figure 5.3 CO Throttle Specific Emissions

\subsubsection{Hydrocarbon Emissions}

HC are formed by incomplete combustion of fuel. Higher levels of HC are also formed at fuel-rich equivalence ratios. Sac volumes (fuel trapped on the tip of an injector after injection stops) can lead to excess HC. This is due to the fuel-rich environment surrounding the injector and the lack of pressure to push this mass of fuel from the sac into the combustion chamber. Other causes of HC formation are from excess oil on cylinder chamber walls intended for 
lubrication, and from reverse blow by occurring forcing fuel and oil trapped between the piston rings back into the crevice volume of the combustion chamber [14].

More aggressive throttle 1 proved to emit less HC than throttle 3 as displayed in Figure 5.5. Throttle 1 also provided more work during the FTP and therefore more average power. Hydrocarbon emissions predominantly decrease as power increases and therefore could explain for the reduction in $\mathrm{HC}$ emissions for throttle 1 . $\mathrm{HC}$ emissions are similar to $\mathrm{CO}$ emissions in that they are generally well below the regulated value (1.3 g/bhp-hr) on a properly functioning HDDE.

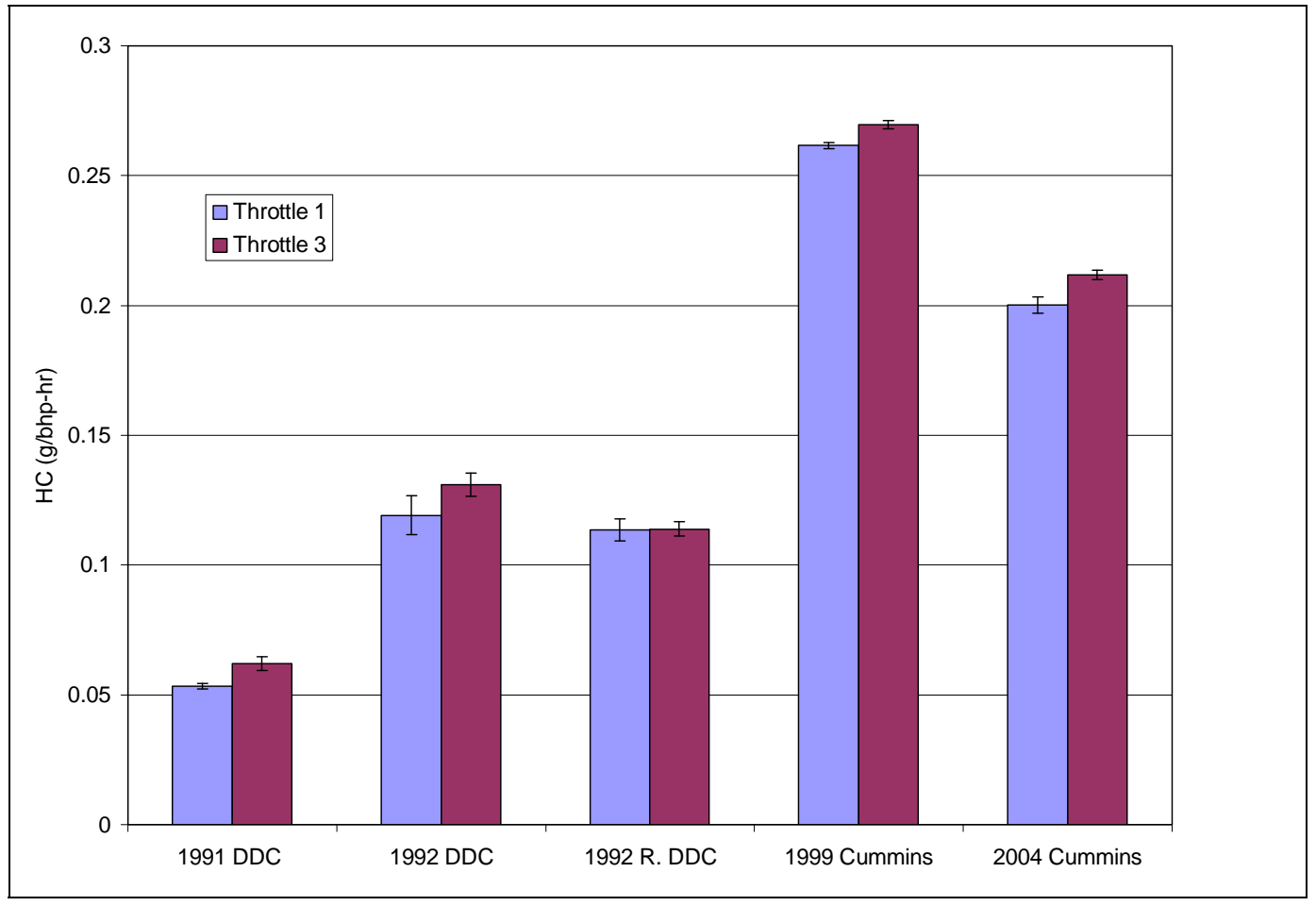

Figure 5.5 HC Throttle Specific Emissions

\subsection{Fuel Economy}

Fuel economy has become a major concern for consumers and manufacturers alike. As fuel prices have fluctuated drastically over the past couple years (circa 2008), improving fuel economy has become of high importance. Carbon dioxide $\left(\mathrm{CO}_{2}\right)$ is also a direct product of 
combustion of hydrocarbon fuels. $\mathrm{CO}_{2}$ has also been criticized for contributing to global warming, as $\mathrm{CO}_{2}$ is considered a greenhouse gas [15].

Figure 5.6 displays the brake specific fuel consumption (BSFC) results for both throttles 1 and 3 utilizing CP 0.05 Cert fuel. The 2004 Cummins had the largest response in BSFC to variations in APPC (0.90\%), while exercising throttle 1. The legacy DDC engines responded less in regards to BSFC ranging from $0.05 \%$ to $0.58 \%$. Figure 5.7 displays the fuel consumption on a mass basis for both throttles utilizing CP 0.05 Cert Fuel. Throttle 3 burned less fuel than throttle 1 for all five engines. The largest decrease in fuel consumption was achieved utilizing throttle 1 on the 2004 Cummins engine (3.3\%). The slight variation in BSFC is minimal, but an operator of a truck would prefer to operate under throttle 1 as opposed to throttle 3 , as it uses less fuel per work, therefore would increase mileage slightly.

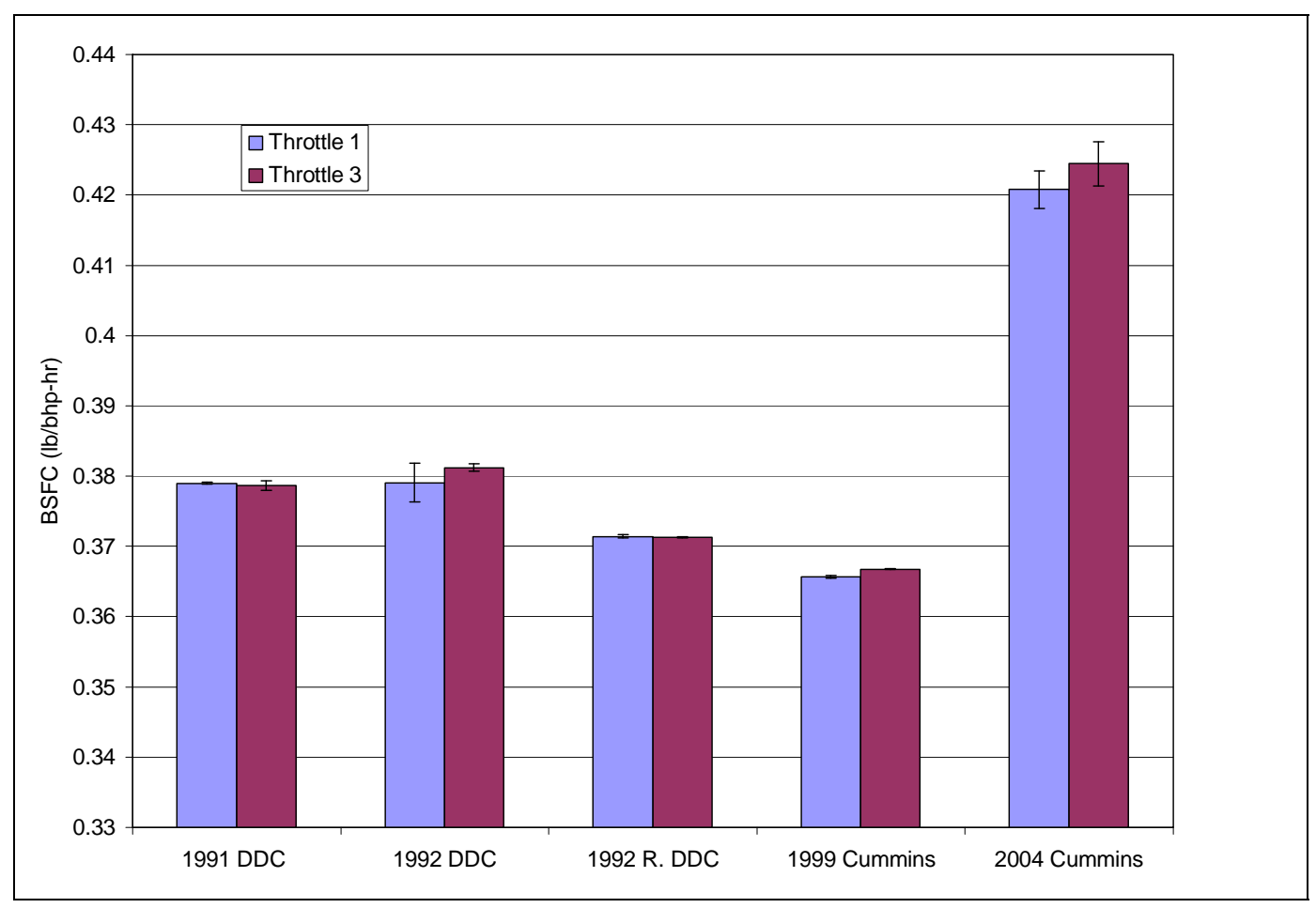

Figure 5.6 Throttle Specific BSFC 


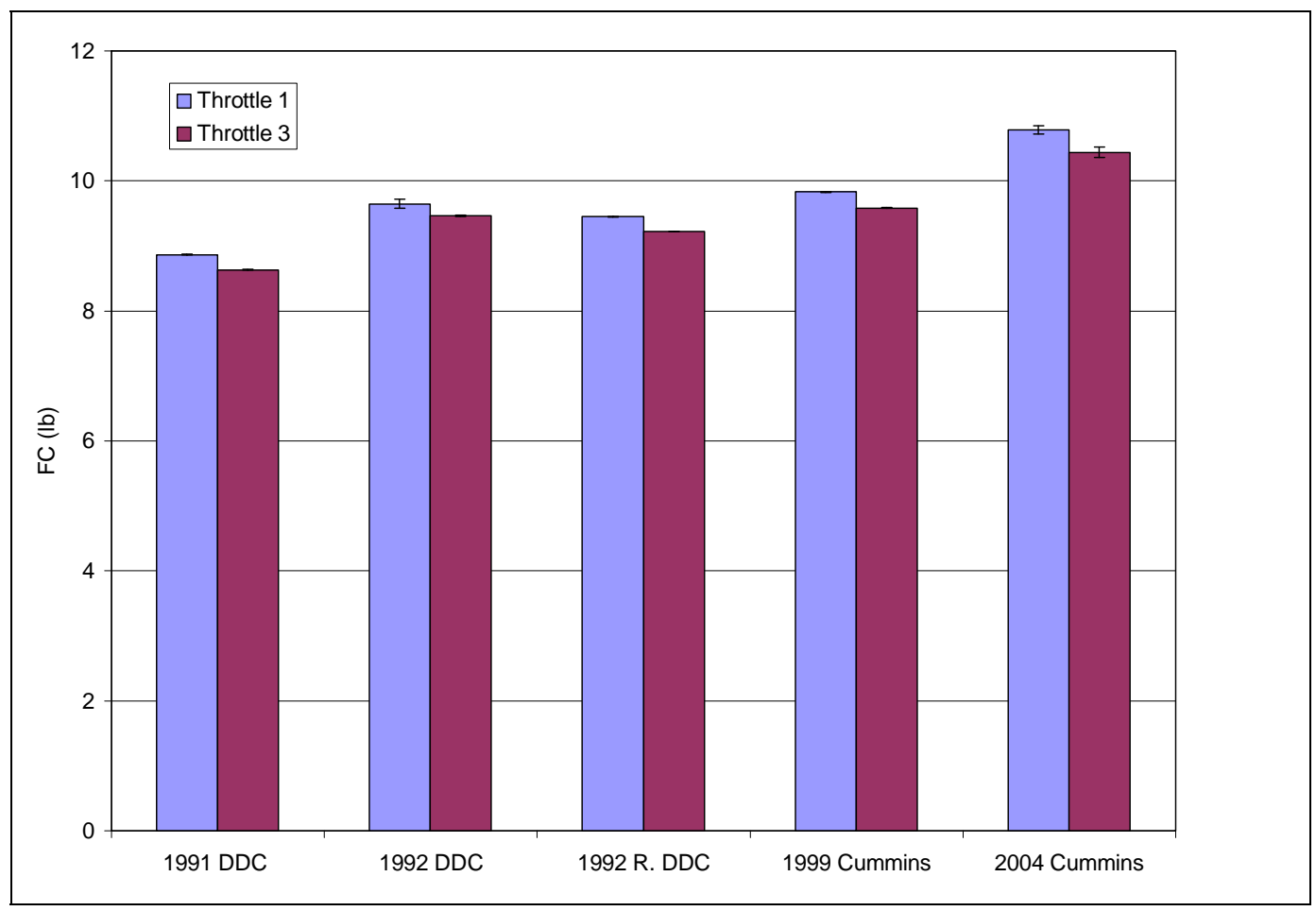

Figure 5.7 Throttle Specific Fuel Consumption

\subsection{Engine Performance}

\subsubsection{Work}

Figure 5.8 displays the work for both throttles 1 and 3 while utilizing CP 0.05 Cert fuel. Throttle 1 control algorithm resulted in increased work compared to throttle 3 on all five engines. The 2004 Cummins showed the greatest difference (4.18\%) in work while the 1992 rebuilt DDC responded the least to the throttle variation (2.39\%). While work is not one of the EPA's concerns, it is of major concern to the consumer. Maximizing work while retaining lower emissions is a primary goal of manufacturers. 


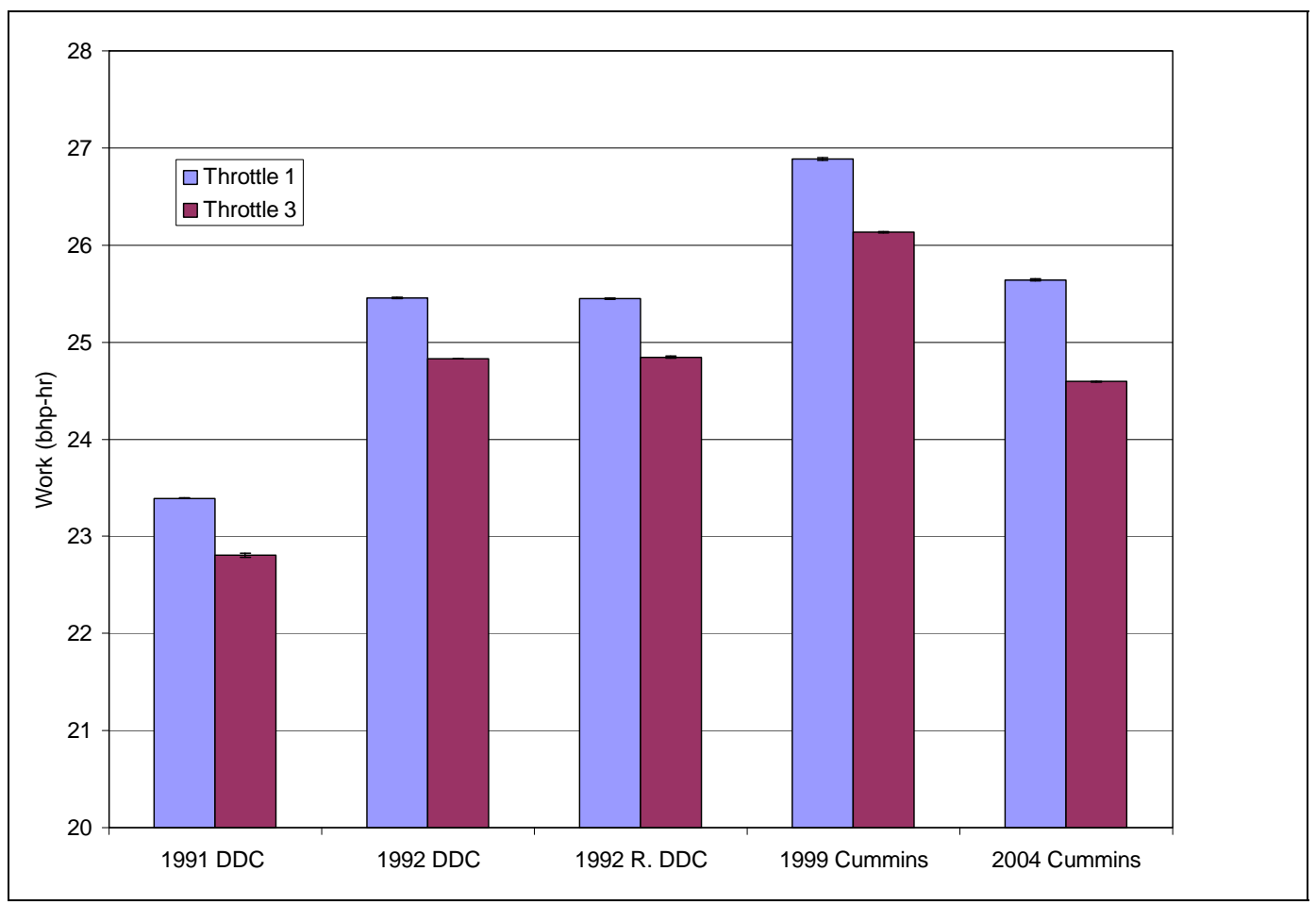

Figure 5.8 Throttle Specific Work

\subsubsection{Boost Pressure}

Figure 5.9 displays the global boost pressure for all five engines using CP 0.05 Cert Fuel. Although each engine has different algorithms for boost pressure control, each engine had a higher global boost pressure under control of throttle 1. Reaching target boost pressures is of the utmost importance in order to achieve the demanded work. The more aggressive throttle 1 shows its ability to reach the required APPC in Figures 4.1 to 4.3 and these throttle trends continued to reproduce themselves throughout testing. As a result, targeted boost pressures were achieved faster and led to a higher global boost pressures for throttle 1 when exercised over the FTP, as displayed in Figure 5.9. 


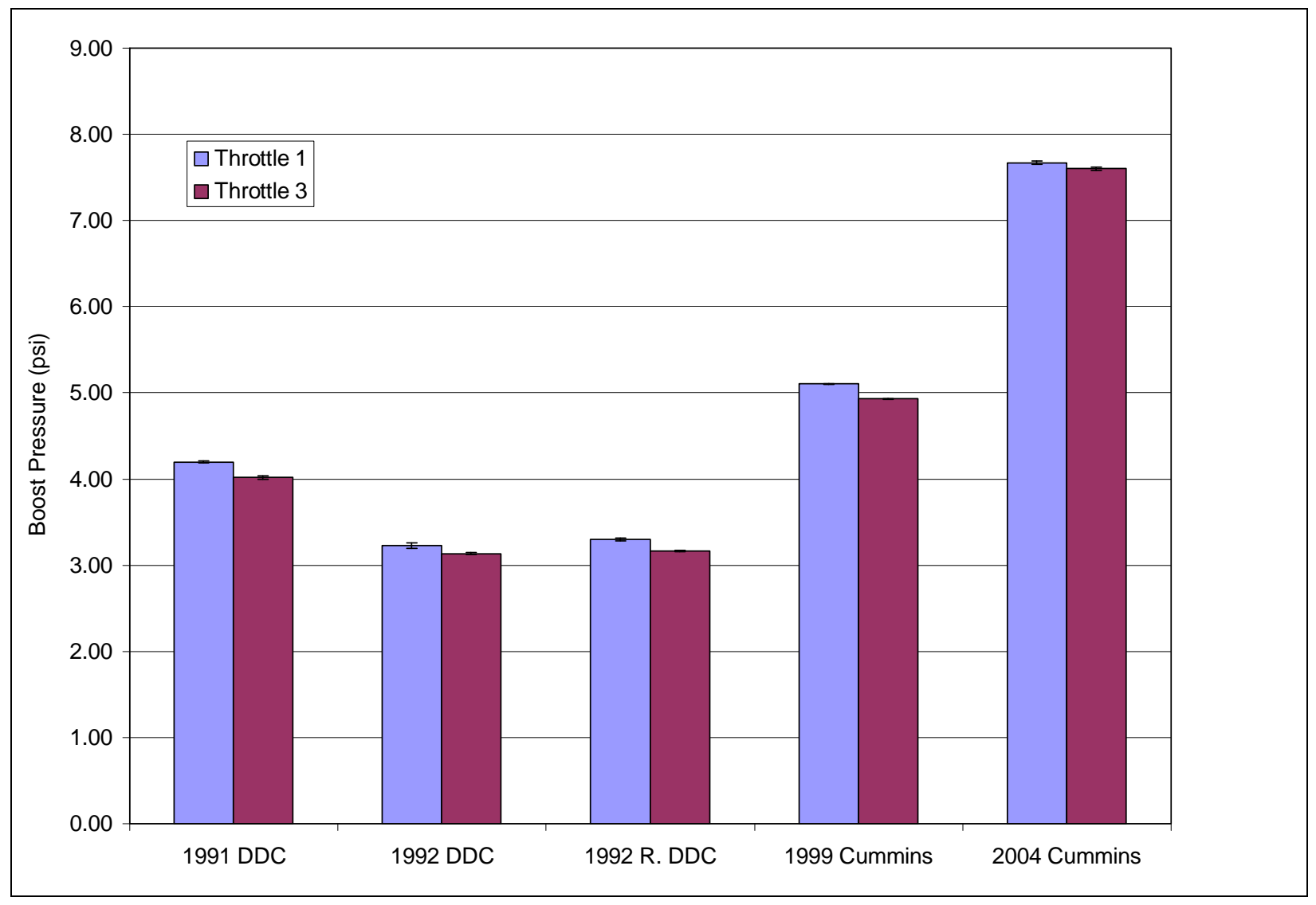

Figure 5.9 Throttle Specific Boost Pressure

\subsubsection{Exhaust Gas Temperature}

Figure 5.10 displays the global average exhaust gas temperature (EGT) for all five engines utilizing CP 0.05 Cert Fuel while exercised over the FTP cycle. The DDC engines had minimal variation of EGT with throttle 3 producing slightly lower temperatures $(1.03 \%$ - 1.10\%). The 2004 Cummins engine had the greatest global temperature difference at $1.65 \%$. Variations in EGT can explain for fluctuations of power and mixture of internal combustion engines. Higher global EGT while utilizing throttle 1 is assumed to be due to the higher boost pressures achieved and more work performed by that throttle as displayed in Figure 5.10. 


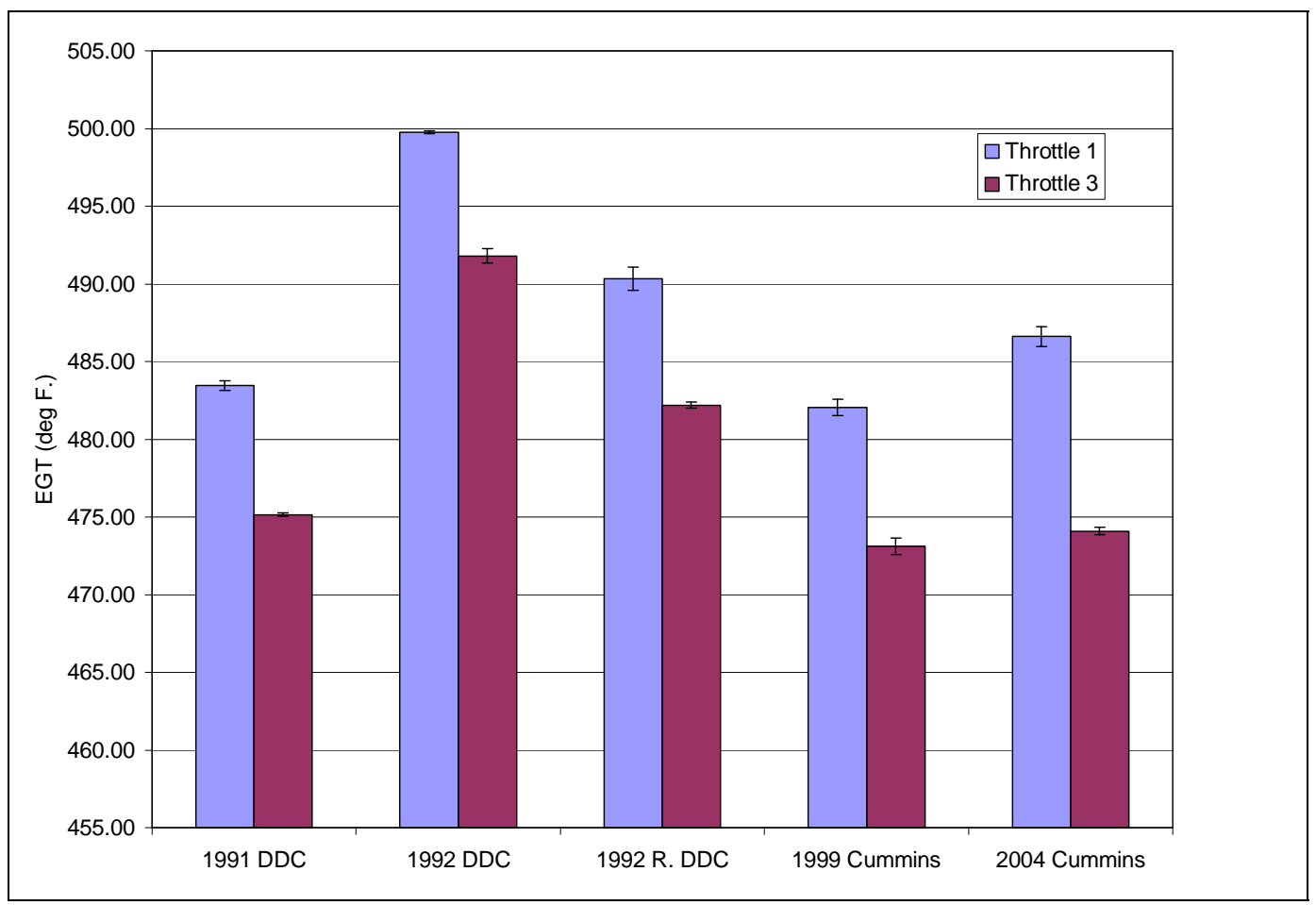

Figure 5.10 Throttle Specific EGT

\subsubsection{Equivalence Ratio}

Figure 5.11 displays a typical transient condition of the equivalence ratio (ER) as well as the APPC for the 1991 DDC fueled with CP 0.05 Cert. Throttle 1, the more aggressive throttle, may achieve a more rich mixture characteristic during transient conditions than throttle 3 . During the transient state displayed in Figure 5.11, throttle 1 was able to achieve richer ER's than throttle 3. Globally, throttle 1 achieved a slightly higher ER than throttle 3 (0.286-0.282).

ER displayed in Figure 5.11 is a calculated entity. Volumetric air flow measured in the intake was first converted to mass based air flow. Following that, the new mass based air flow was divided by the corresponding mass fuel rate at that point in time, to determine the fuel to air ratio. The ER was then determined by dividing the actual fuel to air ratio by a stoichiometric burn fuel to air ratio. 


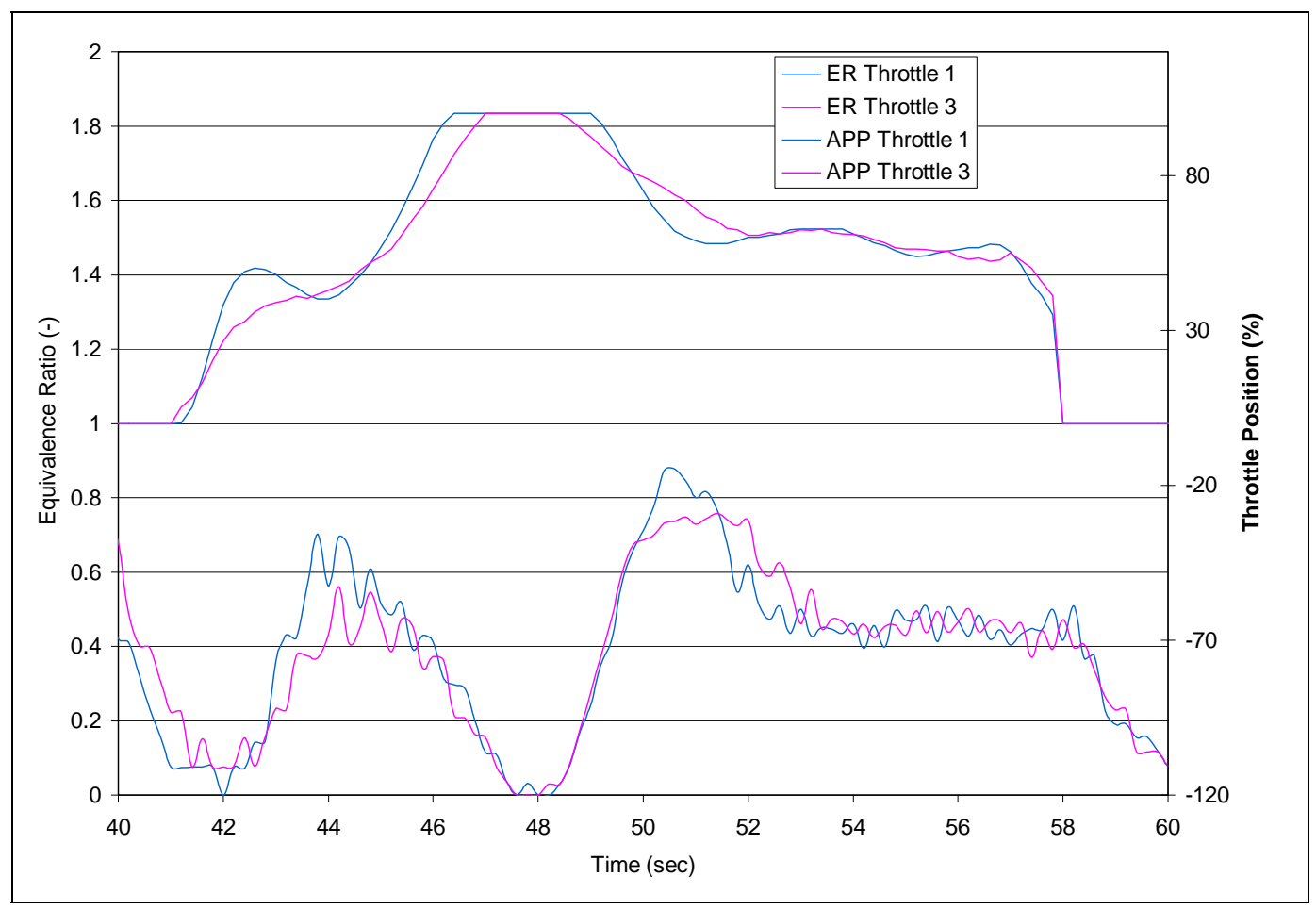

Figure 5.11 ER and APP vs. Time for 1991 DDC with CP 0.05 Cert Fuel

\subsection{Regression Analysis}

In order for a test to be considered a valid FTP, the test must meet certain regression criteria. There are tolerances set for work, power, torque and engine speeds, that are defined in 40 CFR part 86, subpart $\mathrm{N}$. The linear regressions are based on the equation $\mathrm{y}=\mathrm{mx}+\mathrm{b}$, where $\mathrm{y}$ is the best fit value, $\mathrm{m}$ is the slope of the regression line, $\mathrm{x}$ is the independent value, and $\mathrm{b}$ is the y-intercept value [1]. From a plot of the actual and measured data, certain tolerances are implemented including a standard error of estimate (SEE), a coefficient of determination $\left(\mathrm{r}^{2}\right)$, the slope of the regression line (m), and the $\mathrm{Y}$ intercept value of the regression line (b).

Table 5.4 displays the regression analysis for the 1991 DDC engine utilizing CP 0.05 Cert. fuel. Both throttle 1 and throttle 3 passed the regression criteria well within the prescribed tolerances. 
Table 5.4 Regression Analysis for 1991 DDC S60 Engine

\begin{tabular}{|c|c|c|c|}
\hline & $\begin{array}{c}\text { Throttle } 1 \\
\text { Measured Value }\end{array}$ & $\begin{array}{c}\text { Throttle } 3 \\
\text { Measured Value }\end{array}$ & CFR Valid Test Range \\
\hline \multicolumn{4}{|l|}{ SPEED $\quad$ (rpm) } \\
\hline Standard Error & 42.84 & 16.7 & $0--100$ \\
\hline Slope of Regression & 0.9932 & 1.0023 & $0.97--1.03$ \\
\hline Y Intercept & 13.04 & 0.9 & \pm 50.00 \\
\hline Coeff of Regression & 0.9899 & 0.9985 & $0.97-1$ \\
\hline \multicolumn{4}{|l|}{ TORQUE $\quad$ (ft-lb) } \\
\hline Standard Error & 49.92 & 56.65 & $0--172.18$ \\
\hline Slope of Regression & 1.0146 & 0.9672 & $0.83--1.03$ \\
\hline Y Intercept & -2.66 & -1.37 & \pm 15.00 \\
\hline Coeff of Regression & 0.981 & 0.9742 & $0.88--1$ \\
\hline \multicolumn{4}{|l|}{ POWER $\quad$ (bhp) } \\
\hline Standard Error & 17.95 & 19.67 & $0--27.58$ \\
\hline Slope of Regression & 0.9958 & 0.9766 & $0.89--1.03$ \\
\hline Y Intercept & 1.21 & -1.82 & \pm 5.00 \\
\hline Coeff of Regression & 0.9723 & 0.9661 & $0.91-1$ \\
\hline INTEGRATED WORK (bhp-hr) & 23.39 & 22.78 & $19.79--24.45$ \\
\hline
\end{tabular}

\subsection{APPC Analysis}

Figures 5.12 thru 5.20 display the velocities and accelerations for throttles 1 and 3 for the 1991 DDC S60 Engine. All accelerations are derived using a central difference method. All figures in this section are utilizing CP 0.05 Cert. fuel. This section analyzes the 1991 DDC S60 engine, while similar plots of other engines can be found in the appendix for Figures 8.2 through 8.34 . 


\subsubsection{Throttle Rate Profiles}

Figures 5.12 and 5.13 display the APPC for each of throttle 1 and throttle 3. The time rate of change of the throttle of each are also displayed with respect to each throttle setting. Throttle 1, the more aggressive throttle, reaches a faster rate of change state, with the slope of the time derivative of throttle 1 being $115.8 \% /$ s. Throttle 3's fastest rate of change reached was 70.74 $\% /$ s. A typical transient state of 20 seconds of the FTP is displayed in Figure 5.15. At 42 and 46 seconds the transient state of throttle 1 rate of change is at a faster rate than throttle 3 . At 42 seconds throttle 3 reaches a peak rate of change of $35.43 \% / s$ while throttle 1 reached a rate of change of $61.44 \% / s$. At 46 seconds, throttle 1 reaches a rate of change of $39.72 \% / s$ while throttle 3 only reaches a rate of change value of $28.99 \% / \mathrm{s}$. This trend continues throughout the FTP for this engine. Throttle profile for other engines can be found in the appendix from Figures 8.2 through 8.13 .

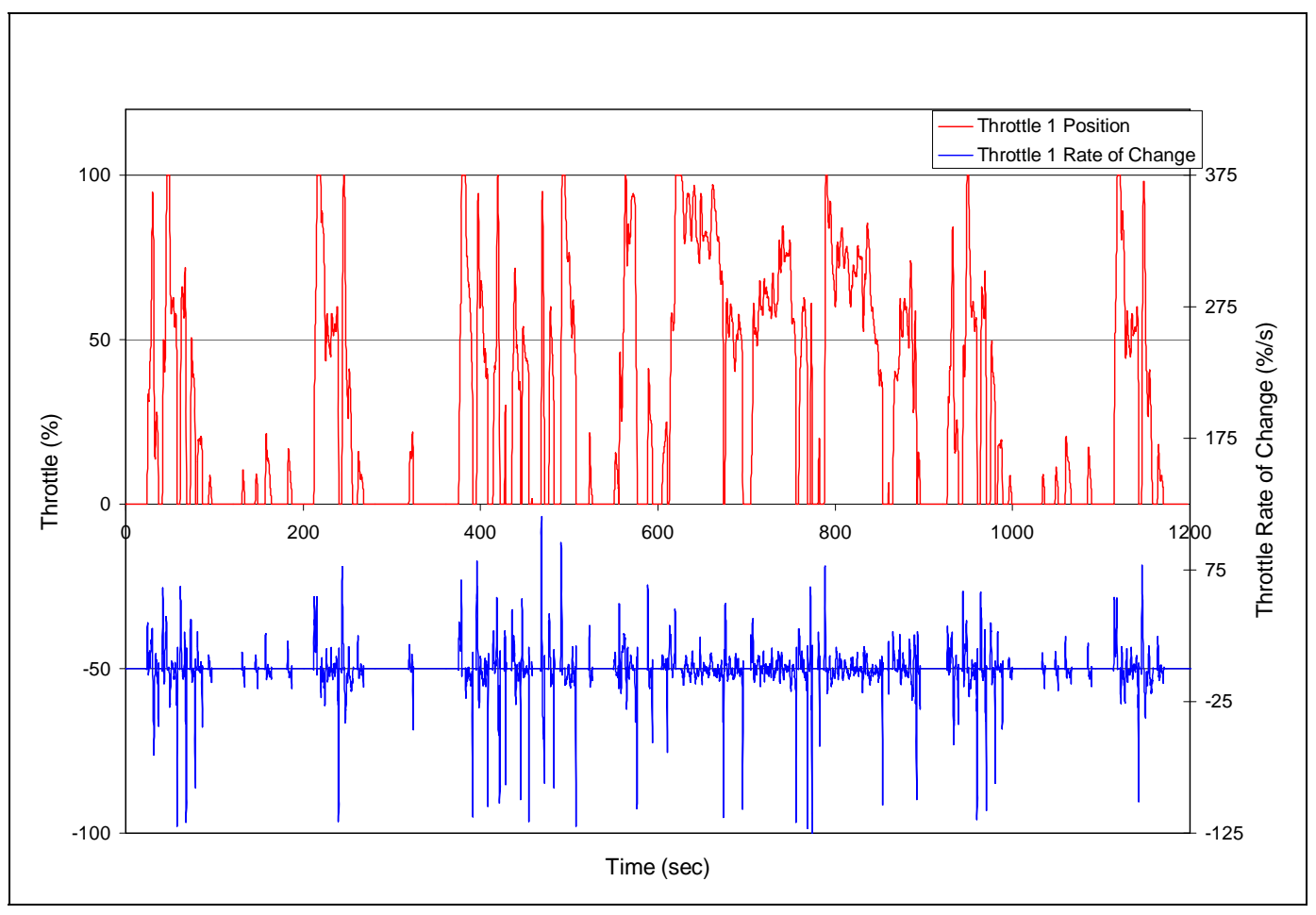

Figure 5.12 Throttle 1 Throttle Position and Rate of Change for 1991 DDC Engine 


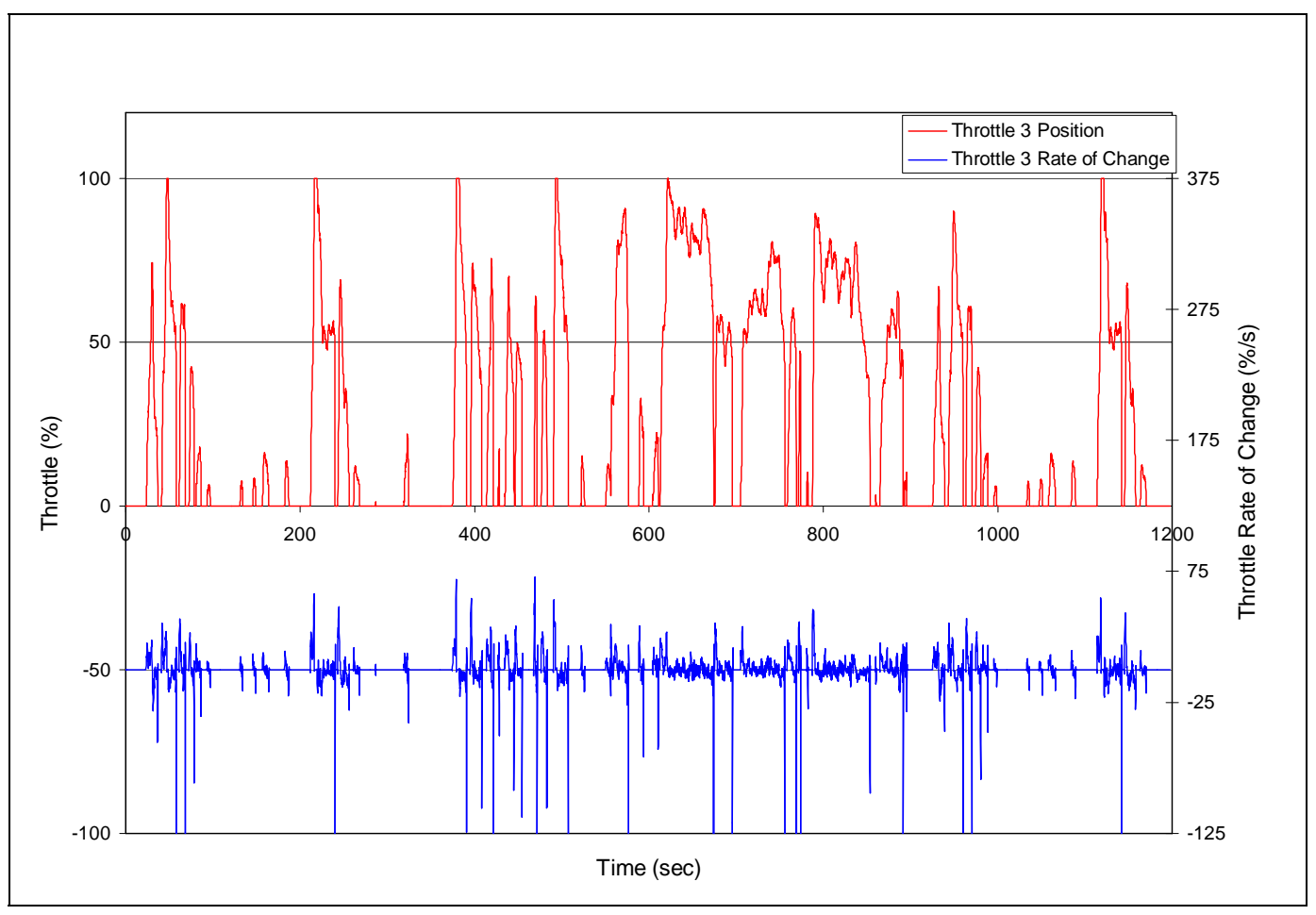

Figure 5.13 Throttle 3 Throttle Position and Rate of Change for 1991 DDC Engine

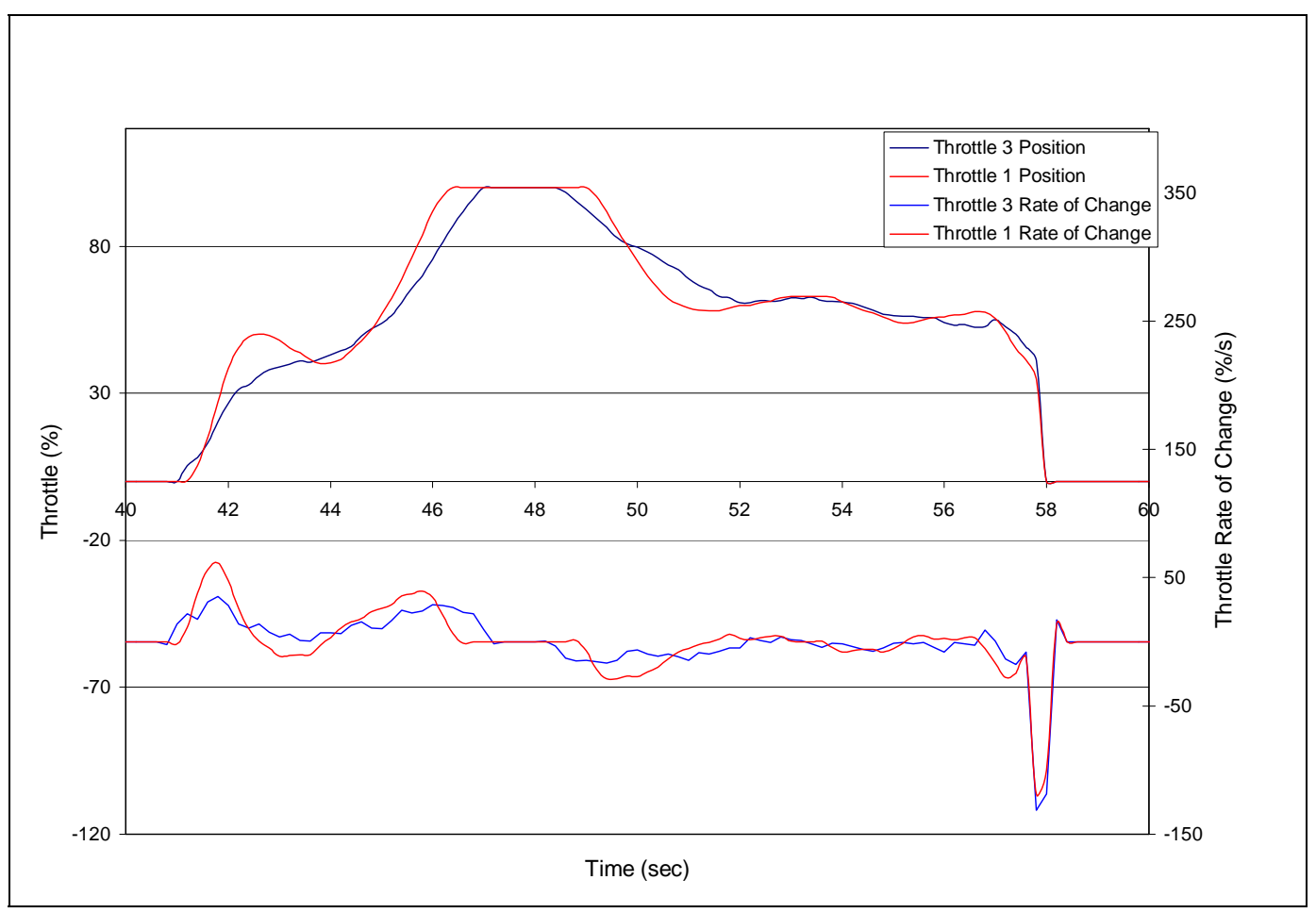

Figure 5.14 Throttle Position and Rate of Change for 1991 DDC Engine 


\subsubsection{Engine Speeds and Accelerations}

Figures 5.15 through 5.16 display the engine speeds for throttles 1 and 3 throughout an FTP for the 1991 DDC S60 Engine as well as their corresponding accelerations. The fastest engine acceleration reached by throttle 1 was $555.2 \% / \mathrm{s}$ while throttle 3 reached a maximum engine acceleration of $461.0 \%$ /s. Figure 5.17 displays the same 20 second transient state analyzed in Figure 5.14. At 44 seconds throttle 1's engine acceleration is $153.2 \% / \mathrm{s}$ while throttle 3 only reaches an engine acceleration of $142.2 \% / \mathrm{s}$. The trend for throttle 1 to accelerate the engine faster as well as decelerate the engine faster (as displayed in Figure 5.17) continues throughout this FTP, as well as for the other engines tested in this study. Similar plots for other engines tested can be found in the appendix with Figures 8.14 through 8.24.

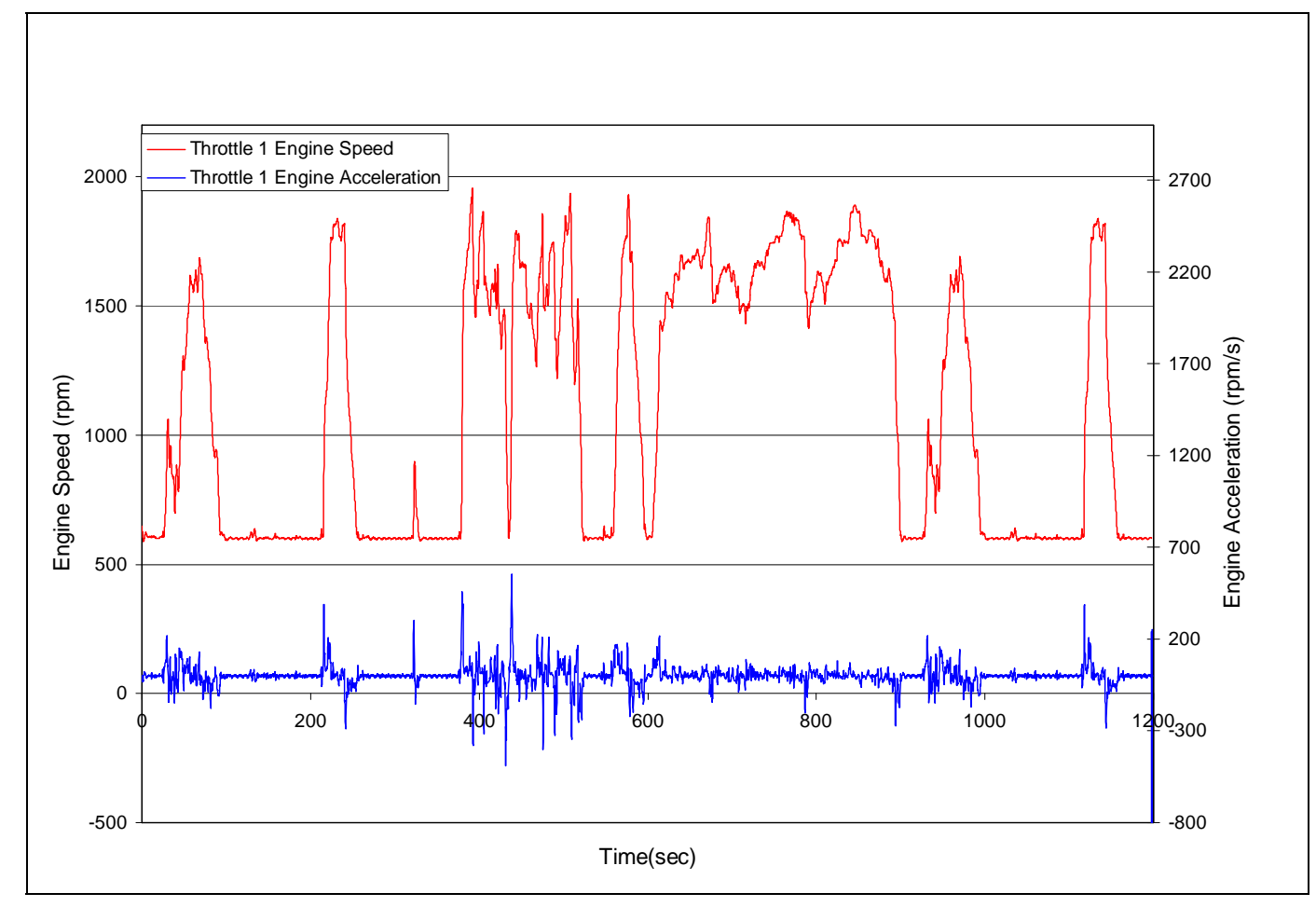

Figure 5.15 Throttle 1 Engine Speeds and Accelerations for 1991 DDC Engine 


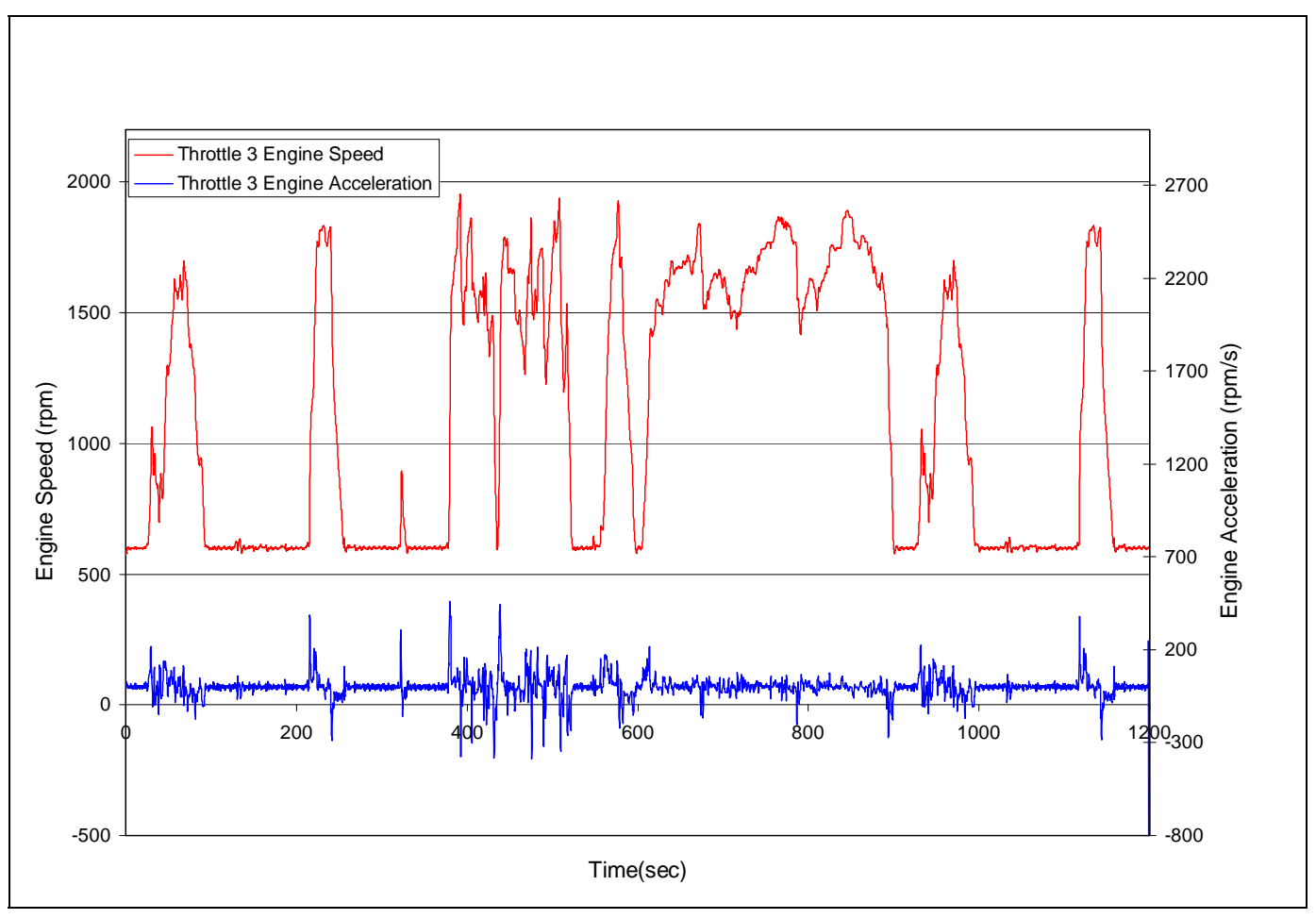

Figure 5.16 Throttle 1 Engine Speeds and Accelerations for 1991 DDC Engine

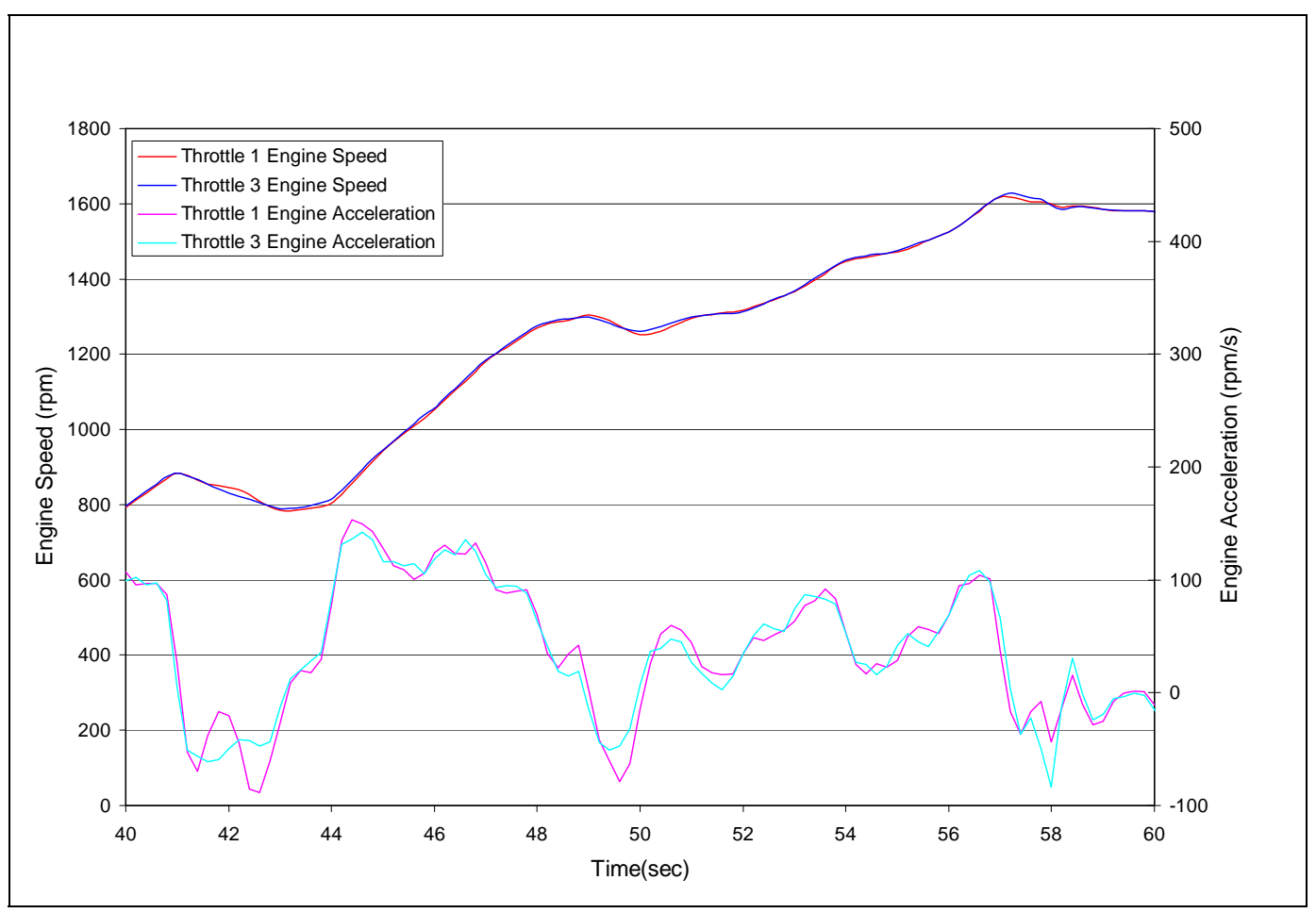

Figure 5.17 Engine Speeds and Accelerations for 1991 DDC Engine 


\subsubsection{Engine Torque and Torque Accelerations}

Figures 5.18 and 5.19 display the engine torque for throttles 1 and 3 throughout an FTP for the 1991 DDC S60 Engine. Torque is produced at a faster rate under guidance of throttle 1 when compared to throttle 3. Throttle 1's torque reaches a peak rate of change of $1613.5 \mathrm{ft}-\mathrm{lb} / \mathrm{s}$ while throttle 3's torque rate of change at a peak value of $1043.0 \mathrm{ft}-\mathrm{lb} / \mathrm{s}$. Figure 5.20 displays the transient 20 second interval analyzed in the previous two sections. At 42 seconds throttle 1 displays it's more aggressive APPC state as it reaches a peak load change of $963.7 \mathrm{ft}-\mathrm{lb} / \mathrm{s}$ while the load change of throttle 3 only reaches a value of $434.5 \mathrm{ft}-\mathrm{lb} / \mathrm{s}$. Plots of engine torque and engine torque accelerations for all other engines tested in this study can be found in the appendix on Figures 8.25 through 8.34 .

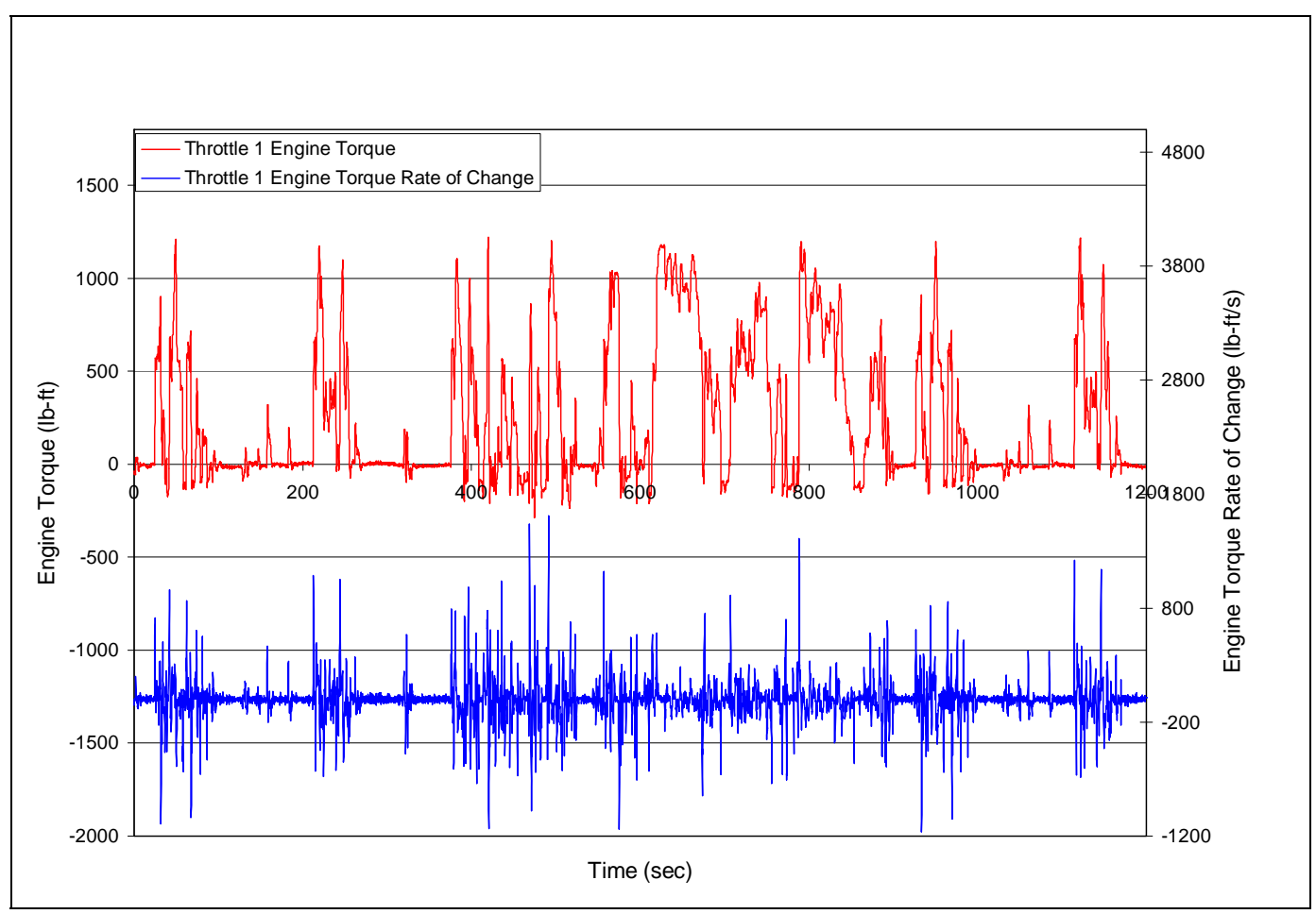

Figure 5.18 Throttle 1 Engine Torque and Engine Torque Rate of Change for 1991 DDC Engine 


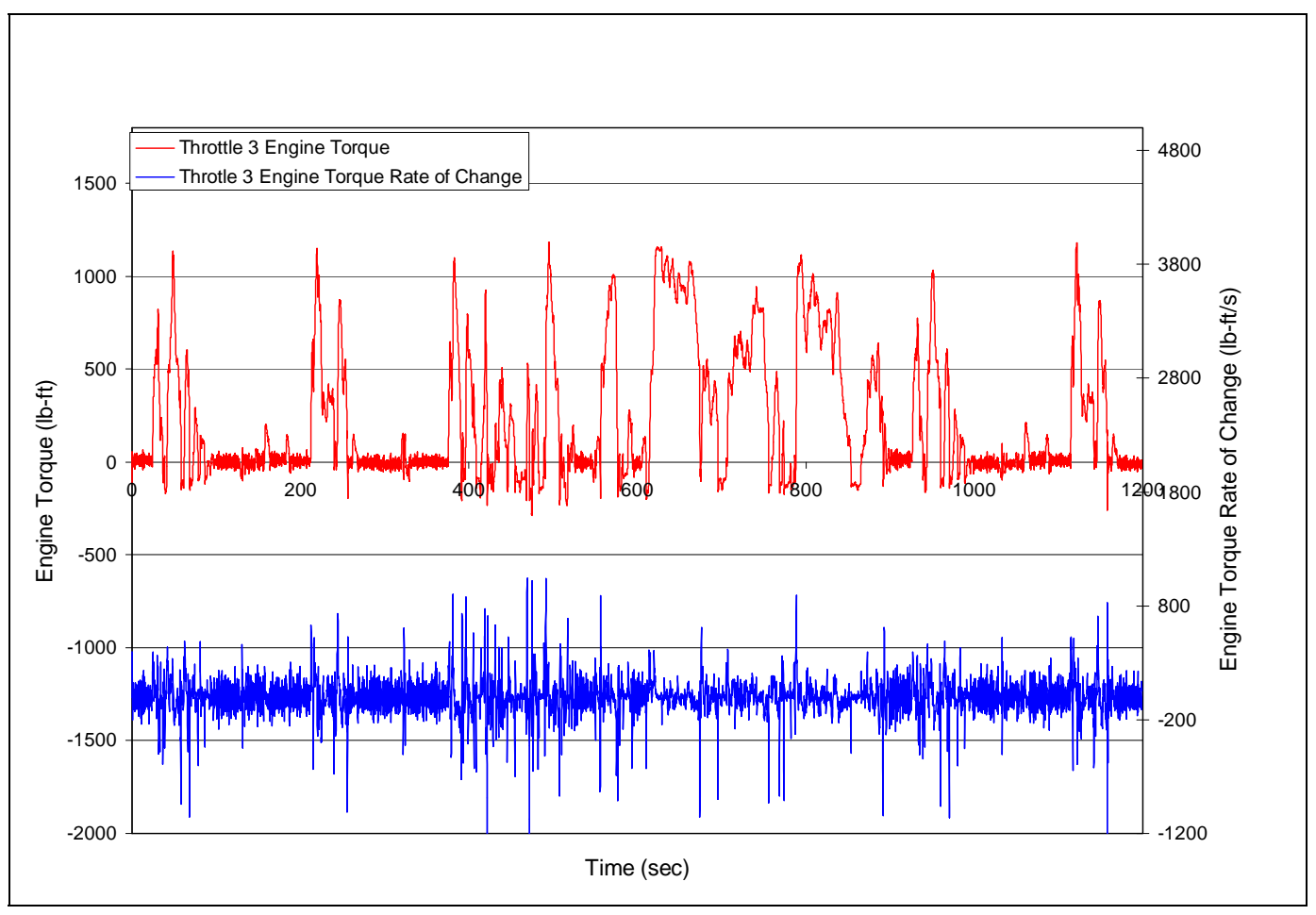

Figure 5.19 Throttle 3 Engine Torque and Engine Torque Rate of Change for 1991 DDC Engine

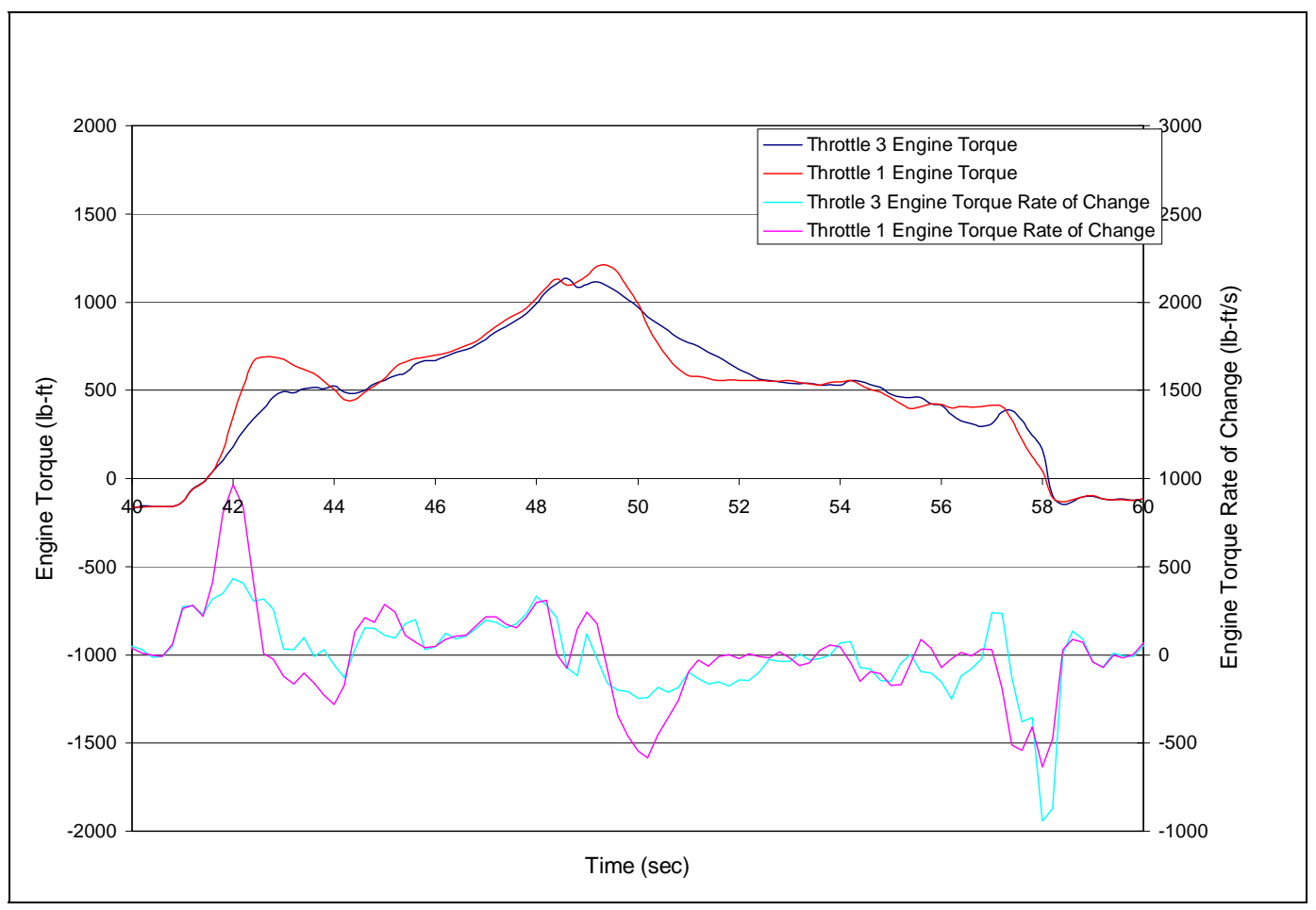

Figure 5.20 Engine Torque and Engine Torque Rate of Change for 1991 DDC Engine 


\subsection{Summary of Results}

NOx was affected minimally from the variations in APPC. The 1991 DDC engine saw the greatest NOx reduction at $2.40 \%$ under control of throttle 1 . The newer Cummins engines saw minimal change in NOx emissions, which could be due to their more advanced engine control units, EGR, and variable geometry turbochargers (2004 Cummins). Figure 5.12 displays a fifth order polynomial trendline of the effects of the APPC on NOx emissions when using the CP 0.05 Cert fuel on the 1991 DDC engine. The APPC effected emissions in the 75 to 250 hp range, and again from 300 to $350 \mathrm{hp.}$

TPM was significantly affected by variations in APPC exercised on the legacy DDC engines, with the greatest reduction coming from the 1991 DDC utilizing throttle 3 (17.6\%). The 2004 Cummins saw the smallest reduction in TPM (3.6\%). The additional TPM collected during testing of throttle 1 were inferred to be due to the rich cylinder mixture conditions associated with turbocharger lag during rapid transient conditions. 


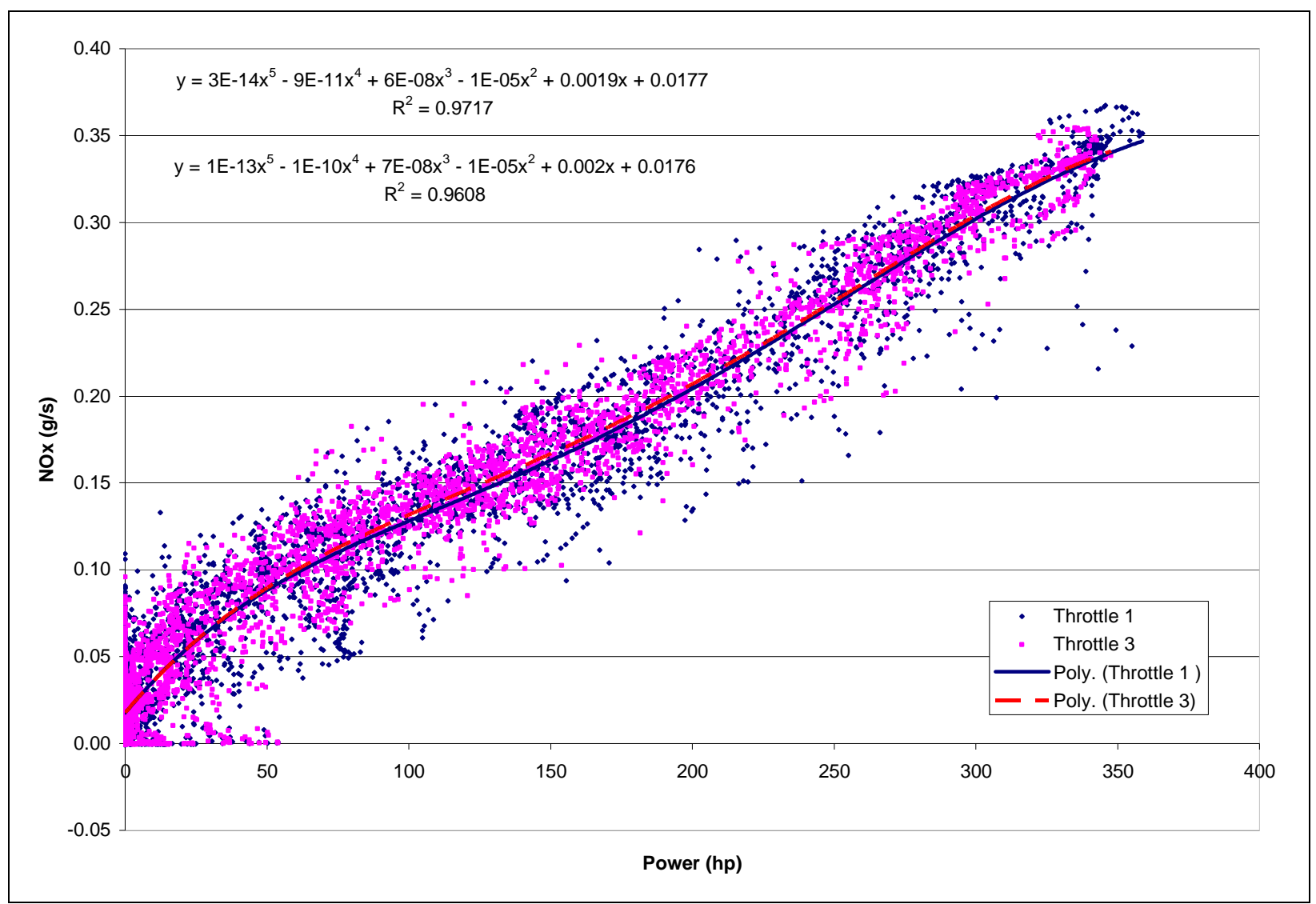

Figure 5.12 1991 DDC 5TH Order Polynomial Trendline for NOx

CO was also significantly impacted by the variations in APPC. Again, the 1991 DDC engine responded the most and emitted $29.0 \%$ less CO under control of throttle 3 . All engines saw a reduction in CO under control of throttle 3. The 2004 Cummins engine provided the smallest reduction at $4.6 \%$

HC emissions were significantly reduced under control of throttle 1 . The 1991 DDC emitted 15.0\% less HC under control of throttle 1. The rebuilt 1992 DDC was least effected by variations in APR, only providing a $0.9 \%$ reduction in $\mathrm{HC}$.

Fuel consumption was moderately effected by the variations in APPC. The less aggressive throttle 3 burned less fuel when exercised over the FTP than throttle 1 . The 2004 Cummins engine responded the most to the variation of APPC by burning 3.3\% under guidance 
of throttle 3. BSFC was minimally affected by varying APPC with the largest variation at $0.9 \%$ for the 2004 Cummins engine.

Work was impacted significantly by variations in APPC. The 2004 Cummins engine provided the most significant response, posting a 4.18\% increase in work for throttle 1 . The 1992 rebuilt DDC provided the smallest change in work, at 2.39\% under control of throttle 1. 


\section{Conclusions and Recommendations}

Variations in APPC affected the engines emissions and performance examined in this study differently based on engine model years. The older DDCs emissions responded more to the variations in APPC than the newer Cummins engines. The newer Cummins engines did not respond as well in regards to emissions as they incorporate technologies that help to reduce emission levels such as higher injection pressure, higher compression ratios, advanced engine control units, and cooled EGR (2004 Cummins Only). Throttle 1 proved to provide reductions in NOx and HC emissions, while throttle 3 was more favorable in reductions of TPM and CO emissions.

Work, fuel consumption, and overall engine performance were also significantly affected by variations in APPC during transient conditions. Globally, throttle 3 consumed less fuel than throttle 1, but throttle 1 produced more unit work. The newer Cummins engines responded the most to variations in APPC. It is inferred that the newer Cummins engines were able to achieve the most net work difference with the more aggressive throttle due to the additional technologies they incorporate including the VGT and EGR. The VGT aims to reduce turbocharger lag during rapid transient conditions, therefore desired boost pressures and work outputs are achieved faster on these Cummins engines when compared to the older legacy DDC engines.

Valid regression analysis proved that both throttle profiles were within specified limits when exercised over the FTP cycle. Emissions variations of up to $2.4 \%$ for NOx and $17.6 \%$ for TPM were noticed between throttle 1 and throttle 3, while both throttles's passed regression criteria well within the tolerances. Utilization of a wider range of throttle profiles could be used and still net valid under current regression tolerances. It is recommended that the regression analysis tolerances be restructured with tighter tolerances in order to achieve more accurate FTP 
results. Tighter regression criteria could also lead to better comparison of FTP results from multiple testing sites.

It is also recommended that the newer Cummins engines fueling algorithms be programmed for on road trucks in favor of more aggressive throttle 1 . The 2004 Cummins engine proved to have significant increase in work output utilizing throttle 1, yet yield a lower BSFC value under this throttle. The variations in throttling also effected emissions minimally, therefore the VGT and EGR seem to correct the known problem of rich mixtures associated with rapid transient load changes on turbocharged HDDE's. 


\section{References}

1. Code of Federal Regulations, CFR Title 40 Part 86-89, Office of Federal Register National Archives and Records Administration, Washington, DC, 2006.

2. Clean Air Act - US EPA, http://www.epa.gov/air/caa/, 2008.

3. Mayer, A., Lutz, T., Lammle, C., Wyser, M., and Legerer, F, “Engine Intake Throttling for Active Regeneration of Diesel Particle Filters," Warrendale, PA, SAE Paper, No. 2003-01-0381, 2003.

4. Tabata, Y., Takeda, Y., and Niimura, K., "Effects of Multi-Hole Nozzle with Throttle Construction on Diesel Combustion and Emissions with High-Pressure Fuel Injection,” Warrendale, PA, SAE Paper, No. 1995-06-0007, 1995.

5. Itoh, S. and Ishii, Y., "Simulation Analysis on Dynamic Characteristics of Diesel Fuel Injection Systems,” Warrendale, PA, SAE Paper, 1985-15-0086, 1985.

6. Gissinger, G.L., "Modern-Based Electronic Diesel Engine and Turbocharger Control,” Warrendale, PA, SAE Paper, 1990-05-0095, 1990.

7. Nieuwstadt, M., “Coordinnated Control of EGR Valve and Intake Throttle for Better Fuel Economy in Diesel Engines,” Warrendale, PA, SAE Paper 2003-01-0362, 2003.

8. Steigherwald, K., Zelenka, B., and Hohenberg, G., "Development of an Intake Based Flow Model Calculating Real Time Exhaust Flow by Accounting for Filling and Emptying of the Engine Manifolds,” Warrendale, PA, SAE Paper 2007-01-0324, 2007.

9. $\quad$ Emission Test Cycles (ESC), http://www.dieselnet.com/standards/cycles/esc.html, Ecopoint Inc, 2007.

10. Tincher, R.R., "Evaluation of Heavy Duty Diesel Engines Regulated Emissions Based on Variation of Fuel Properties by Use of Additives," Masters Thesis, Department of Mechanical and Aerospace Engineering, West Virginia University, Morgantown, WV, 2007.

11. Flaim, K.A.C., "Study of the Variations in Continuous Diesel Particulate Matter Size Measurements and Effect of Fuel Properties on DPM Size,” Masters Thesis, Department of Mechanical and Aerospace Engineering, West Virginia University, Morgantown, WV, 2008.

12. Nuszkowski, J.P., "The Effects of Fuel Additives on Diesel Engine Emissions during Steady State and Transient Operation,” Ph.D. Dissertation, Department of Mechanical and Aerospace Engineering, West Virginia University, Morgantown, WV, 2007.

13. Nuszkowski, J.P., Thompson, G.J., and Ursic, M.C., "The Influence of Fueling during Transient Laboratory Testing on Heavy Duty Diesel Engines,” Warrendale, PA, SAE Paper 2009-01-0619, 2009. 
14. Pulkrabek, W.W., Engineering Fundamentals of the Internal Combustion Engine, Prentice Hall, Upper Saddle River, New Jersey, 1997.

15. Inventory of U.S. Greenhouse Gas Emissions and Sinks: 1990-2004, Environmental Protection Agency, Washington, DC, USEPA \#430-R-06-002, 2006.

16. Assanis, D., Filipi, Z., Fiveland, S., and Syrimis, M., "A Methodology for Cycle-ByCycle Transient Heat Release Analysis in a Turbocharged Direct Injection Diesel Engine,” Warrendale, PA, SAE Paper No. 2000-01-1185, 2000.

17. Emission Standards: USA: Heavy-Duty Truck and Bus Engines, http://www.dieselnet.com/standards/us/hd.php, Ecopoint Inc, 2009.

18. Hardin, J.W., “Quantification of Soluble Organic Fraction Measurement Variation in Diesel Particulate Matter Emissions,” Masters Thesis, Department of Mechanical and Aerospace Engineering, West Virginia University, Morgantown, WV, 2008.

19. Jackson, C., Sze, C., Schenk, C., Olson, B., and Laroo, C., "Comparison of Exhaust Emissions from Application of Ramped Modal Cycle and Steady-State Nonroad Test," Warrendale, PA, SAE Paper No. 2005-01-1615, 2005. 


\section{Appendices}

Table 8.1 FTP Throttle Specific Results for 1992 DDC

\begin{tabular}{|c|c|c|c|c|c|c|c|c|c|c|}
\hline & \multicolumn{2}{|c|}{ CP 0.05 Cert } & \multicolumn{2}{|c|}{$\begin{array}{l}\text { CP } 0.05 \text { Cert with } \\
\text { 12ml - ODA }\end{array}$} & \multicolumn{2}{|c|}{ Grad Ref } & \multicolumn{2}{|c|}{ Grad Cand } & \multicolumn{2}{|c|}{$\begin{array}{c}\text { Grad Cand with } 12 \mathrm{ml} \\
\text { ODA }\end{array}$} \\
\hline & $\begin{array}{l}\text { 를 } \\
\stackrel{0}{0} \\
\stackrel{D}{\bullet} \\
\mapsto\end{array}$ & 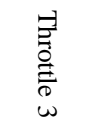 & 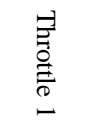 & $\begin{array}{l}\stackrel{-1}{E} \\
0 \\
\stackrel{0}{0} \\
\omega \\
\omega\end{array}$ & 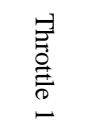 & $\begin{array}{l}\stackrel{-1}{\bar{\sigma}} \\
0 \\
\stackrel{0}{0} \\
\omega\end{array}$ & 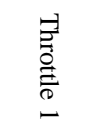 & 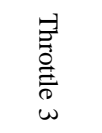 & 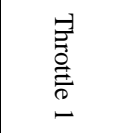 & 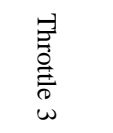 \\
\hline NOx (g/bhp-hr) & 5.127 & 5.221 & 4.960 & 5.069 & 4.640 & 4.747 & 4.989 & 5.080 & 4.852 & 4.967 \\
\hline Standard Deviation & 0.0134 & 0.0036 & 0.0150 & 0.0078 & 0.0110 & 0.0227 & 0.0173 & 0.0155 & 0.0107 & 0.0229 \\
\hline NOx 2 (g/bhp-hr) & 5.112 & 5.218 & 4.944 & 5.043 & 4.604 & 4.686 & 4.949 & 5.032 & 4.839 & 4.938 \\
\hline Standard Deviation & 0.0226 & 0.0198 & 0.0142 & 0.0124 & 0.0000 & 0.0174 & 0.0147 & 0.0211 & 0.0050 & 0.0268 \\
\hline TPM (g/bhp-hr) & 0.2706 & 0.2515 & 0.2640 & 0.2371 & 0.2492 & 0.2310 & 0.2513 & 0.2315 & 0.2585 & 0.2333 \\
\hline Standard Deviation & 0.0017 & 0.0052 & 0.0091 & 0.0048 & 0.0012 & 0.0028 & 0.0060 & 0.0017 & 0.0057 & 0.0059 \\
\hline CO (g/bhp-hr) & 3.765 & 3.267 & 3.511 & 3.006 & 3.556 & 3.175 & 3.547 & 3.195 & 3.448 & 3.026 \\
\hline Standard Deviation & 0.0134 & 0.0283 & 0.0430 & 0.0038 & 0.0382 & 0.0777 & 0.0180 & 0.0323 & 0.0364 & 0.0131 \\
\hline CO2 (g/bhp-hr) & 533.7 & 535.8 & 534.3 & 528.2 & 532.2 & 531.8 & 537.8 & 538.3 & 538.8 & 539.2 \\
\hline Standard Deviation & 1.4170 & 0.5501 & 6.1524 & 2.0438 & 0.8060 & 0.6019 & 2.0141 & 0.7448 & 1.6349 & 0.7261 \\
\hline HC (g/bhp-hr) & 0.1192 & 0.1310 & 0.1008 & 0.0987 & 0.0979 & 0.0976 & 0.1237 & 0.1327 & 0.1129 & 0.1179 \\
\hline Standard Deviation & 0.0075 & 0.0046 & 0.0098 & 0.0038 & 0.0010 & 0.0016 & 0.0079 & 0.0044 & 0.0055 & 0.0026 \\
\hline BSFC (lb/bhp-hr) & 0.3791 & 0.3812 & 0.3795 & 0.3832 & 0.3794 & 0.3776 & 0.3830 & 0.3832 & 0.3824 & 0.3826 \\
\hline Standard Deviation & 0.0028 & 0.0005 & 0.0033 & 0.0034 & 0.0003 & 0.0035 & 0.0009 & 0.0008 & 0.0004 & 0.0005 \\
\hline FC (lb) & 9.648 & 9.465 & 9.658 & 9.519 & 9.539 & 9.265 & 9.620 & 9.400 & 9.604 & 9.387 \\
\hline Standard Deviation & 0.0679 & 0.0127 & 0.0854 & 0.0878 & 0.0057 & 0.0797 & 0.0181 & 0.0225 & 0.0062 & 0.0067 \\
\hline Work (bhp-hr) & 25.46 & 24.83 & 25.45 & 24.84 & 25.14 & 24.54 & 25.12 & 24.53 & 25.12 & 24.53 \\
\hline Standard Deviation & 0.0071 & 0.0000 & 0.0100 & 0.0100 & 0.0058 & 0.0208 & 0.0153 & 0.0100 & 0.0100 & 0.0115 \\
\hline
\end{tabular}

Table 8.2 FTP Variation Analysis 1992 DDC S60

\begin{tabular}{|c|c|c|c|c|c|c|}
\hline & & & Stand & iation & Coefficie & ation (\%) \\
\hline & $\begin{array}{l}\text { 尚 } \\
\text { O } \\
\stackrel{\circ}{\circ} \\
\bullet\end{array}$ & 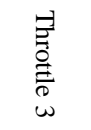 & 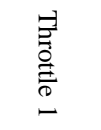 & 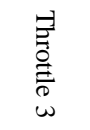 & $\begin{array}{l}\text { 곻 } \\
\stackrel{0}{\circ} \\
\stackrel{\circ}{\bullet}\end{array}$ & 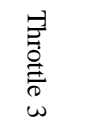 \\
\hline NOx (g/bhp-hr) & 4.914 & 5.017 & 0.1814 & 0.1758 & 3.69 & 3.50 \\
\hline NOx 2 (g/bhp-hr) & 4.890 & 4.983 & 0.1871 & 0.1945 & 3.83 & 3.90 \\
\hline TPM (g/bhp-hr) & 0.259 & 0.237 & 0.0089 & 0.0085 & 3.43 & 3.59 \\
\hline CO (g/bhp-hr) & 3.560 & 3.134 & 0.1192 & 0.1129 & 3.35 & 3.60 \\
\hline CO2 (g/bhp-hr) & 535.4 & 534.7 & 2.8059 & 4.6184 & 0.52 & 0.86 \\
\hline HC (g/bhp-hr) & 0.111 & 0.116 & 0.0113 & 0.0169 & 10.16 & 14.64 \\
\hline BSFC (lb/bhp-hr) & 0.381 & 0.382 & 0.0019 & 0.0024 & 0.49 & 0.62 \\
\hline FC (lb) & 9.614 & 9.407 & 0.0471 & 0.0954 & 0.49 & 1.01 \\
\hline Work (bhp-hr) & 25.257 & 24.654 & 0.1788 & 0.1653 & 0.71 & 0.67 \\
\hline
\end{tabular}


Table 8.3 FTP Throttle Specific Results for 1992 Rebuilt DDC S60

\begin{tabular}{|c|c|c|c|c|c|c|c|c|}
\hline & \multicolumn{3}{|c|}{ CP 0.05 Cert } & \multicolumn{3}{|c|}{ CP 0.05 Cert with $12 \mathrm{ml} \mathrm{-} \mathrm{ODA}$} & \multicolumn{2}{|c|}{$\begin{array}{c}\text { Grad Cand with } 12 \mathrm{ml} \\
\text { ODA }\end{array}$} \\
\hline & 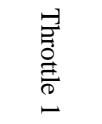 & $\begin{array}{l}\vec{\Xi} \\
\stackrel{\Xi}{0} \\
\stackrel{D}{D} \\
N\end{array}$ & 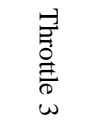 & 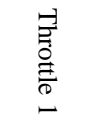 & 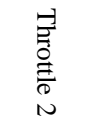 & 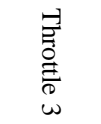 & $\begin{array}{l}\stackrel{ }{\circ} \\
\stackrel{0}{\circ} \\
\stackrel{\circ}{\circ} \\
⺊\end{array}$ & 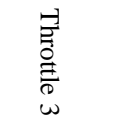 \\
\hline NOx (g/bhp-hr) & 5.147 & 5.124 & 5.205 & 4.959 & 4.950 & 5.028 & 4.913 & 4.991 \\
\hline Standard Deviation & 0.0162 & 0.0136 & 0.0148 & 0.0125 & 0.0091 & 0.0066 & 0.0075 & 0.0188 \\
\hline NOx 2 (g/bhp-hr) & 5.216 & 5.188 & 5.290 & 5.013 & 4.991 & 5.065 & 4.952 & 5.015 \\
\hline Standard Deviation & 0.0059 & 0.0206 & 0.0164 & 0.0173 & 0.0064 & 0.0086 & 0.0102 & 0.0054 \\
\hline TPM (g/bhp-hr) & 0.2762 & 0.2697 & 0.2490 & 0.2791 & - & 0.2560 & 0.2462 & 0.2268 \\
\hline Standard Deviation & 0.0014 & 0.0015 & 0.0027 & 0.0012 & - & 0.0030 & 0.0003 & 0.0023 \\
\hline CO (g/bhp-hr) & 3.977 & 3.935 & 3.496 & 3.748 & 3.686 & 3.183 & 3.411 & 3.002 \\
\hline Standard Deviation & 0.0096 & 0.0074 & 0.0180 & 0.0104 & 0.0197 & 0.0184 & 0.0274 & 0.0086 \\
\hline CO2 (g/bhp-hr) & 530.7 & 530.0 & 529.1 & 528.8 & 528.4 & 528.2 & 526.0 & 524.4 \\
\hline Standard Deviation & 1.6456 & 0.2375 & 0.2161 & 0.4414 & 0.7567 & 1.7735 & 0.8672 & 1.4188 \\
\hline HC (g/bhp-hr) & 0.1136 & 0.1120 & 0.1139 & 0.1012 & 0.1001 & 0.1065 & 0.0835 & 0.0905 \\
\hline Standard Deviation & 0.0042 & 0.0017 & 0.0027 & 0.0010 & 0.0024 & 0.0012 & 0.0002 & 0.0035 \\
\hline BSFC (lb/bhp-hr) & 0.3714 & 0.3716 & 0.3713 & 0.3719 & 0.3715 & 0.3704 & 0.3767 & 0.3759 \\
\hline Standard Deviation & 0.0002 & 0.0001 & 0.0001 & 0.0003 & 0.0003 & 0.0005 & 0.0002 & 0.0004 \\
\hline FC (lb) & 9.452 & 9.446 & 9.224 & 9.487 & 9.472 & 9.237 & 9.545 & 9.304 \\
\hline Standard Deviation & 0.0050 & 0.0010 & 0.0010 & 0.0056 & 0.0042 & 0.0106 & 0.0047 & 0.0079 \\
\hline Work (bhp-hr) & 25.45 & 25.42 & 24.84 & 25.51 & 25.49 & 24.94 & 25.33 & 24.76 \\
\hline Standard Deviation & 0.0096 & 0.0000 & 0.0115 & 0.0058 & 0.0115 & 0.0058 & 0.0058 & 0.0208 \\
\hline
\end{tabular}

Table 8.4 FTP Variation Analysis 1992 Rebuilt DDC S60

\begin{tabular}{|c|c|c|c|c|c|c|}
\hline & \multicolumn{2}{|c|}{ Average } & \multicolumn{2}{|c|}{ Standard Deviation } & \multicolumn{2}{|c|}{ Coefficient of Variation (\%) } \\
\hline & $\begin{array}{l}\text { 光 } \\
\stackrel{0}{0} \\
\stackrel{D}{D} \\
\mapsto\end{array}$ & $\begin{array}{l}\text { 光 } \\
\frac{0}{0} \\
\frac{D}{D} \\
\omega\end{array}$ & 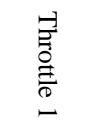 & $\begin{array}{l}\text { 光 } \\
\stackrel{0}{0} \\
\stackrel{D}{D} \\
\omega\end{array}$ & 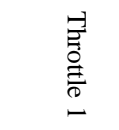 & 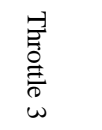 \\
\hline NOx (g/bhp-hr) & 5.006 & 5.075 & 0.1236 & 0.1142 & 2.47 & 2.25 \\
\hline NOx 2 (g/bhp-hr) & 5.061 & 5.123 & 0.1382 & 0.1466 & 2.73 & 2.86 \\
\hline TPM (g/bhp-hr) & 0.267 & 0.244 & 0.0182 & 0.0153 & 6.83 & 6.26 \\
\hline CO (g/bhp-hr) & 3.712 & 3.363 & 0.2847 & 0.2497 & 7.67 & 7.43 \\
\hline CO2 (g/bhp-hr) & 528.5 & 527.2 & 2.3837 & 2.4949 & 0.45 & 0.47 \\
\hline HC (g/bhp-hr) & 0.099 & 0.104 & 0.0151 & 0.0120 & 15.22 & 11.55 \\
\hline BSFC (lb/bhp-hr) & 0.373 & 0.373 & 0.0030 & 0.0029 & 0.79 & 0.79 \\
\hline FC (lb) & 9.494 & 9.255 & 0.0469 & 0.0431 & 0.49 & 0.47 \\
\hline Work (bhp-hr) & 25.429 & 24.845 & 0.0881 & 0.0908 & 0.35 & 0.37 \\
\hline
\end{tabular}


Table 8.5 FTP Throttle Specific Results for 1999 Cummins ISM 370

\begin{tabular}{|c|c|c|c|c|}
\hline & \multicolumn{2}{|c|}{ CP 0.05 Cert } & \multicolumn{2}{|c|}{$\begin{array}{c}\text { CP } 0.05 \text { Cert with } \\
12 \mathrm{ml} \text { - ODA }\end{array}$} \\
\hline & 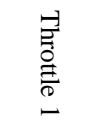 & 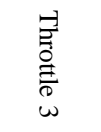 & 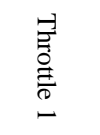 & 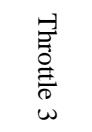 \\
\hline NOx (g/bhp-hr) & 4.082 & 4.101 & 4.026 & 4.050 \\
\hline Standard Deviation & 0.0070 & 0.0060 & 0.0006 & 0.0029 \\
\hline NOx 2 (g/bhp-hr) & 4.035 & 4.067 & 4.017 & 4.019 \\
\hline Standard Deviation & 0.0066 & 0.0067 & 0.0150 & 0.0114 \\
\hline TPM (g/bhp-hr) & 0.1265 & 0.1140 & 0.1138 & 0.0995 \\
\hline Standard Deviation & 0.0058 & 0.0016 & 0.0058 & 0.0023 \\
\hline CO (g/bhp-hr) & 1.037 & 0.907 & 0.976 & 0.814 \\
\hline Standard Deviation & 0.0104 & 0.0050 & 0.0045 & 0.0026 \\
\hline CO2 (g/bhp-hr) & 522.7 & 523.3 & 523.8 & 524.5 \\
\hline Standard Deviation & 0.5037 & 0.5946 & 0.4007 & 0.5312 \\
\hline HC (g/bhp-hr) & 0.2616 & 0.2696 & 0.2537 & 0.2591 \\
\hline Standard Deviation & 0.0012 & 0.0015 & 0.0016 & 0.0016 \\
\hline BSFC (lb/bhp-hr) & 0.3657 & 0.3668 & 0.3651 & 0.3666 \\
\hline Standard Deviation & 0.0002 & 0.0001 & 0.0002 & 0.0003 \\
\hline FC (lb) & 9.832 & 9.586 & 9.818 & 9.583 \\
\hline Standard Deviation & 0.0055 & 0.0021 & 0.0074 & 0.0042 \\
\hline Work (bhp-hr) & 26.89 & 26.13 & 26.89 & 26.14 \\
\hline Standard Deviation & 0.0115 & 0.0058 & 0.0100 & 0.0100 \\
\hline
\end{tabular}

Table 8.6 FTP Variation Analysis 1999 Cummins ISM 370

\begin{tabular}{|c|c|c|c|c|c|c|}
\hline & \multicolumn{2}{|c|}{ Average } & \multicolumn{2}{|c|}{ Standard Deviation } & \multicolumn{2}{|c|}{ Coefficient of Variation (\%) } \\
\hline & $\begin{array}{l}\stackrel{ }{\Xi} \\
\stackrel{0}{\Xi} \\
\stackrel{D}{D} \\
\bullet\end{array}$ & 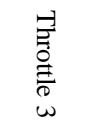 & $\begin{array}{l}\stackrel{ }{\Xi} \\
\stackrel{0}{\Xi} \\
\stackrel{D}{D} \\
\bullet\end{array}$ & $\begin{array}{l}\stackrel{ㄱ}{\Xi} \\
\stackrel{0}{0} \\
\stackrel{D}{0} \\
\omega\end{array}$ & 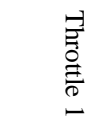 & 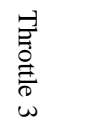 \\
\hline NOx (g/bhp-hr) & 4.054 & 4.075 & 0.0391 & 0.0363 & 0.97 & 0.89 \\
\hline NOx 2 (g/bhp-hr) & 4.026 & 4.043 & 0.0130 & 0.0342 & 0.32 & 0.85 \\
\hline TPM (g/bhp-hr) & 0.120 & 0.107 & 0.0090 & 0.0102 & 7.49 & 9.60 \\
\hline CO (g/bhp-hr) & 1.007 & 0.860 & 0.0431 & 0.0655 & 4.28 & 7.62 \\
\hline CO2 (g/bhp-hr) & 523.3 & 523.9 & 0.7719 & 0.8125 & 0.15 & 0.16 \\
\hline HC (g/bhp-hr) & 0.258 & 0.264 & 0.0056 & 0.0075 & 2.17 & 2.83 \\
\hline BSFC (lb/bhp-hr) & 0.365 & 0.367 & 0.0004 & 0.0001 & 0.11 & 0.03 \\
\hline FC (lb) & 9.825 & 9.585 & 0.0099 & 0.0016 & 0.10 & 0.02 \\
\hline Work (bhp-hr) & 26.888 & 26.137 & 0.0024 & 0.0047 & 0.01 & 0.02 \\
\hline
\end{tabular}


Table 8.7 FTP Throttle Specific Results for 2004 Cummins ISM 370

\begin{tabular}{|c|c|c|c|c|}
\hline & \multicolumn{2}{|c|}{ CP 0.05 Cert } & \multicolumn{2}{|c|}{$\begin{array}{c}\text { CP } 0.05 \text { Cert with } \\
12 \mathrm{ml} \text { - ODA }\end{array}$} \\
\hline & 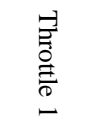 & 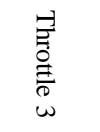 & 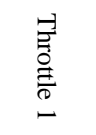 & 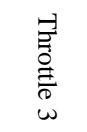 \\
\hline NOx (g/bhp-hr) & 2.355 & 2.336 & 2.352 & 2.338 \\
\hline Standard Deviation & 0.0061 & 0.0104 & 0.0104 & 0.0061 \\
\hline NOx 2 (g/bhp-hr) & 2.335 & 2.307 & 2.334 & 2.345 \\
\hline Standard Deviation & 0.0066 & 0.0062 & 0.0112 & 0.0442 \\
\hline TPM (g/bhp-hr) & 0.0744 & 0.0717 & 0.0745 & 0.0706 \\
\hline Standard Deviation & 0.0057 & 0.0006 & 0.0058 & 0.0042 \\
\hline CO (g/bhp-hr) & 0.617 & 0.589 & 0.571 & 0.552 \\
\hline Standard Deviation & 0.0116 & 0.0044 & 0.0154 & 0.0108 \\
\hline CO2 (g/bhp-hr) & 601.6 & 607.7 & 601.6 & 606.7 \\
\hline Standard Deviation & 0.6056 & 1.0551 & 0.8004 & 0.4044 \\
\hline HC (g/bhp-hr) & 0.2001 & 0.2117 & 0.2035 & 0.2107 \\
\hline Standard Deviation & 0.0031 & 0.0019 & 0.0014 & 0.0007 \\
\hline BSFC (lb/bhp-hr) & 0.4208 & 0.4245 & 0.4184 & 0.4256 \\
\hline Standard Deviation & 0.0027 & 0.0031 & 0.0032 & 0.0026 \\
\hline FC (lb) & 10.788 & 10.439 & 10.687 & 10.467 \\
\hline Standard Deviation & 0.0645 & 0.0802 & 0.0688 & 0.0617 \\
\hline Work (bhp-hr) & 25.64 & 24.59 & 25.54 & 24.60 \\
\hline Standard Deviation & 0.0100 & 0.0058 & 0.1762 & 0.0100 \\
\hline
\end{tabular}

Table 8.8 FTP Variation Analysis 2004 Cummins ISM 370

\begin{tabular}{|c|c|c|c|c|c|c|}
\hline & \multicolumn{2}{|c|}{ Average } & \multicolumn{2}{|c|}{ Standard Deviation } & \multicolumn{2}{|c|}{ Coefficient of Variation (\%) } \\
\hline & 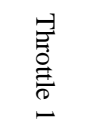 & 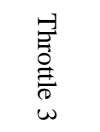 & 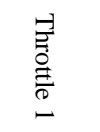 & $\begin{array}{l}\text { 光 } \\
\stackrel{0}{0} \\
\stackrel{\vec{D}}{D} \\
\omega\end{array}$ & $\begin{array}{l}\text { 光 } \\
\stackrel{0}{0} \\
\stackrel{D}{D} \\
\bullet\end{array}$ & 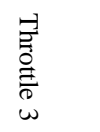 \\
\hline NOx (g/bhp-hr) & 2.353 & 2.337 & 0.0021 & 0.0016 & 0.09 & 0.07 \\
\hline NOx 2 (g/bhp-hr) & 2.334 & 2.326 & 0.0009 & 0.0269 & 0.04 & 1.16 \\
\hline TPM (g/bhp-hr) & 0.074 & 0.071 & 0.0001 & 0.0008 & 0.12 & 1.07 \\
\hline CO (g/bhp-hr) & 0.594 & 0.571 & 0.0323 & 0.0262 & 5.44 & 4.59 \\
\hline CO2 (g/bhp-hr) & 601.6 & 607.2 & 0.0097 & 0.7187 & 0.00 & 0.12 \\
\hline HC (g/bhp-hr) & 0.202 & 0.211 & 0.0024 & 0.0007 & 1.20 & 0.33 \\
\hline BSFC (lb/bhp-hr) & 0.420 & 0.425 & 0.0017 & 0.0008 & 0.40 & 0.18 \\
\hline FC (lb) & 10.738 & 10.453 & 0.0714 & 0.0203 & 0.67 & 0.19 \\
\hline Work (bhp-hr) & 25.592 & 24.597 & 0.0684 & 0.0047 & 0.27 & 0.02 \\
\hline
\end{tabular}




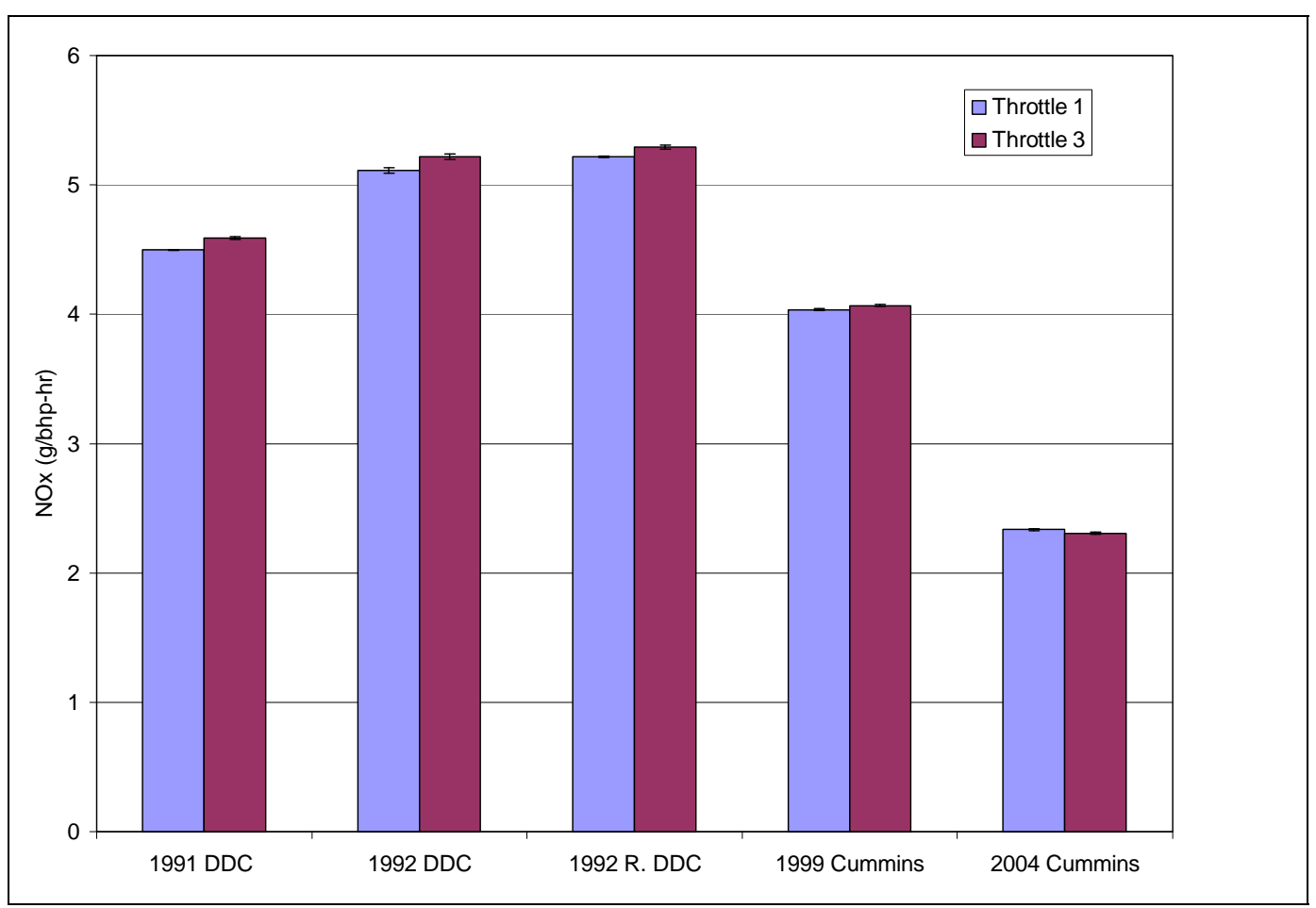

Figure 8.1 NOx 2 Throttle Specific Emissions

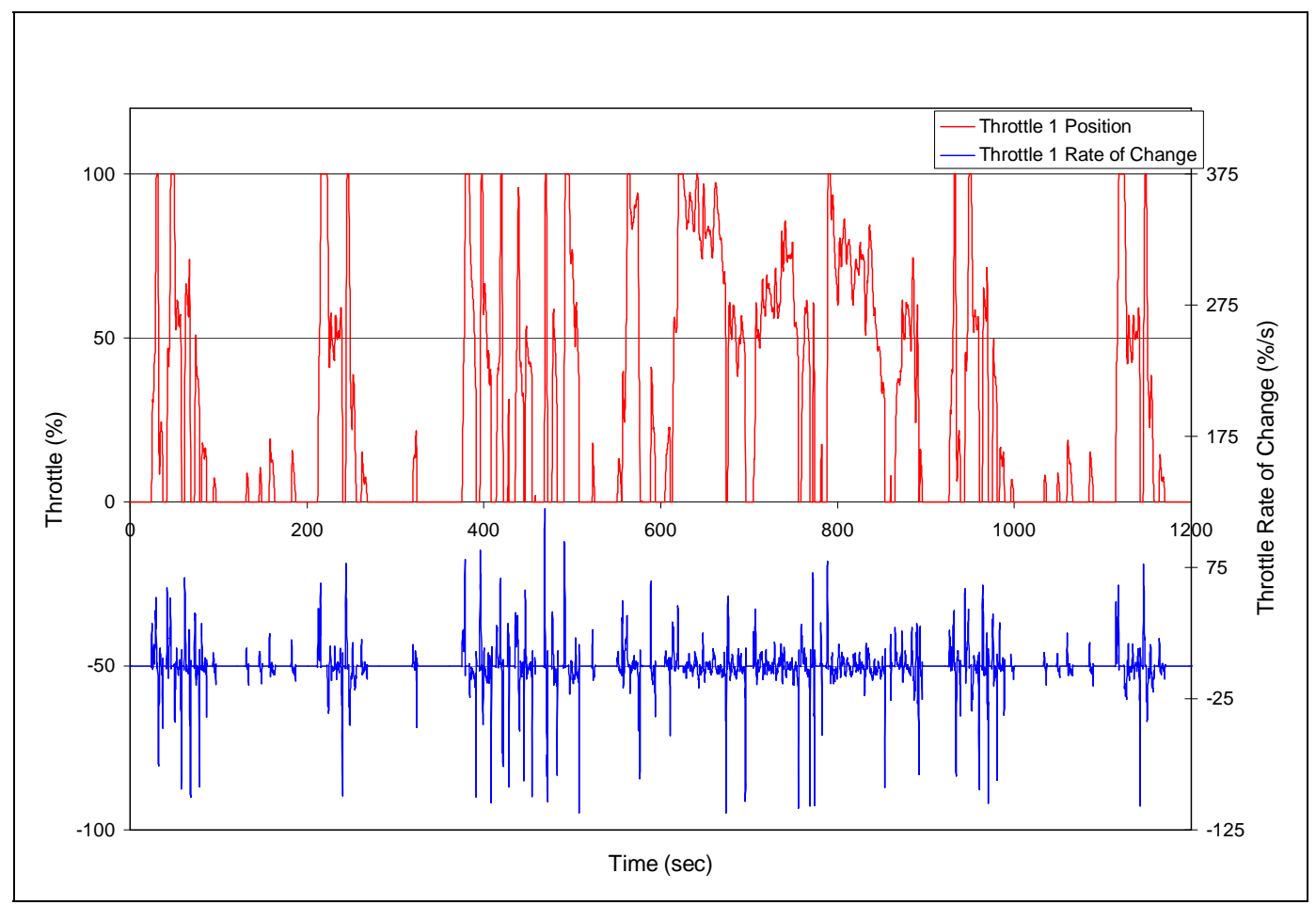

Figure 8.2 Throttle 1 Throttle Position and Rate of Change for 1992 DDC Engine 


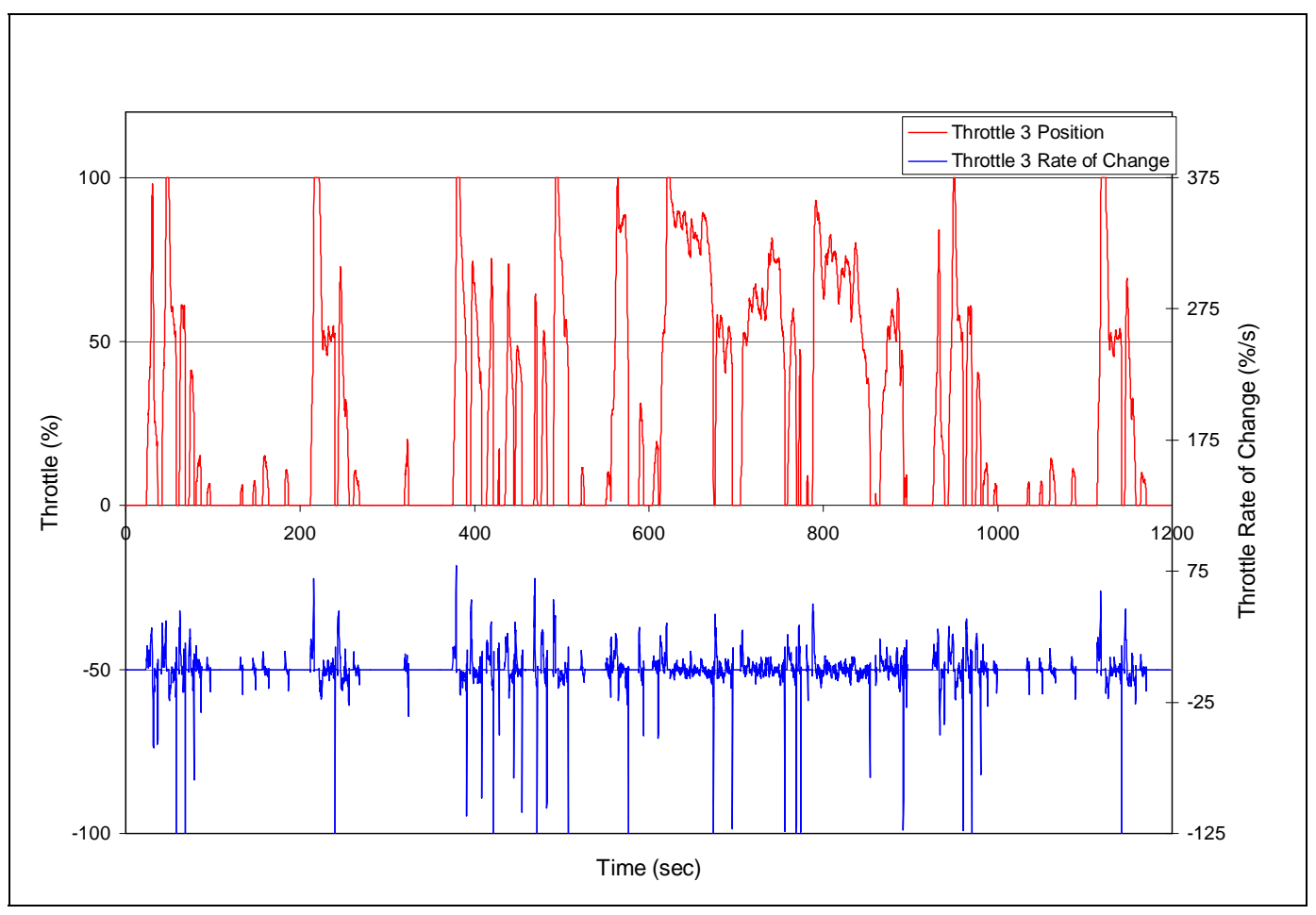

Figure 8.3 Throttle 3 Throttle Position and Rate of Change for 1992 DDC Engine

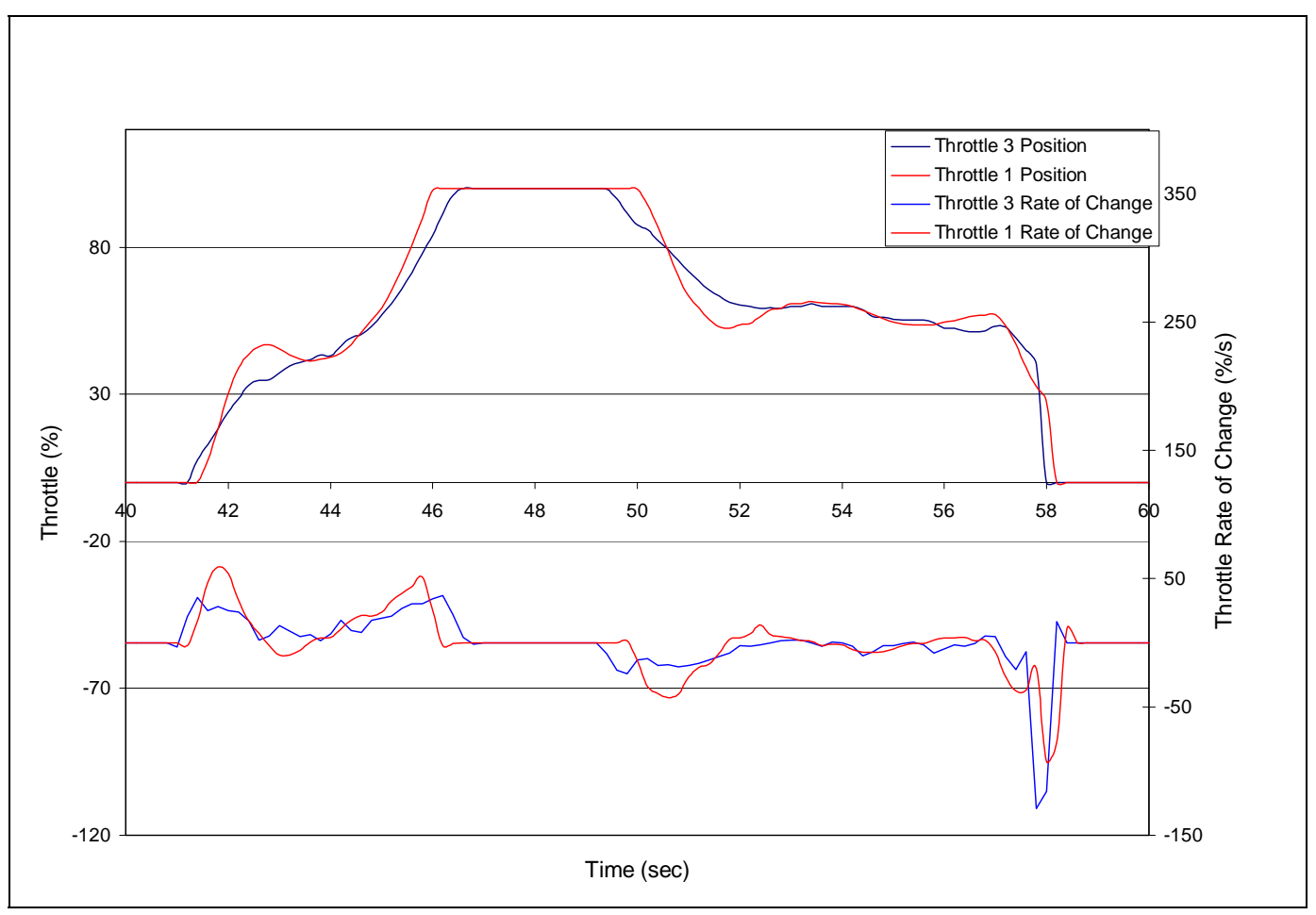

Figure 8.4 Throttle Position and Rate of Change for 1992 DDC Engine 


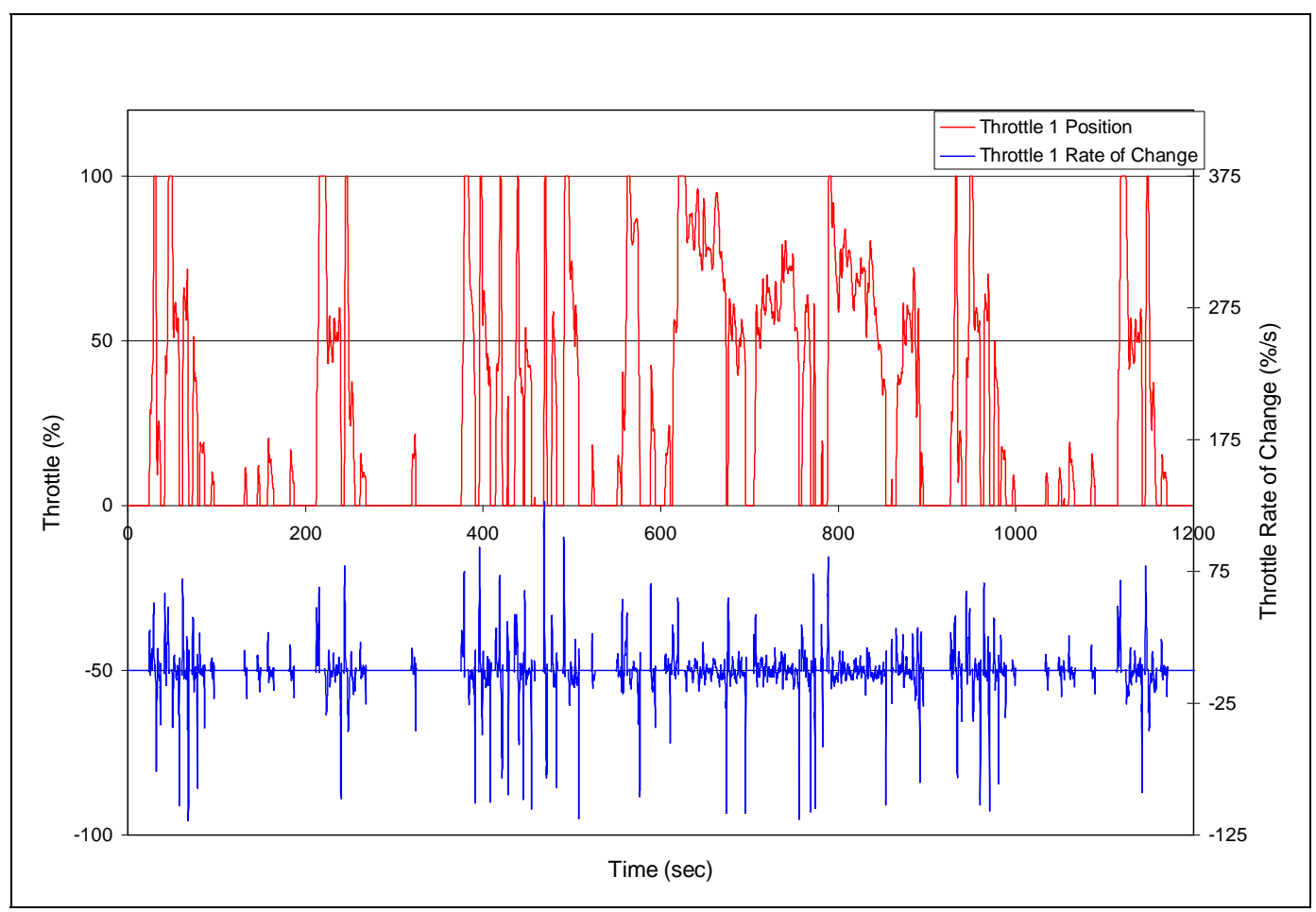

Figure 8.5 Throttle 1 Throttle Position and Rate of Change for 1992 Rebuilt DDC Engine

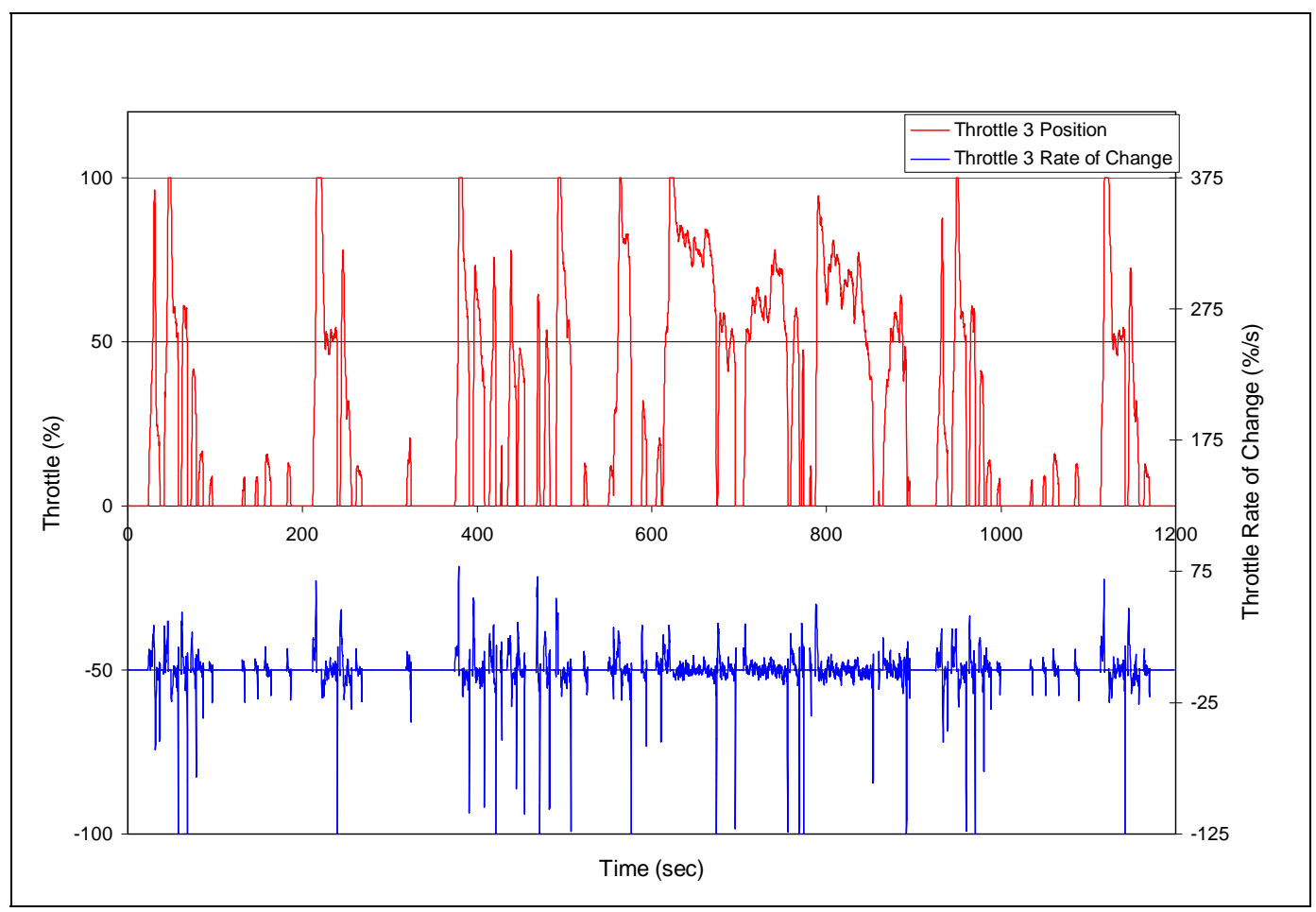

Figure 8.6 Throttle 3 Throttle Position and Rate of Change for 1992 Rebuilt DDC Engine 


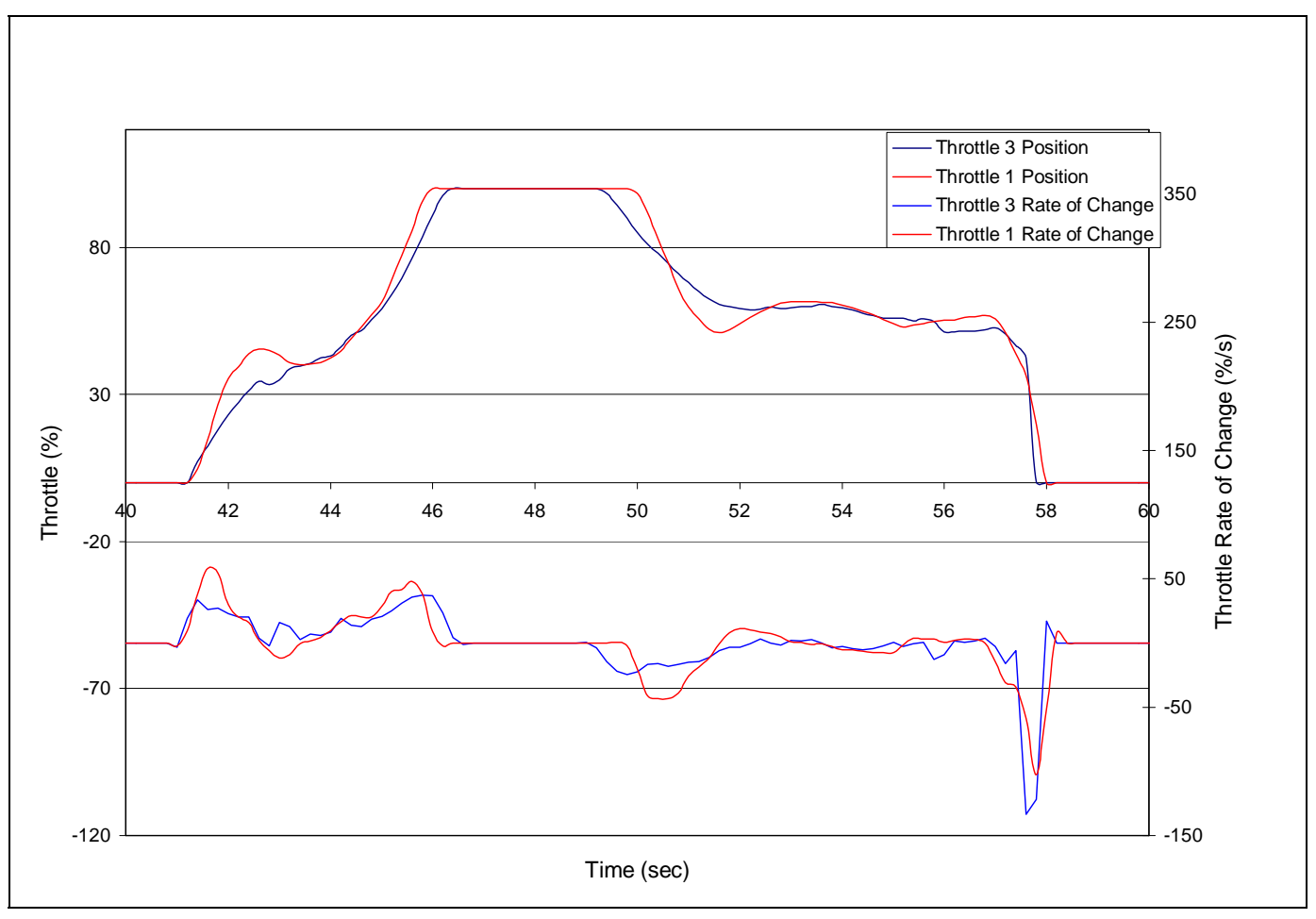

Figure 8.7 Throttle Position and Rate of Change for 1992 Rebuilt DDC Engine

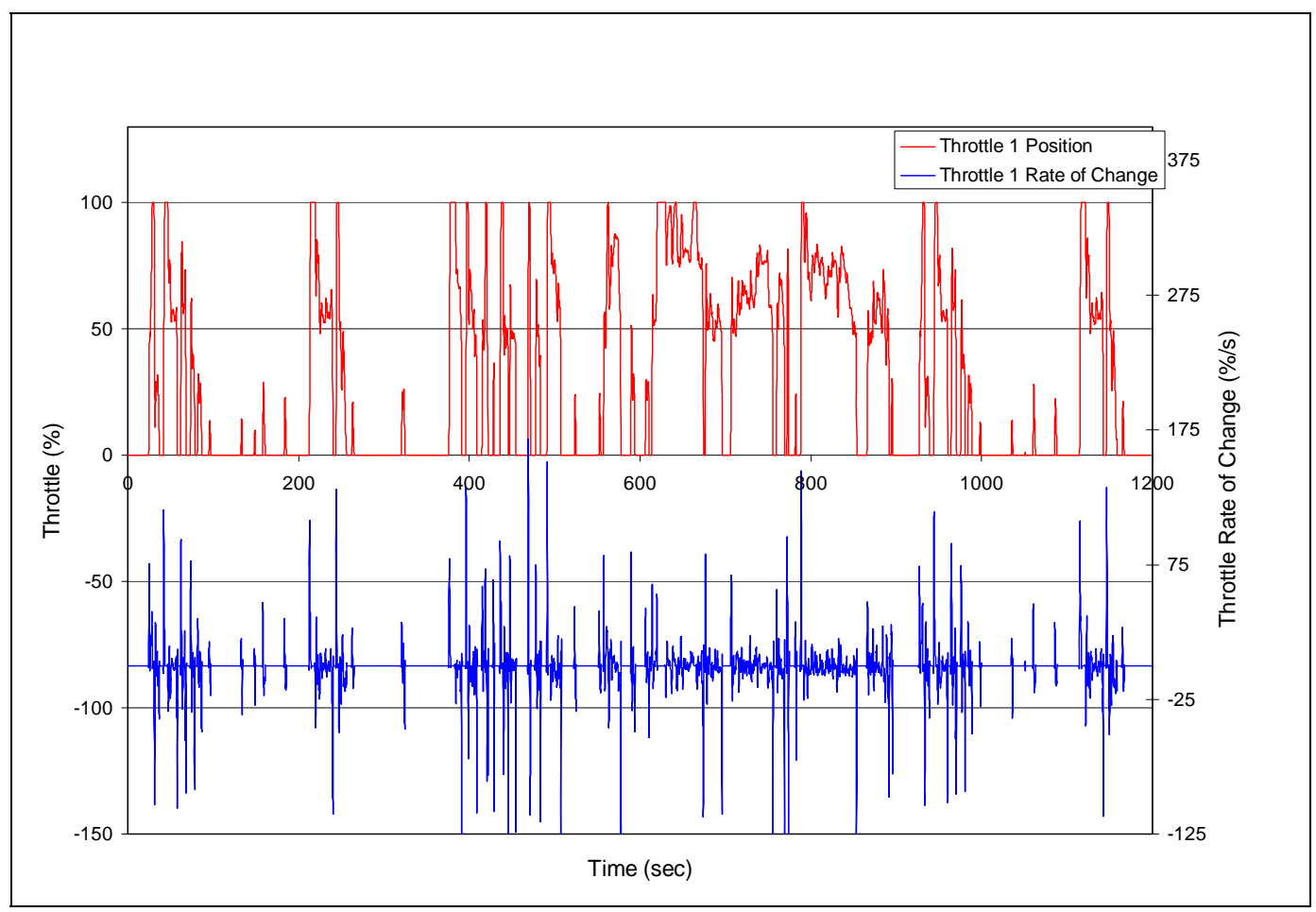

Figure 8.8 Throttle 1 Throttle Position and Rate of Change for 1999 Cummins Engine 


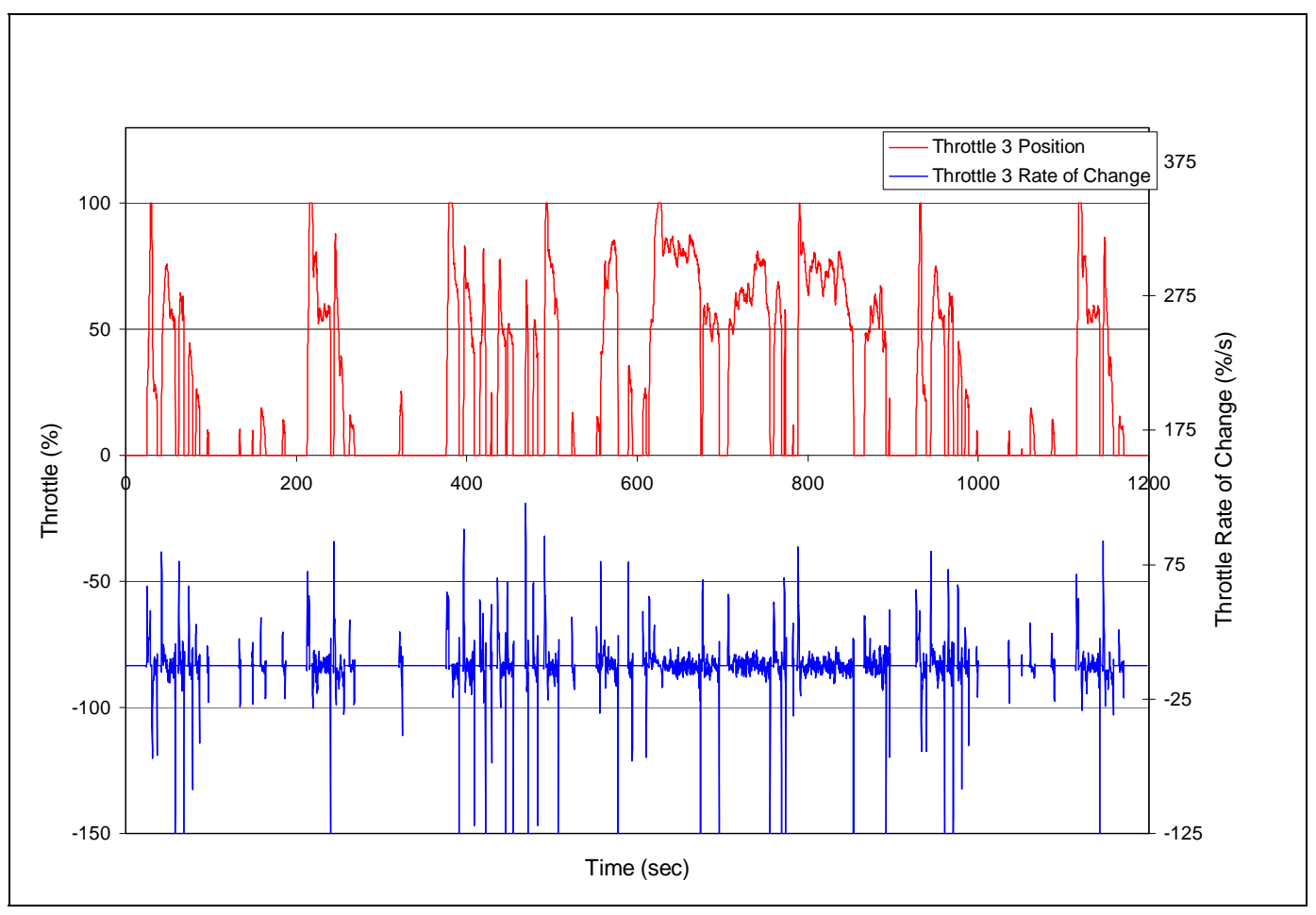

Figure 8.9 Throttle 3 Throttle Position and Rate of Change for 1999 Cummins Engine

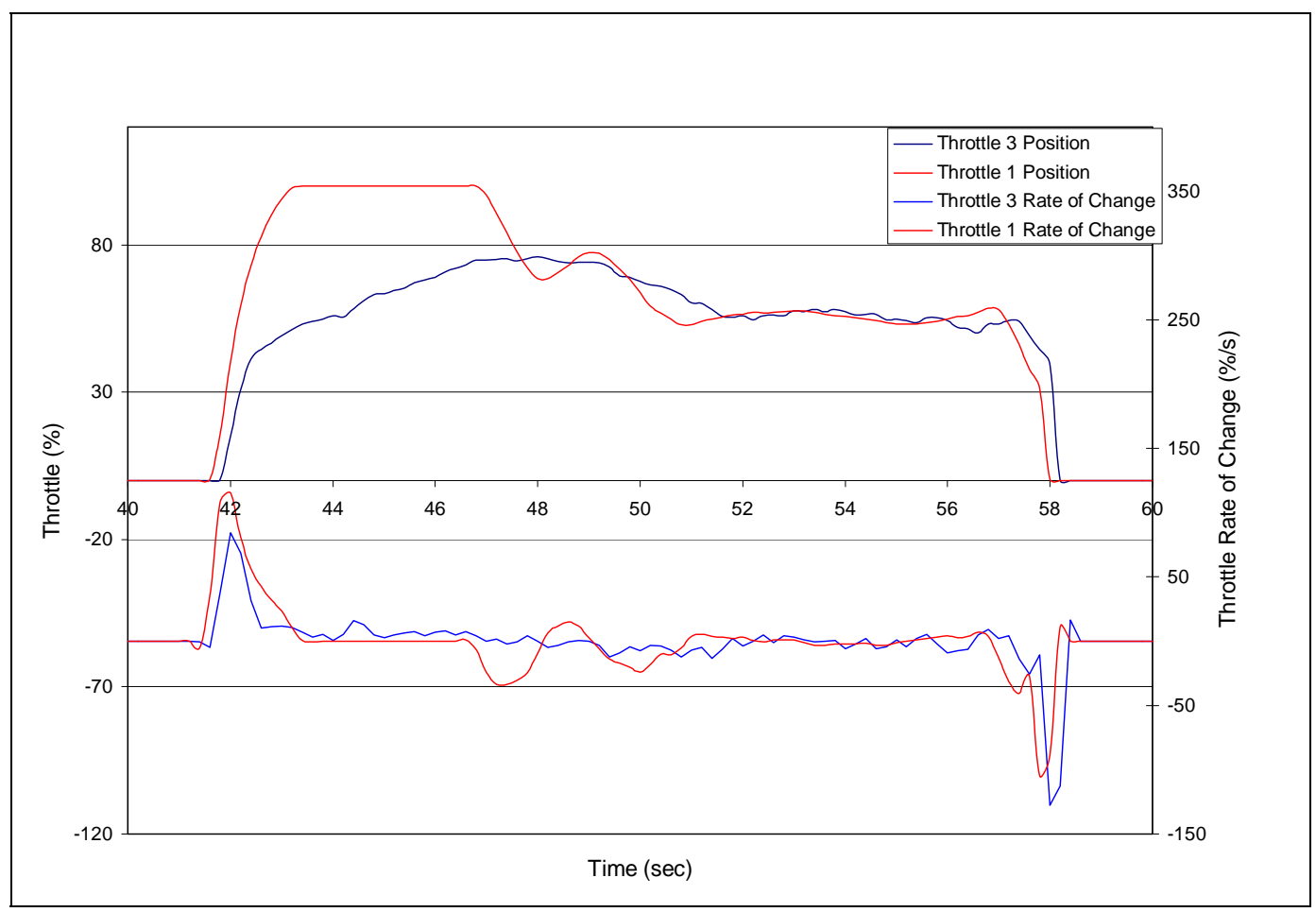

Figure 8.10 Throttle Position and Rate of Change for 1999 Cummins Engine 


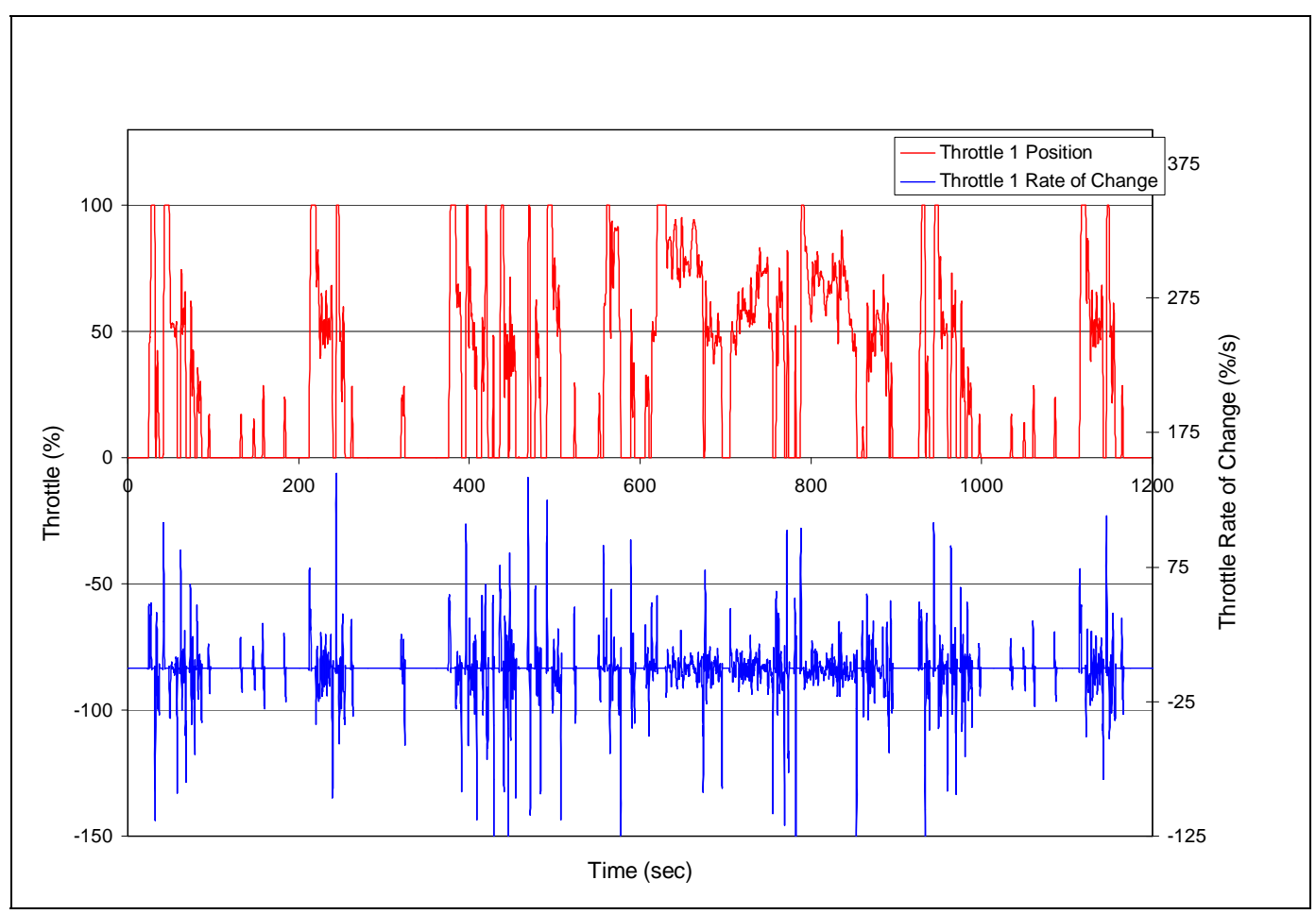

Figure 8.11 Throttle 1 Position and Rate of Change for 2004 Cummins Engine

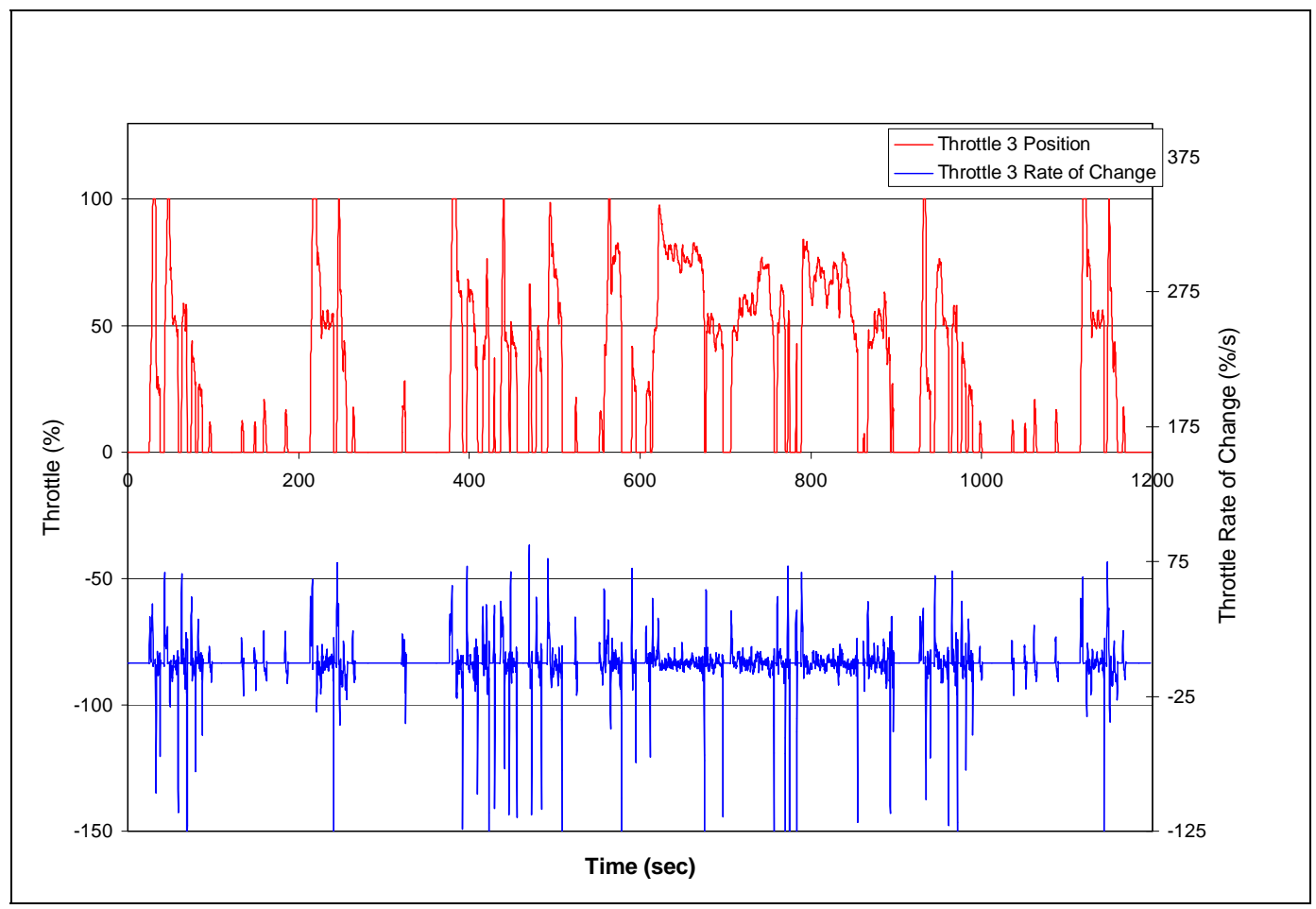

Figure 8.12 Throttle 3 Throttle Position and Rate of Change for 2004 Cummins Engine 


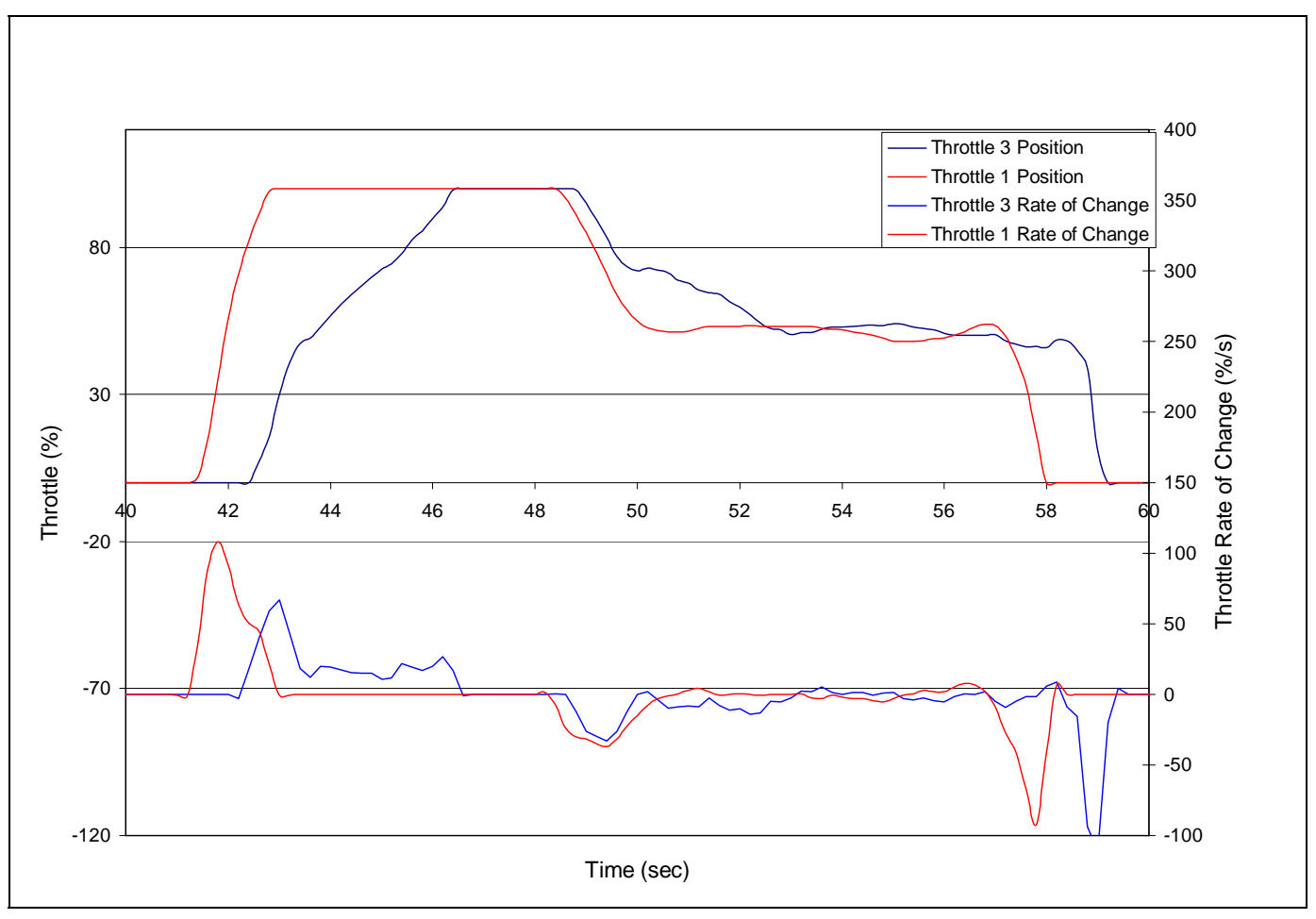

Figure 8.13 Throttle Position and Rate of Change for 2004 Cummins Engine

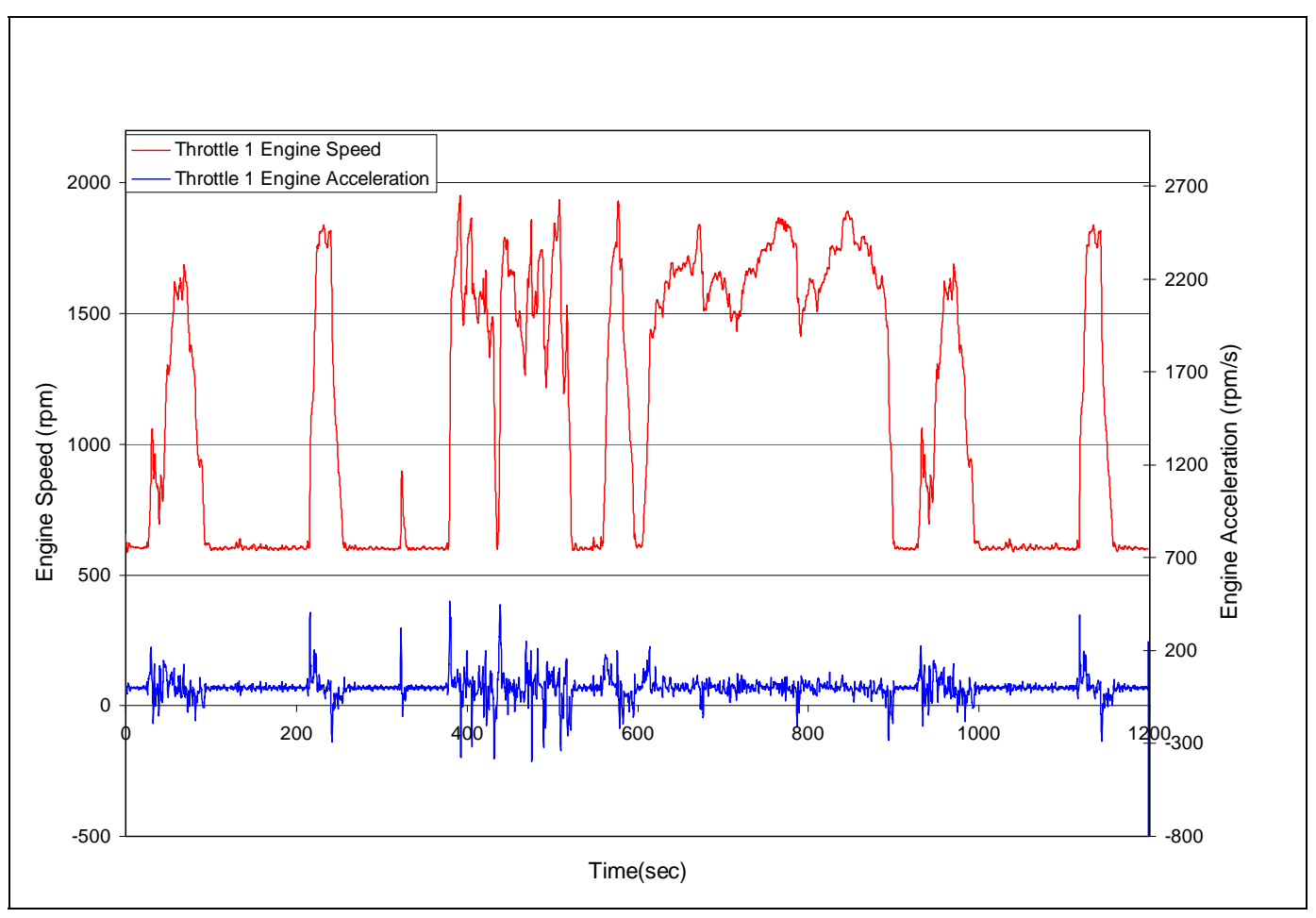

Figure 8.14 Throttle 1 Engine Speeds and Accelerations for 1992 DDC Engine 


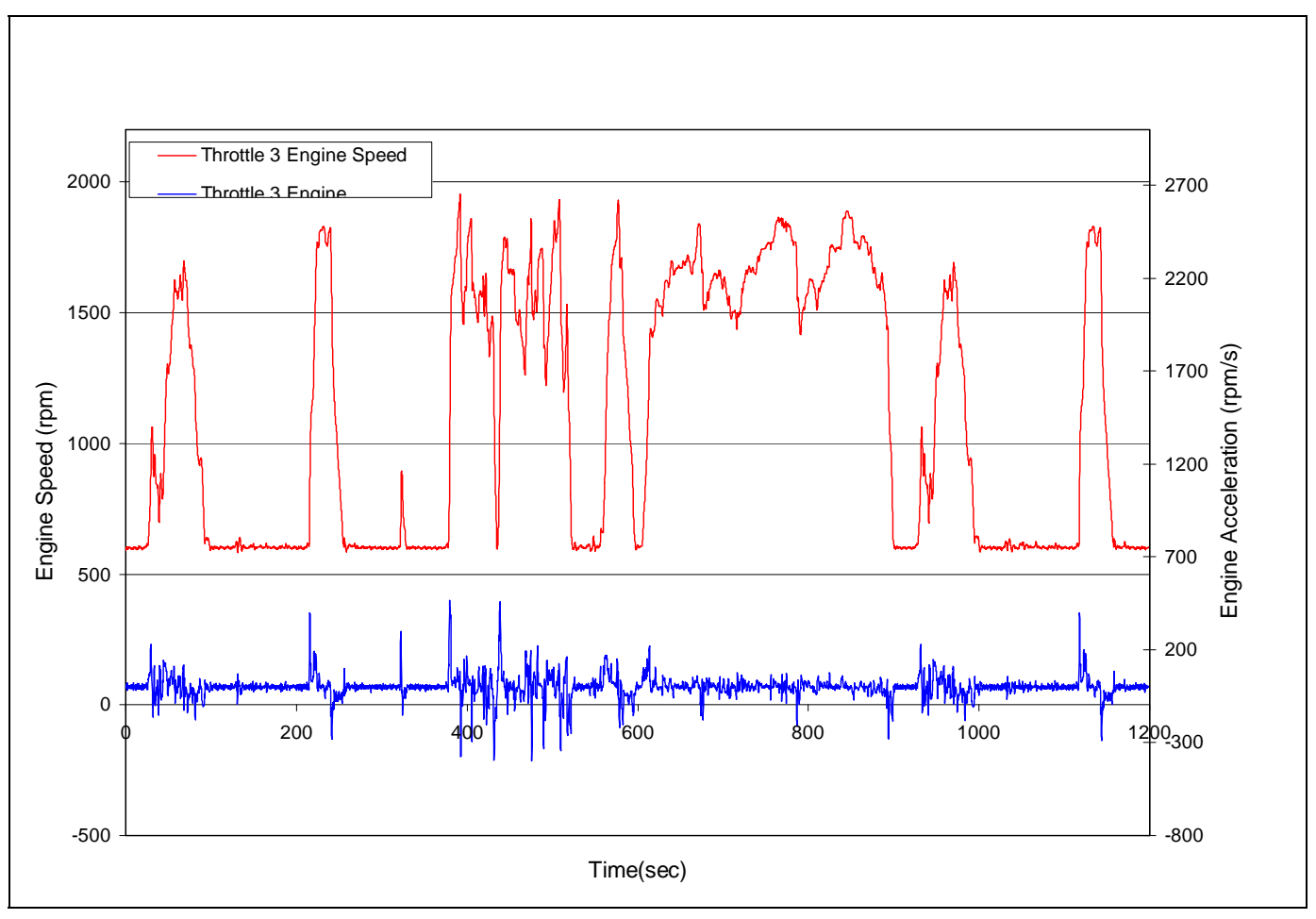

Figure 8.15 Throttle 3 Engine Speeds and Accelerations for 1992 DDC Engine

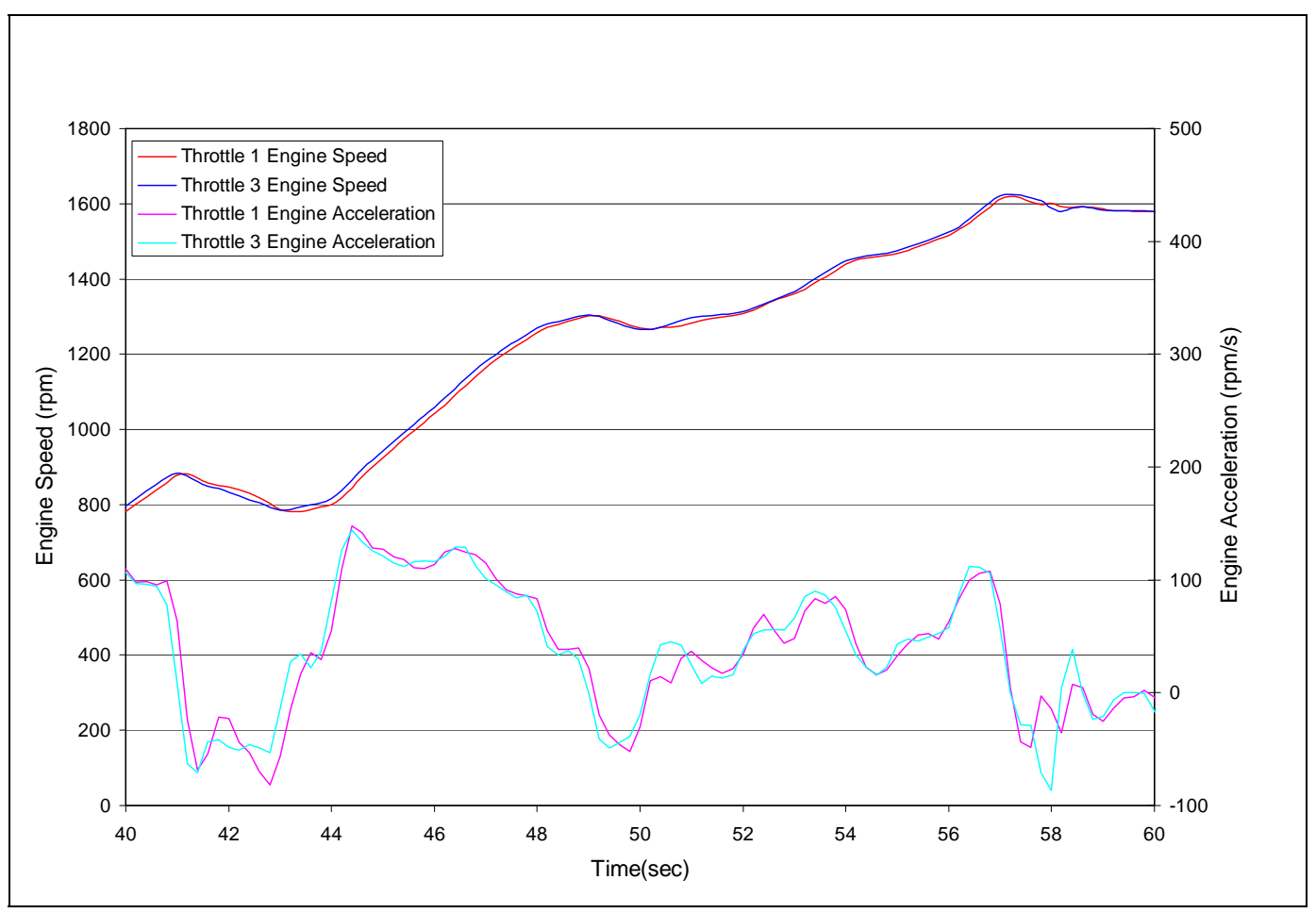

Figure 8.16 Engine Speeds and Accelerations for 1992 DDC Engine 


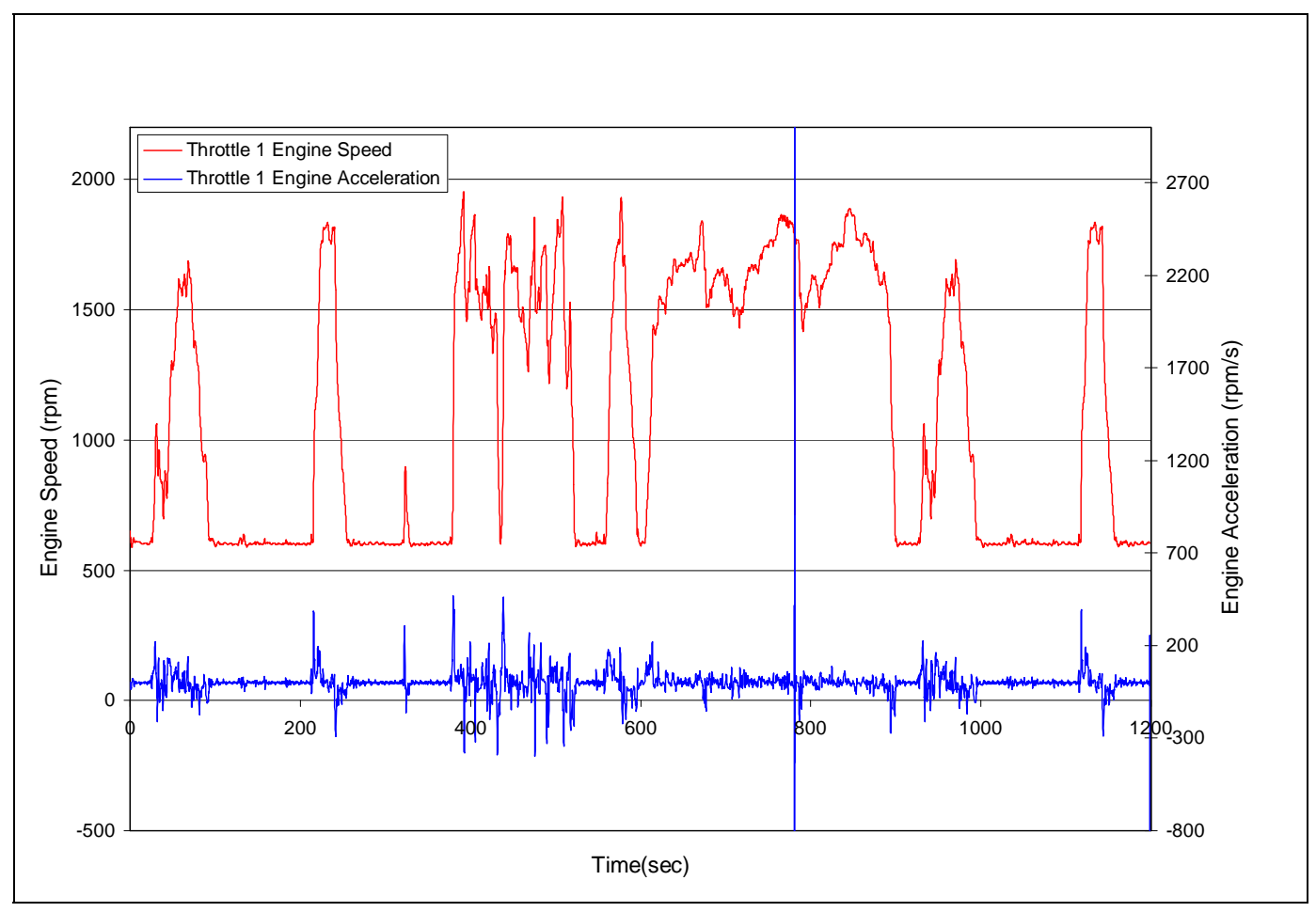

Figure 8.17 Throttle 1 Engine Speeds and Accelerations for 1992 Rebuilt DDC Engine

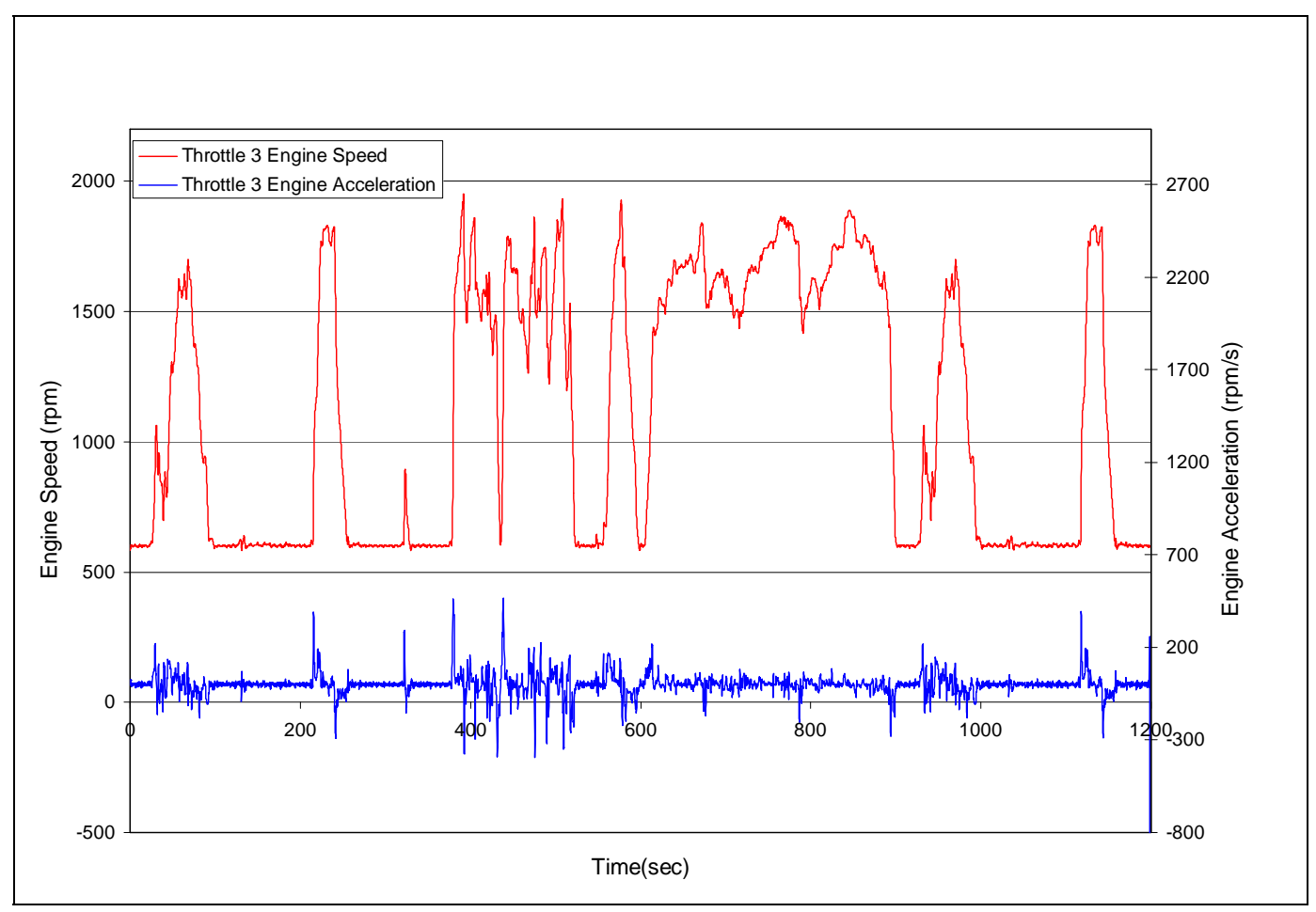

Figure 8.18 Throttle 3 Engine Speeds and Accelerations for 1992 Rebuilt DDC Engine 


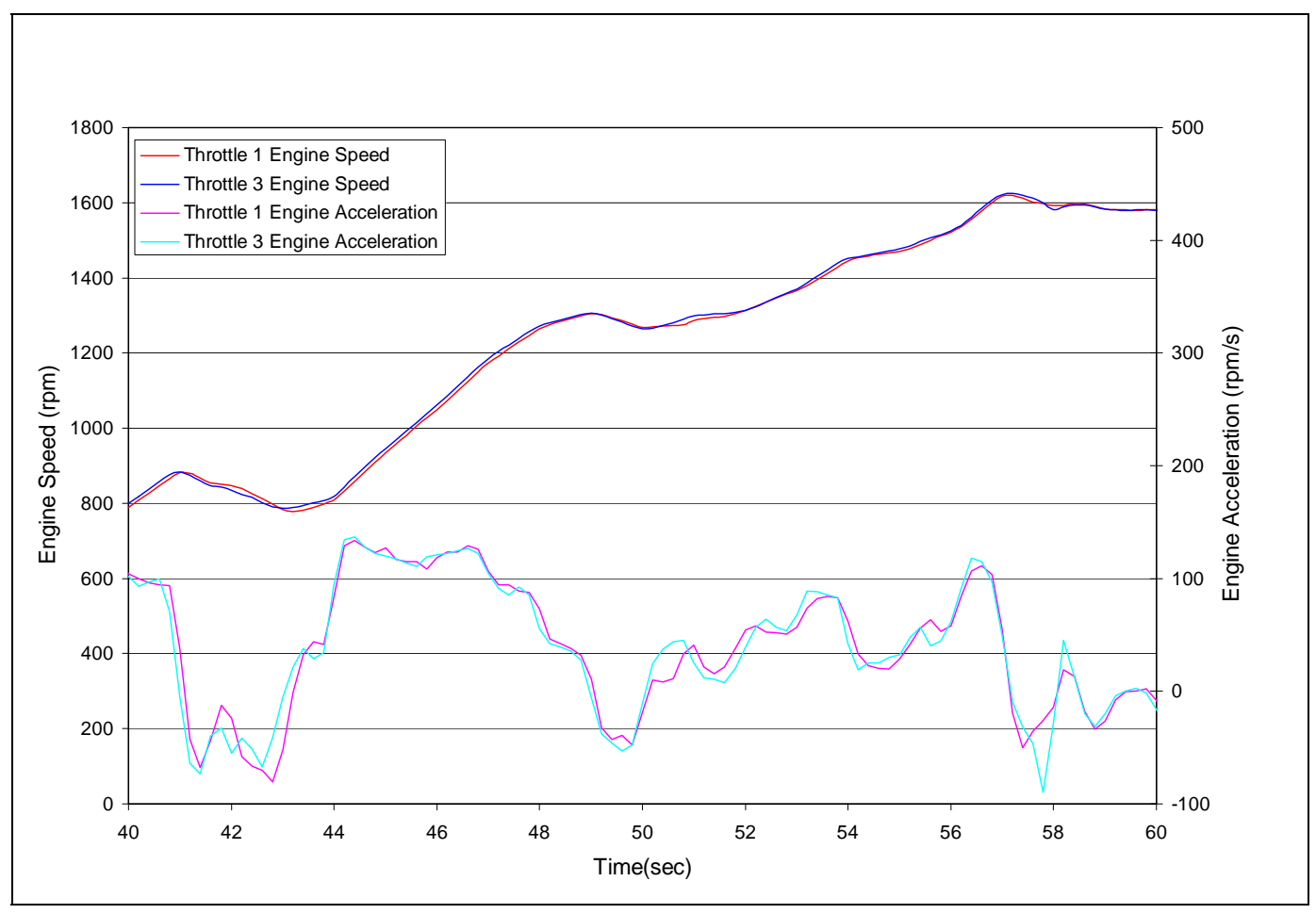

Figure 8.19 Engine Speeds and Accelerations for 1992 Rebuilt DDC Engine

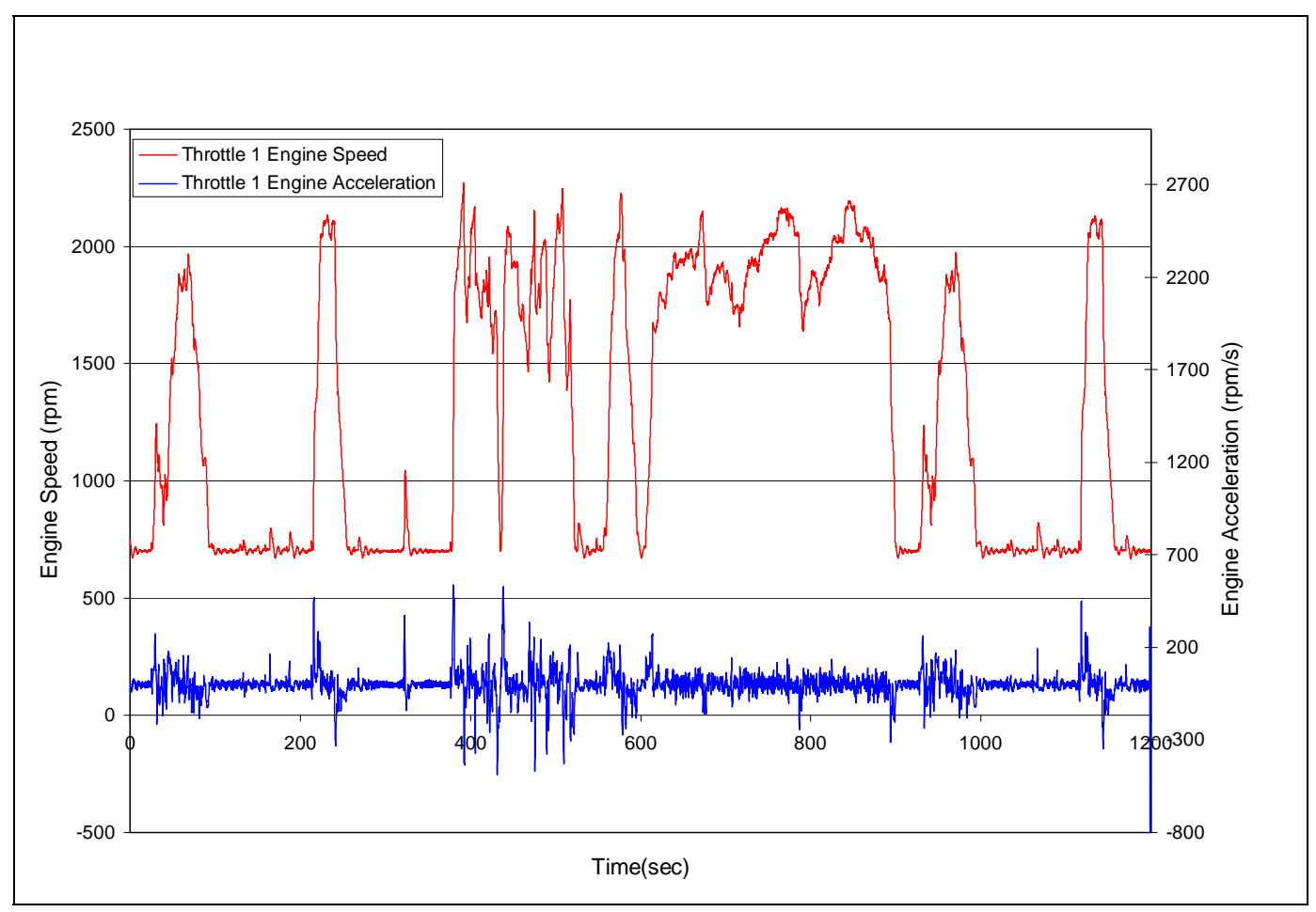

Figure 8.20 Throttle 1 Engine Speeds and Accelerations for 1999 Cummins Engine 


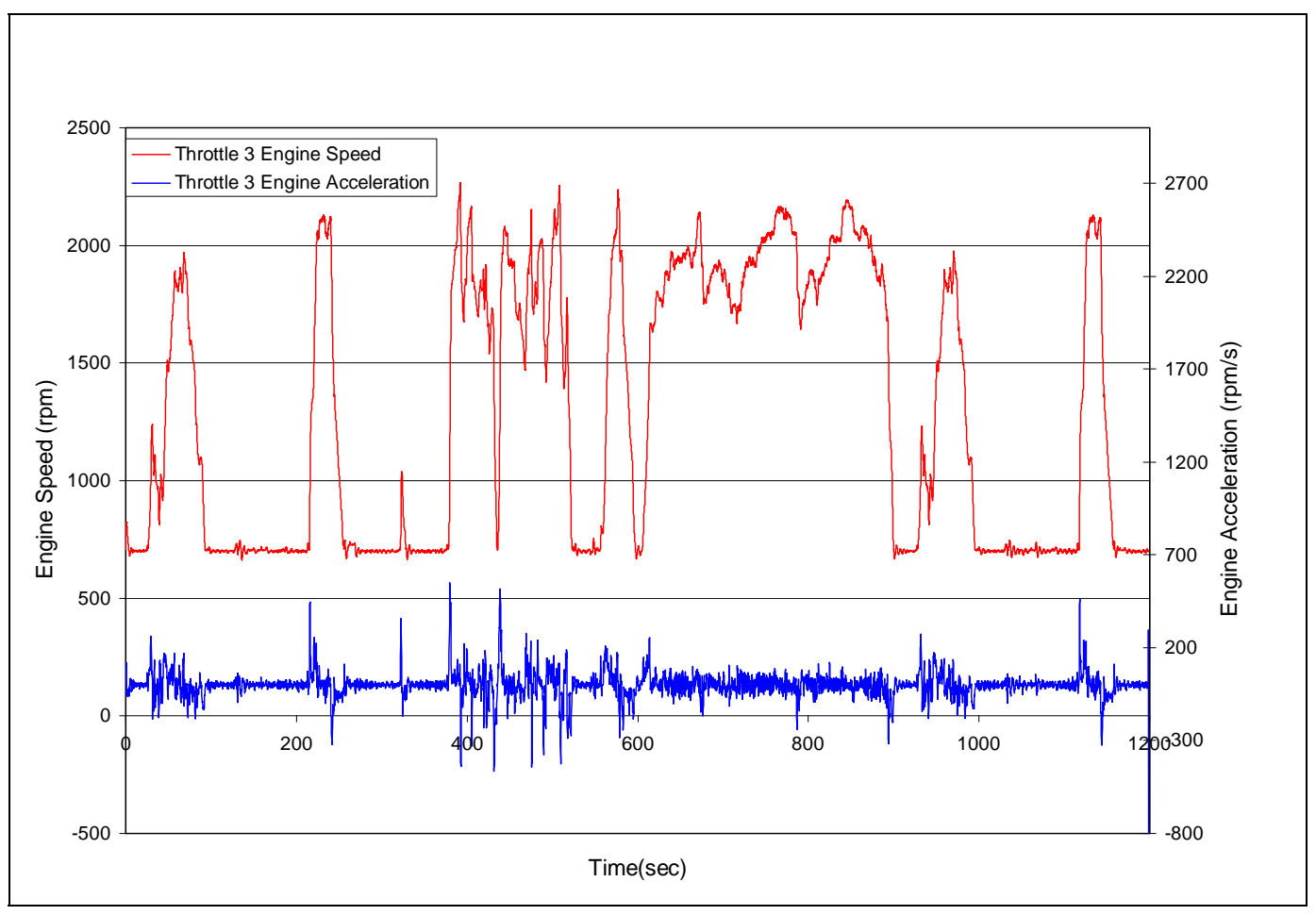

Figure 8.21 Throttle 3 Engine Speeds and Accelerations for 1999 Cummins Engine

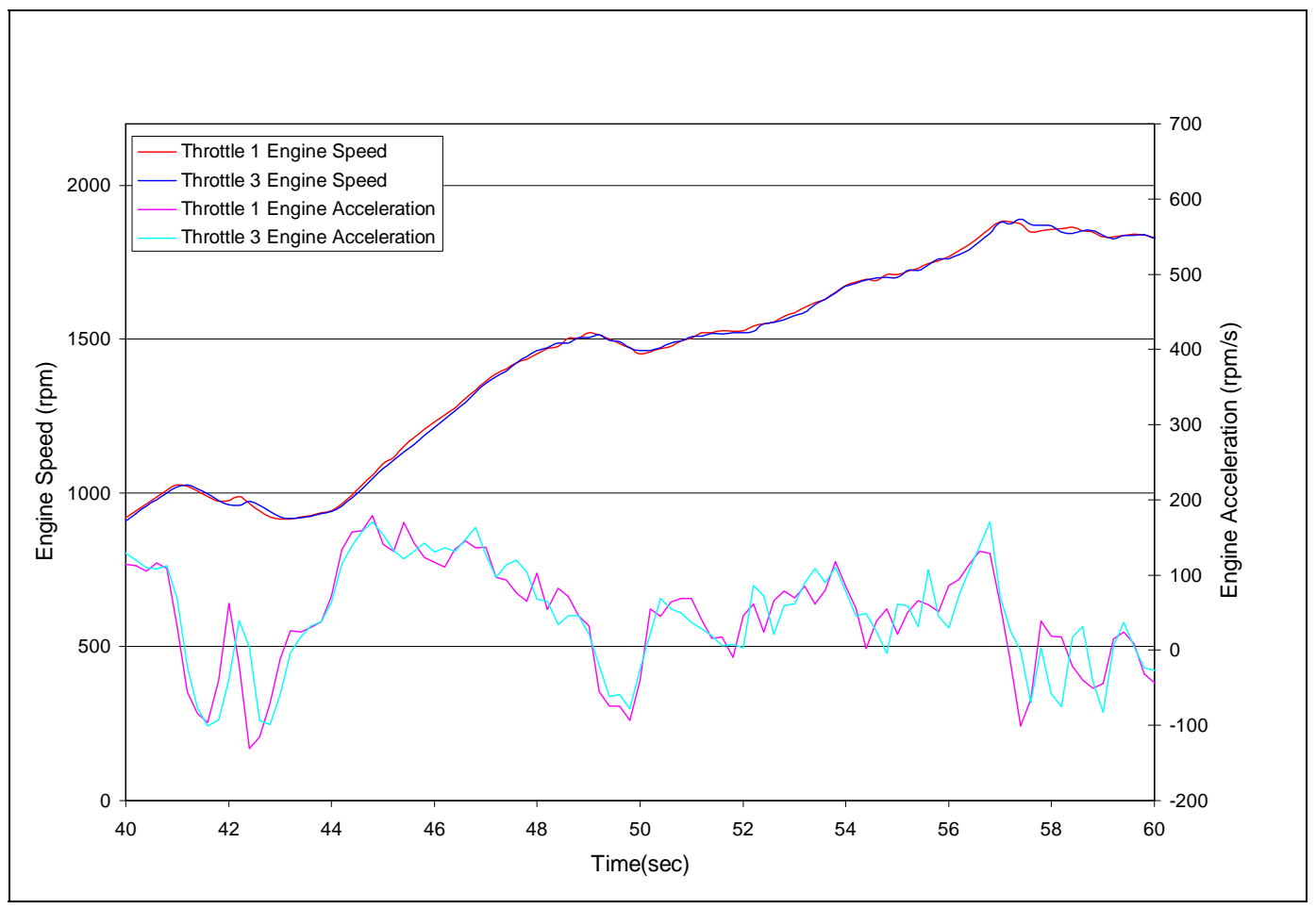

Figure 8.21 Engine Speeds and Accelerations for 1999 Cummins Engine 


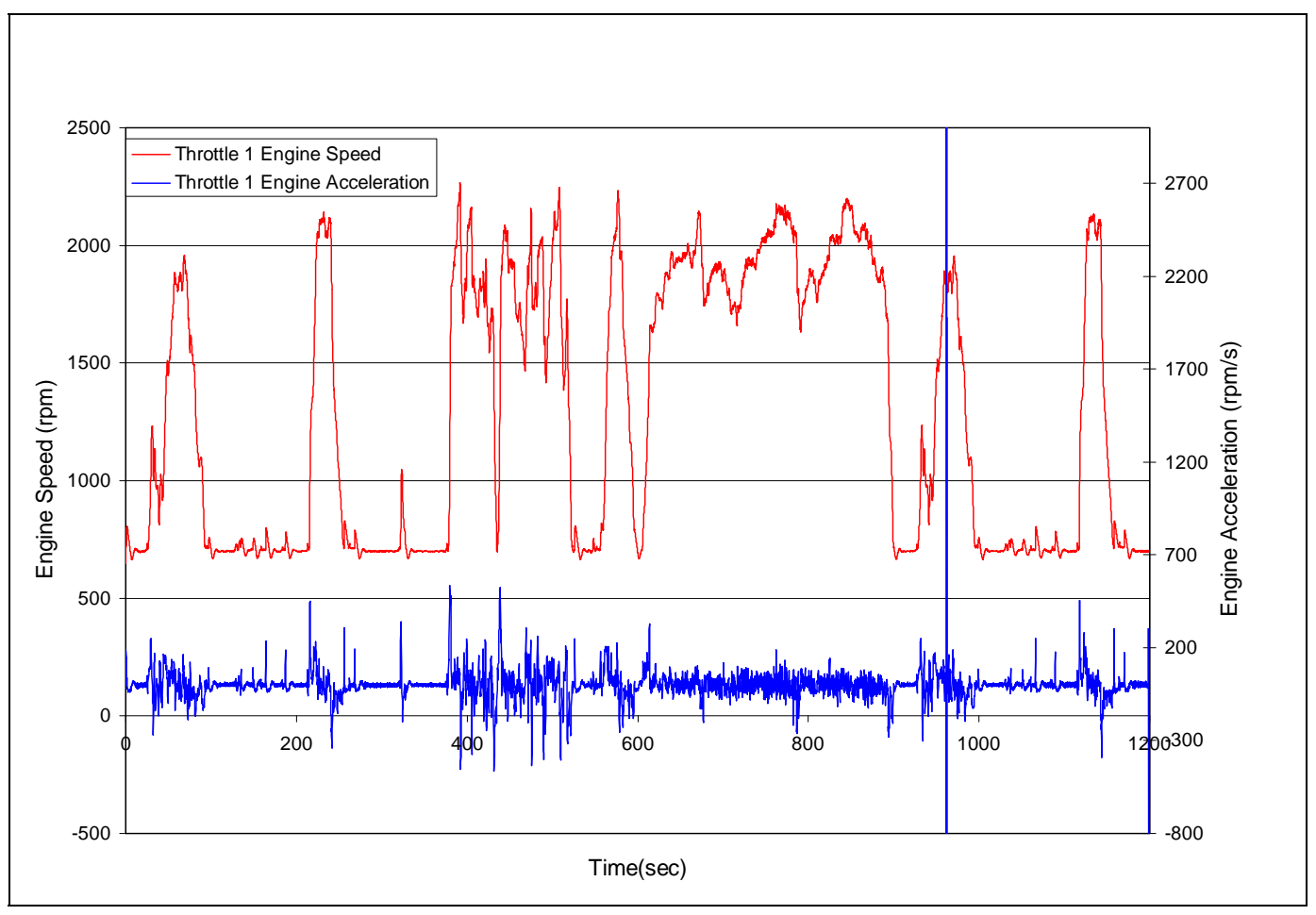

Figure 8.22 Throttle 1 Engine Speeds and Accelerations for 2004 Cummins Engine

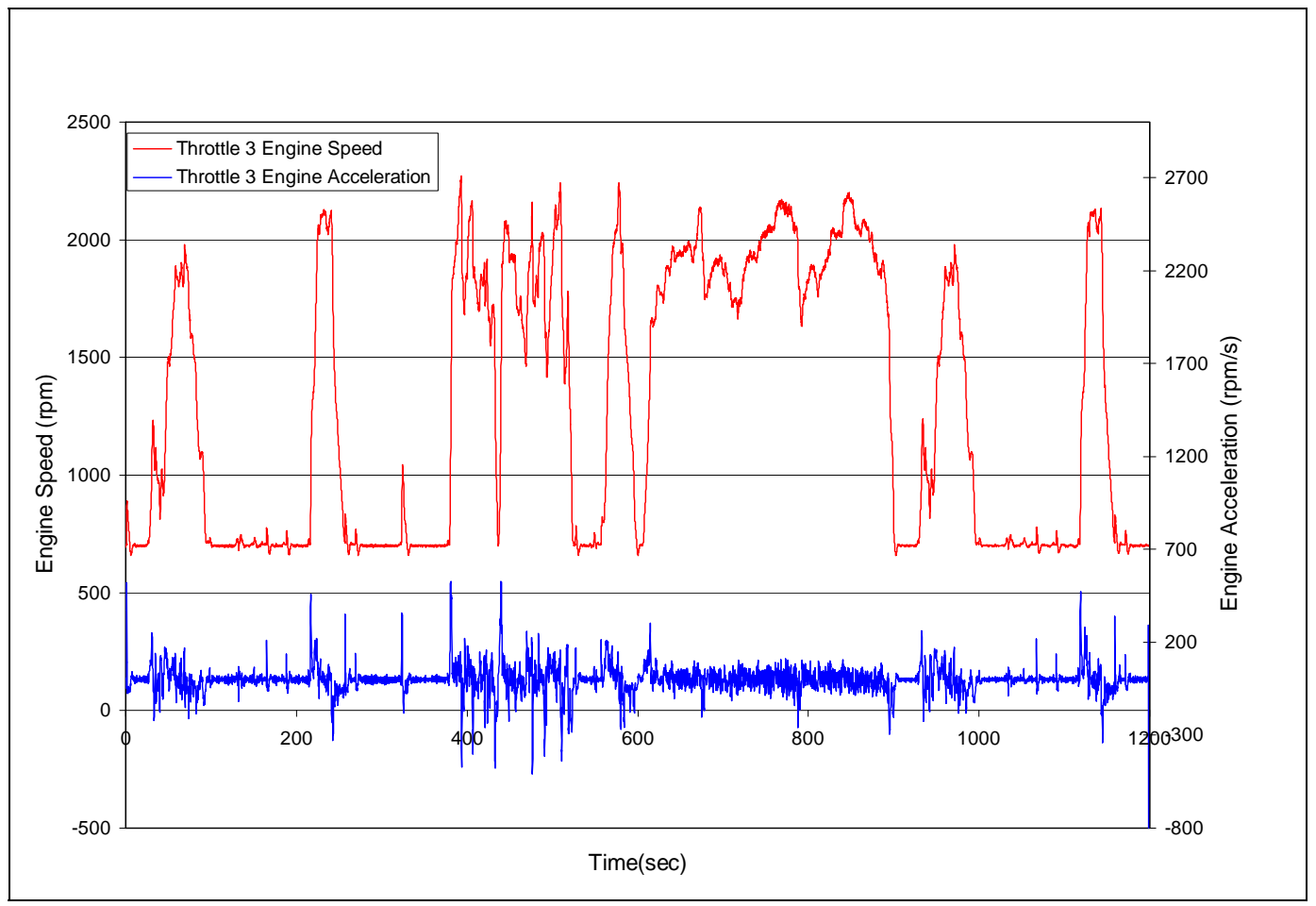

Figure 8.23 Throttle 3 Engine Speeds and Accelerations for 2004 Cummins Engine 


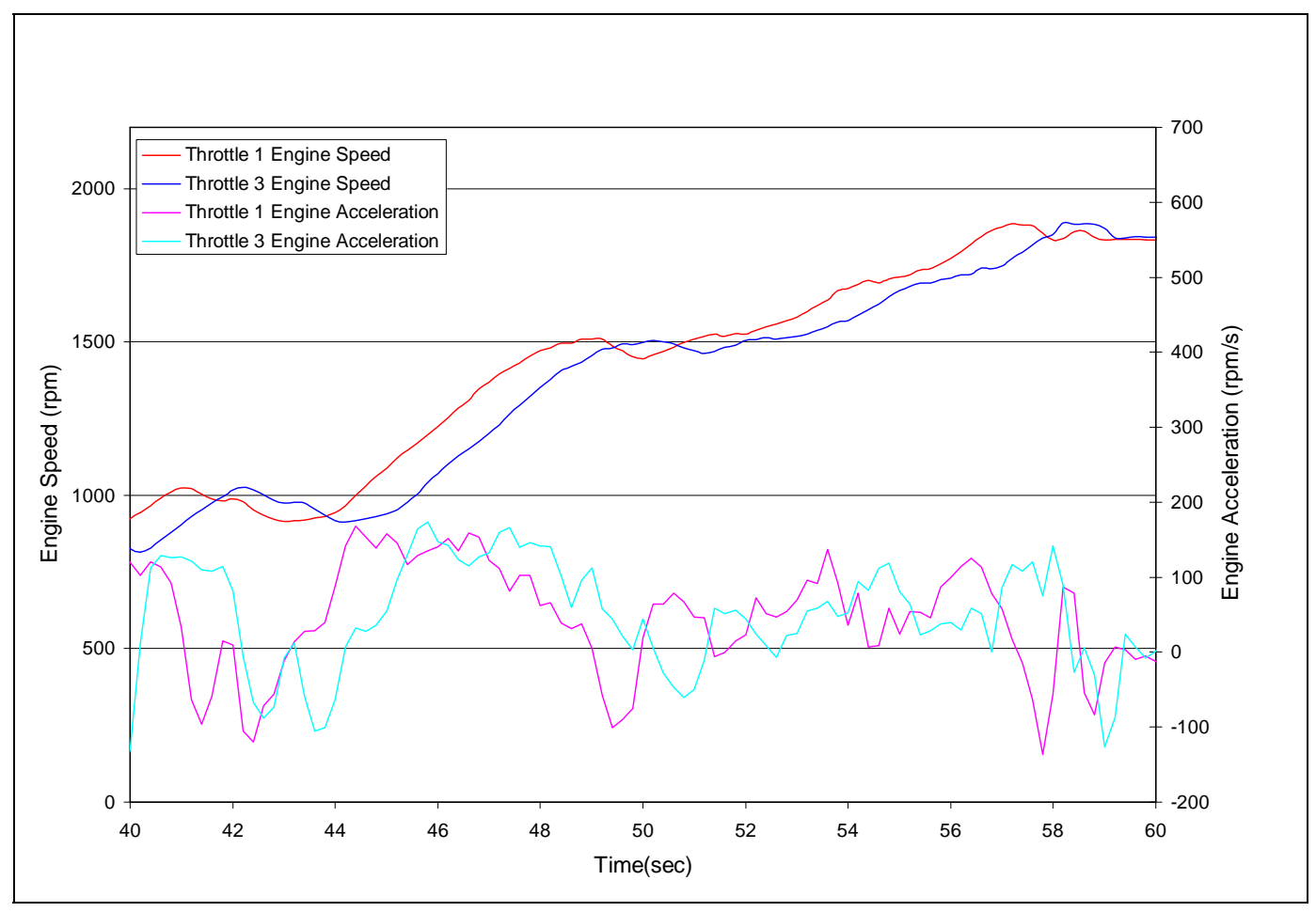

Figure 8.24 Engine Speeds and Accelerations for 2004 Cummins Engine

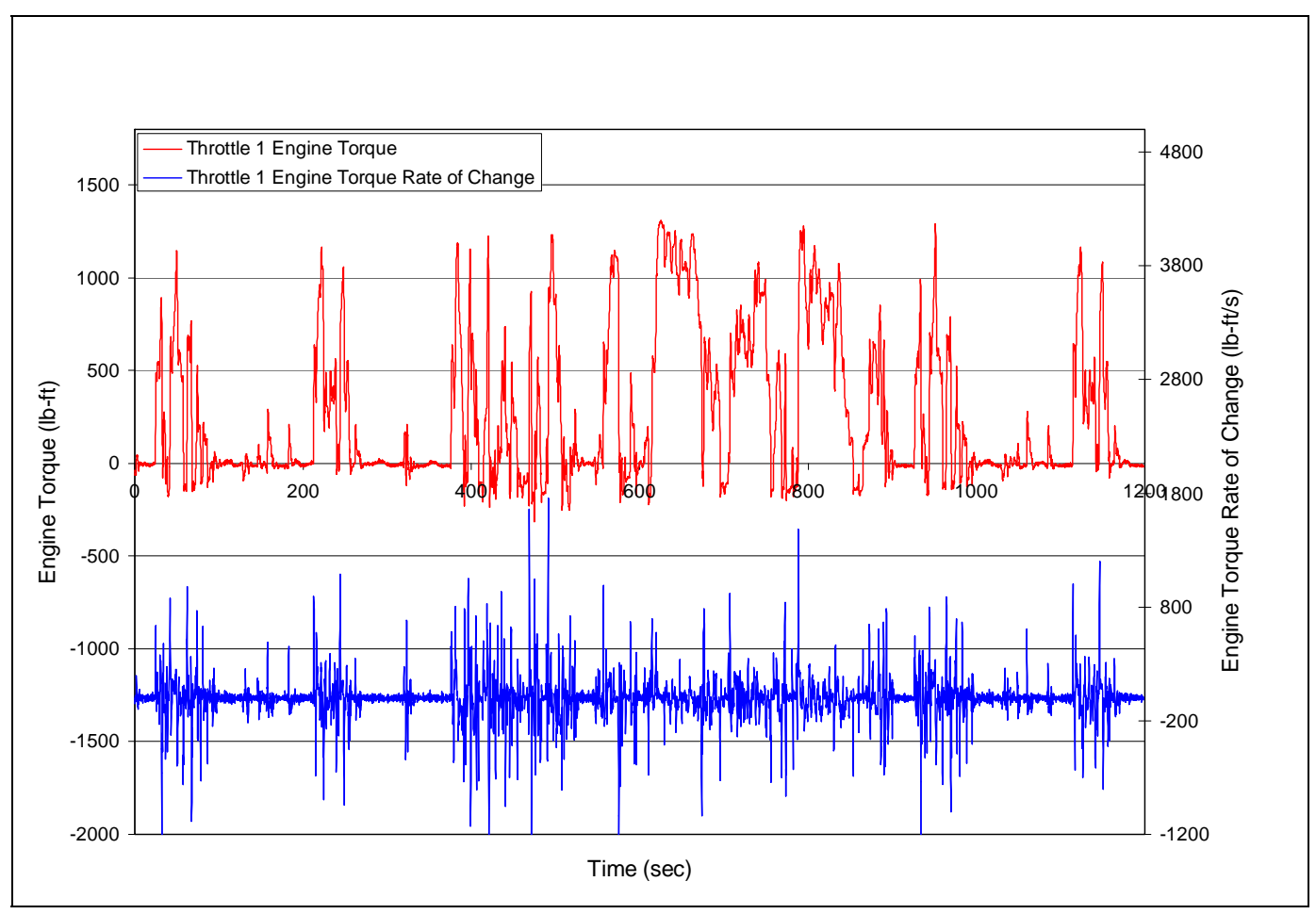

Figure 8.25 Throttle 1 Engine Torque and Torque Rate of Change for 1992 DDC Engine 


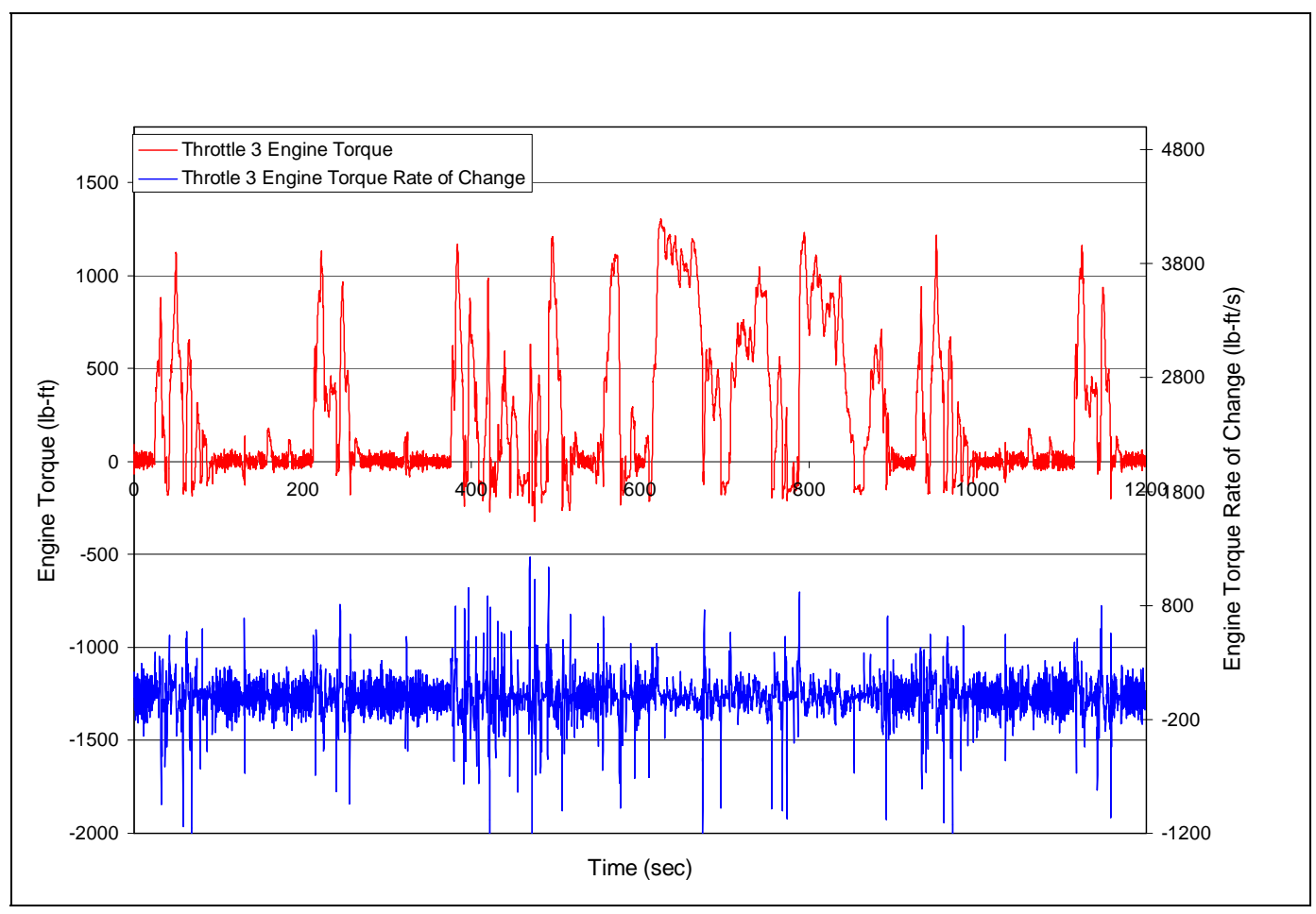

Figure 8.26 Throttle 3 Engine Torque and Torque Rate of Change for 1992 DDC Engine

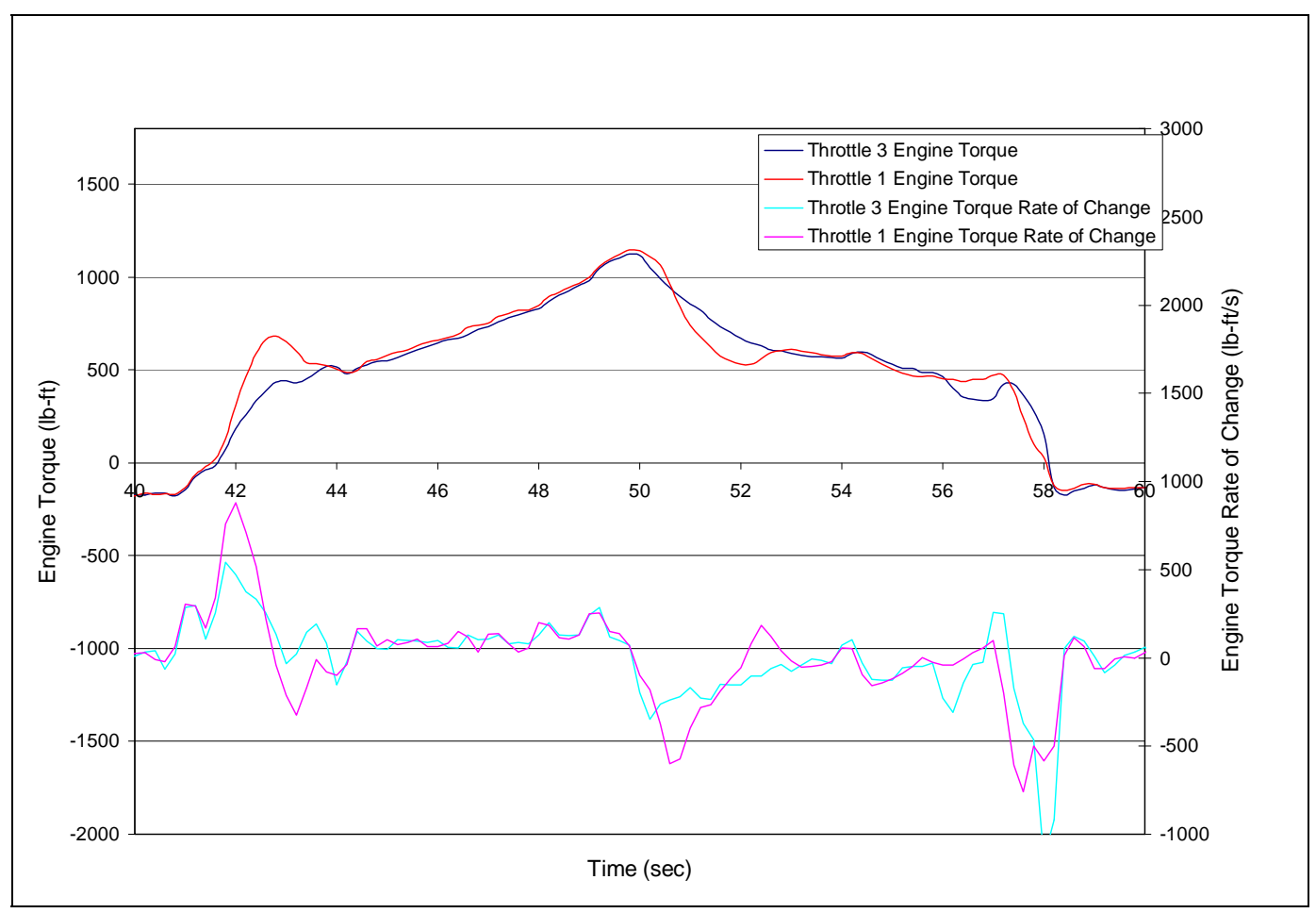

Figure 8.27 Engine Torque and Torque Rate of Change for 1992 DDC Engine 


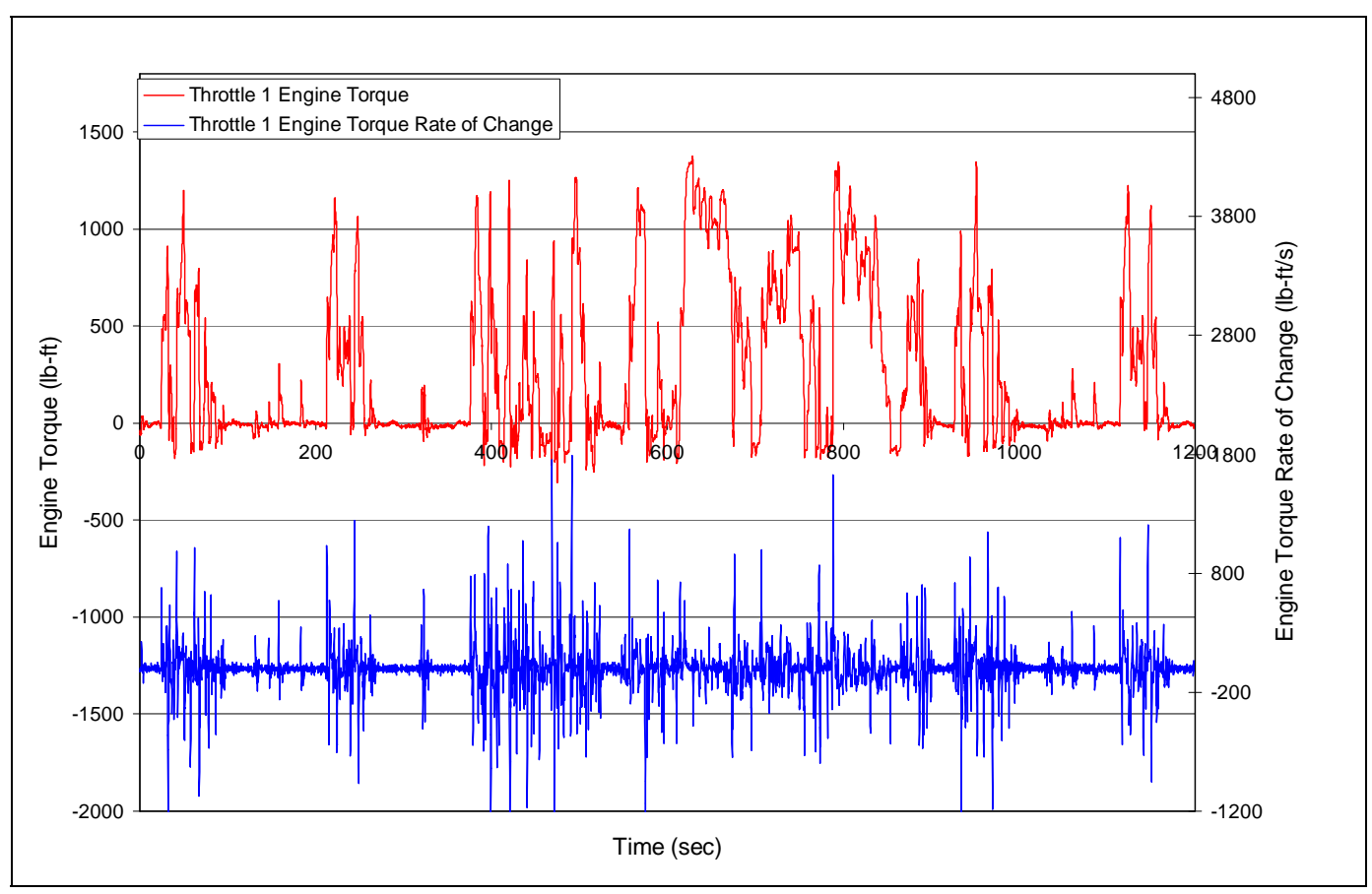

Figure 8.28 Throttle 1 Engine Torque and Torque Rate of Change for 1992 Rebuilt DDC Engine

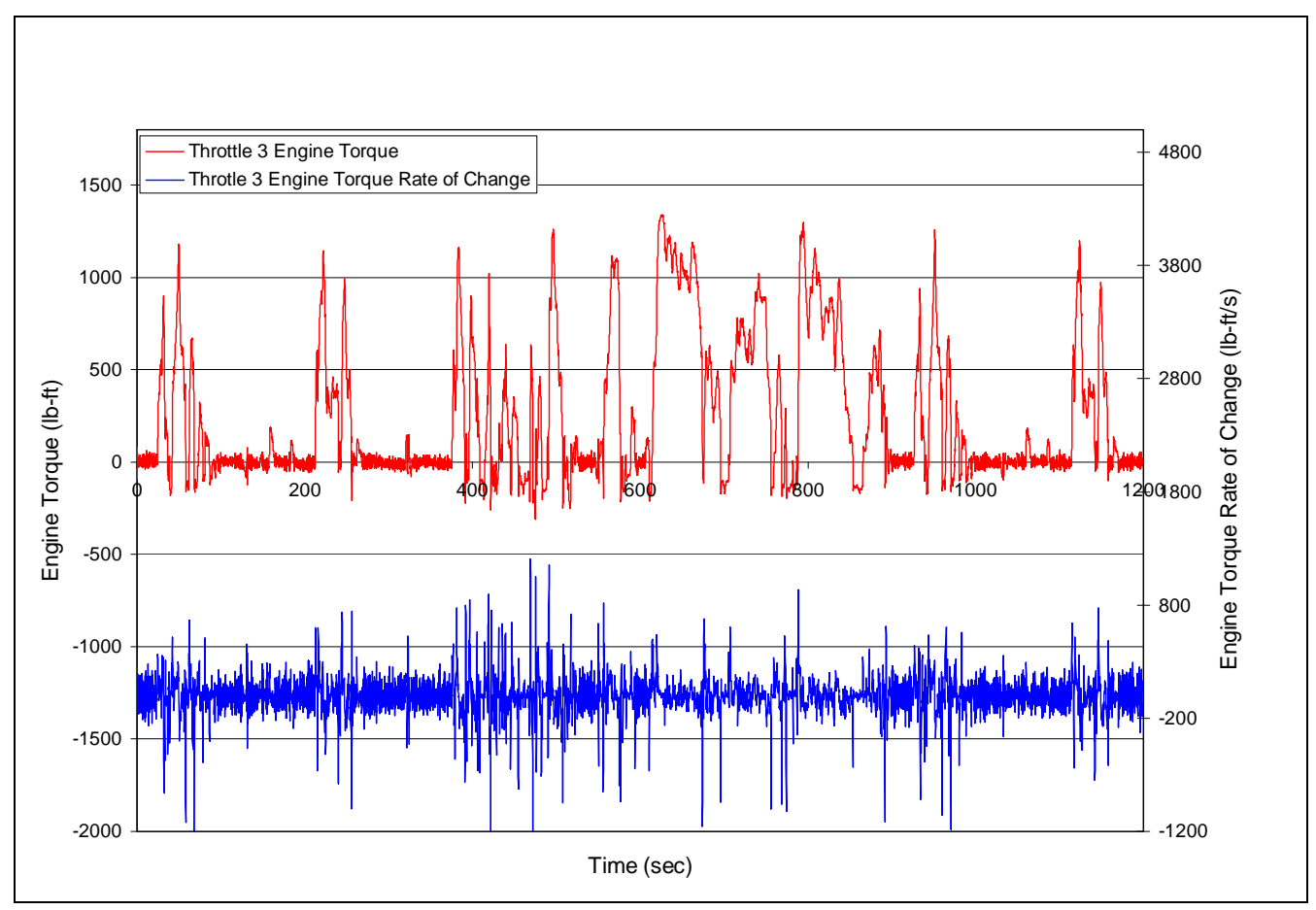

Figure 8.29 Throttle 3 Engine Torque and Torque Rate of Change for 1992 Rebuilt DDC Engine 


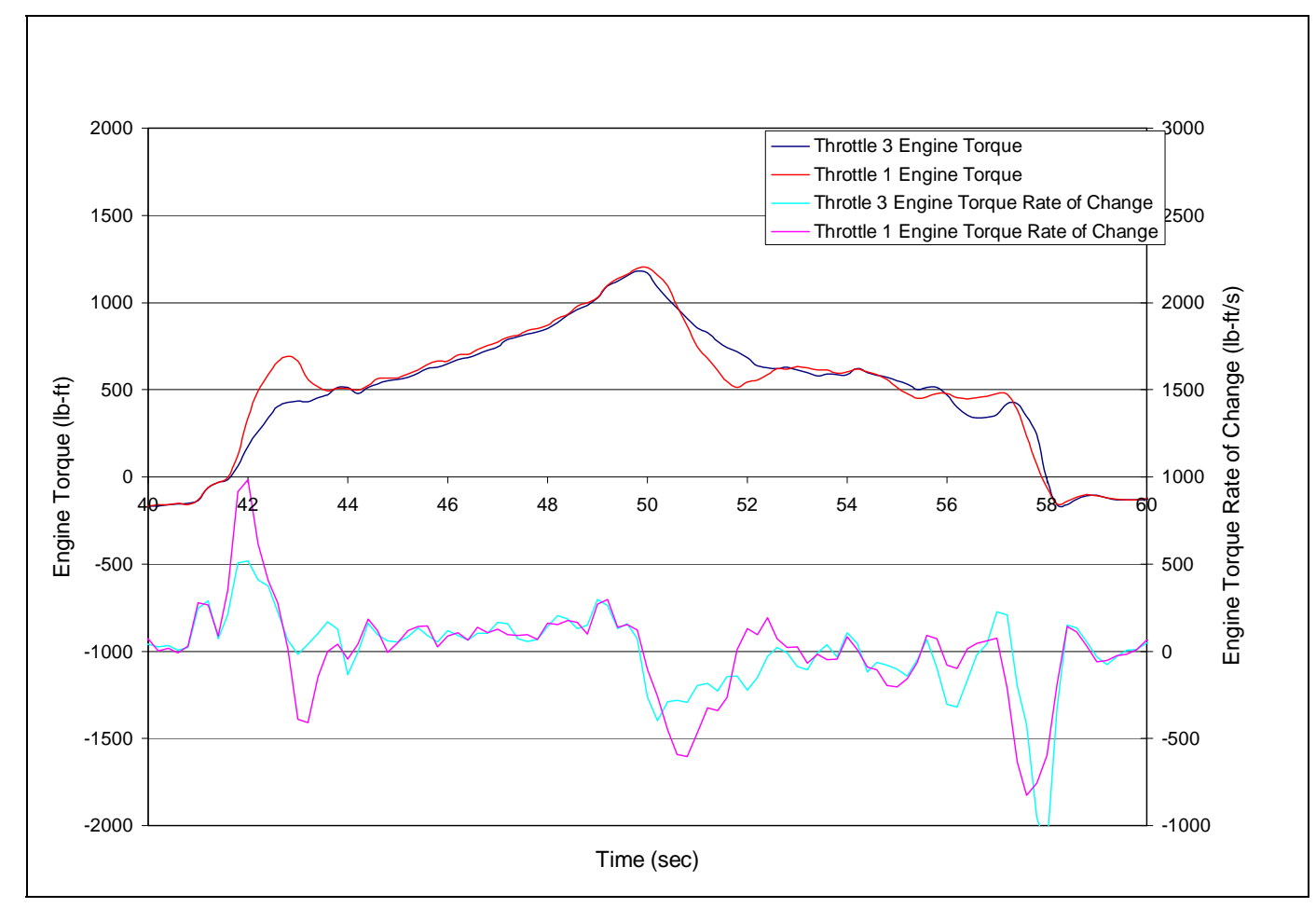

Figure 8.30 Engine Torque and Torque Rate of Change for 1992 Rebuilt DDC Engine

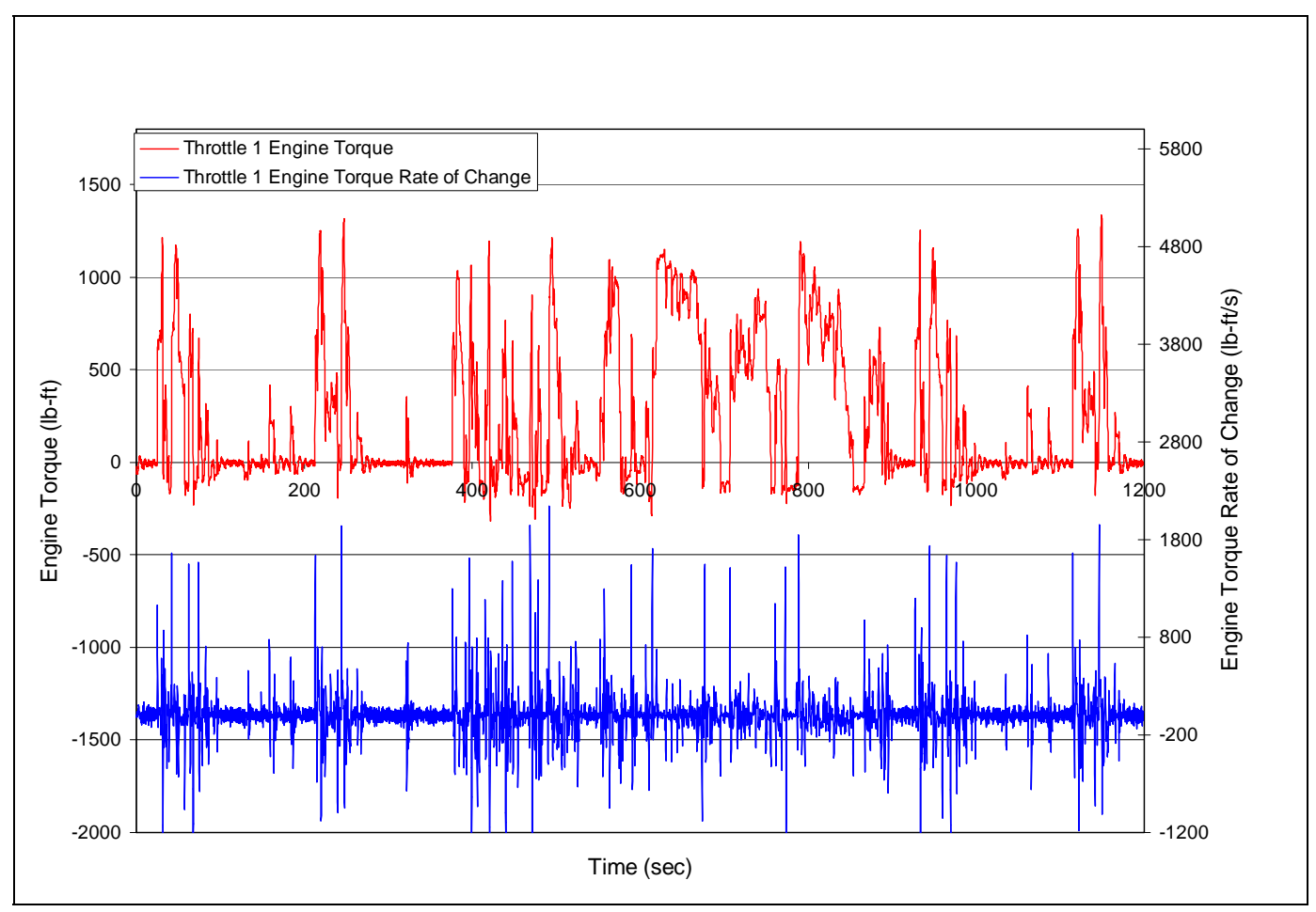

Figure 8.31 Throttle 1 Engine Torque and Torque Rate of Change for 1999 Cummins Engine 


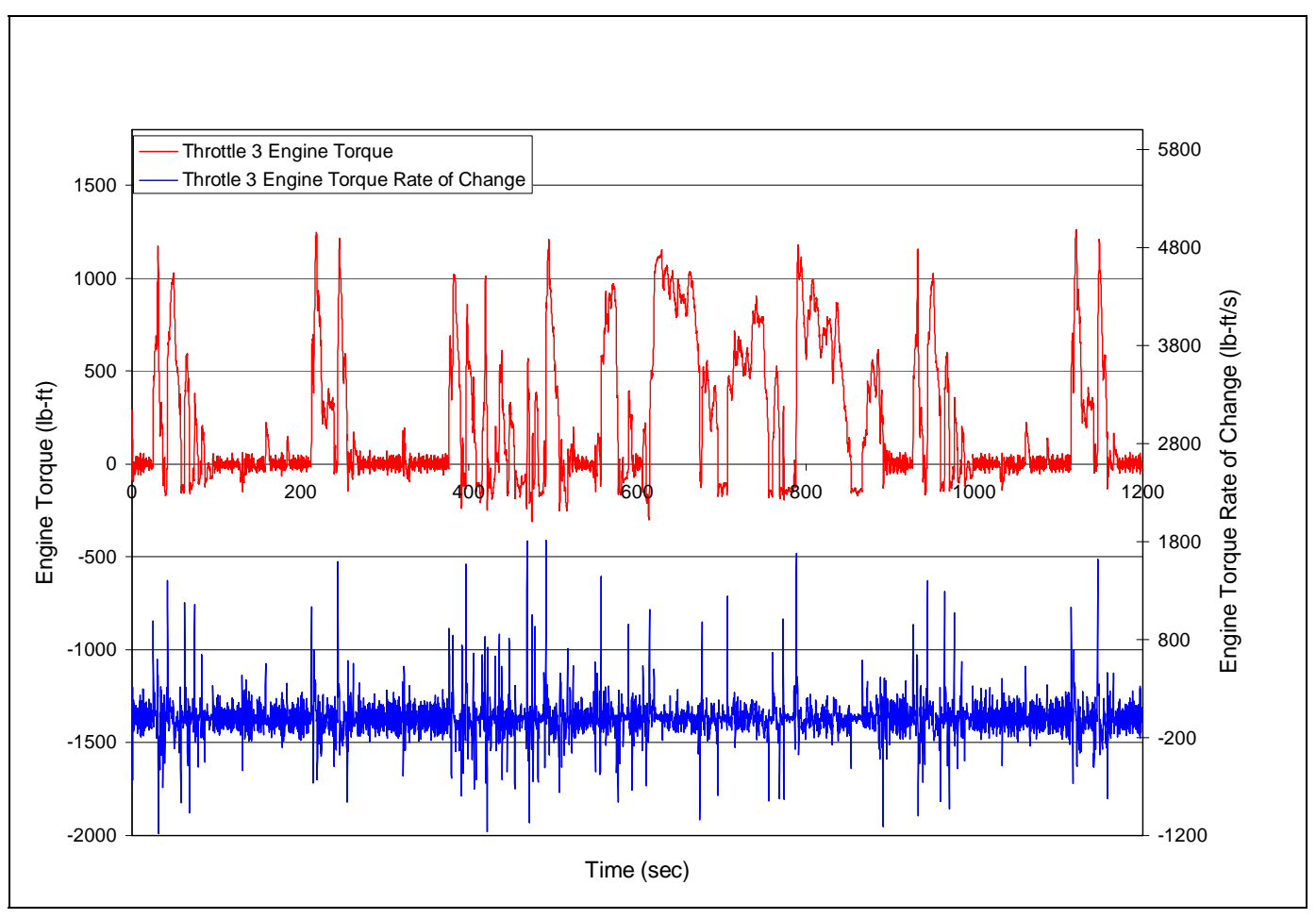

Figure 8.32 Throttle 3 Engine Torque and Torque Rate of Change for 1999 Cummins Engine

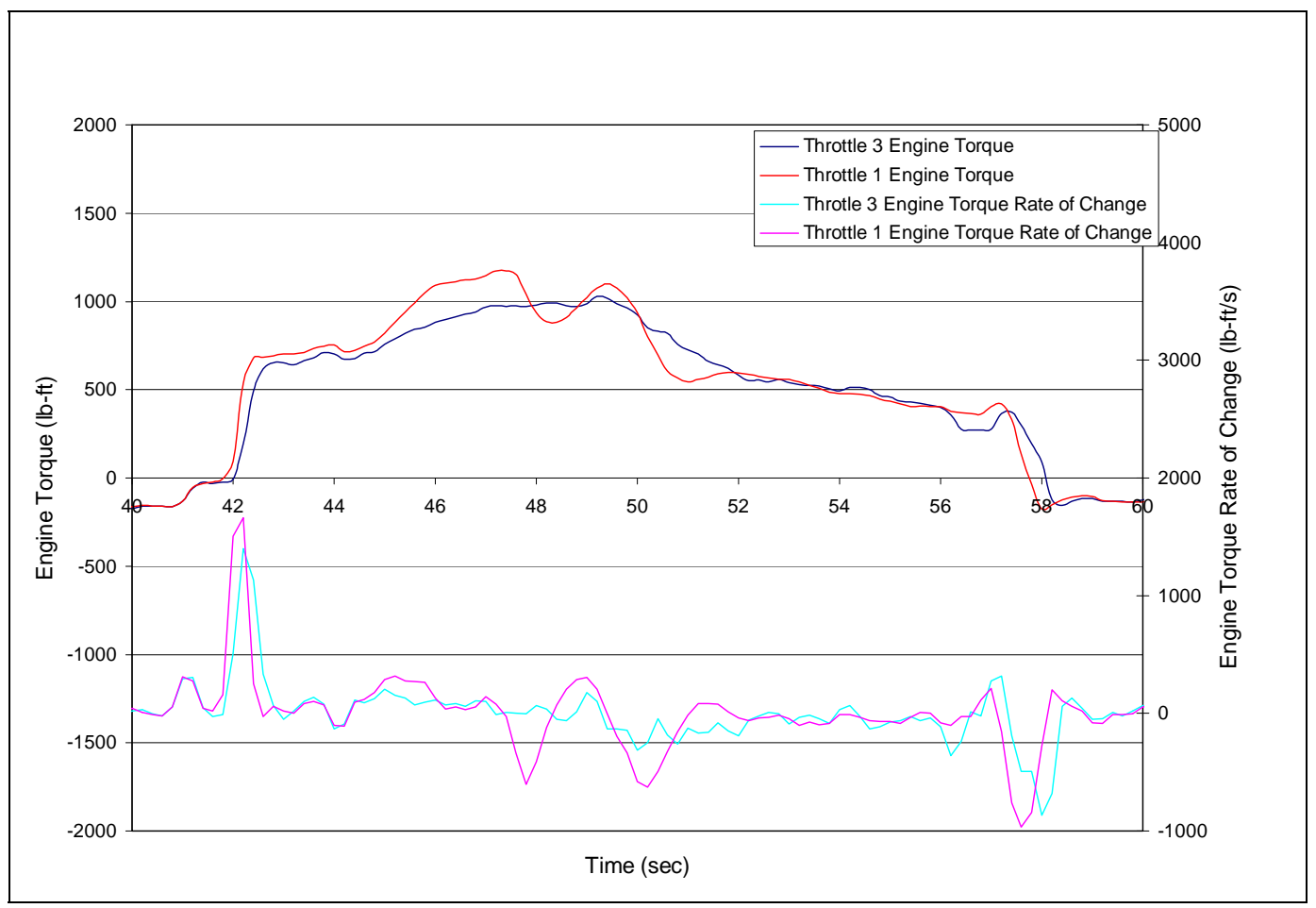

Figure 8.33 Engine Torque and Torque Rate of Change for 1999 Cummins Engine 


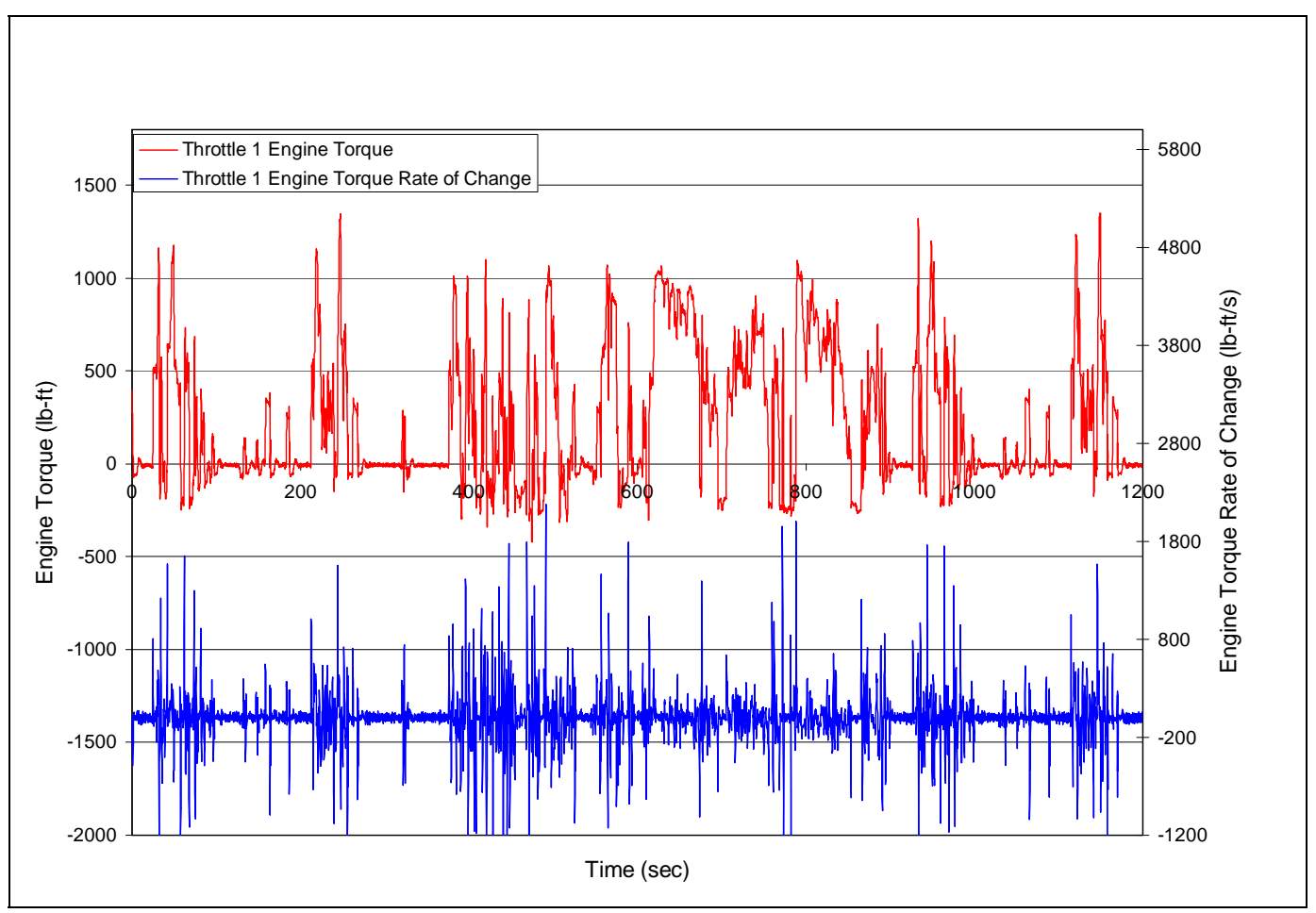

Figure 8.34 Throttle 1 Engine Torque and Torque Rate of Change for 2004 Cummins Engine

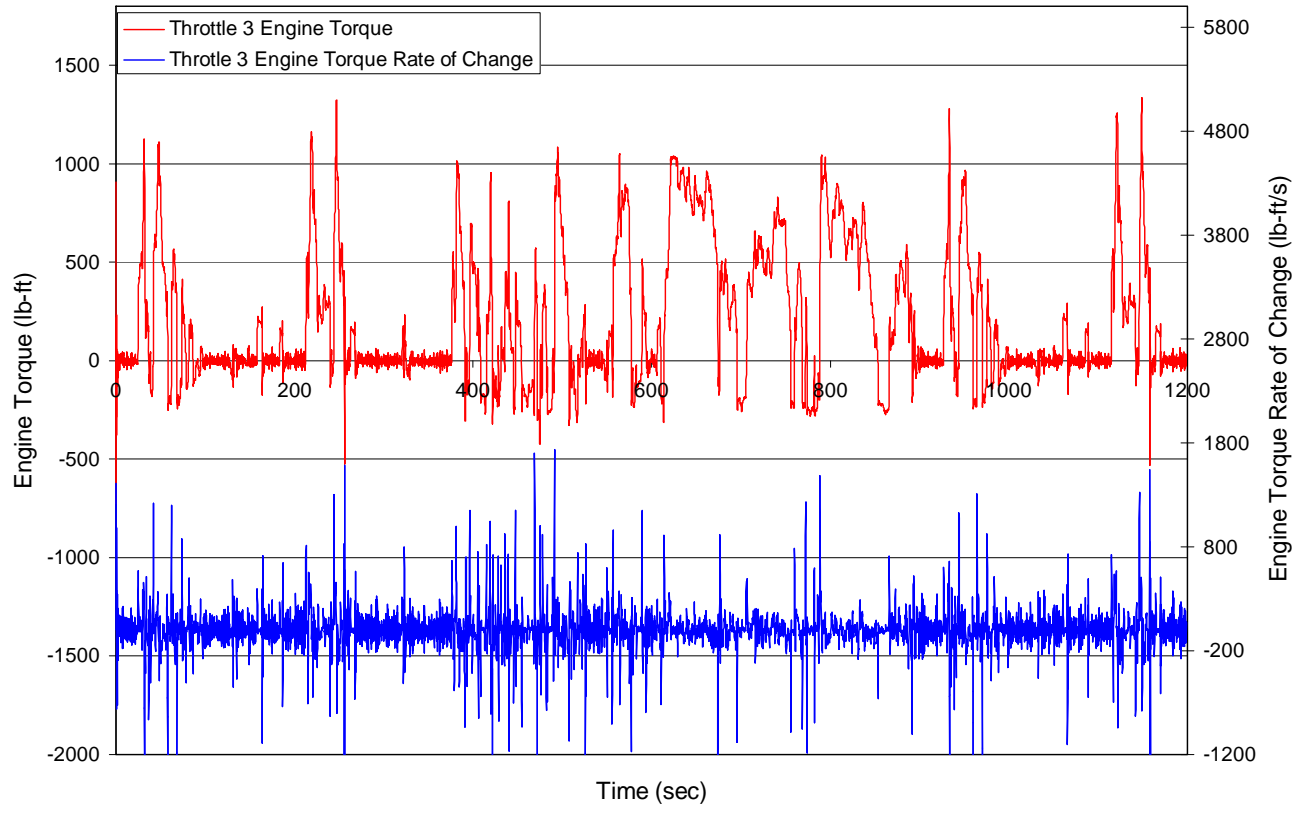

Figure 8.34 Throttle 3 Engine Torque and Torque Rate of Change for 2004 Cummins Engine 


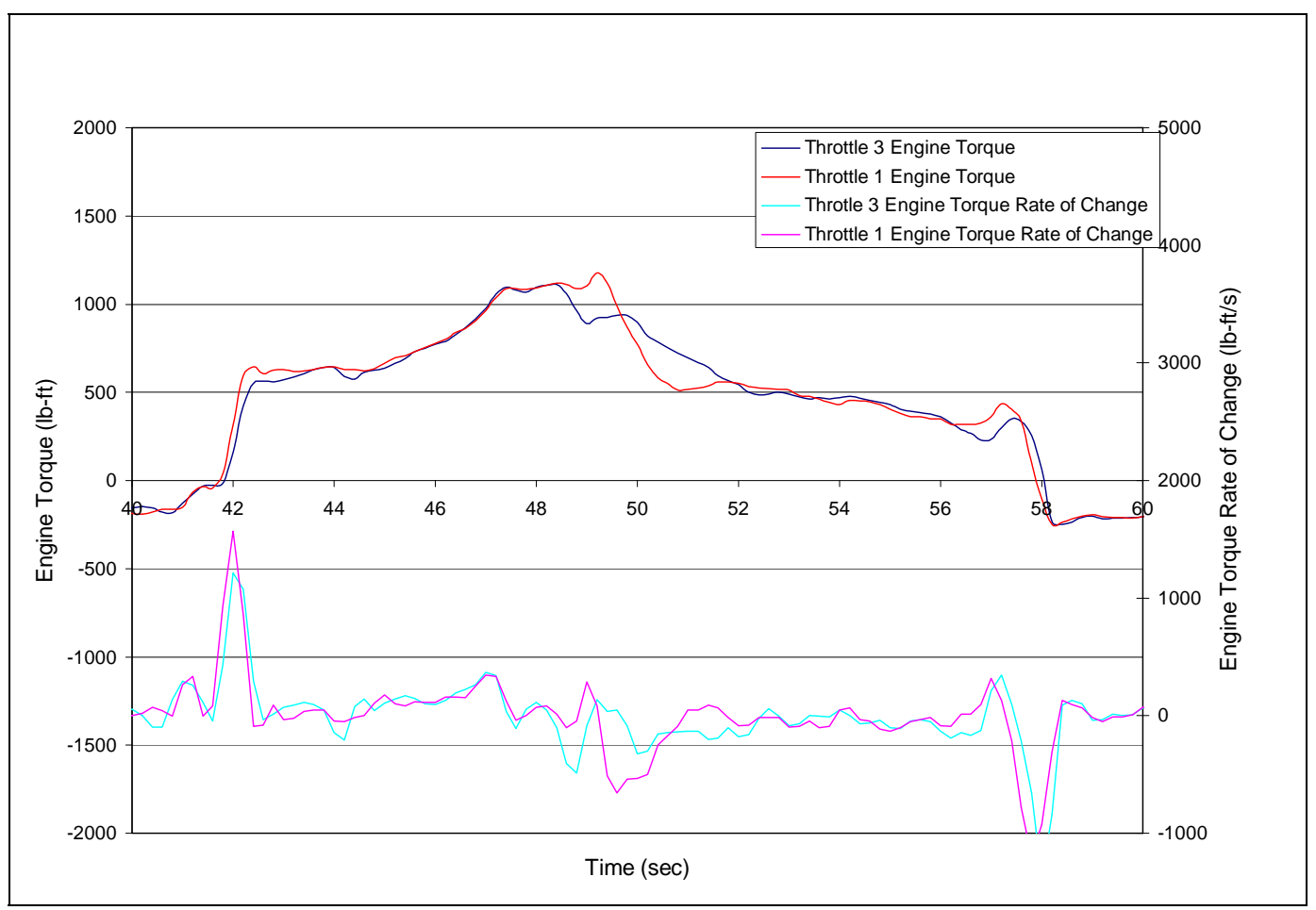

Figure 8.35 Engine Torque and Torque Rate of Change for 2004 Cummins Engine 